\title{
DINÂMICA DA MATÉRIA ORGÂNICA DO SOLO EM SISTEMAS DE MANEJO CONVENCIONAL E PLANTIO DIRETO
}

\author{
JOÃO CARLOS DE MORAES SÁ
}

Engenheiro Agrônomo

Orientador: Prof. Dr. CARLOS CLEMENTE CERRI

\begin{abstract}
Tese apresentada à Escola Superior de Agricultura "Luiz de Queiroz", Universidade de São Paulo, para obtenção do título de Doutor em Agronomia, Área de Concentração: Solos e Nutrição de Plantas.
\end{abstract}

\author{
PIRACICABA \\ Estado de São Paulo - Brasil \\ Janeiro - 2001
}


Dados Internacionais de Catalogação na Publicação (CIP) DIVISÃO DE BIBLIOTECA E DOCUMENTAÇĀO - Campus "Luiz de Queiroz"/USP

\author{
SÄ, João Carlos de Moraes \\ Dinàmica da matéria orgânica do solo em sistemas de manejo convencional e plantio \\ direto / João Carlos de Moraes Sá. - - Piracicaba, 2001. \\ $141 \mathrm{p}$. \\ Tese (doutorado) - Escola Superior de Agricultura Luiz de Queiroz, 2001. \\ Bibliografia. \\ 1. Biomassa microbiana do solo 2. Cronossequência 3. Fertilidade do solo 4. Matéria \\ orgânica do solo 5. Manejo do solo 6. Plantio direto 7. Preparo do solo 8 . Residuo agricola \\ I. Título
}

CDD 631.4 
Ao meu pai Albano, as minhas irmãs

Mariângela e Tereza, e a memória de

minha mãe Yeda e meu irmão Eduardo

pelo amor e carinho

Ofereço

A minha esposa Marcia por seu amor. constante incentivo, companheirismo e compreensão, e aos meus queridos filhos Cássia e Daniel, fonte de inspiração e força que me impulsiona para vencer os desafios,

Dedico 


\section{Agradecimentos}

Meu sincero agradecimento às pessoas e instituições que tornaram possível a realização deste trabalho:

Ao Prof. Dr. Carlos Clemente Cerri pelo pronto atendimento em todas as fases deste trabalho, pela orientação segura, estímulo, confiança e o início de uma grande amizade.

Ao Prof. Dr. Warren Albert Dick, pelo estímulo, confiança, orientação nos trabalhos de laboratório desenvolvidos na The Ohio State University, colaboração na redação dos artigos científicos que compuseram este trabalho e pela amizadade.

Ao Prof. Dr. Rattan Lal, pelo grande estímulo, confiança e amizade durante o período que permaneci na The Ohio State University e pela colaboração na redação dos artigos científicos que compuseram este trabalho.

Ao Dr. Christian Feller pesquisador do IRD-França, pela orientação no fracionamento granulométrico da matéria orgânica, pelas valiosas críticas e sugestões nesta tese e pelo agradável convívio, confiança e amizade.

A Dra. Marisa C. Piccolo e a Dra. Brigitte Feigl, pesquisadores do Laboratório de Biogeoquímica do Ambiental, Centro de Energia Nuclear na Agricultura CENA/USP, pelo auxílio na condução dos trabalhos no laboratório.

Aos laboratoristas Roberto e Sandra pelo inestimável apoio durante as análises laboratoriais.

Aos colegas do CENA: Conceição, Dinailson, Silvana, Martial e Edgar pela agradável convivência e amizade que tivemos durante o curso de doutorado. Um agradecimento especial ao Solismar, que participou ativamente deste projeto tornandose um grande amigo.

À Empresa Lucio Miranda Empreendimentos Agropecuários, e particularmente ao Sr. Lúcio, pelo apoio e suporte irrestrito durante a fase de coleta das amostras de solo na fazenda Santa Branca. Agradecimento especial ao Eng. Agrônomo Jorge do Rocio Ferreira e toda a equipe de campo da fazenda, pelo suporte e participação incansável durante a árdua tarefa da amostragem dos solos. 
À Fazenda Frankanna, na pessoa do Sr. Franke Dijkstra pelo apoio e suporte durante a fase de coleta das amostras de solo.

À equipe técnica dos laboratórios de Física e Mineralogia dos Solos da ESALQUSP (Bete, Wladmir e Luciano) pela amizade e companheirismo.

Aos colegas da The Ohio State University, Vasant Akala, Barbara Baker, Soerd Duiker, Mahmoud Ahmadi e especialmente ao Guilherme P. Holtz, pelo grande apoio durante minha estada em Columbus, Ohio.

À Universidade Estadual de Ponta Grossa e à Escola Superior de Agricultura Luiz de Queiroz, pela oportunidade de realização do curso de doutorado.

À The Ohio State University, School of Natural Researches, pela oportunidade de realização do "doutorado sandwich".

À CAPES, pelo suporte através de concessão de bolsa de estudo e possibilidade de realização do "doutorado sandwich".

À FAPESP, pela concessão de auxilio financeiro ao projeto.

Aos colegas do Depto de Ciência do Solo e Engenharia Agrícola da UEPG pelo apoio durante a minha ausência. Agradecimentos especiais ao Prof. Dr. Altair Justino por se encarregar de nossos negócios pessoais.

À amiga, colega e esposa Marcia pela força e compreensão, em cada passo da realização deste trabalho. 


\section{APRESENTAÇÃO}

Esta Tese foi redigida "em forma de publicação", conforme as Normas para Elaboração de Dissertações e Teses da ESALQ/USP (1997) e é composta pelos seguintes trabalhos cientificos:

- Dinâmica da matéria orgânica e taxas de sequestro de carbono em uma cronossequência sob sistemas de manejo convencional e plantio direto num Oxisol no Brasil. Submetido à revista Soil Science Society of America Journal, entitulado: Organic matter dynamics and carbon sequestration rates for a tillage chronosequence in a Brazilian Oxisol.

- Biomassa microbiana e componentes da matéria orgânica afetados por sistemas de manejo convencional e plantio direto num oxisol no Brasil. Submetido à revista Soil Biology \& Biochemistry, entitulado: Soil microbial biomass and organic matter components affected by a tillage chronosequence in a Brazilian Oxisol.

- Impacto de uma cronossequência sob sistemas de manejo convencional e plantio direto nas interações entre o carbono orgânico e a fertilidade de um Oxisol no Brasil. Submetido à revista Soil \& Tillage Research, entitulado: No-tillage chronosequence impacts on soil organic carbon and fertility interactions in a Brazilian Oxisol.

Antecedendo os trabalhos citados encontram-se uma Introdução e uma Revisão de literatura de caráter geral. O último capítulo é constituído pelas conclusões gerais. 


\section{SUMÁRIO}

Página

RESUMO

SUMMARY .

xii

1 INTRODUÇÃO

2 REVISÃO DE LITERATURA

$2.1 \mathrm{O}$ balanço global de carbono

2.1.1 Os reservatórios de carbono e as mudanças globais ..................................... 3

2.1.2 As perdas históricas de carbono por ações antropogênicas ........................... 5

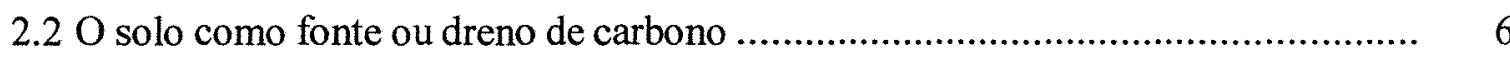

2.2.1 O impacto de sistemas de manejo na matéria orgânica do solo..................... 6

2.2.2 Potencial de sequestro de carbono em sistemas conservacionistas de manejo do solo

2.3 A influência do plantio direto em atributos do solo

2.3.1 Benefícios à fertilidade do solo.

2.3.2 Alterações na biomassa microbiana do solo e em componentes da matéria orgânica.

2.4 Avaliação da matéria orgânica do solo

2.4.1 O fracionamento granulométrico.

2.1 $\mathrm{O}$ uso de técnicas isotópicas na identificação da origem da matéria orgânica do solo

3 DINÂMICA DA MATÉRIA ORGÂNICA E TAXAS DE SEQUESTRO DE CARBONO EM UMA CRONOSSEQUÊNCIA SOB SISTEMAS DE MANEJO CONVENCIONAL E PLANTIO DIRETO NUM OXISOL NO BRASIL

3.1 RESUMO

3.2 SUMMARY: ORGANIC MATTER DYNAMICS AND CARBON SEQUESTRATION RATES FOR A TILLAGE CHRONOSEQUENCE IN A BRAZILIAN OXISOL 
3.4.1 Localização e descrição da área experimental

3.4.2 Conversão da vegetação natural em sistemas agrícolas, descrição da cronossequência, rotação de culturas e práticas culturais..

3.4.3 Desenho experimental e amostragem do solo.

3.4.4 Análises químicas e mineralógicas para caracterização dos perfis de solo.

3.4.5 Preparo das amostras, análises de carbono orgânico total, nitrogênio total, densidade do solo e cálculo do estoque de $\mathrm{C}$ e $\mathrm{N}$.

3.4.6 Fracionamento granulométrico da matéria orgânica do solo.

3.4.7 Determinação da abundância natural do ${ }^{13} \mathrm{C}\left(\delta^{13} \mathrm{C}\right)$, do carbono orgânico e nitrogênio total nas frações granulométricas da matéria orgânica do solo.

3.4.8 Análises estatísticas.

3.5 RESULTADOS E DISCUSSÃO

3.5.1 Alterações no conteúdo de carbono orgânico, nitrogênio total e relação $\mathrm{C} / \mathrm{N}$ do solo.

3.5.2 Alterações no conteúdo de carbono orgânico e nitrogênio total das frações granulométricas da matéria orgânica do solo.

3.5.3 Abundância natural do ${ }^{13} \mathrm{C}$ e taxas de seqüestro do carbono orgânico do solo afetado pelos resíduos culturais associado ao plantio direto há longo período.

3.6 CONCLUSÕES

4 BIOMASSA MICROBIANA E COMPONENTES DA MATÉRIA ORGÂNICA AFETADOS POR SISTEMAS DE MANEJO CONVENCIONAL E PLANTIO DIRETO NUM OXISOL NO BRASIL

4.1 RESUMO

4.2 SUMMARY: SOIL MICROBIAL BIOMASS AND ORGANIC MATTER COMPONENTS AFFECTED BY A TILLAGE CHRONOSEQUENCE IN A BRAZILIAN OXISOI

4.3 INTRODUÇÃO 
4.4.1 Localização e descrição da área experimental.

4.4.2 Conversão da vegetação natural em sistemas agrícolas e descrição da cronossequência.

4.4.3 Análises químicas dos solos na cronossequência

4.4.4 Desenho experimental e amostragem do solo.

4.4.5 Análise de carbono orgânico e nitrogênio total do solo.

4.4.6 Estimativa da biomassa microbiana, respiração basal e cálculo de relações e quocientes.

4.4.7 Determinação de polissacarídeos (total e lábil) e do carbono orgânico dissolvido.

4.4.8 Análises estatísticas.

4.5 RESULTADOS E DISCUSSÃO

4.5.1 Biomassa microbiana $\mathrm{C}$ e $\mathrm{N}$ na cronossequência afetadas pela acidez do solo e distribuição vertical.

4.5.2 Biomassa microbiana $\mathrm{C}$ e $\mathrm{N}$ afetadas por componentes da matéria orgânica do solo (COT, Ntotal, POT, POL, COD).

4.5.3 Atividade da biomassa microbiana $\mathrm{C}$ e $\mathrm{N}$ afetada pela acidez do solo e os componentes da matéria orgânica na cronossequência.

4.6 CONCLUSÕES

5 IMPACTO DE UMA CRONOSSEQUÊNCIA SOB SISTEMAS DE MANEJO CONVENCIONAL E PLANTIO DIRETO NAS INTERAÇÕES ENTRE O CARBONO ORGÂNICO E A FERTILIDADE DE UM OXISOL NO BRASIL......

5.1 RESUMO

5.2 SUMMARY: NO-TILLAGE CHRONOSEQUENCE IMPACTS ON SOIL ORGANIC CARBON AND FERTILITY INTERACTIONS IN A BRAZILIAN OXISOL

5.3 INTRODUÇÃO.

5.4 MATERIAL E MÉTODOS

5.4.1 Localização e descrição da área experimental 
5.4.2 Conversão da vegetação natural em área agrícola, descrição da cronossequência, rotação de culturas e práticas culturais.

5.4.3 Desenho experimental e amostragem do solo................................................... 92

5.4.4 Preparo das amostras e análises...................................................... 93

5.4.5 Análises estatísticas............................................................................................ 94

5.5 RESULTADOS E DISCUSSÃO.......................................... 95

5.5.1 Alterações no conteúdo de carbono orgânico do solo afetado pelos sistemas de manejo

5.5.2 Alterações na acidez potencial e pH na cronossequência afetada pelo carbono orgânico do solo.

5.5.3 Alteração do $\Delta \mathrm{pH}$, da CTC (total e efetiva) e da saturação por bases na cronossequência afetados pelo carbono orgânico do solo.

5.5.4 Dinâmica do fósforo e do potássio na cronossequência afetada pelo carbono orgânico do solo

5.6 CONCLUSÕES

6 CONCLUSÕES GERAIS

ANEXO. 


\title{
DINÂMICA DA MATÉRIA ORGÂNICA DO SOLO EM SISTEMAS DE MANEJO CONVENCIONAL E PLANTIO DIRETO
}

\author{
Autor: JOÃO CARLOS DE MORAES SÁ \\ Orientador: Prof. Dr. CARLOS CLEMENTE CERRI
}

\section{RESUMO}

Em uma cronossequência localizada na região Centro-Sul do Estado do Paraná, foi avaliado a dinâmica da matéria orgânica de um Latossolo Vermelho. A cronossequência é constituída por seis tratamentos representados pelos sistemas de manejo: a) campo nativo $(\mathrm{CN})$, representando a vegetação natural da região; b) preparo do campo nativo $(\mathrm{PCN}-1)$, envolvendo a conversão da vegetação natural em área agrícola; c) plantio direto por 10 anos (PD-10); d) plantio direto por 20 anos (PD-20); e) plantio direto por 22 anos (PD-22); f) preparo convencional por 22 anos (PC-22) envolvendo o preparo com uma aração a $20 \mathrm{~cm}$ de profundidade, após a colheita da cultura de verão e inverno seguido de duas gradagens niveladoras. Amostras de solo para a avaliação dos componentes da matéria orgânica do solo (MOS) e outros atributos foram coletadas de cinco profundidades $(0-2,5 ; 2,5-5 ; 5-10 ; 10-20$ e $20-40 \mathrm{~cm})$.

Nos tratamentos sob plantio direto, 57,9 a $81,2 \%$ do aumento no estoque de carbono orgânico total (COT) e $\mathrm{N}$ total acumulado na camada de $0-40 \mathrm{~cm}$ ocorreu nos primeiros $10 \mathrm{~cm}$ de profundidade. Por outro lado, $97 \%$ do decréscimo em COT no tratamento CT-22 comparado ao campo nativo também ocorreu nesses $10 \mathrm{~cm}$ de profundidade. Análises de regressão indicaram um estreito relacionamento entre o aporte de resíduos culturais e estoque de $\operatorname{COT}\left(R^{2}=0,74 ; p<0,05\right)$ e a adição de $1 \mathrm{Mg}$ de $\mathrm{C}$ via resíduo cultural aumentou em $0,265 \mathrm{Mg}$ o estoque de COT. O conteúdo de 
COT e $\mathrm{N}$ total nas frações granulométricas da MOS aumentou da fração 200-2000 $\mu \mathrm{m}$ para a fração $<2 \mu \mathrm{m}$. A porcentagem do carbono oriundo dos resíduos culturais avaliados pelo $\delta^{13} \mathrm{C}$ na MOS, foi maior $(\mathrm{p}<0,05)$ na camada superficial e nas frações 200-2000 $\mu \mathrm{m}, 53-200 \mu \mathrm{m}$ e 20-53 $\mu \mathrm{m}$ do que nas frações mais finas $(2-20 \mu \mathrm{m}$ e $<2$ $\mu \mathrm{m})$, embora tenha sido significativo a contribuição nestas frações. A taxa de sequestro de carbono no plantio direto foi de $80,6 \mathrm{~g} \mathrm{C} \mathrm{m}^{-2}$ ano-1 para a camada $0-20 \mathrm{~cm}$ e de 99,4 $\mathrm{g} \mathrm{C} \mathrm{m}^{-2}$ ano $^{-1}$ para a camada de $0-40 \mathrm{~cm}$ de profundidade. $\mathrm{O}$ potencial de sequestro de $\mathrm{C}$ no plantio direto para os 9,43 milhões de hectares existentes na região Sul do Brasil foi estimado em 9,37 $\mathrm{Tg} \mathrm{C}$ ano $^{-1}$.

A estimativa de $\mathrm{C}$ e $\mathrm{N}$ na biomassa microbiana (BMC e BMN) do solo sob campo nativo foi significativamente superior a todos os tratamentos na cronossequência. Os valores estimados para o plantio direto foram os que mais se aproximaram da situação sob vegetação natural. A relação entre a BMC e os componentes da MOS, com base na média dos coeficientes de correlação $(n=150)$ decresceu na seguinte ordem: carbono orgânico dissolvido $>\mathrm{N}$ total $>$ carbono orgânico total $>$ polissacarídeos lábeis = polissacarídeos totais. Para a BMN essa ordem foi: $\mathrm{N}$ total > carbono orgânico dissolvido > carbono orgânico total > polissacarídeos lábeis > polissacarídeos totais. Nos tratamentos sob plantio direto foram observados as menores relações entre $\mathrm{C}_{\text {mic }}: \mathrm{C}_{\text {org }}$ na camada de $0-5 \mathrm{~cm}$ de profundidade e os maiores aumentos no estoque de $\mathrm{C}$.

$\mathrm{O}$ aumento do conteúdo de COT correlacionou positivamente com o $\mathrm{pH}$, as cargas negativas avaliadas pelo $\triangle \mathrm{pH}$, a CTC total, a CTC efetiva e negativamente com a acidez potencial. $\mathrm{O}$ aumento da fertilidade na camada superficial do solo nos tratamentos sob plantio direto está relacionado com o aumento da MOS. 


\title{
SOIL ORGANIC MATTER DYNAMICS IN A CONVENTIONAL AND NO-TILLAGE MANAGEMENT SYSTEMS
}

\author{
Autor: JOÃO CARLOS DE MORAES SÁ \\ Orientador: Prof. Dr. CARLOS CLEMENTE CERRI
}

\section{SUMMARY}

The soil organic carbon (SOC) pool was assessed in a Brazilian Oxisol under a plow and no-tillage chronosequence, located in the South Center of Paraná State. The chronosequence consisted of six land use treatments (i) native field (NF) comprising the natural vegetation of this region; (ii) plow tillage of the native field (PNF-1) conversion of natural vegetation to cropland; (iii) no-tillage for 10 years (NT-10); (iv) no-tillage for 20 years (NT-20); (v) no-tillage for 22 years (NT- 22); and (vi) conventional tillage for 22 years (CT-22). Soil samples were collected from five depths $(0-2.5,2.5-5,5-10,10-20$ and 20-40 cm depth).

The $\delta^{13} \mathrm{C}$ natural abundance measurements allowed calculations of the proportions of $\mathrm{C}$ derived from crop residues and natural vegetation. No-tillage compared to the NF treatment, caused a significant increase in SOC storage. This increase 57,9 to $81,2 \%$ occurred in the $0-10 \mathrm{~cm}$ soil layer. There was a decrease in SOC in the CT-22 compared to the NF treatment and $97 \%$ of this loss also occurred in the 0to $10-\mathrm{cm}$ layer. Regression analyses indicated a close relationship between the SOC content and the amount of crop residues input $\left(R^{2}=0.74, p<0.05\right)$ and for $1 \mathrm{MgC}$ of crop residues input increased $0,265 \mathrm{Mg}$ of SOC pool. The enrichment of SOC concentrations occurred from the coarse into the finer size fractions for the no-tillage 
treatments. The significant contribution of crop residues to SOC in the soil surface layers assessed by ${ }^{13} \mathrm{C}$ natural abundance was evident in the 200-2000 $\mu \mathrm{m}, 53-200 \mu \mathrm{m}$ and 20-53 $\mu \mathrm{m}$ particle size fractions. The SOC sequestration rate associated with notillage in this major ecological region of South Brazil was calculated to be $80.6 \mathrm{~g} \mathrm{C} \mathrm{m}^{-2}$ $\mathrm{yr}^{-1}$ for 0 to $20 \mathrm{~cm}$ soil layer and $99.4 \mathrm{~g} \mathrm{C} \mathrm{m}^{-2} \mathrm{yr}^{-1}$ for 0 to $40 \mathrm{~cm}$ layer. The no-tillage $\mathrm{C}$ sequestration potential for South Brazil based in 9.43 million hectares was estimated as

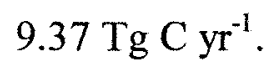

A significant difference for SMBC and SMBN in NF compared with all land use treatments. Therefore, the estimated values for no-tillage treatments were closely related to natural vegetation. The relationship among SMBC and SMBN with organic components based on the average of correlation coefficients decrease in the order of dissolved organic carbon $>$ total nitrogen $>$ soil organic carbon $>$ total polysaccharides $=$ labile polysaccharides and for $\mathrm{SMBN}$ was total nitrogen > dissolved organic carbon > soil organic carbon $>$ labile polysaccharides $>$ total polysaccharides. At no-tillage treatments were observed lower $\mathrm{C}_{\text {mic }}: \mathrm{C}_{\text {org }}$ ratio in 0 to $5 \mathrm{~cm}$ depth, while carbon storage were highest.

SOC concentration positively affected the $\mathrm{pH}$, the negative charge and the effective cation exchange capacity and negatively impacted potential acidity. As organic matter accumulate with long-term no-tillage, there is an attendant increase in soil fertility in these soils with variable charge. 


\section{INTRODUÇÃO}

A matéria orgânica do solo (MOS) é um componente chave dos ecossistemas terrestres e a variação na sua distribuição, conteúdo e qualidade têm um importante efeito nos processos que ocorrem dentro dos sistemas. Sua origem está relacionada ao acúmulo de compostos orgânicos, devido à conversão do $\mathrm{CO}_{2}$ atmosférico em carboidratos através da fotossíntese. Com a evolução da biota, o solo passa a atuar como uma fonte natural de $\mathrm{CO}_{2}$ devido aos processos básicos de oxidação e respiração causados pelos organismos e vegetais. Esse equilíbrio dinâmico é conceitualmente definido pelo princípio de correspondência entre as adições e perdas de matéria orgânica. Dependendo das práticas agrícolas e dos sistemas de manejo adotados, o solo pode atuar como fonte ou dreno do $\mathrm{CO}_{2}$ atmosférico. Em sistemas com perdas de matéria orgânica superiores as adições (levando ao rompimento deste equilíbrio), o solo pode atuar como uma fonte constante de $\mathrm{CO}_{2}$ para a atmosfera, resultando em perdas expressivas do conteúdo original da MOS.

A crescente preocupação com o impacto ambiental da exploração agropecuária tem estimulado a adoção de sistemas conservacionistas de manejo do solo. O perfil desses sistemas preconiza a redução de riscos relacionados aos fatores que afetam a produção agrícola, a viabilidade econômica, e a preservação ambiental. O plantio direto (PD), associado ao retorno de resíduos culturais, tem evoluído sensivelmente dentro do conceito de sistema conservacionista, tornando-se uma alternativa viável para reduzir o impacto ambiental da exploração agropecuária. Três pontos têm sido freqüentemente considerados como relevantes neste sistema: (a) redução sensível das perdas de solo por erosão; (b) aumento da matéria orgânica e da fertilidade do solo; e (c) menor custo de produção em relação ao preparo convencional. 
Do ponto de vista científico, pode-se afirmar que o aumento da MOS pode ser considerado o componente chave no PD, uma vez que inúmeros atributos do solo, alterados com a adoção desse sistema, estão estreitamente correlacionados com a MOS. A evolução nos estudos dos compartimentos da MOS em diferentes ecossistemas, tem sinalizado que o sistema PD pode ser uma alternativa de uso da terra que contribua com a redução da emissão de $\mathrm{CO}_{2}$ para a atmosfera.

No Brasil, a expansão do PD tem sido notável nos últimos anos. A estimativa para a safra atual é de 13,47 milhões de hectares sob esse sistema e que correspondem a aproximadamente $32 \%$ da área cultivada com grãos. Em função das características ecológicas e geomorfológicas das distintas regiões agrícolas no país e das alternativas quanto às opções de cultivo, um intenso questionamento tem sido realizado na avaliação dos beneficios desse sistema. Em vista da necessidade de estabelecer-se estratégias de manejo para as distintas regiões, torna-se fundamental o avanço do conhecimento quanto aos compartimentos da MOS.

A pesquisa foi concebida com base na hipótese de que a manutenção do sistema plantio direto por longo período, associado ao retorno de resíduos culturais, eleva o conteúdo da matéria orgânica do solo ao nível original ou superior ao da vegetação natural. Procurou o avanço no conhecimento da dinâmica da MOS considerando o efeito de uma cronossequência partindo da vegetação natural, envolvendo sistemas de manejo convencional e plantio direto como tratamentos de uso da terra. Os objetivos concentraram-se nos seguintes pontos: a) quantificar os ganhos e perdas de $\mathrm{C}$ e $\mathrm{N}$ no solo e nas frações granulométricas da MOS; b) quantificar a contribuição do $\mathrm{C}$ derivado dos resíduos culturais na MOS; c) as taxas de sequestro de carbono pelo sistema plantio direto; d) avaliar o impacto dos sistemas de manejo da cronossequência nas relações entre a biomassa microbiana do solo e componentes da MOS, e atributos da fertilidade do solo. 


\section{REVISÃO DE LITERATURA}

\subsection{O balanço global de carbono}

\subsubsection{Os reservatórios de carbono e as mudanças globais}

$\mathrm{O}$ equilibrio de $\mathrm{C}$ no globo terrestre é controlado por três reservatórios básicos: o oceânico, o atmosférico e o terrestre (Eswaran, et al., 1993). Esses reservatórios estão em equilíbrio dinâmico, interagindo e trocando carbono entre si.

O reservatório oceânico é o maior deles e foi estimado em $39000 \mathrm{Gt}(1 \mathrm{Gt}=$ Gigatonelada $=10^{15} \mathrm{~g}=1$ bilhão de toneladas métricas). O segundo maior é o reservatório terrestre, sendo constituído pelo geológico, o solo e a biota. O geológico, representado pelos combustíveis fósseis (carvão, petróleo e gás natural), é estimado em 5000 Gt. O reservatório do solo, estimado em 2000 a $2300 \mathrm{Gt}$, é constituído pelo carbono orgânico, cuja estimativa para a profundidade de $1 \mathrm{~m}$ varia de 1220 a $1550 \mathrm{Gt}$, e pelo carbono inorgânico, estimado em 695 a $748 \mathrm{Gt}$. A maior parte deste último situa-se abaixo da profundidade de $1 \mathrm{~m}$ (Eswaran, et al., 1993; Batjes, 1996; IPCC 2000). A biota, que compreende a biomassa vegetal, é o menor "pool" do reservatório terrestre e abriga $560 \mathrm{Gt}$. Na atmosfera, o conteúdo de carbono estimado foi de $760 \mathrm{Gt}$. A figura 1 (IPCC, 2000), sumariza de forma esquemática as inter-relações que ocorrem entre estes reservatórios.

O estoque de carbono orgânico nos solos do globo terrestre é aproximadamente três vezes superior à quantidade estimada para a biota, e o dobro do que existe na atmosfera (Eswaran et al., 1993; Lal et al., 1995; Batjes, 1996). O reservatório atmosférico está crescendo a uma taxa de $3,3 \mathrm{Gt}$ de $\mathrm{C}$ ano ${ }^{-1}$, principalmente devido às intervenções nos "pools" geológico, no C do solo e no biótico (IPCC, 2000). 




Figura 1. Reservatórios globais de carbono e fluxos para a atmosfera (unidades em Gt).

Antes do ser humano produzir distúrbios na biosfera e litosfera, o balanço de radiação na terra estava em equilíbrio, resultando na temperatura média de $15^{\circ} \mathrm{C}$. Se a atmosfera da Terra fosse composta somente de $\mathrm{N}_{2}$ e $\mathrm{O}_{2}$, a temperatura média da superfície terrestre seria de $-18^{\circ} \mathrm{C}$ ao invés da média atual de $15^{\circ} \mathrm{C}$ (IPCC, 1996). Essa diferença de $33^{\circ} \mathrm{C}\left(-18^{\circ} \mathrm{C}\right.$ para $\left.15^{\circ} \mathrm{C}\right)$ deve-se ao efeito estufa natural, controlado pela presença do forçamento radiativo dos gases traços na atmosfera $\left(\mathrm{H}_{2} \mathrm{O}, \mathrm{CO}_{2}, \mathrm{CH}_{4}, \mathrm{~N}_{2} \mathrm{O}\right.$, $\mathrm{O}_{3}$ ), o que torna o planeta habitável (IPCC, 1996). Os gases traços ou raros, possuem uma habilidade diferenciada e contrastante na absorção das ondas longas e no forçamento radiativo. $\mathrm{O}$ forçamento radiativo das moléculas de $\mathrm{CH}_{4}, \mathrm{~N}_{2} \mathrm{O}, \mathrm{O}_{3}$ e CFCs (clorofluorocarbonetos) é respectivamente, 58, 206, 1800 e 4000 vezes mais efetiva do que a molécula de $\mathrm{CO}_{2}$ na retenção da radiação das ondas longas (IPCC, 1996).

O termo "aquecimento global" refere-se a aceleração do efeito estufa natural devido as mudanças induzidas por ações antropogênicas no sistema terra-atmosfera 
(Schimel, 1995; Lal, 1999). A concentração troposférica dos gases traços tem aumentado desde a revolução industrial. Por exemplo, a concentração de $\mathrm{CO}_{2}$ na atmosfera aumentou de 280 para 366 ppm desde a era pré-industrial até a década dos 90 (IPCC, 2000), cuja taxa de incremento anual foi de $0,5 \%$. Da mesma forma, os outros gases causadores do efeito estufa tiveram aumentos expressivos: $\mathrm{CH}_{4}-0,8 \mathrm{ppm}$ para $1,74 \mathrm{ppm}\left(0,75 \%\right.$ ano $\left.^{-1}\right) ; \mathrm{N}_{2} \mathrm{O}-288 \mathrm{ppb}$ para $311 \mathrm{ppb}\left(0,25 \%\right.$ ano $\left.^{-1}\right)$.

Segundo Flach et al. (1997), em algum momento entre as décadas dos 50 e 60, a emissão anual de $\mathrm{CO}_{2}$, oriunda da queima de combustíveis fósseis, excedeu pela primeira vez a emissão de $\mathrm{CO}_{2}$ associada à conversão de florestas e pastagens naturais em áreas cultivadas.

A agricultura é um fator significativo no balanço de $\mathrm{CO}_{2}$ na atmosfera, embora a emissão de $\mathrm{CO}_{2}$ pela queima de combustíveis fósseis seja mais do que o dobro do $\mathrm{CO}_{2}$ emitido pelos sistemas agropecuários. A conversão de ecossistemas naturais em áreas agrícolas (desmatamento e queima de biomassa) e a oxidação da MOS devido ao preparo do solo, contribuem com aproximadamente $33 \%$ da emissão global líquida de $\mathrm{CO}_{2}$ (Flach et al., 1997; IPCC, 2000). O volume de $\mathrm{CO}_{2}$ emitido para a atmosfera contribui com $50 \%$ do efeito estufa, enquanto o $\mathrm{CH}_{4}$ contribui com $19 \%$, o $\mathrm{N}_{2} \mathrm{O}$ com $5 \%$, os CFC's com $15 \%$ e outros com $11 \%$ (IPCC, 2000).

\subsubsection{As perdas históricas de carbono por ações antropogênicas}

Em ecossistemas naturais o carbono orgânico do solo encontra-se em equilíbrio estável. A conversão para agroecossistemas, rompendo esse estado de equilibrio, altera o regime hidrotérmico, os ciclos elementares, a biodiversidade e reduz a MOS. A magnitude das perdas de MOS depende do reservatório de $\mathrm{C}$, da natureza do solo, dos fatores climáticos regionais e dos sistemas de manejo (Oldeman, 1994; Leemans, 1999). Os solos são a fonte natural de $\mathrm{CO}_{2}, \mathrm{CH}_{4}$ e de $\mathrm{N}_{2} \mathrm{O}$ em menor extensão. A decomposição aeróbica do $\mathrm{C}$ do solo produz $\mathrm{CO}_{2}$, enquanto a decomposição anaeróbica produz $\mathrm{CH}_{4}$, e a desnitrificação conduz à formação de $\mathrm{N}_{2} \mathrm{O}$ (Houghton \& Skole, 1990). 
De acordo com Lashof \& Hare (1999) a taxa atual de perdas de C devido às mudanças no uso da terra (conversão da vegetação natural em áreas agrícolas) foi estimada em 0,6 a $2,6 \mathrm{Gt}$ de $\mathrm{C}$ ano ${ }^{-1}$. Essa taxa pode aumentar com a pressão sobre florestas tropicais e a incidência de incêndios naturais ou ocasionais. A estimativa do fluxo líquido do forçamento radiativo dos gases ativos provenientes do desmatamento e queima de biomassa torna-se difícil, porque várias áreas desmatadas são abandonadas após alguns anos de exploração, reiniciando um novo ciclo de sequestro de $\mathrm{C}$ pelo crescimento de matas secundárias (Lashof \& Hare, 1999). Igualmente complexas são as estimativas das perdas históricas de $\mathrm{C}$ resultantes do uso da terra. Estimativas realizadas por diversos autores sobre as perdas globais do reservatório de $\mathrm{C}$ do solo refletem uma ampla faixa de variação: $150 \mathrm{Gt}$ de C (Bohn, 1978); 534 Gt de C (Buringh, 1984); 500 Gt de C (Wallace, 1994); 40 Gt de C (Houghton, 1995); 55 Gt de C (IPCC, 1996; Schimel, 1995). Os cálculos realizados por Eswaran et al. (1995) com base nas ordens dos solos e respectivas áreas de distribuição situaram as perdas históricas entre 66 a 90 Gt de C. Também foram estimadas as perdas de $\mathrm{C}$ devido aos processos de erosão (hídrica e eólica) na faixa de 19 a 32 Gt.

\subsection{O solo como fonte ou dreno de carbono}

\subsubsection{O impacto de sistemas de manejo na matéria orgânica do solo}

A matéria orgânica do solo (MOS) é um componente chave de qualquer ecossistema terrestre e a variação na sua distribuição, conteúdo e qualidade têm um importante efeito nos processos que ocorrem dentro do sistema. Dependendo das práticas de manejo adotadas, o solo pode agir como fonte ou dreno do $\mathrm{CO}_{2}$ atmosférico, contribuindo diretamente no efeito estufa.

Do ponto de vista agrícola, o solo torna-se uma fonte de $\mathrm{CO}_{2}$ para a atmosfera quando as perdas por oxidação são maiores do que as adições de C. Os sistemas de manejo que usam o preparo do solo para a produção vegetal constituem-se no principal fator dessas perdas (Bruce et al., 1999). Os mecanismos envolvidos nesse processo são 
os seguintes: a) a ruptura dos agregados expõe a MOS que está atuando como agente de ligação entre microagregados ao ataque da biomassa microbiana; b) a mistura de material orgânico fresco com o solo, resulta em condições mais favoráveis à decomposição; e c) aumento na atividade da biomassa microbiana devido a maior aeração do solo e ao aumento da oferta de fonte de carbono facilmente oxidável, resulta em maior fluxo de mineralização de C (Elliot, 1986; Powlson et al., 1987; Reicosky et al., 1995).

Por outro lado, o solo torna-se um dreno do $\mathrm{CO}_{2}$ atmosférico quando as adições de C são maiores do que as perdas por oxidação. De acordo com Bruce et al. (1999), a implementação de medidas integradas conforme os itens relacionados a seguir, é o caminho para o solo atuar como um dreno: a) redução e/ou eliminação da intensidade de preparo do solo; b) intensificação de sistemas de rotação de culturas; c) adoção de práticas que promovem o aumento da produtividade das culturas; e d) restabelecimento de cobertura vegetal permanente.

O equilibrio estável (steady-state) do reservatório de carbono no solo é o balanço entre adições (resíduos vegetais e adubos orgânicos), e perdas (decomposição e mineralização da matéria orgânica, resultando na liberação de $\mathrm{CO}_{2}$ para a atmosfera, e por erosão). A MOS é um componente dinâmico e vários modelos têm sido usados para descrever suas alterações com o tempo. A complexidade dos modelos varia desde uma abordagem simplificada e unicompartimental como a proposta de Henin \& Dupuis (1945) aos modelos multicompartimentais propostos por Jenkinson \& Rainer (1977), Van Veen \& Paul (1981), Janssen (1984) e Parton et al. (1987).

De acordo com Henin \& Dupuis (1945), Greenland \& Nye (1959) e Greenland (1971), a avaliação das alterações do $C$ do solo pela função $\mathbf{d C} / \mathbf{d t}=-\mathbf{K}_{\mathbf{2}} \mathbf{C}+\mathbf{K}_{\mathbf{1}} \mathbf{A}$, além de simples é ainda uma ferramenta usual para o entendimento do impacto de sistemas de manejo no $\mathrm{C}$ do solo. Nesse caso, $\mathbf{d C} / \mathbf{d t}$ representa a taxa de variação do $\mathrm{C}$ orgânico do solo com o tempo, $\mathbf{A}$ é a taxa de adição anual de $\mathrm{C}$ no solo $\left(\mathrm{t}\right.$ h $\left.{ }^{-1}\right), \mathrm{K}_{\mathbf{1}}$ representa $\mathrm{o}$ coeficiente de humificação do $\mathrm{C}$ orgânico, $\mathrm{C}$ é o carbono orgânico total do solo $\left(\mathrm{t} \mathrm{ha}^{-1}\right)$ e $K_{2}$ é a taxa de oxidação anual de $C\left(t h^{-1}\right)$ representada pela decomposição e mineralização. 
Três casos podem descrever essa função: a) quando $\mathbf{d C} / \mathbf{d t}=\mathbf{0}$ o C orgânico está em equilíbrio estável (steady-state), e as adições são iguais as perdas $\left(C=K_{I} A / K_{2}\right)$; b) quando $\mathbf{d C} / \mathbf{d t} \neq \mathbf{0}$ o sistema de manejo alterou as entradas e saídas de $\mathrm{C}$ no sistema. Quando a adição de $\mathrm{C}$ for menor do que a taxa de perda $(\mathrm{K} 1 \mathrm{~A}<-\mathrm{K} 2 \mathrm{C})$ ocorrerá um decréscimo na MOS; e c) quando $\mathbf{d C / d t} \neq \mathbf{0}$ e as adições forem superiores as perdas $\left(K_{1} A>-K_{2} C\right)$ ocorrerá aumento no estoque de $\mathrm{C}$ no solo. Adicionalmente, a medida que se aumenta o número de compartimentos, o modelo proporciona um melhor entendimento na dinâmica da MOS.

Inúmeros trabalhos mostraram que a conversão de ecossistemas naturais em áreas cultivadas, associadas ao uso de práticas de preparo do solo por longo período, causou perdas expressivas no conteúdo original da MOS. Em regiões de clima temperado, solos sob pastagens nativas no Canadá, perderam 41 a $53 \%$ do conteúdo original da MOS nos primeiros 40 a 50 anos (Campbell \& Souster, 1982) e em áreas sob floresta nos EUA, ocorreram perdas de 56 a $68 \%$ nos primeiros 25 anos (Mann, 1985). Em contraste, a perda de COT em regiões tropicais ocorre em períodos mais curtos (Lal \& Logan, 1995). Na região Nordeste do Brasil, Resck (1998) reportou perdas de $69 \%$ no conteúdo de COT em areias quartzosas ( $<15 \%$ de argila) e $49 \%$ em um Latossolo Vermelho ( $>30 \%$ de argila) nos primeiros cinco anos de cultivo com grade aradora.

Segundo Houghton \& Skole (1990), até a década dos 50, a fonte primária de emissão terrestre de $\mathrm{CO}_{2}$ eram os solos e a vegetação da região de clima temperado. A partir desta década, a região tropical tornou-se a principal fonte na emissão terrestre de $\mathrm{CO}_{2}$ devido ao avanço da exploração dos solos associado ao desmatamento e queima de biomassa. A taxa líquida de perda de C estimada por Houghton \& Skole (1990) foi de $0,2 \mathrm{Gt}$ para a região temperada e até $2,0 \mathrm{Gt}$ para a região tropical.

De uma maneira geral, o carbono orgânico tende a aumentar com a adoção de sistemas conservacionistas de manejo do solo. Dentre esses sistemas, o PD, associado ao retorno de resíduos vegetais e rotação de culturas tem se constituído como a principal alternativa para a recuperação da MOS, tanto para as regiões sob clima temperado quanto tropical. Nos EUA, Kern \& Johnson (1993) sumarizaram os resultados de 17 
experimentos de campo que incluíam 28 locais, comparando o efeito do PD com o preparo convencional no COT. O ganho aparente em COT nas parcelas sob PD em relação ao PC foi de $27 \%$ na camada de $0-8 \mathrm{~cm}, 16 \%$ na camada de $8-15 \mathrm{~cm}$ e ausência de ganho abaixo de $15 \mathrm{~cm}$ de profundidade. Da mesma forma, Dick et al. (1998) agruparam os resultados dos ensaios com mais de 20 anos de implantação, em solos da região leste do cinturão do milho dos EUA, e concluíram que os ganhos no $\mathrm{PD}$ em relação ao PC também ocorreram na camada superficial. Os resultados recentes de Lal (1997) e Bayer et al. (2000 b) para regiões tropicais e subtropicais indicaram a mesma tendência no acúmulo de COT.

\subsubsection{Potencial de sequestro de carbono em sistemas conservacionistas de manejo do solo}

O conhecimento dos processos envolvidos no sequestro de $\mathrm{C}$ torna-se importante no entendimento do potencial do solo como dreno para o $\mathrm{CO}_{2}$ atmosférico. A proteção física da MOS durante a agregação do solo tem sido o processo mais discutido (Tisdall \& Oades, 1982; Elliot, 1986; Carter, 1992; Cambardella \& Elliot, 1994; Beare et al., 1994a e b; Jastrow et al., 1996; Six, et al., 1999; Lal, 1999; Balesdent et al., 2000).

Vários trabalhos têm mostrado que a manutenção dos resíduos culturais na superficie do solo associada à redução e/ou eliminação do preparo do solo aumentam a agregação dos solos (Havlin et al., 1990; Carter, 1992; Beare, et al., 1994a e b). As transformações químicas de compostos orgânicos oriundos da decomposição lenta e gradual dos resíduos culturais e sua associação com a fase mineral promovendo a proteção fisica da MOS, tem sido a proposta geral do mecanismo que explica o sequestro de C no solo (Oades, 1988; Carter, 1992; Six, et al., 1999; Balesdent et al., 2000).

A maior evidência do papel da estrutura do solo na proteção fisica da MOS é a observação do aumento no fluxo de mineralização de $\mathrm{C}$ quando ocorre a ruptura de agregados, em comparação aos agregados intactos (Powlson, 1980; Elliot, 1986). Posteriormente, Reicosky et al. (1995) em medições "in situ", observaram que o maior 
fluxo de $\mathrm{CO}_{2}$ estava estreitamente correlacionado com a intensidade do preparo e o grau de fraturamento do solo. Estes argumentos convergem com as observações de Cambardella \& Elliot (1994), Beare et al. (1994 a) e Six et al.(1999), que comentaram sobre a localização e a função dọ $\mathrm{C}$ nos compartimentos dentro do agregado e a sua susceptibilidade aos processos de oxidação microbial.

O modelo conceitual para a formação hierárquica de agregados no solo apresentado por Tisdall \& Oades (1982) e posteriormente discutidos por Oades (1984), Elliot (1986), Dexter (1988) e outros, descreve a associação da MOS com três tipos de unidades físicas: as partículas primárias livres (areia, silte e argila), os microagregados e os macroagregados. Nesse modelo, os autores propuseram que a formação de agregados ocorre de uma forma hierárquica com a participação de três tipos de agentes cimentantes: a) transientes - são constituídos por polissacarídeos derivados da atividade microbial e de resíduos vegetais, os quais são rapidamente decompostos pelos microorganismos do solo; b) temporários - incluem raízes e hifas, especialmente de micorrizas; e c) persistentes - incluem as substâncias húmicas e aromáticas em associação com compostos amorfos de $\mathrm{Fe}, \mathrm{Al}$ e cátions metálicos polivalentes.

As partículas primárias e microestruturas de argila são ligadas através de restos de bactérias e fungos em microagregados de 2-20 $\mu \mathrm{m}$ de diâmetro, que por sua vez podem ser ligados aos restos e fragmentos de fungos e resíduos vegetais formando microagregados entre 20-250 $\mu \mathrm{m}$ de diâmetro. Nesta fase, acredita-se que os agentes orgânicos de ligação envolvidos na estabilização dos microagregados sejam os classificados como persistentes. Por outro lado, os microagregados unem-se para a formação de macroagregados (> $250 \mu \mathrm{m}$ de diâmetro), através de agentes de ligação transientes e temporários. Conforme vai aumentado o diâmetro dos macroagregados, os agentes temporários tornam-se mais importantes (Tisdall, 1996). O efeito direto de raízes vivas e hifas de fungos podem ser encarados dentro da visão tri-dimencional, que fisicamente enlaça microagregados e partículas primárias criando macroagregados estáveis (Oades \& Waters, 1991). Ao mesmo tempo, a natureza dessas associações organo-minerais e a sua distribuição espacial dentro da hierarquia do agregado, determina o grau em que o COT está fisicamente protegido da decomposição e os 
compartimentos orgânicos com diferentes entradas e taxas de retorno (Jastrow et al., 1996).

As estimativas do potencial de sequestro de $\mathrm{C}$ em sistemas conservacionistas de manejo do solo apresentam uma ampla faixa de variação. Nos EUA, Paustian et al. (1997) sumarizaram os resultados de 27 estudos, com 5 a 20 anos de implantação, nos quais foram medidos os ganhos de $\mathrm{C}$ no sistema $\mathrm{PD}$ comparado ao preparo convencional. Nesse período, os ganhos de C no PD variaram de -4 a $+10 \mathrm{Mg} \mathrm{ha}^{-1}$ $\left(\right.$ média $=+3 \mathrm{Mg} \mathrm{ha}^{-1}$ ). No Canadá, Janzen et al. (1997) também revisaram os dados de 17 diferentes locais onde havia a comparação entre o PD e PC e observaram resultados semelhantes aos encontrados nos EUA. Os autores enfatizaram os seguintes pontos sobre as alterações no $\mathrm{C}$ do solo: a) as perdas de $\mathrm{C}$ em solos de áreas cultivadas reduziram; b) os ganhos significativos de $\mathrm{C}$ (em torno de $3 \mathrm{Mg} \mathrm{ha}^{-1}$ ou menos) podem ser atribuídos em alguns solos a adoção de melhores práticas de manejo, tais como intensificação da rotação de culturas, redução da intensidade do preparo do solo; melhoria na nutrição das plantas, uso de adubos orgânicos e a adoção de vegetação perene; c) as mudanças no $\mathrm{C}$ do solo ocorreram predominantemente em frações jovens ou lábeis; d) os ganhos de C são de magnitude e duração finita e estão diretamente relacionados com a manutenção das melhorias adotadas no manejo do solo; e) as estimativas de $\mathrm{C}$ oriundas de pontos isolados são limitadas localmente e os melhores resultados são obtidos quando os locais estão inseridos em uma rede de trabalho; f) as entradas e saídas de energia devem ser incluídas no balanço de $\mathrm{C}$.

Recentemente, Bruce et al. (1999) sumarizaram as estimativas da taxa de sequestro de $\mathrm{C}$ para as áreas agrícolas dos EUA e Canadá. A taxa média de acúmulo de $\mathrm{C}$ estimada com razoável acurácia de dados oriundos de experimentos de longa duração é de $0,3 \mathrm{Mg} \mathrm{C}^{-1} \mathrm{ano}^{-1}$. Para estimar a taxa potencial de sequestro de $\mathrm{C}$ para o ano 2020, foram consideradas as seguintes condições: a) as melhores práticas possíveis (citadas por Janzen et al., 1997) para conservar o C no solo deverão ser adotadas em todas as áreas cultivadas e não degradadas nos EUA e Canadá a partir do ano 2000; e b) durante as primeiras duas décadas após a adoção dessas práticas, a taxa prevista de sequestro de $\mathrm{C}$ em resposta a essas medidas seria de $0,2 \mathrm{Mg} \mathrm{C}^{-1} \mathrm{ano}^{-1} \mathrm{em}$ solos onde 
a produtividade é limitada por baixa temperatura ou aridez, e $0,4 \mathrm{Mg} \mathrm{C} \mathrm{ha}^{-1} \mathrm{ano}^{-1} \mathrm{em}$ outros solos. Com base nessas condições, o ganho de C nessas áreas, nas próximas duas décadas, seria ao redor de $765 \mathrm{Tg}$ C. Somando esses ganhos aos estimados com a recuperação de áreas degradadas e com a conservação de solo e água, esse montante aumentaria para $1111 \mathrm{Tg}$ de C. Esse valor representa $65 \%$ do total estimado (1705 $\mathrm{Tg}$ de C).

Em regiões tropicais os dados ainda são incipientes e as projeções são limitadas, especialmente em relação a sistemas conservacionistas de manejo do solo. Embora $32 \%$ do estoque de $\mathrm{C}$ dos solos do mundo encontrarem-se na região tropical (Eswaran, 1993; Batjes, 1996) o banco de dados sobre experimentos de longa duração bem como as avaliações dos estoques de carbono ainda carecem de maiores detalhes. A amplitude de variação de taxas de sequestro de $C$ situa-se entre $0,17 \mathrm{Mg} \mathrm{ha}^{-1}$ ano ${ }^{-1}$ em solos do oeste da Nigéria (Lal, 1997) até $2,18 \mathrm{Mg} \mathrm{ha}^{-1}$ ano $^{-1}$ de $\mathrm{C}$ em um Oxisol sob o sistema PD no Brasil Central (Corazza, 1999). As estimativas para regiões subtropicais variam entre 1,33 $\mathrm{Mg} \mathrm{ha}^{-1}$ ano $^{-1}$ (Bayer et al., 2000 b) a 1,6 $\mathrm{Mg} \mathrm{ha}^{-1}$ ano $^{-1}$ (Amado et al., 1999).

A estimativa de áreas sob PD na América do Sul situa-se em 20,5 milhões de ha (FEBRAPDP, 2000; AAPRESID, 2000). Somente no território brasileiro, a área estimada situa-se em torno de 13,47 milhões de ha (65 \% da área total da América do Sul), a qual compreende $32 \%$ da área com produção de grãos.

\subsection{A influência do plantio direto em atributos do solo}

\subsubsection{Benefícios à fertilidade do solo}

Do ponto de vista da fertilidade do solo, os primeiros trabalhos de avaliação do sistema PD em região de clima temperado mostraram o efeito dos resíduos culturais no armazenamento de água no solo e da ciclagem de nutrientes no rendimento de grãos de milho (Triplett et al., 1969). Também foi constatado o efeito dos resíduos culturais no acúmulo de nutrientes na camada superficial e a estreita relação com o aumento nos teores de matéria orgânica em experimentos de longa duração (Triplett \& Van Doren, 
1969; Shear \& Moschler, 1969; Moschler et al., 1972). Da mesma forma, observou-se nesses experimentos de longa duração, a formação de camadas estratificadas com teores diferenciados dos nutrientes. Tem sido constatada a ocorrência de maior enriquecimento dos nutrientes na camada de 0 a $5 \mathrm{~cm}$. Dentre estes o fósforo têm apresentado os maiores incrementos, podendo ser 4 a 7 vezes superior no PD em relação ao preparo convencional (Shear \& Moschler, 1969).

Em regiões tropicais, Lal (1976) também observou a mesma tendência encontrada em solos sob clima temperado, e comentou que o efeito da interação entre os componentes do clima (temperatura e precipitação) na mineralização dos resíduos, e o não revolvimento do solo seriam os principais responsáveis pelo acúmulo de nutrientes nas camadas superficiais. Blevins et al. (1977) respalda a importância da interação desses fatores quanto a redução da amplitude térmica e da perda de água por evaporação devido a cobertura morta, resultando na melhoria do ambiente para a biomassa microbiana. Além disso, o contato dos resíduos culturais com o solo é limitado a uma estreita camada da superficie, propiciando decomposição lenta e gradual (Burle, 1997).

A alteração na dinâmica da matéria orgânica interfere não somente no ciclo de transformações dos nutrientes no sistema $\mathrm{PD}$, mas também na estrutura do solo na camada superficial (Oades, 1984). A manutenção da arquitetura de poros pela permanência das raízes das culturas, a ação da meso e macro fauna na fragmentação dos resíduos e formação de galerias influenciam na aeração e no movimento descendente da água, resultando em trocas mais intensas nesse sistema. A interligação dos processos de troca entre a camada superficial e a subsuperficial reflete nos mecanismos de adsorçãodessorção e retenção-lixiviação (Thomas et al., 1973; McMahon \& Thomas, 1976; Dick \& Van Doren, 1985; Dick et al., 1991).

Em condições brasileiras, provavelmente as primeiras citações sobre o efeito do preparo reduzido foram feitas no estado de Minas Gerais, em 1961, por Vieira e Frazier (Muzilli, 1981). Posteriormente, os trabalhos pioneiros de Ramos (1976) na região Centro-Sul do Paraná, Wunsche \& Denardin (1978) no planalto do Rio Grande do Sul e Mondardo (1978) no Norte do Paraná enfatizaram a eficiência do PD no controle das perdas de solo por erosão. 
Em relação à fertilidade do solo, também foi constatado o efeito dos resíduos culturais no acúmulo de nutrientes e sua influência nas culturas em sucessão (Muzilli, 1981, 1983 e 1985; Sidiras \& Pavan, 1985; Sá, 1993). Nestes trabalhos enfatizou-se o efeito da mineralização dos resíduos culturais, tal como nos resultados da década dos 70 nos EUA. Naturalmente, diferenças entre os resultados devem ser atribuídas a amplitude das condições edafoclimáticas das regiões brasileiras.

$\mathrm{Na}$ década dos 70 e 80 , o questionamento quanto ao manejo da fertilidade do solo no PD foi intenso em diversos segmentos da pesquisa e assistência técnica, principalmente sobre a correção da acidez e o modo de aplicação de fertilizantes. Entre os macronutrientes, o fósforo, devido a sua baixa mobilidade no solo e suscetibilidade às reações de fixação, ocupou a atenção em inúmeros trabalhos relacionados ao modo de aplicação.

Apesar das evidências apresentadas, os dados disponíveis ainda não explicam como os nutrientes oriundos da decomposição dos resíduos culturais ficam retidos na camada superfícial do solo. Esta questão está relacionada com a mineralogia dos solos brasileiros. Em geral, esta se caracteriza pela presença de argilas com baixa atividade, elevado conteúdo de óxidos e hidróxidos de $\mathrm{Fe}$ e $\mathrm{Al}$ e baixa capacidade de retenção de cátions. Além disso, a formação de cargas é predominantemente variável.

Os dados de Burle et al. (1997) mostraram que o sistema PD, com elevada adição de resíduos culturais tem efeitos significativos no aumento da CTC do solo. $\mathrm{Na}$ camada de 0-2,5 cm ocorreu um aumento de $70 \%$ na CTC, com menor expressão nas camadas de 2,5-7,5 e 7,5-15 cm de profundidade. A análise de regressão entre o COT e a CTC efetiva (CTCe) foi significativa $\left(\mathrm{R}^{2}=0,74 ; \mathrm{p}<0,01\right)$ e observaram um aumento de $1 \mathrm{cmol} \mathrm{kg}^{-1}$ na CTCe para cada 0,56 unidades de COT. Posteriormente, Bayer \& Bertol (1999) também constaram que esse efeito depende da quantidade de resíduos e da composição da rotação de culturas. A importância da MOS na CTC de solos brasileiros já havia sido discutida por Raij (1969), Pavan et al. (1985) e Silva et al. (1994). Esses autores mostraram que a MOS é responsável por 74 a $80 \%$ da CTC total. Alguns autores têm sugerido que para solos com carga variável, a estratégia apropriada de manejo é aumentar a carga negativa líquida e a CTCe (Sanchez, 1976; Uehara \& 
Keng, 1975; Uehara, 1995). O manejo da calagem, da gessagem e o uso de $\mathrm{P}$ nesses solos, são as medidas básicas para a elevação da MOS e de cargas negativas (Fox, 1980; Uehara, 1995).

\subsubsection{Alterações na biomassa microbiana do solo e em componentes da matéria orgânica}

A biota do solo representa entre 1 a $3 \%$ do COT e 3 a $5 \%$ do $\mathrm{N}$ total do solo (Anderson \& Domsch, 1989) e o componente microbial varia entre 100 a $1000 \mu \mathrm{g} \mathrm{C} \mathrm{g}^{-1}$ de solo. O fluxo de energia contido na biomassa é a força que controla a decomposição dos resíduos e detritos vegetais e animais, e determina quando o sistema está aumentando ou reduzindo o reservatório da MOS (Jenkinson \& Ladd, 1981).

O reservatório de carbono microbiano $\left(\mathrm{C}_{\text {mic }}\right)$ é fortemente influenciado pelos sistemas de manejo do solo (Carter \& Rennie, 1982; Juma \& McGill, 1986; Doran, 1987), pelo tipo e intensidade da rotação de culturas (Anderson \& Domsch, 1986; Bierderbeck et al., 1984) e pela incorporação de adubos orgânicos e resíduos culturais (Jenkinson \& Rayner, 1977; Insam \& Haselwander, 1989; Powlson et al., 1987; Anderson \& Domsch, 1986).

Os sistemas conservacionistas de manejo do solo afetam a distribuição horizontal e vertical da biota do solo (Doran, 1980; Staley et al., 1988; Arshad et al., 1990). Da mesma forma, a taxa de adição e os tipos de resíduos culturais mantidos na superficie do solo alteram a atividade da biomassa microbiana do solo (Franzluebbers et al., 1994).

Nas duas últimas décadas, a avaliação da biomassa microbiana de carbono (BMC) tem sido utilizada como um sensível indicador das primeiras alterações da MOS em sistemas agrícolas (Carter, 1986; Powlson et al., 1987; Sparling, 1992). A BMC responde mais rapidamente as alterações provocadas pelo manejo do solo na MOS antes que elas possam ser detectadas no COT (Jenkinson \& Ladd, 1981; Powlson, 1980; Powlson et al., 1987; Carter, 1992). 
Alguns autores têm proposto a utilização de parâmetros como a relação entre o carbono microbiano e o carbono orgânico $\left(\mathrm{C}_{\mathrm{mic}}: \mathrm{C}_{\text {org }}\right)$ e o quociente respiratório $\left(q \mathrm{CO}_{2}\right)$ para o entendimento da dinâmica da MOS (Anderson \& Domsch, 1989, 1990; Anderson \& Gray, 1990; Sparling, 1992). Uma extensa avaliação da relação $\mathrm{C}_{\mathrm{mic}}: \mathrm{C}_{\text {org }}$ foi realizada por Anderson \& Domsch (1989) em 134 parcelas de experimentos agrícolas de longa duração. Eles encontraram valores contrastantes cuja faixa de variação (expressa em porcentagem de $\mathrm{C}_{\text {mic }}$ em relação ao $\mathrm{C}_{\mathrm{org}}$ ) foi de $0,27 \%$ a $7 \%$, e citaram que esta variação se deve as diferenças no tipo de solo e manejo, à cobertura vegetal, à época de amostragem e as condições analíticas. Alterações na relação $\mathrm{C}_{\text {mic }}: \mathrm{C}_{\text {org }}$ indicam as entradas de matéria orgânica (conteúdo e qualidade), a eficiência da conversão do $\mathrm{C}$ orgânico, as perdas de $\mathrm{C}$ do solo e a estabilização do $\mathrm{C}$ orgânico pela fração mineral do solo (Sparling, 1992). Anderson \& Domsch (1989) sugeriram valores de equilibrio para a $\mathrm{C}_{\text {mic }}: \mathrm{C}_{\text {org }}$ de $2,3 \%$ para o tipo de uso da terra que adota somente monoculturas e de $2,9 \%$ para sistemas com rotação de culturas. Afirmaram que o uso de adubos verdes ou resíduos culturais aumentaria esses valores para 3,7 a $4,0 \%$. Posteriormente, Franzluebbers et al. (1994) mostraram que a intensidade da rotação de culturas associada ao $\mathrm{PD}$ aumentou para $5,5 \%$ e foi significativamente superior ao preparo convencional.

A relação $\mathrm{C}_{\text {mic }}: \mathrm{C}_{\text {org }}$ pode ser considerada um bom indicador das alterações da MOS na avaliação de sistemas de manejo do solo, entretanto, estas relações necessitam ser interpretadas considerando as condições climáticas locais. Por exemplo, foram obtidos os valores de $0,73 \%$ e $0,04 \%$ para a relação $\mathrm{C}_{\text {mic }}$ : $\mathrm{C}_{\text {org }}$ por Cerri et al. (1985) em um Oxisol sob floresta natural e floresta queimada da região Amazônica, respectivamente. Além destes, Balota et al. (1998) reportou relações $\mathrm{C}_{\text {mic }}: \mathrm{C}_{\text {org }}$ para o $\mathrm{PD}$ e PC inferiores as reladas por Anderson \& Domsch (1989) e Chaga (2000) em amostras da região dos cerrados, não encontrou diferença significativa entre os valores da BMC da mata nativa comparada as parcelas sob PD. Essas discrepâncias indicam que outros fatores estão influenciando na relação $\mathrm{C}_{\text {mic }}: \mathrm{C}_{\text {org }}$ e que a sua interpretação deve ser ajustada às condições locais. 
Do ponto de vista do manejo do solo, a sugestão de Duxbury et al. (1989) alocando os diferentes estágios da dinâmica do $\mathrm{C}$ em quatro compartimentos ou "pools", representa as possíveis alterações causadas pelo manejo:

- "Pool" ativo ou lábil - é constituído por compostos orgânicos facilmente oxidáveis derivados de fragmentos de vegetais recentes. É controlado principalmente pela adição de resíduos culturais, pelo clima e é fortemente afetado pelo tipo de manejo do solo. As modificações são rápidas e elevadas quantidades de $\mathrm{C}$ e $\mathrm{N}$ estão em função das transformações da biomassa microbiana;

- "Pool" lentamente oxidóvel - está relacionado com os macroagregados e é controlado pela mineralogia e pelos fatores agronômicos que interferem na agregação. Dentre estes os sistemas de manejo do solo afetam o tamanho desse reservatório;

- "Pool" muito lentamente oxidável - está relacionado com os microagregados e o fator controlador é a sua estabilidade em água. O sistema de manejo do solo tem um pequeno impacto nesse compartimento;

- "Pool" passivo ou recalcitrante - está relacionado com o $\mathrm{C}$ associado às partículas primárias do solo. É controlado pela mineralogia da fração argila, formando complexos organo-argílicos através decomposição microbial que reduz o $\mathrm{C}$ para formas elementares. Os sistemas de manejo do solo não influenciam esse compartimento.

A fração ativa da MOS é de particular interesse devido a sua contribuição no suprimento de nutrientes, e ao mesmo tempo pode responder mais rapidamente às mudanças nas práticas de manejo do solo. Considerando este ponto de vista, Bonde (1991) mostrou que o tempo de retorno do $C$ foi de 0,15 anos em dois solos sob clima tropical enquanto no solo sob clima temperado foi de 2 anos. Na mesma condição, observou que o reservatório ativo de $\mathrm{C}$ representou 21 a $25 \%$ do $\mathrm{C}$ total enquanto na condição temperada situou-se em $6 \%$. Isto significa que nos solos sob clima tropical, o tempo de retorno do $\mathrm{C}$ foi 13,3 vezes mais rápido e o reservatório ativo foi 3,5 a 4,2 vezes maior do que nas condições temperadas. Este e outros exemplos têm mostrado a 
magnitude dessas diferenças e por isso, as atenções sobre sistemas de manejo em regiões tropicais têm um enorme interesse.

Em condições tropicais, o compartimento ativo de $\mathrm{C}$ tem duas funções, além do suprimento de nutrientes age como fornecedor de compostos orgânicos que atuam como agentes de agregação do solo e na retenção de cátions (Duxbury et al., 1989; Oades et al., 1989). Outra questão está relacionada com o tipo e a quantidade de compostos orgânicos liberados durante o processo de mineralização dos resíduos culturais. Kuo et al. (1997) verificaram que coberturas de inverno alteraram significativamente o conteúdo de polissacarídeos, destacando a contribuição das leguminosas. Os polissacarídeos constituem os agentes transientes de agregação do solo (Greenland e Oades, 1975) e ao mesmo tempo também constituem a energia prontamente disponível para a biomassa microbiana do solo (Dalal \& Henry, 1988). Esses autores avaliaram o efeito do cultivo no conteúdo de polissacarídeos no solo e observaram que na fração leve da MOS, 27 a $43 \%$ do COT era devido aos polissacarídeos.

Considerando ainda que este compartimento é fortemente influenciado pelo sistema de manejo do solo, e que a magnitude dessas alterações indica se o sistema está ou não tendendo para perdas de MOS, torna-se imprescindível o conhecimento do impacto dos sistemas agrícolas em diferentes eco-regiões.

\subsection{Avaliação da matéria orgânica do solo}

O carbono orgânico está presente em muitas formas no solo e inúmeras abordagens têm sido aplicadas para a interpretação da dinâmica da MOS. As alterações nos conceitos da MOS estão relacionadas com a evolução dos métodos de avaliação nas diversas áreas da ciência (Christensen, 1992). A evolução dos conhecimentos na química tiveram um forte impacto nos métodos de pesquisa da MOS, e muitos experimentos e esforços em bases teóricas foram realizados para a identificação da sua estrutura (Kononova, 1961).

Nas últimas duas décadas, o avanço na instrumentação científica e a maior preocupação com o impacto ambiental dos sistemas agrícolas, desencadearam inúmeros 
trabalhos com a preocupação na interação entre os componentes dos compartimentos do C orgânico do solo (Jenkinson \& Ladd, 1981; Tisdall \& Oades, 1982; Cerri et al., 1985; Elliot, 1986; Parton et al., 1987; Christensen, 1992; Cambardella \& Elliot, 1994). Até então vigoravam basicamente duas linhas de pensamento sobre o estudo da MOS: a) os que procuravam saber o que é a matéria orgânica; e b) os que estavam preocupados em estudar o que a matéria orgânica faz. A integração desses pensamentos através da evolução científica adicionou novos desafios no entendimento da dinâmica da MOS.

\subsubsection{O fracionamento granulométrico}

As técnicas de fracionamento físico da MOS têm sido uma eficiente abordagem para caracterizar as relações entre a matéria orgânica e a agregação em macro e micro escala. O conceito que respalda o fracionamento físico da MOS enfatiza o papel dos minerais do solo na estabilização e nas taxas de retorno. As técnicas de fracionamento físico são consideradas menos destrutíveis e os resultados obtidos com este procedimento estão diretamente relacionados com a estrutura e as funções da MOS "in situ".

O fracionamento físico da MOS tem sido aplicado em estudos cujo objetivo é: a) recuperar a fração leve que é constituída de resíduos vegetais não decompostos e produtos de decomposição parcial; b) identificar a natureza da MOS em complexos organo-minerais; e c) determinar os tipos de MOS envolvidos na estabilização de agregados estáveis em água (Stevenson et al., 1989). Pode ser realizado com base em dois princípios gerais: - a densidade e o tamanho da partícula e/ou agregado. $\mathrm{O}$ fracionamento por densidade é utilizado para isolar a MOS que não está firmemente associada com a parte mineral do solo. Neste caso o solo é disperso em líquidos orgânicos pesados ou soluções salinas com densidades variando entre $1,6 \mathrm{a} \mathrm{2,2} \mathrm{g} \mathrm{mL}^{-1}$. $\mathrm{O}$ fracionamento granulométrico é baseado no conceito de que as frações da MOS associadas com partículas de tamanho e composição mineralógica diferentes, diferem em estrutura e função e cumprem papel específico na taxa de retorno da MOS (Christensen, 1992). 
Do ponto de vista metodológico, o fator que mais contribuiu para o avanço do fracionamento granulométrico foi a aplicação de vibrações ultrasônicas na dispersão de agregados sem alterar a configuração e as propriedades biológicas da MOS (Watson, 1971; Watson \& Parsons, 1974; Anderson et al., 1981; Tiessen \& Stewart , 1983; Christensen \& Sorensen, 1985).

Feller (1993) descreveram de forma sucinta a característica da MOS associada com diferentes frações granulométricas de solos tropicais: a) frações $>20 \mu \mathrm{m}$ - predominam restos de vegetais em diferentes estágios de decomposição, cuja relação $\mathrm{C} / \mathrm{N}$ varia de 12 a 33 (média $=20$ ); b) frações entre $2-20 \mu \mathrm{m}$ - é constituída principalmente por complexos organo-siltosos oriundos de restos de fungos e vegetais muito humificados, associados a microagregados organo-minerais estáveis. Não são destruídos durante o fracionamento e a relação $\mathrm{C} / \mathrm{N}$ varia entre 10 a 21 (média $=15$ ); e c) frações $<2 \mu \mathrm{m}$ - constituída por frações organo-argilosas, onde a matéria orgânica amorfa é o agente cimentante predominante. Em algumas situações, em solos sob vegetação de floresta e/ou savanas, foi verificado a presença de células da parede celular na fração grosseira da argila. Frequentemente, células de bactérias, ou mesmo colônias em diferentes estágios de decomposição podem ser encontradas em ambas frações. A relação $\mathrm{C} / \mathrm{N}$ varia de 7 a 12 (média $=10$ ).

Dependendo do tipo de solo e manejo, a fração 200-2000 $\mu \mathrm{m}$, descrita como a fração de restos de vegetais, representa em torno de 8 a $51 \%$ (média $=26 \%$ ) do COT. $\mathrm{Na}$ fração 2-20 $\mu \mathrm{m}$, a porcentagem de $\mathrm{C}$ em relação ao COT, varia de 11 a $40 \%$ (média $=26 \%$ ) e na fração $0-2 \mu \mathrm{m}$ o $\mathrm{C}$ varia de 20 a $70 \%$ do COT cuja média é de $44 \%$ (Feller, 1996).

$\mathrm{Na}$ última década, a aplicação do fracionamento granulométrico em estudos sobre a avaliação do impacto de sistemas de manejo no COT proporcionou um avanço notável no conhecimento dos compartimentos da MOS. Os resultados obtidos tanto em solos sob clima temperado quanto tropical têm mostrado que as frações granulométricas refletem as alterações provocadas pelo sistema de manejo do solo (Feller et al., 1993, 1994 e 1996; Carter, 1992; Cambardella \& Elliot, 1994; Beare et al., 1994a; Six, et al., 
1999). Em geral, a contribuição da adição de resíduos culturais é mais evidente nas frações mais grosseiras $(>200 \mu \mathrm{m})$ e/ou nos macroagregados (Cambardella \& Elliot, 1994; Beare et al., 1994a). Por outro lado, tem sido mostrado que há um aumento de substâncias humificadas associadas aos complexos organo-siltosos e organo-argilosos.

\subsubsection{0 uso de técnicas isotópicas na identificação da origem da matéria orgânica} do solo

A medida da abundância natural do ${ }^{13} \mathrm{C}$ têm sido usada como um traçador das alterações da MOS em estudos sob condições de campo (Cerri et al., 1985; Balesdent et al., 1987). O princípio básico dessa abordagem está baseado no fato das plantas terrestres discriminarem o ${ }^{13} \mathrm{C}$ durante a fotossíntese de forma diferenciada, de acordo com a sua habilidade na conversão do $\mathrm{CO}_{2}$ atmosférico em açúcares assimiláveis (Farquar et al., 1989). As plantas que possuem o ciclo de Calvin, e conhecidas como $\mathrm{C}_{3}$, apresentam valores para o $\delta^{13} \mathrm{C}$ que variam de $-35 \mathrm{a}-20 \%$. Por outro lado, as plantas sob o ciclo de Hatch-Slack, chamadas de $\mathrm{C}_{4}$, apresentam valores muito superiores às $\mathrm{C}_{3}$, variando de -19 a $-9 \%$. A abundância natural do ${ }^{13} \mathrm{C}$ representa aproximadamente $1,11 \%$ dos átomos de carbono da terra, e o material biológico varia em torno dessa média (Craig, 1957). A abundância do isótopo natural é expressa usando-se a notação $\delta$ e os valores por mil. A taxa isotópica é expressa como valores $\delta^{13} \mathrm{C}$, conforme a equação abaixo:

$$
\delta^{13} \mathrm{C}(\% 0)=\left[\left(\mathrm{R}_{\text {amostra }}-\mathrm{R}_{\text {padrão }}\right) / \mathrm{R}_{\text {padrão }}\right] \times 1000
$$

Onde $\mathrm{R}_{\text {amostra }}={ }^{13} \mathrm{C} /{ }^{12} \mathrm{C}$ da amostra e $\mathrm{R}_{\text {padrão }}={ }^{13} \mathrm{C} /{ }^{12} \mathrm{C}$ do padrão internacional, Pee Dee Beleminite (PDB) representado por uma amostra de calcário.

A composição isotópica da MOS reflete a vegetação original e sofre alterações na medida em que são introduzidas espécies vegetais com sinal de $\delta^{13} \mathrm{C}$ contrastante. Nesse caso, os valores de $\delta^{13} \mathrm{C}$ podem ser usados para identificar a MOS derivada dos resíduos da MOS original. 
Cerri et al. (1985), foram os primeiros a utilizar essa técnica no balanço da MOS envolvendọ a vegetação original (floresta natural, $\mathrm{C}_{3}$ ) e o cultivo de cana-de-açúcar $\left(\mathrm{C}_{4}\right)$. Mostraram que foi possível calcular a contribuição dos resíduos da cana na MOS como também as taxas de retorno do C. Na França, Balesdent et al. (1987) fizeram este balanço em frações granulométricas separadas por peneiramento úmido e constataram que nas frações acima de $200 \mu \mathrm{m}$ predominava a matéria orgânica mais jovem, provavelmente devido ao impacto do sistema adotado. Também calcularam a taxa de decomposição em função dos dados de COT. Assumindo-se uma decomposição exponencial, a taxa de retorno naquela situação foi estimada em 36 anos.

A partir desses trabalhos, outras variáveis foram introduzidas, principalmente para explicar a compartimentalização da MOS considerando o conceito de hierarquia na formação dos agregados (Tisdall e Oades, 1982). Os trabalhos de Cambardella \& Elliot (1992) e Beare et al. (1994a) mostraram as alterações nos compartimentos da MOS em várias unidades de agregados. $\mathrm{O}$ uso dessa técnica em sistemas envolvendo a mudança de vegetação $\mathrm{C}_{3}$ para $\mathrm{C}_{4}$ ou vice versa, tem sido ajustado na tentativa de avaliar o impacto da rotação de culturas associado aos sistemas de manejo. Recentemente Huggins et al., (1998) introduziram a componente rotação de culturas para avaliar a contribuição dos resíduos culturais na MOS. Apesar da pequena variação no $\delta^{13} \mathrm{C}$ de -1 a $-2 \%$, foi possível calcular a contribuição dos diversos sistemas de cultura em relação a MOS original. Os ajustes que vêm sendo introduzidos para a maximização do uso dessa técnica serão muito úteis para a modelagem da MOS em sistemas de manejo do solo associado à rotação de culturas. 


\section{DINÂMICA DA MATÉRIA ORGÂNICA E TAXAS DE SEQUESTRO DE CARBONO EM UMA CRONOSSEQUÊNCIA SOB SISTEMAS DE MANEJO CONVENCIONAL E PLANTIO DIRETO NUM OXISOL NO BRASIL}

\subsection{RESUMO}

A quantidade e a taxa de sequestro de carbono em sistemas de cultivo sob plantio direto não é conhecida em uma importante região ecológica no Sul do Brasil. O reservatório de carbono orgânico total (COT) foi avaliado em uma cronossequência envolvendo o preparo do solo e o plantio direto de um Latossolo Vermelho localizado na região Centro-Sul do Estado do Paraná. A cronossequência constituiu-se de seis tratamentos: a) campo nativo $(\mathrm{CN})$; b) preparo do campo nativo (PCN-1) envolvendo a conversão da vegetação natural em área agrícola; c) plantio direto por 10 anos (PD-10); d) plantio direto por 20 anos (PD-20); e) plantio direto por 22 anos (PD-22); e f) preparo convencional por 22 anos (PC-22) envolvendo o preparo do solo com uma aração a $20 \mathrm{~cm}$ de profundidade, após a colheita da cultura de verão e de inverno seguido de duas gradagens niveladoras. Amostras de solo foram coletadas em cinco profundidades $(0-2,5 ; 2,5-5 ; 5-10 ; 10-20$ e $20-40 \mathrm{~cm})$. A medida da abundância natural do ${ }^{13} \mathrm{C}$ permitiu que fosse calculada a proporção do $\mathrm{C}$ derivado dos resíduos culturais $\mathrm{e}$ da vegetação natural. Os tratamentos há longo período sob plantio direto (PD-20, PD22) comparados ao campo nativo proporcionaram aumento significativo no estoque de COT. Valores superiores a $60 \%$ desse aumento ocorreram na camada de $0-10 \mathrm{~cm}$ de profundidade. Por outro lado, $97 \%$ do decréscimo em COT no tratamento PC-22 também ocorreu nos primeiros $10 \mathrm{~cm}$ de profundidade. Análises de regressão indicaram estreito relacionamento entre o conteúdo de COT e o aporte de resíduos culturais $\left(R^{2}=\right.$ $0,74, \mathrm{p}<0,05)$. O aumento no conteúdo de COT no plantio direto a longo período foi 
maior nas frações granulométricas $200-2000 \mu \mathrm{m}, 53-200 \mu \mathrm{m}$ e $20-53 \mu \mathrm{m}$ do que nas frações finas. A taxa de sequestro de $\mathrm{C}$ no plantio direto foi de $80,6 \mathrm{~g} \mathrm{~m}^{-2}$ ano ${ }^{-1}$ para a camada 0-20 cm e de 99,4 $\mathrm{g} \mathrm{m}^{-2}$ ano $^{-1}$ para a camada de $0-40 \mathrm{~cm}$ de profundidade. $O$ potencial de sequestro de $\mathrm{C}$ no plantio direto para a região Sul do Brasil foi estimado em 9,37 $\mathrm{Tg} \mathrm{C} \mathrm{ano}^{-1}$.

\subsection{SUMMARY: ORGANIC MATTER DYNAMICS AND CARBON SEQUESTRATION RATES FOR A TILLAGE CHRONOSEQUENCE IN A BRAZILIAN OXISOL}

The amounts and rates of $\mathrm{C}$ sequestration under no-tillage are not know for a major ecological region of South Brazil. Soil organic carbon (SOC) pool was assessed in a Brazilian Oxisol under a plow and no-tillage chronosequence, located in the South Center of Paraná State. The chronosequence consisted of six treatments (i) native field (NF); (ii) plow tillage of the native field (PNF-1) - conversion of natural vegetation to cropland; (iii) no-tillage for 10 years (NT-10); (iv) no-tillage for 20 years (NT-20); (v) no-tillage for 22 years (NT-22); and (vi) conventional tillage for 22 years (CT-22). Soil samples were collected from five depths $(0-$ to $2.5-\mathrm{cm}, 2.5-$ to $5-\mathrm{cm}, 5-$ to $10-\mathrm{cm}, 10$ - to $20-\mathrm{cm}$ and $20-$ to $40-\mathrm{cm})$. The $\delta^{13} \mathrm{C}$ natural abundance measurements allowed calculations of the proportions of $\mathrm{C}$ derived from crop residues and natural vegetation. No-tillage compared to the NF treatment, caused a significant increase in SOC storage. More than $60 \%$ of this increase occurred in the $0-$ to $10-\mathrm{cm}$ soil layer. There was a decrease in SOC in the CT-22 compared to the NF soil treatment and $97 \%$ of this loss occurred in the 0 - to $10-\mathrm{cm}$ layer. Regression analyses indicated a close relationship between the SOC content and the amount of crop residues input $\left(\mathrm{R}^{2}=0.74, \mathrm{p}<0.05\right)$. The SOC derived from crop residues in no-tillage treatments assessed by $\delta^{13} \mathrm{C}$ natural abundance was significantly greater in the coarse (200- to $2000-\mu \mathrm{m}$, and $53-$ to $200-\mu \mathrm{m}$, and $20-$ to $53-\mu \mathrm{m})$ than the fine particle size fractions. However, increased SOC concentrations in long-term no-tillage soil were greater in the finer fractions (2- to 20- 
$\mu \mathrm{m}$. and 0 - to 2- $\mu \mathrm{m})$. The $\mathrm{C}$ sequestration rate for no-tillage was $80.6 \mathrm{~g} \mathrm{C} \mathrm{m}^{-2} \mathrm{yr}^{-1}$ for 0 to $20-\mathrm{cm}$ and $99.4 \mathrm{~g} \mathrm{C} \mathrm{m}^{-2} \mathrm{yr}^{-1}$ for $0-$ to $40-\mathrm{cm}$ depth. The no-tillage $\mathrm{C}$ sequestration

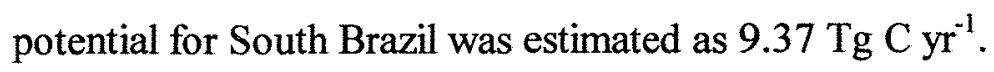

\subsection{INTRODUÇÃo}

O reservatório de carbono orgânico total (COT) nos solos do mundo em $1 \mathrm{~m}$ de profundidade situa-se na faixa de 1462 a $1576 \mathrm{Gt}\left(1 \mathrm{Gt}=10^{15} \mathrm{~g}=1\right.$ bilhão de toneladas métricas). Isto representa aproximadamente três vezes mais do que está armazenado na biomassa vegetal (parte aérea) e o dobro da quantidade existente na atmosfera (Eswaran et al., 1993; Batjes, 1996; IPCC, 2000). Aproximadamente 32\% desse total estão armazenados nos solos da região tropical (Eswaran et al., 1993; Lal et al., 1995).

As práticas culturais podem conduzir o solo a atuar como fonte ou dreno do $\mathrm{CO}_{2}$ atmosférico, influenciando diretamente no efeito estufa (Lugo \& Brown, 1993; Lal et al., 1995). A contribuição do $\mathrm{CO}_{2}$ atmosférico no forçamento radiativo é cerca de $50 \% \mathrm{e}$ $33 \%$ das emissões totais de $\mathrm{CO}_{2}$ para atmosfera é atribuída à agricultura, o desmatamento e ao uso da terra (IPCC, 2000).

Em regiões sob clima temperado, a tendência da redução do conteúdo original de $\mathrm{C}$ de solos sob pastagens nativas situa-se em 30 a 50\% nos primeiros 40 a 50 anos de cultivo (Campbell \& Souster, 1982; Mann, 1985). Por outro lado, a perda de C em regiões tropicais pode ser várias vezes superior (Lal \& Logan, 1995). Na região nordeste do Brasil, Resck (1998) reportou perdas de $69 \%$ do $\mathrm{C}$ nos primeiros cinco anos de cultivo utilizando implementos de disco (grade aradora e niveladora) em solos com menos de $150 \mathrm{~g} \mathrm{~kg}^{-1}$ de argila (areias quartzosas) e de $49 \%$ do $\mathrm{C}$ em Latossolos com mais de $300 \mathrm{~g} \mathrm{~kg}^{-1}$ de argila. $\mathrm{O}$ preparo do solo reduz a estabilidade dos agregados, causa o rompimento de macroagregados e expõe o $\mathrm{C}$ ao ataque microbiano (Tisdall \& Oades, 1982). Como consequêencia, há o aumento da taxa de mineralização de $\mathrm{C}$ devido à aeração, resultando num elevado fluxo de $\mathrm{CO}_{2}$ para a atmosfera (Elliot, 1986; Reicosky et al., 1995). 
Vários autores reportaram que a cobertura do solo devido ao resíduo cultural, associada ao manejo do solo sob plantio direto melhora a agregação e aumenta o conteúdo de carbono orgânico do solo (Havlin et al., 1990; Carter, 1992; Cambardella \& Elliot, 1992; 1993). Todavia, de acordo com Kern \& Johnson (1993), esse incremento no COT no solo tem sido restrito à camada superficial do solo. Esses autores revisaram os dados de 17 estudos de campo nos EUA, comparando o efeito de sistemas de manejo do solo convencional e plantio direto no conteúdo de COT. Constataram ganhos em COT no PD comparados ao PC de $27 \%$ na camada de $0-8 \mathrm{~cm}$, $16 \%$ na camada de $8-15 \mathrm{~cm}$ e nenhum aumento abaixo de $15 \mathrm{~cm}$ de profundidade. Em regiões tropicais, também tem sido reportado, que os ganhos significativos no conteúdo de COT no plantio direto ocorrem basicamente na camada de $0-10 \mathrm{~cm}$ de profundidade (Lal, 1976; Sá, 1993; Resk, 1998; Bayer et al., 2000 b).

A combinação de técnicas como a determinação do tamanho dos agregados estáveis em água, o fracionamento granulométrico da MOS e o uso da abundância natural do ${ }^{13} \mathrm{C}$ e técnicas de ressonância magnética e eletrônica, tem sido ferramentas muito úteis na investigação sobre o impacto do manejo dos resíduos culturais e do plantio direto na dinâmica do carbono no solo (Balesdent et al., 1987, 1990, 2000; Havlin et al., 1990; Carter, 1992; Christensen, 1992; Cambardella \& Elliot, 1992, 1993, 1994; Beare, et al., 1994 a, 1994 b; Jastrow et al., 1996; Feller et al., 1996; Rasmussen et al., 1998; Bayer et al., 2000 a).

Em solos da região tropical, o fracionamento granulométrico da MOS tem sido usado para caracterizar o relacionamento entre o $\mathrm{C}$ e a agregação em macro e micro escala (Feller, 1996). O conceito se baseia na associação das frações orgânicas do solo com as partículas minerais primárias de diferentes tamanhos, que diferem em estrutura $\mathrm{e}$ função, e tem papéis diferentes na ciclagem do carbono orgânico do solo (Christensen, 1992). Assim, a aplicação dessas técnicas é fundamental para o entendimento da dinâmica do $\mathrm{C}$ orgânico do solo, do efeito dos resíduos culturais na composição e no reservatório de $\mathrm{C}$, e o tempo de ciclagem e residência do $\mathrm{C}$ no solo. Bayer et al. (2000 a; b), usando a técnica do fracionamento granulométrico associado à ressonância eletrônica do spin e a ressonância magnética eletrônica do ${ }^{13} \mathrm{C}$ em solos do sul do Brasil, 
mostraram que as adições de resíduos culturais de diferentes sistemas de sucessão de culturas resultaram no aumento do $\mathrm{C}$ orgânico na camada superficial, cuja taxa de sequestro foi de $1,33 \mathrm{Mg} \mathrm{C} \mathrm{ha}^{-1} \mathrm{ano}^{-1}$. Ainda reportaram que o COT associado com a fração areia e a fração silte era menos humificado do que a associação com a fração argila. Guggenberg et al.(1995) também já havia reportado essa constatação em um Oxisol sob pastagens. Todavia, há outros estudos (Balesdent et al., 1987; Anderson \& Paul, 1984; Oades et al., 1987; Six et al., 1999; Six et al., 2000; Wander \& Yang, 2000) reportando que a fração mais humificada ou mais antiga está associada com as partículas de silte.

Em Oxisols, têm sido raros os estudos sobre a dinâmica do $\mathrm{C}$ em diferentes sistemas de manejo do solo, tendo como ponto de referência as condições originais da vegetação natural, representando o nível de equilíbrio estável do $\mathrm{C}$. Torna-se essencial a obtenção desses dados para o entendimento da magnitude dos ganhos e perdas de C, devido ao efeito de confundimento causado pela erosão dos solos e pela respiração microbiana nos fluxos e no conteúdo de C. Da mesma forma, informações sobre o potencial de sequestro de $\mathrm{C}$ em solos sob plantio direto constituindo uma cronossequência, ainda são escassas. Assim sendo, torna-se importante a geração dessas informações para desenvolver estratégias de manejo dos solos que conduzam para à sustentabilidade ambiental.

Este trabalho, teve como objetivo avaliar o efeito de uma cronossequência há longo período sob sistemas de manejo convencional e plantio direto em um Latossolo Vermelho nos seguintes aspectos: a) alterações no conteúdo total de $\mathrm{C}$ e $\mathrm{N}$ no solo e nas frações granulométricas da MOS; b) contribuição do $\mathrm{C}$ dos resíduos culturais no conteúdo do $\mathrm{C}$ orgânico total do solo, avaliado pela técnica da abundância natural de ${ }^{13} \mathrm{C}$; c) estimativa da taxa de sequestro de $\mathrm{C}$ devido ao plantio direto. 


\subsection{MATERIAL E MÉTODOS}

\subsubsection{Localização e descrição da área experimental}

As faixas selecionadas para a condução do experimento de campo estão localizadas em duas áreas sob produção agrícola comercial. Uma das áreas localiza-se na Fazenda Santa Branca (FSB), próxima a cidade de Tibagi e a outra na Fazenda Frankanna (FF), próxima a cidade de Ponta Grossa. Estas áreas estão enquadradas na região Centro-Sul do Estado do Paraná (Figura 2) cujas coordenadas geográficas de referência são: $50^{\circ} 23^{\prime} \mathrm{W}$ e $24^{\circ} 36^{\prime} \mathrm{S}$ (FSB); $50^{\circ} 20^{\prime} \mathrm{W}$ e $25^{\circ} 20^{\prime} \mathrm{S}$ (FF).

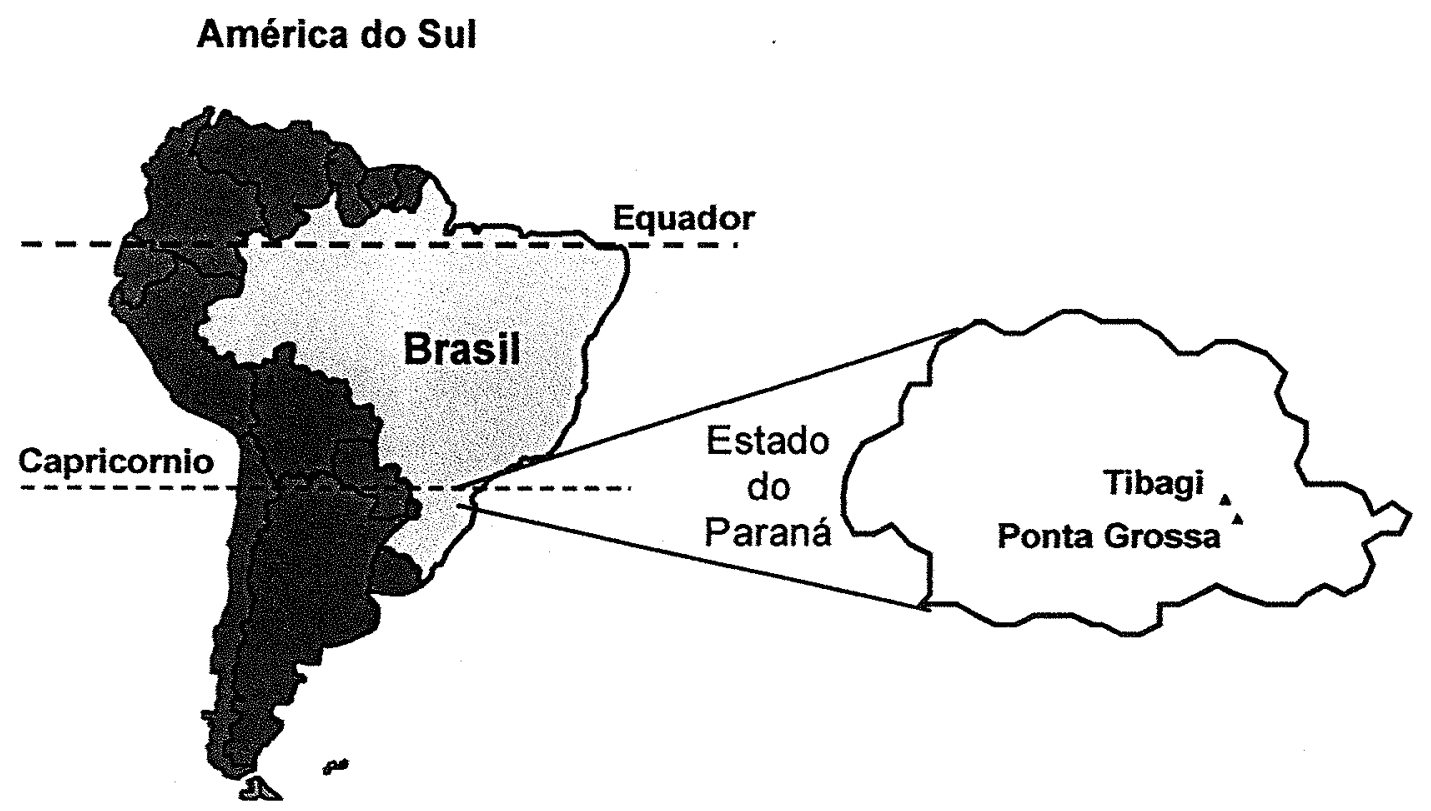

Figura 2. Mapa geral indicando a localização da área de estudo.

As áreas experimentais estão localizadas entre 880 a $910 \mathrm{~m}$ acima do nível do mar, sob o clima subtropical úmido, mesotérmico, do tipo cfb (classificação de Koeppen). Os verões são frescos, as geadas são freqüentes no inverno, a temperatura média no mês mais quente é $<22^{\circ} \mathrm{C}$ e do mês mais frio $<18^{\circ} \mathrm{C}$ e sem estação seca definida (Figura 3). 

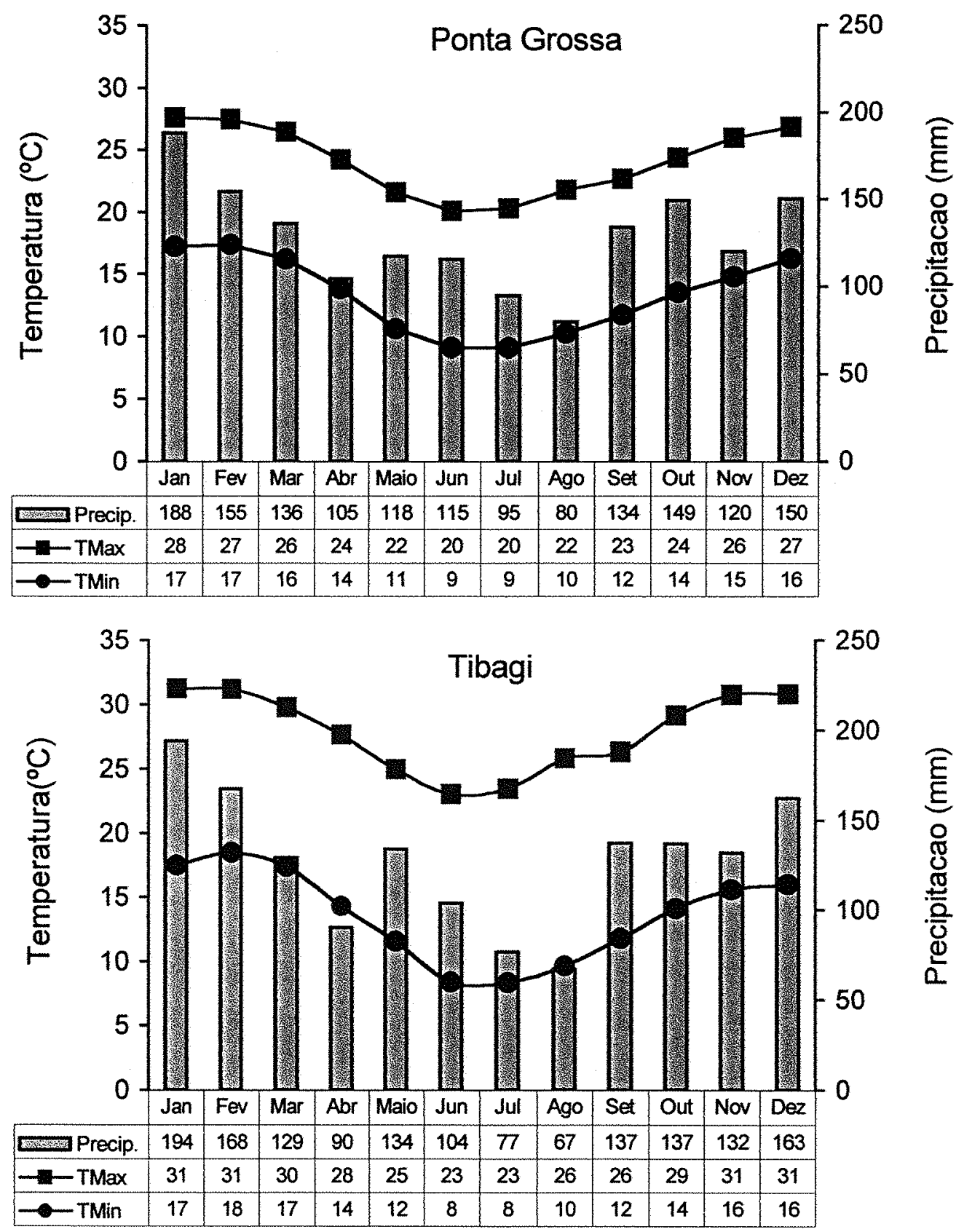

Figura 3.Distribuição mensal da precipitação pluviométrica (barras) acompanhada da média da temperatura máxima ( TMax) e temperatura mínima ( TMin) em Ponta Grossa e Tibagi. 
A pluviosidade média anual da cidade de Ponta Grossa (média de 44 anos IAPAR, $1998^{\mathrm{I}}$ ) e Tibagi (média de 24 anos - Fundação $\mathrm{ABC}, 1998^{2}$ ) são de $1545 \mathrm{~mm}$ e $1532 \mathrm{~mm}$, respectivamente. A vegetação natural é dominada por espécies $\mathrm{C}_{4}$ representadas por algumas gramíneas resistentes ao fogo tais como o Andropogon sp., Aristida sp., Paspalum sp., Panicum sp., e ao longo dos canais naturais de drenagem há ocorrência de floresta de galeria. $\mathrm{O}$ relevo caracteriza-se com suave ondulado com pendentes entre 2 a $7 \%$ de declividade.

O material de origem é constituído por sedimentos clásticos do período Devoniano, caracterizados por materiais retrabalhados de arenitos da formação Furnas e folhelhos da formação Ponta Grossa. Os solos foram classificados como Latossolos Vermelho (Typic Hapludox), textura argilosa, profundos, muitos bem estruturados e drenados.

Esses solos apresentam baixa fertilidade natural, possuem elevado conteúdo de Al trocável e estão situados na posição de topo. A descrição morfológica dos perfis e a coleta das amostras para as análises químicas e mineralógicas foram realizadas em trincheiras com dimensões de $1,5 \mathrm{~m} \times 1,5 \mathrm{~m} \times 1,5 \mathrm{~m}$ (Tabela $1 \mathrm{e} 2$ ).

A escolha das áreas experimentais baseou-se na existência de uma cronossequência bem definida, tendo como referência as condições originais de vegetação e solo. Além disso, possuem o mesmo material de origem, a mesma classe textural e localização na vertente (posição de topo). Foram também manejadas com práticas culturais e rotação de culturas similares (Tabela 1 e 2). Essa cronossequência oportuniza a avaliação do impacto do preparo do solo e do plantio direto há longo período nos compartimentos da MOS e de atributos da fertilidade do solo.

\footnotetext{
${ }^{1}$ INSTITUTO AGRONÔMICO DO PARANÁ. Área de ecofisiologia, Londrina, 1998. Dados climáticos.

${ }^{2}$ FUNDAÇÃO ABC. Castro, 1998. Dados climáticos.
} 
Tabela 1.Descrição morfológica dos perfis de Latossolos Vermelhos (Typic Hapludox) nas faixas selecionadas para constituir a cronossequência.

\begin{tabular}{|c|c|c|c|c|c|c|c|}
\hline$\underset{\ddagger}{\text { Tratmentos }}$ & Horiz & Prof. $^{\dagger}$ & $\begin{array}{l}\text { Cor da } \\
\text { Matrix }\end{array}$ & Textura & Consistência & Estrutura & $\begin{array}{l}\text { Dens. } \\
\text { Solo }\end{array}$ \\
\hline & & $\mathrm{cm}$ & Úmida & & & & $\mathrm{Mg} \mathrm{m}^{-3}$ \\
\hline $\mathrm{CN}$ & A & $0-19$ & $5 \mathrm{YR} 3 / 4$ & Argilosa & Friável & M.fina, gran. ${ }^{\S}$ & 1,39 \\
\hline \multirow[t]{4}{*}{ (Tibagi) } & $\mathrm{AB}$ & $20-29$ & SYR 4/4 & Argilosa & Friável & M.fina, gran. & 1,24 \\
\hline & $\mathrm{BA}$ & $30-39$ & 2,5 YR $3 / 6$ & Argilosa & Friável & M.fina, gran. & 1,34 \\
\hline & Bw1 & $40-85$ & 2,5 YR $3 / 6$ & Argilosa & Friável & M.fina, gran. & 1,29 \\
\hline & $\mathrm{Bw} 2$ & $86-150+$ & $2,5 \mathrm{YR} 4 / 6$ & Argilosa & Friável & M.fina, gran. & 1,37 \\
\hline PCN-1 & A & $0-19$ & $2,5 \mathrm{YR} 3 / 4$ & Argilosa & Friável & M.fina, gran. & 1,04 \\
\hline \multirow[t]{4}{*}{ (Tibagi) } & $\mathrm{AB}$ & $20-29$ & $2,5 Y R \quad 3 / 4$ & Argilosa & Friável & M.fina, gran. & 1,16 \\
\hline & $\mathrm{BA}$ & $30-38$ & $2,5 Y R 3 / 6$ & Argilosa & Friável & M.fina, gran. & 1,22 \\
\hline & Bw1 & $39-77$ & $2,5 Y R 3 / 6$ & Argilosa & Friável & M.fina, gran. & 1,20 \\
\hline & $\mathrm{Bw} 2$ & $78-150+$ & $2,5 Y R 3 / 6$ & Argilosa & Friável & M.fina, gran. & 1,19 \\
\hline PD-10 & A & $0-14$ & $5 Y R 3 / 3$ & Argilosa & Friável & M.fina, gran. & 1,55 \\
\hline \multirow[t]{4}{*}{ (Tibagi) } & $\mathrm{AB}$ & $15-21$ & $5 Y R 4 / 4$ & Argilosa & Friável & M.fina, gran. & 1,64 \\
\hline & $\mathrm{BA}$ & $22-33$ & 2,5 YR $3 / 6$ & Argilosa & Friável & M.fina, gran. & 1,56 \\
\hline & Bw1 & $34-80$ & 2,5 YR $3 / 6$ & Argilosa & Friável & M.fina, gran. & 1,46 \\
\hline & $\mathrm{Bw} 2$ & $81-150+$ & $2,5 \mathrm{YR} 4 / 6$ & Argilosa & Friável & M.fina, gran. & 1,44 \\
\hline PD-20 & A & $0-20$ & 5YR $3 / 4$ & Argilosa & Friável & M.fina, gran. & 1,31 \\
\hline \multirow[t]{4}{*}{ (Tibagi) } & $\mathrm{AB}$ & $21-27$ & $5 Y R 4 / 4$ & Argilosa & Friável & M.fina, gran. & 1,26 \\
\hline & $\mathrm{BA}$ & $28-38$ & $2,5 Y R 3 / 6$ & Argilosa & Friável & M.fina, gran. & 1,32 \\
\hline & Bw1 & $39-88$ & $2,5 Y R 3 / 6$ & Argilosa & Friável & M.fina, gran. & 1,33 \\
\hline & $\mathrm{Bw} 2$ & $89-150+$ & $2,5 \mathrm{YR} 4 / 6$ & Argilosa & Friável & M.fina, gran. & 1,37 \\
\hline $\mathrm{PD}-22^{\dagger \dagger}$ & A & $0-20$ & $5 Y R 3 / 4$ & Argilosa & Friável & M.fina, gran. & 1,25 \\
\hline PC-22 & $\mathrm{AB}$ & $21-33$ & 2,5YR 3/4 & Argilosa & Friável & M.fina, gran. & 1,20 \\
\hline \multirow[t]{3}{*}{ (P.Grossa) } & $\mathrm{BA}$ & $34-56$ & 2,5 YR $4 / 4$ & Argilosa & Friável & M.fina, gran. & 1,18 \\
\hline & Bw1 & $57-93$ & 2,5 YR $4 / 6$ & Argilosa & Friável & M.fina, gran. & 1,14 \\
\hline & $\mathrm{Bw} 2$ & $94-150+$ & 2,5YR 4/6 & Argilosa & Friável & M.fina, gran. & 1,12 \\
\hline
\end{tabular}

‡ Foi aberta uma trincheira em cada faixa selecionada da cronossequência. $\mathrm{CN}=$ campos nativos representando a vegetação natural, $\mathrm{PCN}-1$ = preparo do campo nativo, representando a fase inicial da conversão para área agrícola, $\mathrm{PD}-10=$ plantio direto há 10 anos, PD-20 = plantio direto há 20 anos, PD-22 = plantio direto há 22 anos e PC-22 = preparo convencional há 22 anos; ${ }^{\S} \mathrm{M}$. fina gran. = muito fina e granular; ${ }^{\dagger \dagger}$ Para esses dois tratamentos foi aberta uma trincheira; ${ }^{\dagger}$ Profundidade do perfil $>150 \mathrm{~cm}$. 
Tabela 2. Propriedades químicas e mineralógicas do Latossolo Vermelho (Typic Hapludox) nas áreas dos diferentes sistemas de manejo da cronossequência.

\begin{tabular}{|c|c|c|c|c|c|c|c|}
\hline \multirow[t]{2}{*}{ Propriedades } & \multirow{2}{*}{$\begin{array}{l}\text { Prof. } \\
\text { (cm) }\end{array}$} & \multicolumn{6}{|c|}{ Tratamentos ${ }^{\S}$} \\
\hline & & $\mathrm{NF}$ & PCN-1 & PD-10 & PD-20 & PD-22 & PC-22 \\
\hline \multicolumn{8}{|l|}{ Químicas } \\
\hline \multirow[t]{2}{*}{$\mathrm{pH}\left(1: 2,5\right.$ solo $\left./ \mathrm{H}_{2} \mathrm{O}\right)$} & $0-20$ & 4,9 & 5,6 & 6,3 & 6,3 & 6,3 & 6,0 \\
\hline & $20-40$ & 5,0 & 4,7 & 5,7 & 5,3 & 5,2 & 4,9 \\
\hline \multirow{2}{*}{ Acidez potencial, $\mathrm{mmol}_{\mathrm{c}} \mathrm{kg}^{-1}$} & $0-20$ & 97 & 132 & 42 & 62 & 51 & 53 \\
\hline & $20-40$ & 80 & 127 & 47 & 71 & 58 & 80 \\
\hline \multirow[t]{2}{*}{ Al trocável, $\mathrm{mmol}_{\mathrm{c}} \mathrm{kg}^{-1}$} & $0-20$ & 13 & 22 & 0,7 & 0,8 & 0,7 & 1,5 \\
\hline & $20-40$ & 9,7 & 37 & 2,0 & 4,0 & 3,0 & 5,0 \\
\hline \multirow{2}{*}{ Ca trocável, $\mathrm{mmol}_{\mathrm{c}} \mathrm{kg}^{-1}$} & $0-20$ & 5,4 & 34 & 48 & 53 & 47 & 45 \\
\hline & $20-40$ & 1,6 & 3,6 & 14 & 12 & 9 & 11 \\
\hline \multirow{2}{*}{$\mathrm{Mg}$ trocável, $\mathrm{mmol}_{\mathrm{c}} \mathrm{kg}^{-1}$} & $0-20$ & 1,7 & 22 & 19 & 22 & 21 & 22 \\
\hline & $20-40$ & 1,0 & 2,0 & 7,0 & 5,0 & 6,0 & 6,0 \\
\hline \multirow{2}{*}{$\mathrm{K}$ trocável, mmol $_{\mathrm{c}} \mathrm{kg}^{-1}$} & $0-20$ & 1,2 & 3,4 & 2,2 & 3,7 & 4,6 & 4,1 \\
\hline & $20-40$ & 0,3 & 1,2 & 0,7 & 1,1 & 2,1 & 2,2 \\
\hline \multirow{2}{*}{ CTC, mmolc kg ${ }^{-1}$} & $0-20$ & 105 & 179 & 109 & 137 & 123 & 124 \\
\hline & $20-40$ & 83 & 134 & 69 & 89 & 75 & 99 \\
\hline \multirow{2}{*}{$\mathrm{P}, \mathrm{mg} \mathrm{kg}^{-1}$} & $0-20$ & 6,3 & 15 & 24 & 35 & 73 & 27 \\
\hline & $20-40$ & 3,0 & 5,0 & 4,0 & 4,0 & 4,0 & 3,0 \\
\hline \multicolumn{8}{|l|}{ Mineralógicas } \\
\hline \multirow{4}{*}{ Raio X da Fração argila } & Bwl & $\mathrm{Ct}^{\ddagger \neq}$ & $\mathrm{Ct}$ & $\mathrm{Ct}$ & $\mathrm{Ct}$ & $\mathrm{Ct}$ & - \\
\hline & & Gib & Gib & Gib & Gib & Gib & - \\
\hline & & Hem & Hem & Hem & Hem & Hem & - \\
\hline & & Goe & Goe & Goe & Goe & Goe & - \\
\hline \multicolumn{8}{|l|}{$\mathrm{ATD}^{\ddagger \ddagger \ddagger}$ (\% fração argila) } \\
\hline $\mathrm{Ct}^{\ddagger \ddagger}$ & Ap & 17,6 & 16,8 & 16,0 & 11,5 & 14,1 & - \\
\hline Gib & & 39,7 & 17,6 & 45,2 & 46,7 & 44,3 & - \\
\hline $\mathrm{Ct}$ & Bw1 & 16,3 & 15,5 & 11,8 & 10,2 & 10,9 & - \\
\hline Gib & & 39,4 & 20,8 & 38,4 & 46,4 & 37,4 & - \\
\hline
\end{tabular}

§Ver tabela 1 sobre a descrição dos sistemas de manejo; ${ }^{\ddagger} \mathrm{A}$ análise de Raios-X foi realizada em amostras do horizonte $\mathrm{Bw1} ;{ }^{\ddagger \ddagger} \mathrm{Ct}=$ Caulinita, Gib $=$ Gibbsita, Hem $=$ Hematita, Goe $=$ Goethita; ${ }^{\ddagger \ddagger}$ ATD $=$ Análise Térmica Diferencial, resultados expressos em porcentagem da fração argila. A ATD foi realizada em amostras do horizonte Ap e Bw1.

3.4.2 Conversão da vegetação natural em sistemas agrícolas, descrição da cronossequência, rotação de culturas e práticas culturais

Antes do início da exploração agrícola na FSB e FF, as áreas estavam sob a vegetação natural, denominada "Campos Gerais" que representa o tratamento $\mathrm{CN}$. A 
conversão dos campos nativos em áreas de cultivo na FSB iniciou em 1969. Nesta época, foi aplicado $3,5 \mathrm{Mg} \mathrm{ha}^{-1}$ de calcário dolomítico para a correção da acidez e incorporado através de uma grade aradora com discos de $70 \mathrm{~cm}$ de diâmetro. A complementação da incorporação do calcário, o quebramento dos torrões e o nivelamento do terreno foram através de duas gradagens niveladoras. Antes dessa operação foram aplicados $117 \mathrm{~kg} \mathrm{ha}^{-1}$ de $\mathrm{P}_{2} \mathrm{O}_{5}$.

Entre 1969 e 1979 foi cultivado arroz (Oryza sativa) nos primeiros três anos e mantendo-se pousio no inverno. No restante do período, cultivou-se soja (Glicine max. L. Merril) no verão e trigo (Triticum aestivum) no inverno e sob preparo convencional. Durante este período de 10 anos, para complementar a correção da acidez foi incorporado calcário dolomítico três vezes na dose de $2 \mathrm{Mg} \mathrm{ha}^{-1}$.

Em 1979, foi adotado o plantio direto em aproximadamente $30 \%$ do total da área. O tratamento com 20 anos sob plantio direto (PD-20) está representado por esta área. Entre 1979 e 1998 foram 39 cultivos assim distribuídos: no verão cultivou-se soja 15 vezes e milho (Zea mays L.) cinco vezes e durante o inverno foram 11 cultivos de aveia preta (Avena strigosa, Schreb), sete cultivos de trigo e dois cultivos de tremoço azul (Lupinus angustifollios). Os cultivos de aveia preta e tremoço azul foram destinados exclusivamente para adubação verde e formação de cobertura do solo. Em 1989, a área vizinha ao PD-20, que estava em pousio, foi convertida para o plantio direto. Esta representa o tratamento com plantio direto há 10 anos (PD-10). Entre 1989 e 1998, foram 20 cultivos, sendo sete vezes soja e três vezes milho no verão, e 6 cultivos de aveia preta e quatro cultivos de trigo no inverno.

Nos tratamentos PD-20 e PD-22 foram realizadas quatro aplicações de calcário em superfície na dose de $1,5 \mathrm{Mg} \mathrm{ha}^{-1}$ e duas aplicações no PD-10. Em junho de 1996, outra área adjacente foi convertida em agricultura para representar a fase inicial da conversão da vegetação natural em área agrícola. Esta se refere ao tratamento denominado preparo do campo nativo (PCN-1). Nesta área foi aplicado $3,5 \mathrm{Mg} \mathrm{ha}^{-1} \mathrm{de}$ calcário, $140 \mathrm{~kg} \mathrm{ha}^{-1}$ de superfosfato simples, incorporados à profundidade de $20 \mathrm{~cm}$, seguindo o mesmo procedimento realizado anteriormente aos tratamentos PD-10 e PD20. Durante o período de conversão do campo nativo (um ano e seis meses) foi 
cultivado soja (outubro/96), aveia preta (maio/97) e milho (setembro/97). A figura 4 ilustra o uso da terra e a distribuição temporal dos tratamentos.

\section{Fazenda Santa Branca}

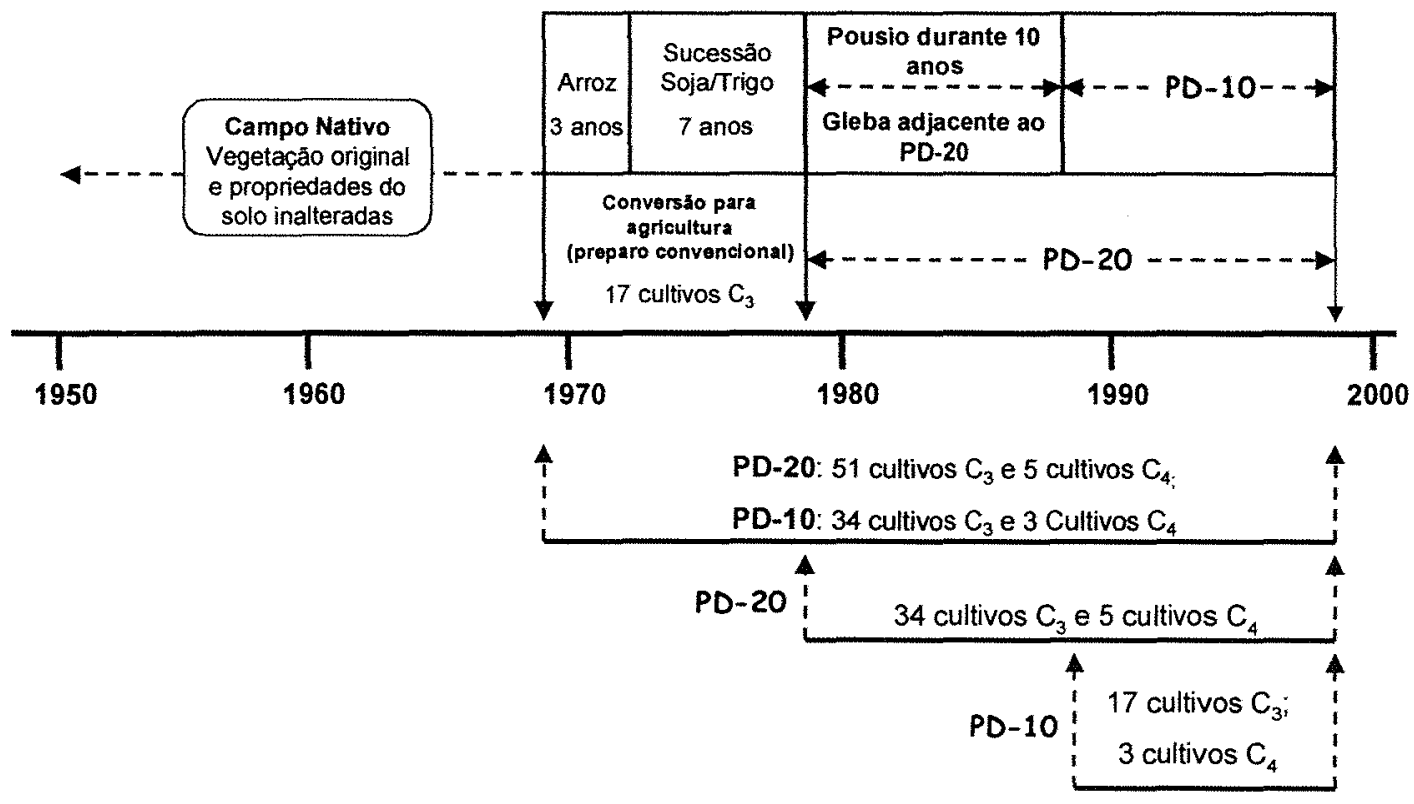

\section{Fazenda Frankanna}

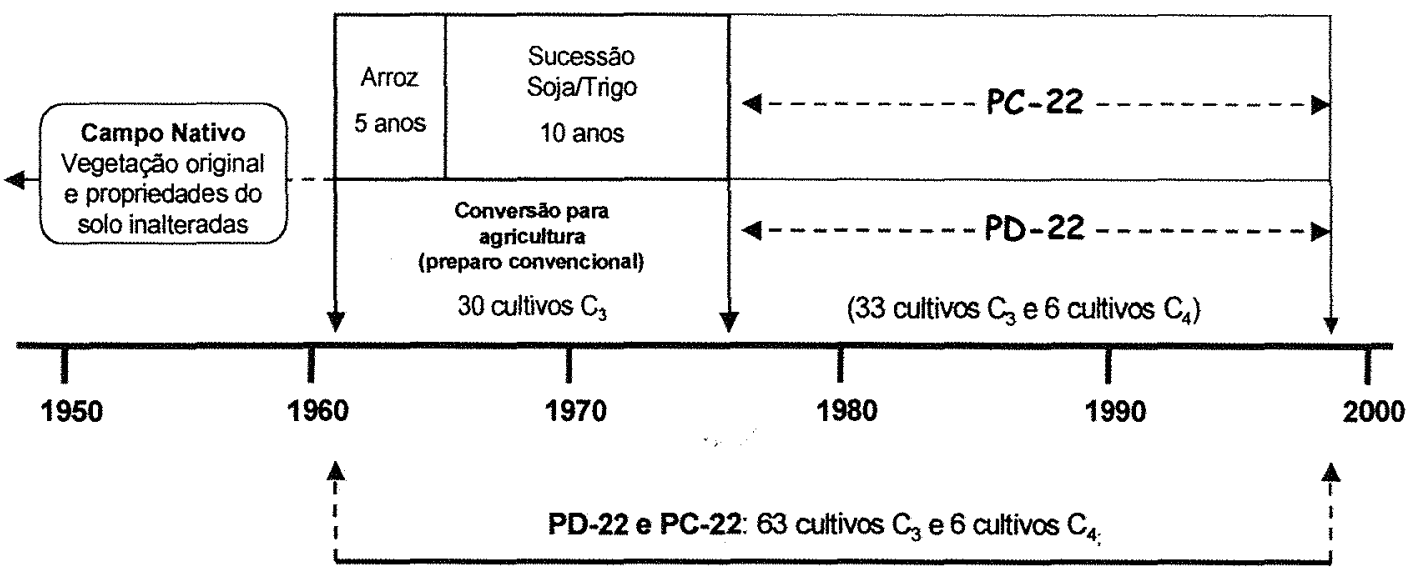

Figura 4. Representação esquemática do uso da terra nas Fazendas Santa Branca e Frankanna. Plantio direto há 10 (PD-10), plantio direto há 20 anos (PD-20), plantio direto há 22 anos (PD-22) e preparo convencional a 22 anos (PC-22). 
Na Fazenda Frankanna o início da exploração agrícola ocorreu em 1961. O manejo do solo realizado entre 1961 e 1976 (preparo do solo, culturas, calagem e quantidade de P) foi semelhante à Fazenda Santa Branca. Em 1976, duas áreas com três ha cada foram destinadas à comparação entre o preparo convencional e o plantio direto, os quais representam os tratamentos com plantio direto há 22 anos (PD-22) e o preparo convencional há 22 anos (PC-22). Neste último, o preparo do solo foi realizado após a colheita da cultura de verão e de inverno, através de uma aração e duas gradagens para atingir a profundidade de $20 \mathrm{~cm}$. No período entre 1976 e 1998 houveram 15 cultivos de soja e seis de milho no verão. No inverno houveram 10 cultivos de trigo, quatro de aveia preta, um de tremoço azul e o azevém (Lollium multiflorum) nas últimas quatro estações. Em 1996 e 1997, nesses dois tratamentos foram aplicados 15 a $20 \mathrm{~m}^{-3} \mathrm{ha}^{-1}$ de esterco líquido de bovinos. A rotação de culturas nas áreas estudadas foi constituída por uma seqüência de seis cultivos que se reiniciam a cada três anos ilustrada na figura 5 .

\section{Sequência de 3 anos}

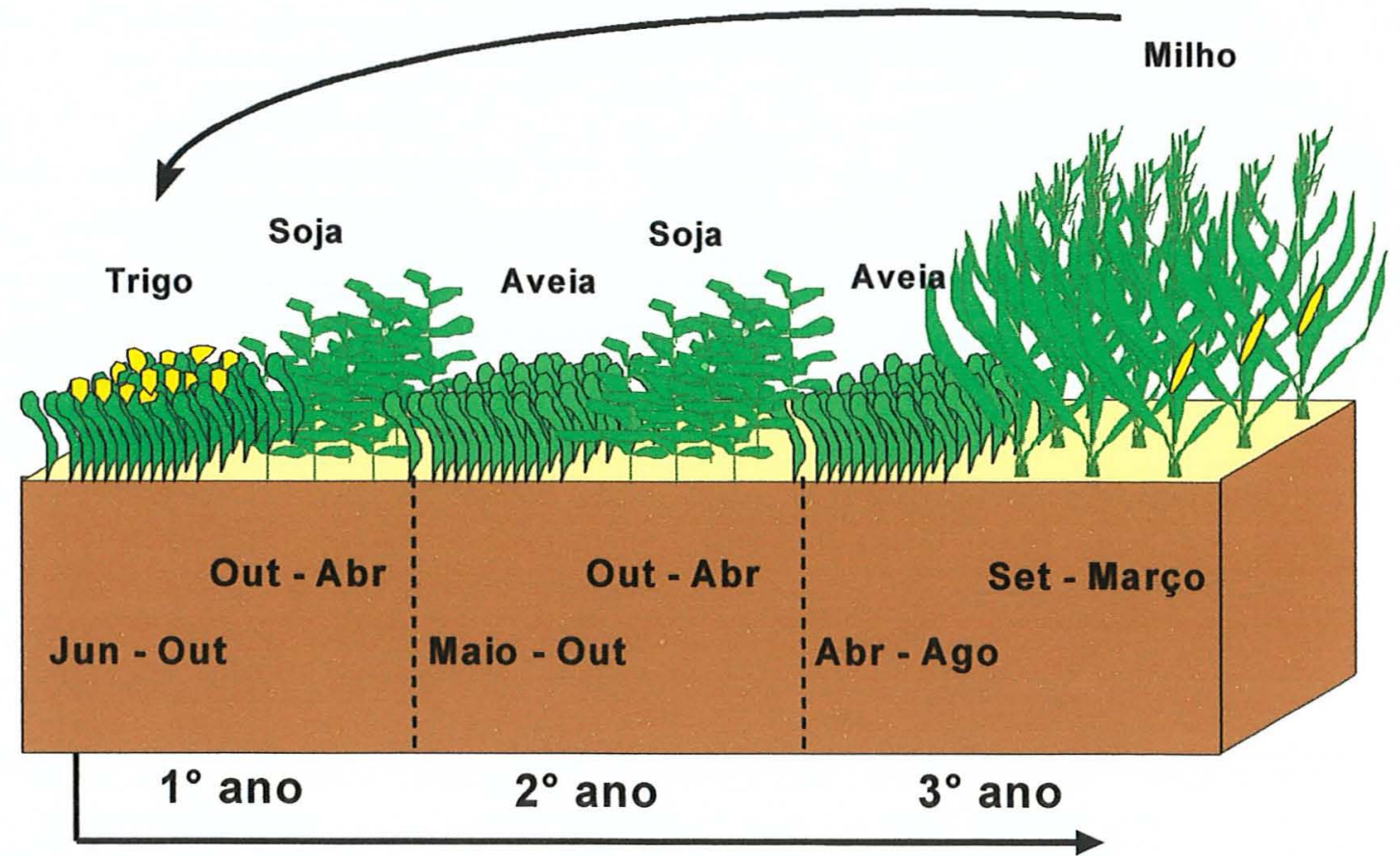

Figura 5. Sequência de culturas nas áreas que representam os tratamentos PD-10, PD20, PD-22 e PC-22. (meses representam o período entre semeadura e colheita). 
Tabela 3. Quantidade total de fertilizante utilizado em cada cultura, biomassa seca total (parte aérea + raiz) e porcentagem da biomassa seca de cada cultura nas adições totais nos tratamentos sob plantio direto

\begin{tabular}{|c|c|c|c|c|c|c|}
\hline \multirow[t]{2}{*}{ Tratamentos } & \multirow[t]{2}{*}{ Culturas } & \multicolumn{3}{|c|}{ Fertilizantes $^{\S}$} & \multicolumn{2}{|c|}{ Biomassa seca $^{\ddagger}$} \\
\hline & & $\mathrm{N}$ & $\mathrm{P}_{2} \mathrm{O}_{5}$ & $\mathrm{~K}_{2} \mathrm{O}$ & Total & Relativa \\
\hline & & & $\cdots$ & $\mathrm{ha}^{-1}$ & -a- &.$-- \%$ \\
\hline \multirow[t]{9}{*}{ PD-10 } & Soja & - & 285 & 326 & 21887 & 23,91 \\
\hline & Aveia & - & - & - & 25480 & 27,84 \\
\hline & Milho & 269 & 216 & 228 & 31749 & 34,68 \\
\hline & Trigo & 138 & 184 & 160 & 12418 & 13,57 \\
\hline & Tremoço $^{\ddagger \ddagger}$ & - & - & - & - & - \\
\hline & Azevém $^{\ddagger \ddagger}$ & - & - & - & - & - \\
\hline & Feijão & - & - & - & - & - \\
\hline & Adição total & 407 & 685 & 714 & $91534^{\ddagger}$ & 100 \\
\hline & Adição anual & 40,7 & 68,5 & 71,4 & 9153 & - \\
\hline \multirow[t]{9}{*}{ PD-20 } & Soja & 38 & 611 & 625 & 48444 & 27,33 \\
\hline & Aveia & - & - & - & 48100 & 27,13 \\
\hline & Milho & 383 & 350 & 363 & 55728 & 31,44 \\
\hline & Trigo & 222 & 511 & 333 & 20218 & 11,40 \\
\hline & Tremoço $^{\ddagger \ddagger}$ & - & - & - & 4782 & 2,70 \\
\hline &  & - & - & - & - & - \\
\hline & Feijão & - & - & - & - & - \\
\hline & Adição total & 643 & 1472 & 1321 & 177272 & 100 \\
\hline & Adição anual & 32,2 & 73,6 & 66,1 & 8859 & - \\
\hline PD-22 & Soja & 100 & 730 & 730 & 51200 & 30,58 \\
\hline \multirow[t]{8}{*}{ PC-22 } & Aveia & - & - & - & 14300 & 8,54 \\
\hline & Milho & 541 & 531 & 513 & 55852 & 33,36 \\
\hline & Trigo & 190 & 735 & 735 & 32151 & 19,20 \\
\hline & Tremoço ${ }^{\ddagger \ddagger}$ & - & - & - & 4375 & 2,61 \\
\hline & Azevém & 225 & 450 & 450 & 7175 & 4,29 \\
\hline & Feijão & 55 & 75 & 75 & 2380 & 1,42 \\
\hline & Adição total & 1111 & 2521 & 2503 & 167433 & 100 \\
\hline & Adição anual & 50,5 & 114,5 & 113,7 & 7610 & - \\
\hline
\end{tabular}

$\$$ Quantidade total fertilizantes utilizados em cada cultura; ${ }^{\ddagger}$ Somatório da biomassa da

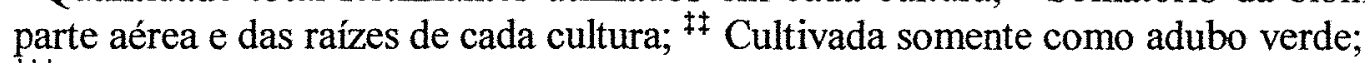

$\ddagger \neq \ddagger$ Cultivado para silagem; $\uparrow$ Refere-se a participação porcentual da quantidade de resíduo cultural de cada cultura. 
O histórico de uso de fertilizantes, a produção de grãos obtida e a massa seca (parte aérea e biomassa de raiz) dos tratamentos sob plantio direto e convencional estão sumarizados na tabela 3. A produção da biomassa seca da parte aérea foi estimada com base na relação produção de grãos/biomassa da parte aérea considerando o índice 0,9 para cultura de soja, 1,0 para o milho e 1,0 para a cultura de trigo. Para estimar a biomassa de raizes considerou-se o índice 0,2 para soja, 0,25 para o milho, 0,2 para o trigo, 0,3 para aveia preta e 0,3 para o azevém. $O$ cálculo da biomassa da parte aérea e da raiz foi obtido multiplicando a produção de grãos em $\mathrm{kg} \mathrm{ha}^{-1}$ pelos índices acima citados. A biomassa total que retornou ao solo foi a soma da biomassa da parte aérea $\mathrm{e}$ da raiz.

\subsubsection{Desenho experimental e amostragem do solo}

A situação selecionada constitui um delineamento experimental em faixas com um arranjo em parcelas subdividas não aleatória com cinco repetições. As faixas referem-se aos tratamentos de uso da terra implantados em épocas distintas que constituem a cronossequência. A faixa é constituída por seis níveis: a) Campo nativo $(\mathrm{CN})$; b) Preparo do campo nativo (PCN-1); c) Plantio direto há 10 anos (PD-10); d) Plantio direto há 20 anos (PD-20); e) Plantio direto há 22 anos (PD-22) e f) Preparo convencional há 22 anos (PC-22). O arranjo em parcelas subdivididas não aleatória é representado pela profundidade de amostragem com cinco níveis $(0-2,5 ; 2,5-5,0 ; 5,0$ $10,0 ; 10,0-20,0$ e $20-40 \mathrm{~cm})$. As dimensões de cada faixa da cronossequência foram de $200 \mathrm{~m} \times 50 \mathrm{~m}$ e de cada repetição de $40 \mathrm{~m} \times 50 \mathrm{~m}$.

A coleta das amostras de solo em cada repetição foi realizada em minitrincheiras com dimensões de $20 \mathrm{~cm}$ x $50 \mathrm{~cm}$ (área) x $50 \mathrm{~cm}$ (profundidade). Para constituir uma amostra composta foram cavadas 9 mini-trincheiras e retirado fatias referente as camadas de 0-2.5, 2.5-5, 5-10, 10-20 e 20-40 cm (Figura 6). 


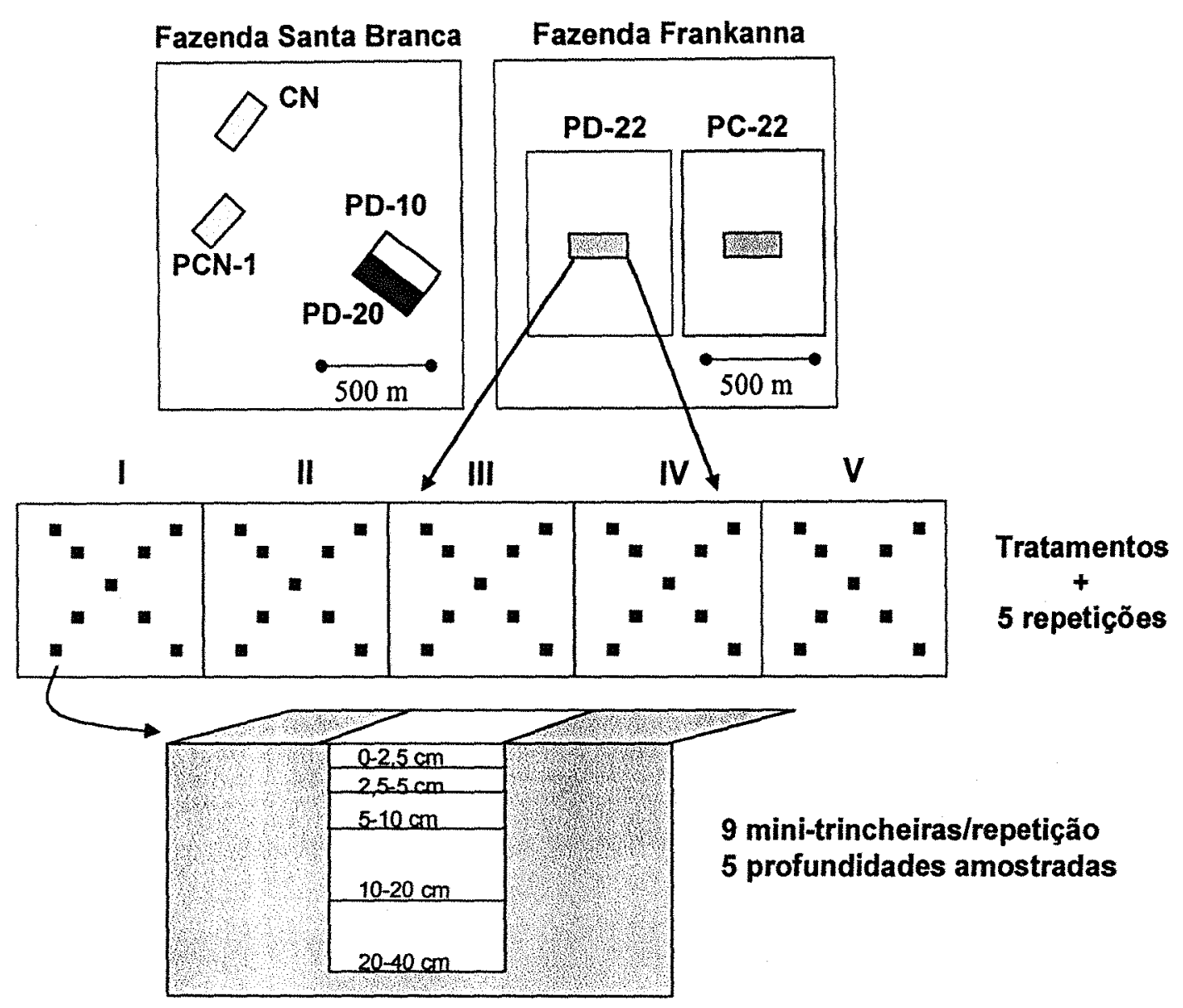

Figura 6. Disposição dos tratamentos, repetições, número de pontos de coleta em cada repetição e esquema da mini-trincheira com as profundidades amostradas.

\subsubsection{Análises químicas e mineralógicas para caracterização dos perfis de solo}

$\mathrm{O} \mathrm{pH}$ do solo foi determinado usando-se a proporção de 1:2,5 (solo: $\mathrm{H}_{2} 0$ ) conforme EMBRAPA (1979). Os cátions trocáveis $\left(\mathrm{Al}^{3+}, \mathrm{Ca}^{2+}, \mathrm{Mg}^{2+}, \mathrm{K}^{+}\right)$e o $\mathrm{P}$ foram extraídos pela resina trocadora de cátions e ânions, conforme descrito por Raij \& Quaggio (1983). A acidez potencial foi determinada pelo método descrito pela EMBRAPA (1979), extraindo o $\mathrm{H}+\mathrm{Al}$ com uma solução de $\mathrm{Ca}(\mathrm{OAc})_{2} 1 \mathrm{~N}$ tamponada a $\mathrm{pH} 7,0$. A CTC foi obtida através da soma do valor da acidez potencial e das bases trocáveis $\left(\mathrm{Ca}^{2+}, \mathrm{Mg}^{2+}, \mathrm{K}^{+}\right)$. No perfil do solo de cada tratamento, foram coletadas amostras do horizonte Bw1 para a identificação do mineral de argila através do uso da 
difração de raios X (Jackson, 1969). As quantidades relativas de caulinita e gibbisita foram determinadas em amostras do horizonte Ap e Bwl, utilizando a técnica da análise térmica diferencial descrita por Jackson (1969). A composição granulométrica da terra fina seca ao ar para definição da classe textural dos horizontes de todos os perfis foi determinada pelo método da pipeta (Gee \& Bauder, 1986).

\subsubsection{Preparo das amostras, análises de carbono orgânico total, nitrogênio total, densidade do solo e cálculo do estoque de $\mathrm{C}$ e $\mathrm{N}$}

As amostras de solo foram secas ao ar, homogeneizadas e destorroadas para transpassar a peneira de $2 \mathrm{~mm}$. Em cada amostra retirou-se uma subamostra que foi moída em moinho de aço inox para transpassar a peneira de $150 \mu \mathrm{m}$. O N total foi determinado pelo sistema micro Kjeldahl e o COT pelo método da combustão seca (Nelson \& Sommers, 1982) utilizando um Carbon Analyser - LECO ${ }^{\circledR}$ CR-412. A densidade do solo foi determinada em amostras indeformadas, coletadas através de anéis de aço inox com diâmetro e altura de $5 \mathrm{~cm}$ (Blake \& Hartge) nas profundidades de 5-10, 10-20 e 20-40 cm (anéis retirados do meio da camada). Para as camadas de 0-2,5 $\mathrm{cm}$ e $2,5-5 \mathrm{~cm}$ de profundidade, os anéis utilizados tinham $5 \mathrm{~cm}$ de diâmetro e $2,5 \mathrm{~cm}$ de altura. Para cada repetição de cada tratamento foram coletados três anéis em cada profundidade amostrada e feita a média (Tabela 15, Anexo). $\mathrm{O}$ cálculo do estoque de $\mathrm{C}$ e N (Tabela 15, Anexo) se baseou nos dados do conteúdo de COT e N-total $\mathrm{em} \mathrm{g} \mathrm{kg}^{-1}$, transformados para $\mathrm{kg} \mathrm{Mg}^{-1}$, na densidade do solo (DS) determinada em $\mathrm{g} \mathrm{cm}^{-3} \mathrm{e}$ transformada para $\mathrm{Mg} \mathrm{m}^{-3}$ e no volume da profundidade de amostragem (VPA) $\mathrm{em} \mathrm{m}^{3}$. Os resultados finais foram expressos em $\mathrm{Mg} \mathrm{ha}^{-1}$ para cada profundidade amostrada, conforme o exemplo a seguir:

\section{Estoque de $C\left(\mathrm{Mg} \mathrm{ha}^{-1}\right)=\operatorname{COT}\left(\mathrm{kg} \mathrm{Mg}^{-1}\right) \times \operatorname{DS}\left(\mathrm{Mg} \mathrm{m}^{-3}\right) \times \operatorname{VPA}\left(\mathrm{m}^{3}\right)$}

Exemplo de cálculo do estoque de COT na camada de $0-2,5 \mathrm{~cm}$ de profundidade Conteúdo de COT $=30 \mathrm{~g} \mathrm{~kg}^{-1} \equiv 30 \mathrm{~kg} \mathrm{Mg}^{-1}$ 
Densidade do solo (DS) $=1,42 \mathrm{~g} \mathrm{~cm}^{-3} \equiv 1,42 \mathrm{Mg} \mathrm{m}^{-3}$

Volume da profundidade Amostrada (VPA) $=10000 \mathrm{~m}^{2} \mathrm{ha}^{-1} \times 0,025 \mathrm{~m}=250 \mathrm{~m}^{3} \mathrm{ha}^{-1}$ Estoque COT $=30 \mathrm{~kg} \mathrm{Mg}^{-1} \times 1,42 \mathrm{Mg} \mathrm{m}^{-3} \times 250 \mathrm{~m}^{3} \mathrm{ha}^{-1}=10500 \mathrm{~kg} \mathrm{ha}^{-1} \equiv 10,5 \mathrm{Mg} \mathrm{ha}^{-1}$

$\mathrm{O}$ estoque total de COT e $\mathrm{N}$ para a profundidade de $0-40 \mathrm{~cm}$ foi calculado através do somatório dos valores obtidos em cada camada amostrada.

\subsubsection{Fracionamento granulométrico da matéria orgânica do solo}

O fracionamento granulométrico da matéria orgânica foi realizado de acordo com o método descrito por Feller (1994). O procedimento foi realizado em amostras secas ao ar, destorroadas, homogeneizadas e peneiradas em peneira de $2 \mathrm{~mm}$. Em um frasco plástico de $1 \mathrm{~L}$ pesou-se $40 \mathrm{~g}$ da amostra e adicionou-se $200 \mathrm{~mL}$ de $\mathrm{H}_{2} \mathrm{O}$ e $0,5 \mathrm{~g}$ de hexametafosfato e três bolas de vidro. Após ligeira agitação manual, os frascos foram mantidos em geladeira durante 16 hs. Os frascos foram agitados durante duas horas em um agitador rotativo na freqüência de $50 \mathrm{rpm}$. O solo em suspensão foi passado em peneira de $200 \mu \mathrm{m}$ sobre um Becker de $500 \mathrm{~mL}$ para obter a fração 200$2000 \mu \mathrm{m}$. As frações remanescentes na peneira, foram lavadas com $\mathrm{H}_{2} \mathrm{O}$ deionizada e colocadas junto as demais frações que passaram pela peneira de $200 \mu \mathrm{m}$. A suspensão do solo com as frações menores que $200 \mu \mathrm{m}$ recebeu energia ultrasônica (240 watts) durante 10 minutos. Esse nível de energia foi determinado para atingir o mínimo requerido e promover a ruptura dos microagregados das frações areia e silte e associados com a matéria orgânica e as partículas primárias. Após cada sonificação, foi retirada uma amostra da suspensão para verificar o grau de dispersão com o auxilio de um microscópio. Na seqüência, o solo em suspensão foi passado em peneira de $53 \mu \mathrm{m}$ e $20 \mu \mathrm{m}$, para obter as frações 53-200 $\mu \mathrm{m}$ e 20-53 $\mu \mathrm{m}$. O material remanescente em cada peneira foi lavado e adicionado a suspensão correspondente. A separação das frações silte $(2-20 \cdot \mathrm{m})$ e argila $(<2 \cdot \mathrm{m})$ foi obtida através da centrifugação da suspensão que transvazou a peneira de $20 \mu \mathrm{m}$. O tempo de cada centrifugação foi de três minutos e ajustada na freqüência de $700 \mathrm{rpm}$. O sobrenadante de cada centrifugação foi sifonado e 
armazenado em uma proveta de $1 \mathrm{~L}$. Adicionou-se $10 \mathrm{~mL}$ de $\mathrm{H}_{2} \mathrm{O}$ deionizada a cada tubo e esta operação foi repetida várias vezes (seis a sete vezes) até o sobrenadante ficar límpido. O pelete de solo no fundo de cada tubo representou a fração silte $(2-20 \mu \mathrm{m})$. A suspensão de argila armazenada na proveta de $1 \mathrm{~L}$ foi floculada adicionando-se $0,77 \mathrm{~g}$ de $\mathrm{CaCl}_{2}$, para a obtenção da fração argila $(<2 \mu \mathrm{m})$.

\subsubsection{Determinação da abundância natural do $13 \mathrm{C}\left(\delta^{13} \mathrm{C}\right)$, do carbono orgânico e nitrogênio total nas frações granulométricas da matéria orgânica do solo}

A relação da abundância natural do isótopo estável de $\mathrm{C}$ foi determinada nas diferentes frações de cada profundidade amostrada, pelo método descrito por Cerri et al. (1985), Balesdent et al. (1987) e Angers \& Giroux (1996). A relação ${ }^{13} \mathrm{C}:{ }^{12} \mathrm{C}$, o conteúdo do carbono orgânico e do nitrogênio total foram determinados por um Espectrômetro de Massa, Delta Plus, Finnigran Mat, equipado com um cromatógrafo de gás, modelo EA $1110 \mathrm{CHN}$. $\mathrm{O}$ valor do $\delta^{13} \mathrm{C}$ foi calculado determinando-se a relação do isótopo de $\mathrm{C}(\mathrm{R})$ da amostra e o gás padrão do laboratório foi calibrado com o padrão internacional de calcário (Pee Dee Belemite - PDB) (Eq.1):

$$
\delta^{13} \mathrm{C}(\% \mathrm{o})=\left[\left(\mathrm{R}_{\text {sample }}-\mathrm{R}_{\text {standard }}\right) / \mathrm{R}_{\text {standard }}\right] \times 10^{3}
$$

A proporção do $\mathrm{C}$ derivado dos resíduos culturais $(\mathrm{X})$, foi calculado de acordo com a expressão usada por Angers \& Giroux (1996) (Eq.2):

$$
\mathrm{X}=\left[\left(\delta_{\mathrm{cs}}-\delta_{\mathrm{nf}}\right) /\left(\delta_{\mathrm{cr}}-\delta_{\mathrm{nf}}\right)\right] \times 100
$$

onde $\delta_{\mathrm{cs}}=$ valor do $\delta^{13} \mathrm{C}$ da amostra do solo cultivado (tratamentos: PCN-1, PD-10, PD20, PD-22 e PC-22) em cada fração granulométrica de cada profundidade amostrada; $\delta_{\mathrm{nf}}$ $=$ valor do $\delta^{13} \mathrm{C}$ do tratamento $\mathrm{CN}$ de cada fração granulométrica em cada profundidade amostrada (representa a vegetação natural dominada por espécies $\mathrm{C}_{4}$ ); $\delta_{\mathrm{cr}}=$ valor do $\delta^{13} \mathrm{C}$ determinado nos resíduos culturais. $\mathrm{O}$ valor do $\delta^{13} \mathrm{C}$ dos resíduos culturais $(-23.8$ $\%, \pm 0.26 \%)$ se baseou na média de 10 subamostras da palhada da superficie do solo (parte aérea) coletada antes da colheita do milho no tratamento PD-20. 


\subsubsection{Análises estatísticas}

Os resultados foram submetidos à análise de variância (ANOVA) e as médias comparadas pelo teste de Tukey ao nível de $5 \%$ de significância $(\mathrm{p}<0,05)$, para caracterizar as diferenças entre os tratamentos. Análises de correlação de Pearson entre as variáveis foram utilizadas para avaliar seu grau de afinidade. Equações de regressão foram selecionadas pelo procedimento de Stepwise (SAS Institute, 1990) para ajuste dos modelos e usadas para avaliar as mudanças temporais para o estoque de $\mathrm{C} \mathrm{e} \mathrm{N} \mathrm{em}$ cada profundidade de amostragem, considerando o campo nativo como a linha de base ou ponto de referência. A taxa das mudanças temporais que representam o sequestro de $C$, foram calculadas computando a tangente da linha de regressão (dy/dx) em cada profundidade amostrada incluindo os tratamentos CN, PD-10, PD-20 e PD-22. O nível de significância estatístico para as equações de regressão e os coeficientes de correlação de Pearson foi descrito como $\mathrm{p}<0,05 ; \mathrm{p}<0,01 \mathrm{e} \mathrm{p}<0,001$ representado por $*,{ }^{* *},{ }^{* *}$, respectivamente.

\subsection{RESULTADOS E DISCUSSÃO}

\subsubsection{Alterações no conteúdo de carbono orgânico, nitrogênio total e relação $\mathrm{C} / \mathrm{N}$} do solo

Os sistemas de manejo do solo afetaram significativamente o conteúdo e o estoque de $\mathrm{C}$ e $\mathrm{N}$. A média do conteúdo de COT e $\mathrm{N}$ total na camada superficial de 0 a $5 \mathrm{~cm}$ de profundidade foi significativamente superior $(\mathrm{p}<0,05)$ nos solos há longo período sob plantio direto do que aqueles sob CN e PC-22 (Tabela 4).

Em contraste, a queda do conteúdo de COT e $\mathrm{N}$ total no solo sob preparo convencional há longo período (PC-22) comparada ao $\mathrm{CN}$, também ocorreu nesta camada. Esses resultados são similares aos observados por Bayer et al. (2000 b) na região sul do Brasil e a outros reportados por Kern \& Johnson (1993) e Dick et al. (1998) em diferentes regiões nos EUA. 
Tabela 4. Alterações no $\mathrm{COT}, \mathrm{N}$ total e relação $\mathrm{C} / \mathrm{N}$ nos sistemas de manejo do solo na cronossequência

\begin{tabular}{llllllll}
\hline Variável & \multicolumn{1}{c}{$\begin{array}{c}\text { Prof. } \\
(\mathrm{cm})\end{array}$} & \multicolumn{6}{c}{ Sistemas de manejo do solo } \\
\cline { 4 - 8 } & \multicolumn{1}{c}{$\mathrm{CN}$} & PCN-1 & PD-10 & PD-20 & PD-22 & PC-22 \\
\hline COT & $0-2,5$ & $34,5 \mathrm{Ab}$ & $38,4 \mathrm{Ac}$ & $36,3 \mathrm{Ac}$ & $45,9 \mathrm{Ad}$ & $52,8 \mathrm{Ad}$ & $30,1 \mathrm{Aa}$ \\
$\left(\mathrm{g} \mathrm{kg}^{-1}\right)$ & $2,5-5,0$ & $29,5 \mathrm{Ba}$ & $37,2 \mathrm{Ab}$ & $25,7 \mathrm{Ba}$ & $34,6 \mathrm{Bb}$ & $35,1 \mathrm{Bb}$ & $28,0 \mathrm{Aa}$ \\
& $5,0-10,0$ & $25,3 \mathrm{Bb}$ & $35,5 \mathrm{Ac}$ & $18,9 \mathrm{Ca}$ & $24,7 \mathrm{Cb}$ & $25,1 \mathrm{Cb}$ & $25,9 \mathrm{Ab}$ \\
& $10,0-20,0$ & $21,6 \mathrm{Cb}$ & $31,2 \mathrm{Bc}$ & $14,6 \mathrm{Da}$ & $21,6 \mathrm{Cb}$ & $20,7 \mathrm{Db}$ & $23,5 \mathrm{Bb}$ \\
& $20,0-40,0$ & $16,9 \mathrm{Db}$ & $22,0 \mathrm{Cc}$ & $12,7 \mathrm{Da}$ & $17,9 \mathrm{Db}$ & $16,9 \mathrm{Db}$ & $19,3 \mathrm{Cc}$ \\
& & & & & & & \\
N-total & $0-2,5$ & $2,3 \mathrm{Ab}$ & $2,6 \mathrm{Ac}$ & $3,0 \mathrm{Ac}$ & $3,7 \mathrm{Ad}$ & $4,0 \mathrm{Ad}$ & $2,1 \mathrm{Aa}$ \\
$\left(\mathrm{g} \mathrm{kg}^{-1}\right)$ & $2,5-5,0$ & $1,9 \mathrm{Ba}$ & $2,5 \mathrm{Ab}$ & $2,1 \mathrm{Ba}$ & $2,7 \mathrm{Bb}$ & $2,6 \mathrm{Bb}$ & $1,8 \mathrm{Aa}$ \\
& $5,0-10,0$ & $1,6 \mathrm{Bb}$ & $2,3 \mathrm{Ac}$ & $1,4 \mathrm{Ca}$ & $1,8 \mathrm{Cb}$ & $1,7 \mathrm{Cb}$ & $1,6 \mathrm{Ab}$ \\
& $10,0-20,0$ & $1,4 \mathrm{Bb}$ & $2,1 \mathrm{Ac}$ & $0,9 \mathrm{Da}$ & $1,4 \mathrm{Db}$ & $1,2 \mathrm{Db}$ & $1,3 \mathrm{Bb}$ \\
& $20,0-40,0$ & $1,0 \mathrm{Cb}$ & $1,5 \mathrm{Bc}$ & $0,8 \mathrm{Da}$ & $1,1 \mathrm{Db}$ & $1,0 \mathrm{Db}$ & $1,0 \mathrm{Bb}$ \\
& & & & & & & \\
C/N & $0-2,5$ & $15,2 \mathrm{Ab}$ & $14,6 \mathrm{Ab}$ & $12,1 \mathrm{Aa}$ & $12,3 \mathrm{Aa}$ & $13,2 \mathrm{Aa}$ & $14,6 \mathrm{Ab}$ \\
& $2,5-5,0$ & $15,3 \mathrm{Ab}$ & $14,9 \mathrm{Ab}$ & $12,2 \mathrm{Aa}$ & $12,6 \mathrm{Aa}$ & $13,4 \mathrm{Aa}$ & $15,5 \mathrm{Ab}$ \\
& $5,0-10,0$ & $15,9 \mathrm{Ab}$ & $15,5 \mathrm{Ab}$ & $13,1 \mathrm{Aa}$ & $13,8 \mathrm{Aa}$ & $14,8 \mathrm{Ab}$ & $16,3 \mathrm{Ab}$ \\
& $10,0-20,0$ & $16,0 \mathrm{Aa}$ & $15,0 \mathrm{Aa}$ & $15,4 \mathrm{Ba}$ & $15,8 \mathrm{Ba}$ & $17,2 \mathrm{Bb}$ & $18,0 \mathrm{Bb}$ \\
& $20,0-40,0$ & $16,6 \mathrm{Bb}$ & $14,4 \mathrm{Aa}$ & $16,3 \mathrm{Bb}$ & $16,6 \mathrm{Bb}$ & $17,3 \mathrm{Bb}$ & $18,9 \mathrm{Bc}$ \\
\hline
\end{tabular}

Nota: Médias seguidas da mesma letra na coluna (maiúscula) e na linha (minúscula) não diferem entre si pelo teste de Tukey ao nível de $5 \%$ de probabilidade.

A relação $\mathrm{C} / \mathrm{N}$ do solo nas camadas superficiais dos tratamentos sob PD (Tabela 4), foi significativamente inferior $(\mathrm{p}<0,05)$ aos encontrados nos tratamentos $\mathrm{CN}, \mathrm{PCN}-1$ e PC-22. Esta relação também aumentou com a profundidade em todos os tratamentos exceto no PCN-1. Isto sugere que o elevado suprimento de $\mathrm{N}$ na camada superficial tenha sido o componente chave para estabilizar o C na MOS e aumentar o seu conteúdo. Essa diferença na relação $\mathrm{C} / \mathrm{N}$ entre as camadas superficiais $(0-10 \mathrm{~cm})$ e as subsuperficiais $(10-40 \mathrm{~cm})$ também indica que o grau de humificação da MOS na camada superficial seja superior, apesar dos processos biológicos serem mais intensos. Por outro lado, no tratamento PC-22, o aumento da relação C/N comparado ao PD seja na superfície ou em subsuperficie, pode ser atribuído ao efeito da incorporação de resíduos orgânicos frescos após a colheita das culturas de verão e inverno. Dessa forma, a mistura constante de resíduos culturais frescos, agregados e agentes de decomposição, podem reduzir o grau de humificação da MOS. Todavia, no tratamento PCN-1 a relação 
$\mathrm{C} / \mathrm{N}$ se manteve igual em todas as camadas apesar da incorporação dos resíduos. Isto indica que o intervalo entre a conversão da vegetação natural em agricultura e a amostragem foi insuficiente para detectar alterações no COT que afeta esta relação. Mesmo assim, esse aumento significativo $(\mathrm{p}<0,05)$ no conteúdo de COT e do $\mathrm{N}$ total (Tabela 4) no PCN-1 comparado ao $\mathrm{CN}$ em todas as profundidades pode ser devido a rápida mineralização da biomassa da vegetação natural, estimulada pela melhoria da química do solo resultante da calagem e da aplicação de P (Fox, 1980). Adicionalmente, a adição e a incorporação dos resíduos das culturas de soja, aveia preta e milho cultivados anteriormente à amostragem, também podem ter contribuído para o aumento do conteúdo de COT e do $\mathrm{N}$ total.

$\mathrm{O}$ conteúdo de COT e $\mathrm{N}$ total no PD-10 foi o inferior aos outros tratamentos sob PD e em profundidade abaixo de $5 \mathrm{~cm}$ também foi inferior ao $\mathrm{CN}$. Estas alterações podem ser atribuídas aos seguintes fatores: a) após a conversão da vegetação natural em agricultura, o longo período em pousio (10 anos) antes da adoção do PD (Figura 4) pode ter estimulado a atividade microbiana e a liberação de $\mathrm{C}$ pela respiração; b) o tempo de residência do COT no perfil do solo pode também ter sido alterado durante o pousio influenciando a sua disponibilidade para a decomposição microbiana (Cihacek \& Ulmer, 1997); c) a taxa de aporte de resíduos culturais durante este período não compensou as elevadas perdas devido à mineralização.

Em comparação com o tratamento sob $\mathrm{CN}$, as alterações no estoque de COT e $\mathrm{N}$ na camada de 0-40 $\mathrm{cm}$ de profundidade foram $+21,9 \mathrm{Mg} \mathrm{C}^{-1} \mathrm{e}+2,01 \mathrm{Mg} \mathrm{N}^{-1}$ para o PCN-1, -4,83 Mg Cha ${ }^{-1}$ e +0,39 Mg N ha ${ }^{-1}$ para o PD-10, +17,4 $\mathrm{Mg} \mathrm{C}^{-1} \mathrm{e}+1,69$ $\mathrm{Mg} \mathrm{N} h^{-1}$ para o PD-20, $+18,9 \mathrm{Mg} \mathrm{C}^{-1}$ e $+1,4 \mathrm{Mg} \mathrm{N}^{-1}$ para PD-22 e $-0,13 \mathrm{Mg} \mathrm{C}$ $\mathrm{ha}^{-1} \mathrm{e}-0,51 \mathrm{Mg} \mathrm{N}^{-1}$ para o PC-22 (Figura 7). Os ganhos e perdas do estoque de COT e $\mathrm{N}$ (Figura 8) nos diferentes tratamentos variaram de acordo com a profundidade do solo e foram influenciados pela densidade do solo. Os valores da densidade do solo encontrados nos tratamentos sob PD foram superiores ao CN, PCN-1 e PC-22. O aumento da densidade do solo em áreas há longo período sob PD tem sido frequentemente reportado na literatura. 

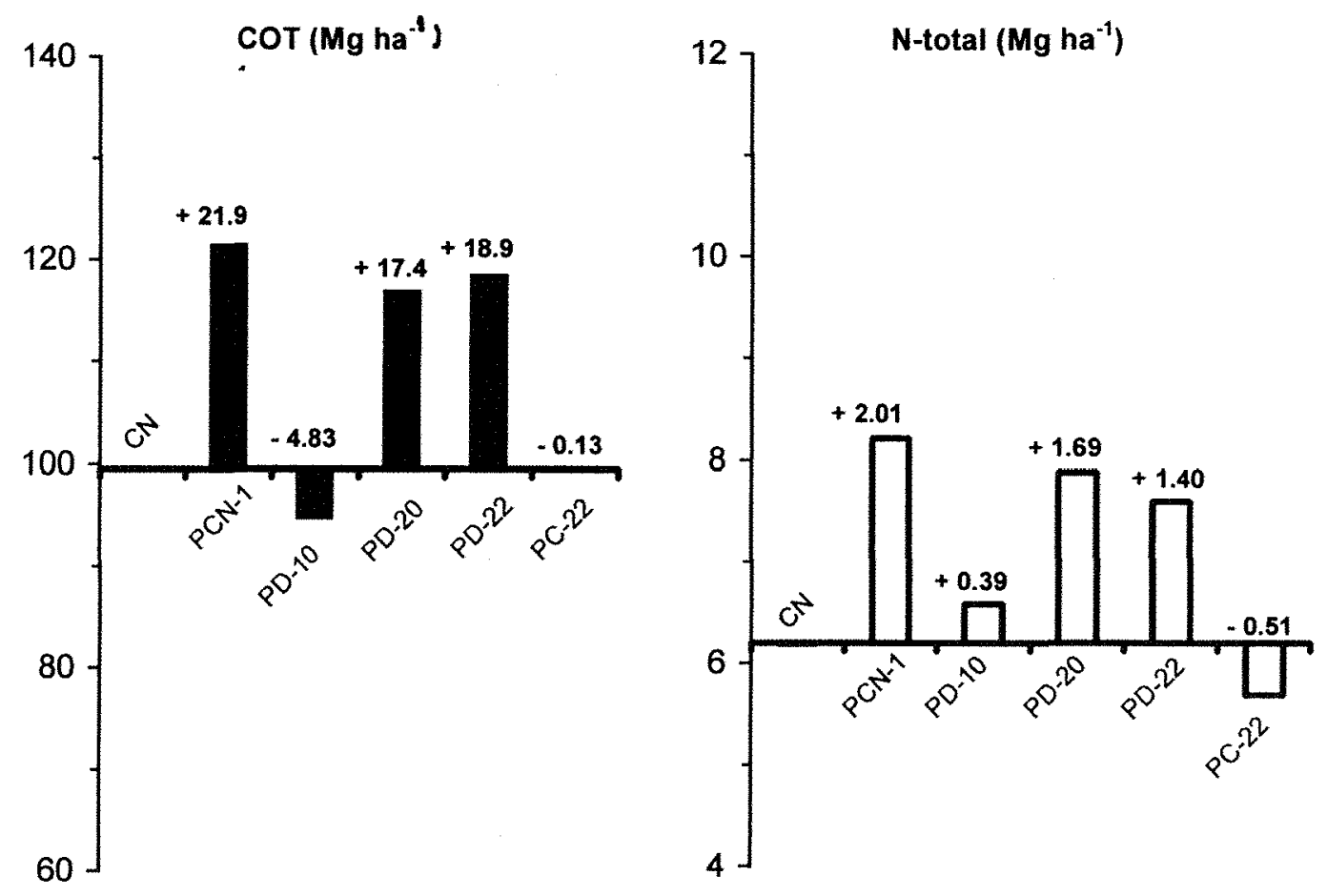

Figura 7. Estoque de carbono orgânico total (COT) e $\mathrm{N}$-total na camada de $0-40 \mathrm{~cm}$ de profundidade afetados pela cronossequência. A linha horizontal grossa representa o estoque no tratamento sob campo nativo $(\mathrm{CN})$.

Atribui-se à combinação do tráfego de máquinas (para as operações de controle de plantas daninhas, semeadura, fertilização e colheita) com a ausência do revolvimento do solo, resultando na redução da porosidade total do solo. Esse efeito é mais acentuado nas camadas superficiais até $10 \mathrm{~cm}$ e pode ser uma das razões da proteção física da MOS nesse sistema de manejo do solo. A ausência de revolvimento do solo permite a formação de uma arquitetura com poros contínuos, induzindo a ocorrência de um fluxo dirigido dos gases. Desse modo, a abordagem de Reicosky et al. (1995) sugere a existência de uma taxa controlada de $\mathrm{O}_{2}$ e $\mathrm{CO}_{2}$ nesses poros, que por sua vez influenciam a atividade da biomassa microbiana. 

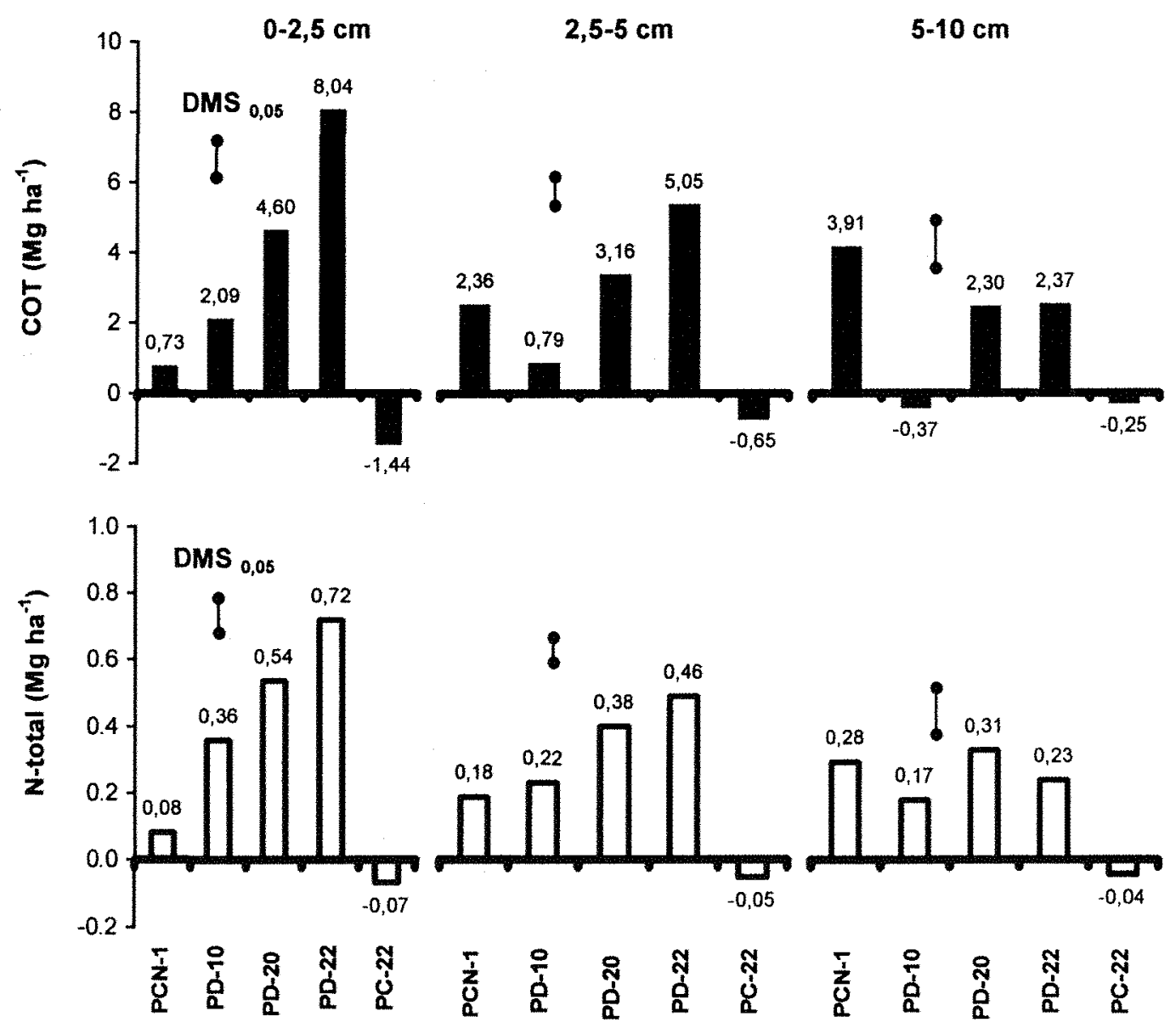

Figura 8. Ganhos e perdas no estoque de $\mathrm{C}$ e $\mathrm{N}$ (números acima das barras) nas camadas superficiais do solo $(0-2,5 ; 2,5-5 ; 5-10 \mathrm{~cm}$ - no topo) nos tratamentos de uso da terra da cronossequência comparados ao estoque no campo nativo ( $\mathrm{CN}$ linha grossa horizontal). As médias dos tratamentos em cada profundidade foram comparados pelo teste de Tukey ao nível de $5 \%$ de probabilidade representado pelo indicador $\mathrm{DMS}_{0,05}$.

Portanto, o constante fraturamento dos agregados e especialmente dos macroagregados, provocados pelo preparo do solo, deixa de existir ou ficam restritos à linha de semeadura. Em consequência, a entrada repentina de elevada quantidade de $\mathrm{O}_{2}$ é sensivelmente reduzida criando um ambiente menos oxidativo. Assim, a exposição da MOS ao ataque microbiano é minimizada e permite que os agentes de agregação atuem 
como os ligantes na formação de macroagregados. Dessa forma, parece ocorrer um efeito benéfico com o aumento da densidade do solo nos tratamentos sob plantio direto.

A maior contribuição no estoque de COT e $\mathrm{N}$ nos tratamentos sob PD comparada à situação original $(\mathrm{CN})$ ocorreu na camada de 0-10 cm (Figura 8). No PD10 , essa contribuição restringiu-se até $5 \mathrm{~cm}$ de profundidade e representou $100 \%$ e 96,9 do ganho de COT e N, respectivamente. No PD-20 e no PD-22 essa contribuição se estendeu até a camada de $0-10 \mathrm{~cm}$ e o ganho em COT e $\mathrm{N}$ representou $57,9 \%$ e $96,6 \%$ PD-20 e $81,8 \%$ e 98,9 no PD-22. Em contraste, a comparação entre o PCN-1 e o CN mostrou que nessa camada os ganhos no estoque de COT representaram apenas $31 \%$, indicando o efeito da incorporação do material orgânico da vegetação natural e a distribuição em profundidade.

A análise de regressão entre o estoque de COT para a camada de $0-10 \mathrm{~cm}$ nos tratamentos sob PD e o aporte de $\mathrm{C}$ pelos resíduos culturais (CRC) em $\mathrm{Mg} \mathrm{ha}^{-1}$ no sistema PD revelou significativo relacionamento $(p<0,05)$ entre esses parâmetros (Eq. 3):

$$
\operatorname{COT}\left(\mathrm{Mg} \mathrm{ha}^{-1}\right)=26,62+0,265(\mathrm{CRC}) \quad\left(\mathrm{R}^{2}=0,74\right)
$$

Neste caso, pode-se afirmar que cada tonelada de $\mathrm{C}$ adicionada no sistema PD via resíduo cultural foi transformada em $265 \mathrm{~kg}$ de $\mathrm{C} \mathrm{ha}^{-1}$ do solo na camada de $0-10 \mathrm{~cm}$. Assim, a taxa de conversão do $\mathrm{C}$ dos resíduos culturais em $\mathrm{C}$ do solo $(26,5 \%)$ representa o coeficiente de humificação de $\mathrm{C}$.

Em contraste, a perda significativa $(\mathrm{p}<0,05)$ de $\mathrm{C}$ no tratamento há longo período sob preparo convencional (PC-22) comparado ao PD-22, também ocorreu na camada de $0-10 \mathrm{~cm}$ de profundidade. A porcentagem de perda do COT associada à camada de solo de 0-2,5 cm, 2,5-5 cm, e 5-10 cm, foi de $62,1 \%, 27,6 \%$ e 10,3\%, respectivamente. A diferença no estoque de COT e $\mathrm{N}$ entre os tratamentos PD-22 e PC22 (camada de $0-40 \mathrm{~cm}$ de profundidade) foi de $+19,0 \mathrm{Mg} \mathrm{ha}^{-1} \mathrm{COT}$ e $+1,91 \mathrm{Mg} \mathrm{ha}^{-1} \mathrm{~N}$ no PD-22 (Figura 9). Embora a taxa de erosão do solo não tenha sido medida, a observação visual na faixa selecionada não apresentava sinais de erosão. Isto pode estar relacionado com a declividade inferior a $1 \%$ e a boa condição de drenagem do perfil na faixa que representam os tratamentos. Portanto, a diferença no estoque de COT e N 
entre o PD-22 e PC-22 pode ser atribuída às diferentes taxas de decomposição e assimilação dos resíduos culturais existente nos dois sistemas de manejo do solo.

\section{$\operatorname{COT}\left(\mathrm{Mg} \mathrm{ha}^{-1}\right)$}



Figura 9. Comparação do estoque de $\mathrm{C}$ e $\mathrm{N}$ na camada de $0-40 \mathrm{~cm}$ de profundidade entre o plantio direto (PD-22) e convencional (PC-22) há longo período. 


\subsubsection{Alterações no conteúdo de carbono orgânico e nitrogênio total das frações granulométricas da matéria orgânica do solo}

A distribuição porcentual das frações granulométricas da MOS expressas em base de peso seco representou a classe textural do solo. $O$ somatório das frações granulométricas $>53 \mu \mathrm{m}$ situou-se entre $24,3 \%$ a $54,7 \%$ do peso seco total nas camadas amostradas (Figura 10) enquanto as frações $<53 \mu \mathrm{m}$ representaram $45,3 \%$ a $75,7 \%$ do peso total. As frações granulométricas $>53 \mu \mathrm{m}$, representadas pelas frações de 200$2000 \mu \mathrm{m}$ e $53-200 \mu \mathrm{m}$, são constituídas principalmente por resíduos vegetais mais grosseiros e não decompostos assim como fragmentos da biomassa microbiana. Os compostos orgânicos que constituem estas frações apresentam diferentes estágios de decomposição (Feller, 1994). A relação $\mathrm{C} / \mathrm{N}$ mais elevada nesta fração (Tabela 16, Anexo) suporta o argumento de que o COT é constituído principalmente por material orgânico fresco ou pouco alterado.

$\mathrm{O}$ aumento do COT em todas as profundidades amostradas deu-se das frações mais grosseiras $(200-2000 \mu \mathrm{m})$ para as frações mais finas $(<2 \mu \mathrm{m})$ da matéria orgânica (Figura 10), indicando a ocorrência de associações que formam complexos do tipo “organo-silticos" e "organo-argilicos" (Feller, 1996).

Essa tendência foi semelhante nos tratamentos sob PD e no $\mathrm{CN}$ e a diferença no conteúdo de COT na fração argila superou a fração areia (equivalente às frações granulométricas $>53 \mu \mathrm{m}$ ) em 1,72 a 2,75 vezes na camada de $0-2,5 \mathrm{~cm}, 2,4$ a 4,6 vezes na camada de 2,5-5 cm, 2,75 a 12,5 vezes na camada de $5-10 \mathrm{~cm}, 3,68$ a 16,2 vezes na camada de $10-20 \mathrm{~cm}$ e 3,84 a 14,5 vezes na camada de $20-40 \mathrm{~cm}$ de profundidade. A matéria orgânica nas frações granulométricas mais grosseiras atua como fonte de energia para a biomassa microbiana e os compostos orgânicos mais estáveis liberados desse processo atuam como agentes de ligação das frações mais finas (Angers et al., 1996). Na mesma linha de pensamento, Golchin (1994) havia reportado que o fluxo contínuo de compostos orgânicos liberados durante a mineralização dos resíduos 
culturais em associação com a atividade dos fungos do solo, podem certamente conduzir para a formação de complexos organo minerais estáveis.
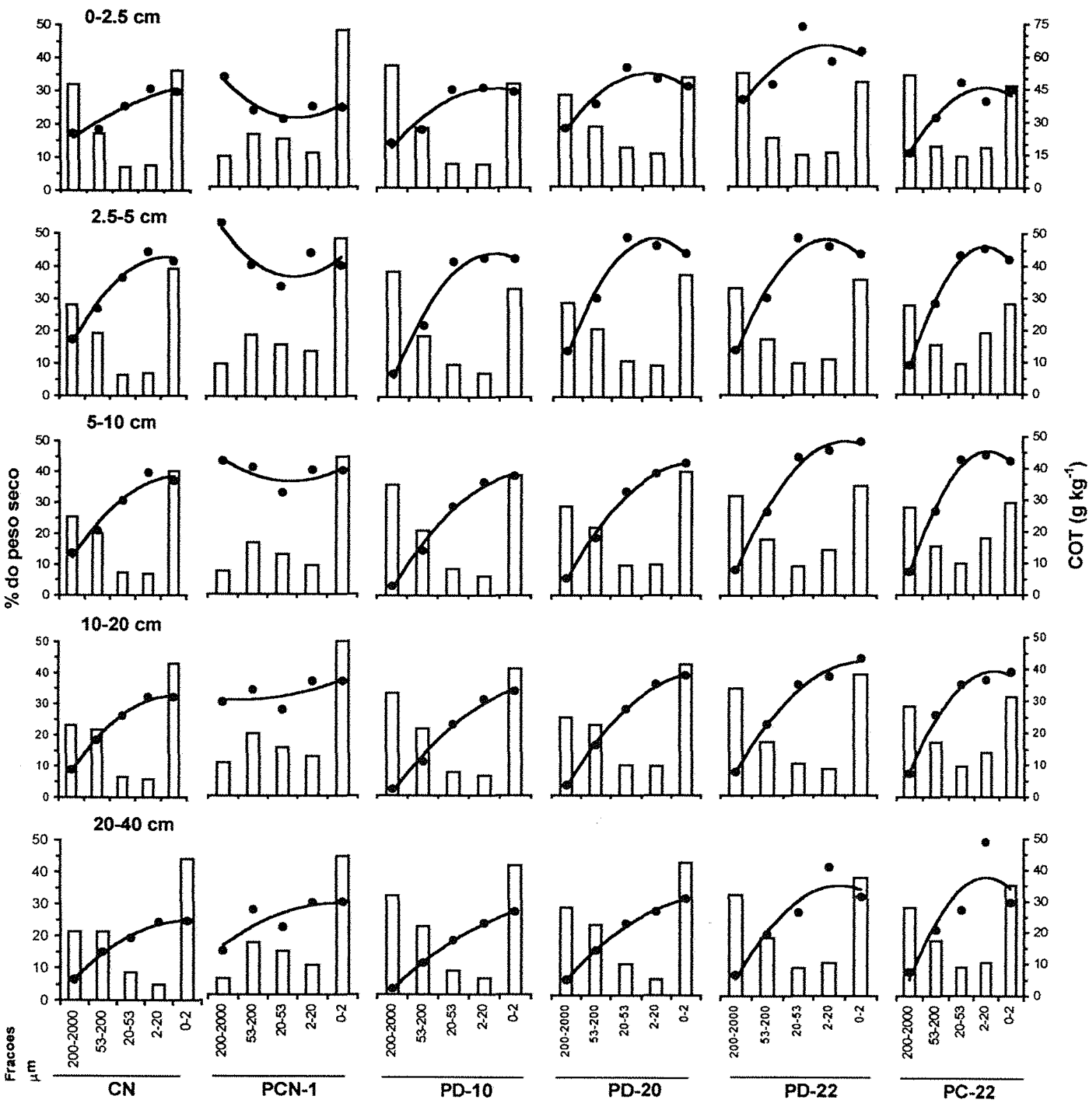

Cronossequencia

Figura 10. Frações granulométricas expressas em \% do peso seco (barras verticais) e conteúdo de COT (linha e pontos) em cada fração nas cinco profundidades de amostragem $(0-2,5 ; 2,5-5 ; 5-10 ; 10-20$ e $20-40 \mathrm{~cm})$. 
$\mathrm{O}$ conteúdo de COT no tratamento PCN-1 apresentou tendência contrastante comparado aos demais tratamentos sob PD (Figura 10) nas frações 200-2000 $\mu \mathrm{m}$ e 53$200 \mu \mathrm{m}$. Nestas frações o conteúdo de COT e $\mathrm{N}$ no PCN-1 foi superior aos demais tratamentos e igual ao da fração argila até a camada de 10-20 cm de profundidade. Essa tendência pode ser atribuída ao efeito da incorporação e da mineralização do material orgânico da vegetação natural associado aos resíduos das culturas nas frações mais grosseiras da matéria orgânica. Também foi observado no tratamento PCN-1 a alteração significativa no conteúdo de COT e $\mathrm{N}$ total da fração 200-2000 $\mu$ m nas profundidades amostradas, com redução de $51 \mathrm{~g} \mathrm{C} \mathrm{kg}^{-1}$ na camada de $0-2,5 \mathrm{~cm}$ para $12,9 \mathrm{~g} \mathrm{~kg}^{-1}$ na camada de $20-40 \mathrm{~cm}$ de profundidade.

A tendência de enriquecimento do COT e do $\mathrm{N}$ das frações granulométricas grosseiras $(200-2000 \mu \mathrm{m})$ em direção as frações mais finas $(<2 \mu \mathrm{m})$ representa um modelo quadrático. Este comportamento associado à relação $\mathrm{C} / \mathrm{N}$ indica que o COT está em diferentes estágios de decomposição. Também na figura 10, pode ser observado na fração silte até a camada de $5-10 \mathrm{~cm}$ de profundidade, e na fração argila abaixo de 10 $\mathrm{cm}$ de profundidade, o pico de maior concentração de C. Isto indica que o plantio direto há longo período associado à adição de elevada quantidade de resíduos culturais $(>6$ $\mathrm{Mg} \mathrm{ha}^{-1}$ ano $^{-1}$ ) conduz a formação de complexos envolvendo as frações $20-53 \mu \mathrm{m}, 2-20$ $\mu \mathrm{m}$ e $<2 \mu \mathrm{m}$ que resultam na proteção do carbono orgânico. No plantio direto, de acordo com Doran (1980) e Hendrix et al. (1986; 1998), essa proteção tem início com a acumulação de lisados de hifas de fungo, quando os resíduos culturais são mantidos na superficie e a comunidade microbiana é dominada por fungos. Adicionalmente, é sabido que quantidades elevadas de polissacarideos são secretadas pelos microorganismos e atuam como um forte agente de ligação entre as partículas primárias e os agregados do solo (Greenland et al., 1962). Recentemente, Bayer et al. (2000 a) em solos da região sul do Brasil constataram que a fração areia fina é menos decomposta, possui maior relação $\mathrm{C} / \mathrm{N}$ e maior concentração de $\mathrm{C}$ no grupo $\mathrm{O}$-alkyl do que as frações $<20 \mu \mathrm{m}$.

$\mathrm{Na}$ fração silte $(2-20 \mu \mathrm{m})$ e na fração argila $(<2 \mu \mathrm{m})$ a relação $\mathrm{C} / \mathrm{N}$ foi significativamente inferior às frações $>53 \mu \mathrm{m}$ na camada de $0-2,5 \mathrm{~cm}$ e $2,5-5 \mathrm{~cm}$ de 
profundidade. Conforme Oades \& Waters (1991), isso pode ser devido às alterações microbianas na matéria orgânica, e a estabilização das frações finas por produtos microbiais incluindo polissacarídeos, fragmentos de hifas de fungos e células ou colônias de bactérias incrustadas com partículas de argila. Corroborando com estas observações, Monrozier et al. (1991) reportaram que ao redor de 40 a $60 \%$ da biomassa microbiana pode estar associada com os microagregados $(2-20 \mu \mathrm{m})$ dependendo da quantidade e tipo de argila. Adicionalmente, Feller et al. (1996) observaram que colônias ou paredes de células de bactérias em diferentes estágios de decomposição podem ser identificadas em frações $<20 \mu \mathrm{m}$. Também comentaram que a matéria orgânica amorfa de origem microbial na fração argila pode ser devida a relação xilose/manose.

As frações granulométricas $<53 \mu \mathrm{m}$ foram responsáveis pela maior porcentagem do carbono orgânico total em todos os tratamentos e camadas amostradas. A faixa referente à média dos valores do COT encontrados em cada profundidade por tratamento situaram-se entre 61,0 a $71,2 \%$ na camada de $0-2,5 \mathrm{~cm}, 68,4$ a $78,1 \%$ na camada de $2,5-5 \mathrm{~cm}, 71,8$ a $81,7 \%$ na camada de $5-10 \mathrm{~cm}, 73,2$ a $85,1 \%$ e 75,0 a $83 \%$ na camada de $20-40 \mathrm{~cm} 70,7$ a 77,7\% (Tabela 17, Anexo).

Embora não tenha sido apresentado, a tendência para o $\mathrm{N}$ total foi similar em quase todos os casos citados para o COT nas frações granulométricas (Tabela 18, Anexo) e pode ser atribuída ao elevado coeficiente de correlação entre o COT e o N nesses solos $(r=0,97 ; n=150 ; p<0,001)$.

\subsubsection{Abundância natural do ${ }^{13} \mathrm{C}$ e taxas de sequestro do carbono orgânico do solo afetado pelos resíduos culturais associado ao plantio direto há longo período}

A conversão da vegetação natural $\mathrm{C}_{4}$ para sistemas agrícolas com a predominância de espécies $C_{3}$ (ver figura 4) resultou em alterações significativas $(p<$ $0,05)$ na assinatura original do $\delta^{13} \mathrm{C}$ em vários tratamentos da cronossequência (Figura 11). $\mathrm{O}$ enriquecimento no $\delta^{13} \mathrm{C}$ ocorreu da fração granulométrica mais grosseira (200- 
$2000 \mu \mathrm{m})$ para a mais fina $(<2 \mu \mathrm{m})$ e da camada superficial $(0-2,5 \mathrm{~cm})$ para a mais profunda $(20-40 \mathrm{~cm})$. Esses resultados confirmam que a entrada de resíduos culturais com predominância de espécies $\mathrm{C}_{3}$ tenha alterado a composição da matéria orgânica $\mathrm{e}$ sugere distintos graus de humificação nas diferentes frações granulométricas.

$\mathrm{Na}$ camada de $0-10 \mathrm{~cm}$ de profundidade, os tratamentos sob plantio direto comparados ao $\mathrm{CN}$ causaram um fracionamento nos valores do $\delta^{13} \mathrm{C}$. A contribuição das espécies $\mathrm{C}_{3}$ introduzidas na rotação de culturas sobre a vegetação original $(\mathrm{CN})$ foi maior nas frações granulométricas mais grosseiras do que nas frações mais finas. Os valores do $\delta^{13} \mathrm{C}$ no tratamento $\mathrm{PC}-22$ foram mais próximos do $\mathrm{CN}$ na camada de $0-5 \mathrm{~cm}$ de profundidade e semelhante aos demais abaixo de $10 \mathrm{~cm}$ de profundidade. A diferença entre valores de $\delta^{13} \mathrm{C}$ obtidos nos tratamentos sob PD e CN foram: $-6,83$ a $-4,77 \%$ na camada de $0-2,5 \mathrm{~cm},-5,54$ a $-4,08 \%$ na camada de $2,5-5 \mathrm{~cm} \mathrm{e}-4,0$ a $-3,05 \%$ na camada de 5-10 $\mathrm{cm}$ de profundidade (Figura 11). Por outro lado, nas camadas abaixo de $10 \mathrm{~cm}$ de profundidade as alterações no $\delta^{13} \mathrm{C}$ não foram significativas entre os tratamentos, sugerindo que os resíduos culturais mantidos na superficie do solo tiveram maior contribuição no COT do que as raízes. Esta observação contrasta com os resultados reportados por Gale et al. (2000 a; b) e Wander \& Yang (2000) que mostraram maior participação das raízes na formação e estabilização de agregados. Todavia, a metodologia do fracionamento granulométrico da MOS aplicada a amostras de solo peneiradas em peneira de $2 \mathrm{~mm}$ tem princípios e enfoques distintos da metodologia para obtenção de classes de agregados estáveis em água aplicada em amostras não destorroadas. O princípio do fracionamento granulométrico se baseia na associação das frações da MOS com as partículas minerais de tamanho e composição mineralógica diferentes e que diferem em estrutura e função (Christensen, 1992). Por outro lado, a obtenção de classes de agregados estáveis em água está fundamentada na teoria da hierarquização aplicada à formação de micro e macroagregados (Tisdall \& Oades, 1982). A principal diferença entre estes métodos é o nível de energia aplicado na ruptura dos agregados no método do fracionamento granulométrico. 


\section{Cronossequência}

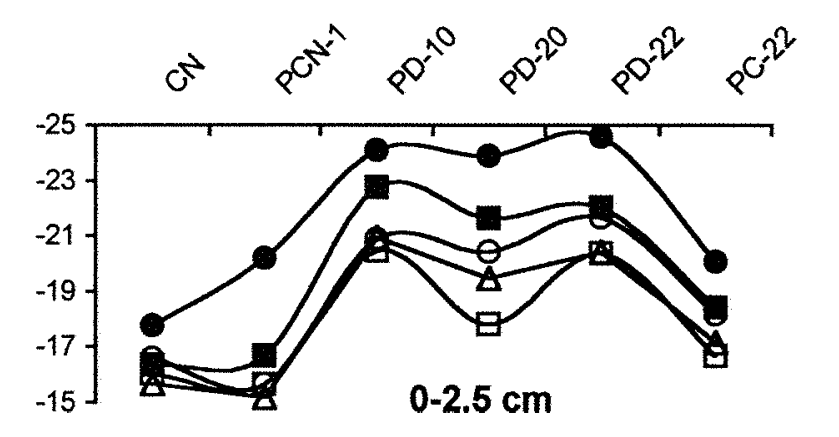

Frações granulométricas
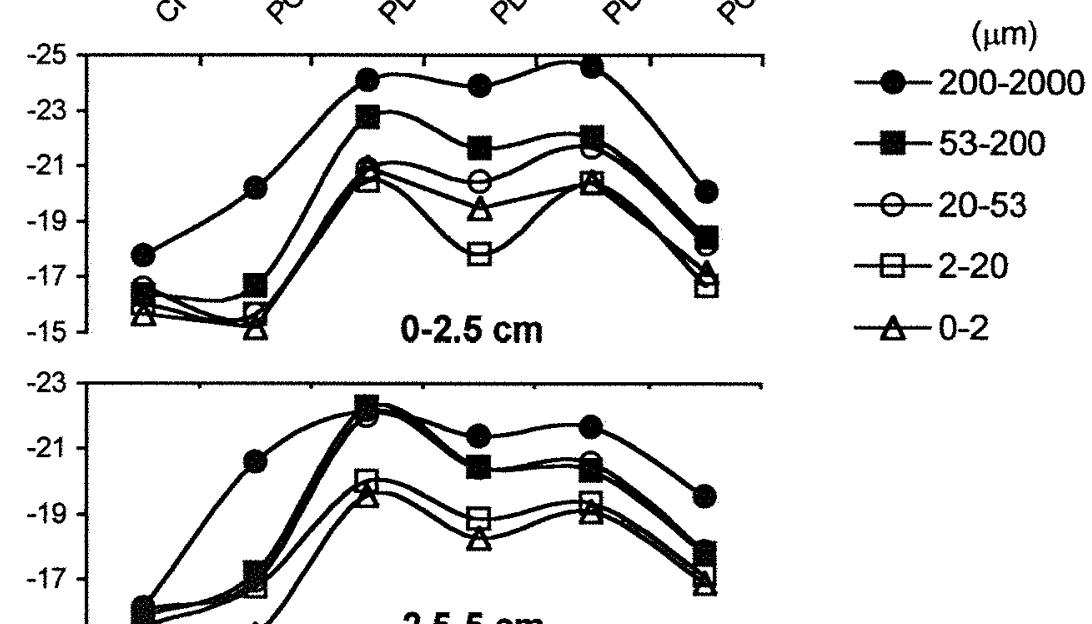

$2.5-5 \mathrm{~cm}$


Figura 11. $\delta^{13} \mathrm{C}(\%)$ nas frações granulométricas da MOS em cada profundidade de amostragem nos sistemas de manejo do solo na cronossequência. 
Estes enfoques se complementam e tem sido sugeridos em trabalhos de compartimentalização do C (Christensen, 1992, Feller et al., 1996).

$\mathrm{O}$ sinal do $\delta^{13} \mathrm{C}$ dos resíduos culturais de milho na rotação de cultura pode ter diluído o efeito das espécies $C_{3}$. Embora a relação $C_{3} / C_{4}$ nos tratamentos sob PD tenha sido 7:1, não foi isolada essa fonte de interferência na interpretação dos resultados, conforme realizado por Huggins et al. (1996). Entretanto, se for considerado todo o período de cultivo desde a conversão da vegetação natural ao momento da avaliação, esta relação aumentará para 10:1 (ver Figura 4). Os tipos de cultura na rotação e a mineralização dos resíduos culturais são os principais fatores que controlam o sinal do $\delta^{13} \mathrm{C}$ e a mineralização desses resíduos é fortemente afetada pela relação $\mathrm{C} / \mathrm{N}$. A relação $\mathrm{C} / \mathrm{N}$ dos resíduos das culturas em uso na rotação, estimada por Derpsch (1983), foi de 13 a 16 para a cultura de soja, 28 a 32 para aveia preta, 34 a 42 para o trigo e 64 a 68 para a cultura do milho. Essas relações sugerem que a taxa de mineralização tende a aumentar após a colheita de soja e a influência desses resíduos pode se estender até a entrada dos resíduos de aveia preta. $\mathrm{O}$ suprimento de $\mathrm{N}$ dos resíduos de soja e o maior aporte de $\mathrm{C}$ via resíduos de aveia preta. Estes podem também estimular a atividade da biomassa microbiana para o consumo de fontes mais ricas em $\mathrm{C}$ que virão a seguir na rotação (ver Figura 5). Assim sendo, a adição de resíduos com relação elevada relação $\mathrm{C} / \mathrm{N}$ sobre resíduos com menor relação pode ser usada principalmente para a respiração microbiana, resultando em menos $C$ armazenado no solo (Smith et al., 1992).

A estimativa de COT derivado dos resíduos culturais (Figura 12) nos tratamentos sob plantio direto na camada de $0-10 \mathrm{~cm}$ foi significativamente superior nas frações granulométricas mais grosseiras $(200-2000 \mu \mathrm{m}, 53-200 \mu \mathrm{m}, 20-53 \mu \mathrm{m})$ do que as mais finas $(2-20 \mu \mathrm{m},<2 \mu \mathrm{m})$. Nesses tratamentos, a porcentagem do COT proveniente dos resíduos culturais nas frações $>20 \mu \mathrm{m}$ variou de: a) PD-10: 59,2 a $100 \%$ na camada de $0-2,5 \mathrm{~cm} ; 76,1$ a $80,3 \%$ na camada de 2,5 a $5 \mathrm{~cm}$ e 48,2 a $96,8 \%$ na camada de 5-10 cm de profundidade; b) PD-20: 52,8 a 100\% na camada de 0-2,5 cm; 55,7 a $68,2 \%$ na camada de $2,5-5 \mathrm{~cm}$ e 40,4 a $49,0 \%$ na camada de $5-10 \mathrm{~cm}$ de 
profundidade; c) PD-22: 69,7 a 100\% na camada de 0-2,5 cm; 57,8 a 71,7\% na camada de $2,5-5 \mathrm{~cm}$ e 32,9 a $45,5 \%$ na camada de $5-10 \mathrm{~cm}$ de profundidade.

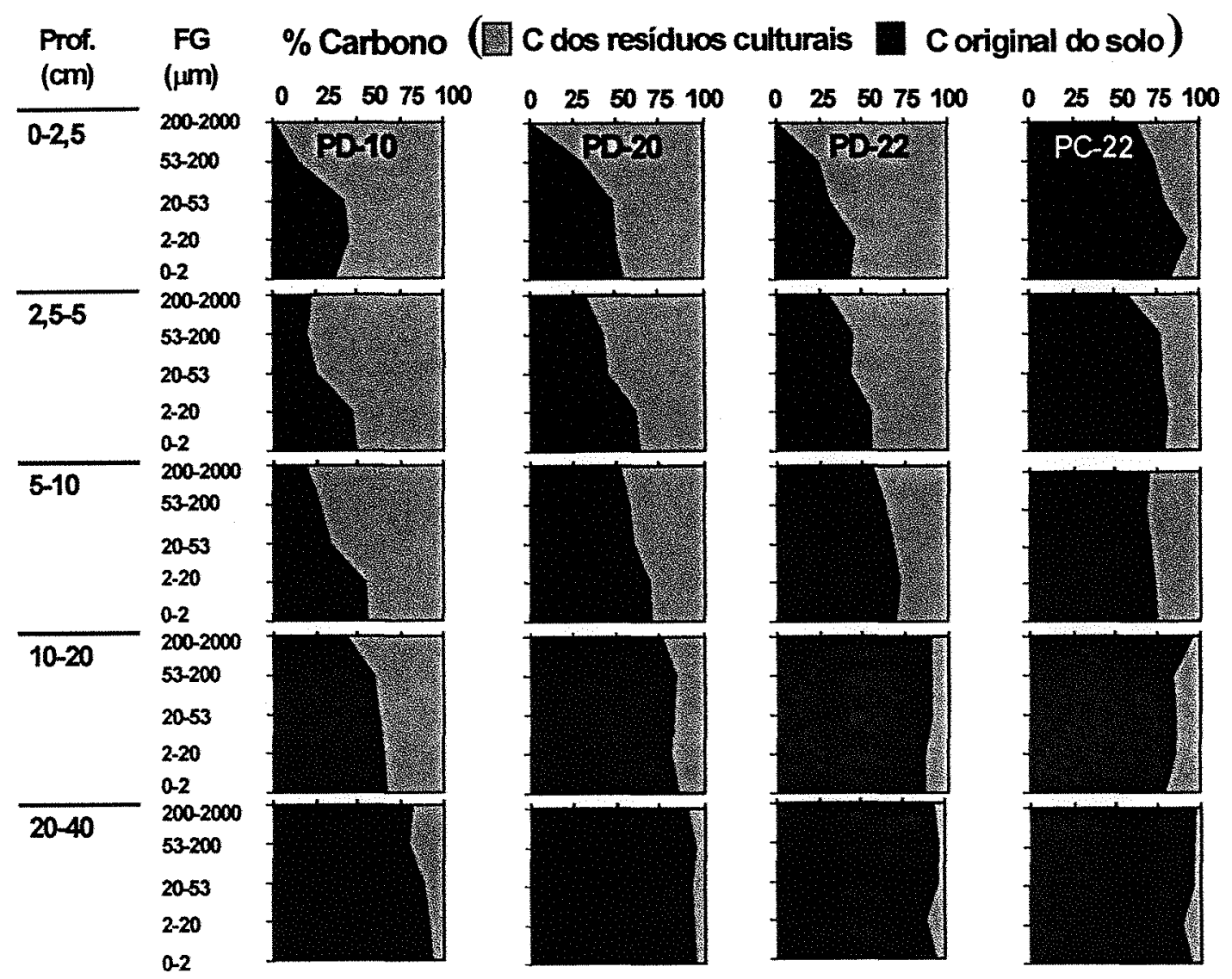



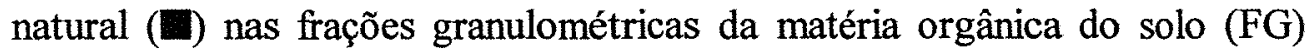
nos tratamentos sob plantio direto e convencional em cada profundidade amostrada.

Embora a contribuição porcentagem do COT proveniente dos resíduos culturais nas frações granulométricas mais finas tenha sido menor, foi significativamente $(\mathrm{p}<$ 0,05 ) superior ao $\mathrm{CN}$. Até a camada de $5-10 \mathrm{~cm}$ de profundidade essa participação no COT variou no PD-10 de 56,6 a 64,6\% (0-2,5 cm); 51,7 a 53,7\% (2,5-5 cm) e 40,5 a $42,0 \%(5-10 \mathrm{~cm})$. No PD-20 a variação foi de 46,3 a 50,9\% (0-2,5 cm); 37,0 a 39,8\% $(2,5-5 \mathrm{~cm})$ e 29,7 a $30,5 \%(5-10 \mathrm{~cm})$ enquanto no $P D-22$ a variação foi de 55,6 a 58,2\% 
$(0-2,5 \mathrm{~cm}) ; 45,6$ a $46 \%(2,5-5 \mathrm{~cm})$ e 29,3 a $30,7 \%(5-10 \mathrm{~cm})$. Isto indica que o fluxo contínuo de $\mathrm{C}$ resultante da mineralização, e a humificação dos compostos orgânicos nos tratamentos a longo periodo sob PD, parecem ser os fatores chave influenciando as associações do COT com os agregados e as frações granulométricas da MOS. Assim sendo, estes resultados convergem aos de Balesdent et al. (2000) que reportaram forte relacionamento entre a dinâmica do $\mathrm{C}$ e a proteção física em solos de clima temperado. No tratamento PCN-1 a contribuição dos resíduos culturais no COT do solo restringiuse a fração de 200-2000 $\mu \mathrm{m}$ e reflete o período curto da conversão da vegetação natural.

Por outro lado, a queda no conteúdo de COT pela conversão do ecossistema natural para o agroecossistema tende a alcançar um novo equilibrio em 30 a 50 anos (Wagner, 1981). A perda de COT no presente estudo durante 20 anos (representado pela primeira fase de cultivo sob preparo convencional após a conversão da vegetação natural e 10 anos de PD) foi de $1,09 \mathrm{Mg} \mathrm{ha}^{-1}$ ano $^{-1}$.

A ocorrência de um novo nível de equilíbrio estável, no presente estudo, foi prevista em aproximadamente 40 anos após a adoção do plantio direto associado ao retorno de elevada taxa de resíduos culturais (Figura 13).

$\mathrm{O}$ estoque de COT estimado para esse novo nível de equilibrio, considerando a camada de 0-20 cm de profundidade seria de 88,0 a $90,0 \mathrm{Mg} \mathrm{ha}^{-1}$. Estes valores representam um incremento de 47,1 a $50,5 \%$ no estoque de COT em relação ao estoque original encontrado no campo nativo. Também pode ser afirmado que a técnica do $\delta^{13} \mathrm{C}$ aplicada a sistemas agrícolas desenvolvida por Cerri et al. (1985) e Balesdent et al. (1987) mostrou-se uma valiosa ferramenta para detectar as alterações do $\mathrm{C}$ afetadas por sistemas de rotação de culturas e manejo do solo, conforme observação anteriormente feita por Huggins et al. (1996). A amplitude de variação no $\delta^{13} \mathrm{C}$ entre o campo nativo e os tratamentos sob PD nesse estudo, foi similar as encontradas por Balesdent et al. (1988). A taxa de sequestro de $\mathrm{C}$ associada ao plantio direto (cálculos incluíram o $\mathrm{CN}$ e os tratamentos sob PD) nessa importante região do Sul do Brasil foi estimada em 80,6 g $\mathrm{C} \mathrm{m}^{-2}$ ano $^{-1}$ para $0-20{\mathrm{~cm} \mathrm{e} 99,4 \mathrm{~g} \mathrm{C} \mathrm{m}^{-2} \text { ano }}^{-1}$ para a profundidade total amostrada (0-40 $\mathrm{cm})$. A taxa de sequestro calculada para cada camada é apresentada a seguir: $31,9 \mathrm{~g} \mathrm{C}$ $\mathrm{m}^{-2}$ ano $^{-1}(0-2,5 \mathrm{~cm}) ; 21,2 \mathrm{~g} \mathrm{C} \mathrm{m}^{-2}$ ano $^{-1}(2,5-5 \mathrm{~cm}) ; 12,5 \mathrm{~g} \mathrm{C} \mathrm{m}^{-2}$ ano $^{-1}(5-10 \mathrm{~cm}) ; 15,1 \mathrm{~g}$ 
$\mathrm{C} \mathrm{m}^{-2}$ ano $^{-1}(10-20 \mathrm{~cm})$ e $18,7 \mathrm{~g} \mathrm{C} \mathrm{m}^{-2}$ ano $^{-1}(20-40 \mathrm{~cm})$. A maior contribuição na taxa total de sequestro de $\mathrm{C}$ ocorreu na camada de $0-10 \mathrm{~cm}$ e representou $66 \%$ do $\mathrm{C}$ sequestrado, confirmando os argumentos expostos neste capítulo. Os resultados do presente trabalho são superiores aos $30 \mathrm{a} 70 \mathrm{~g} \mathrm{C} \mathrm{m}^{-2}$ ano $^{-1}$ reportados por Lal et al. (1998) e próximo às $130 \mathrm{~g} \mathrm{C} \mathrm{m}^{-2}$ ano-1 encontrados por Bayer et al. (2000 b) no Rio Grande do Sul.

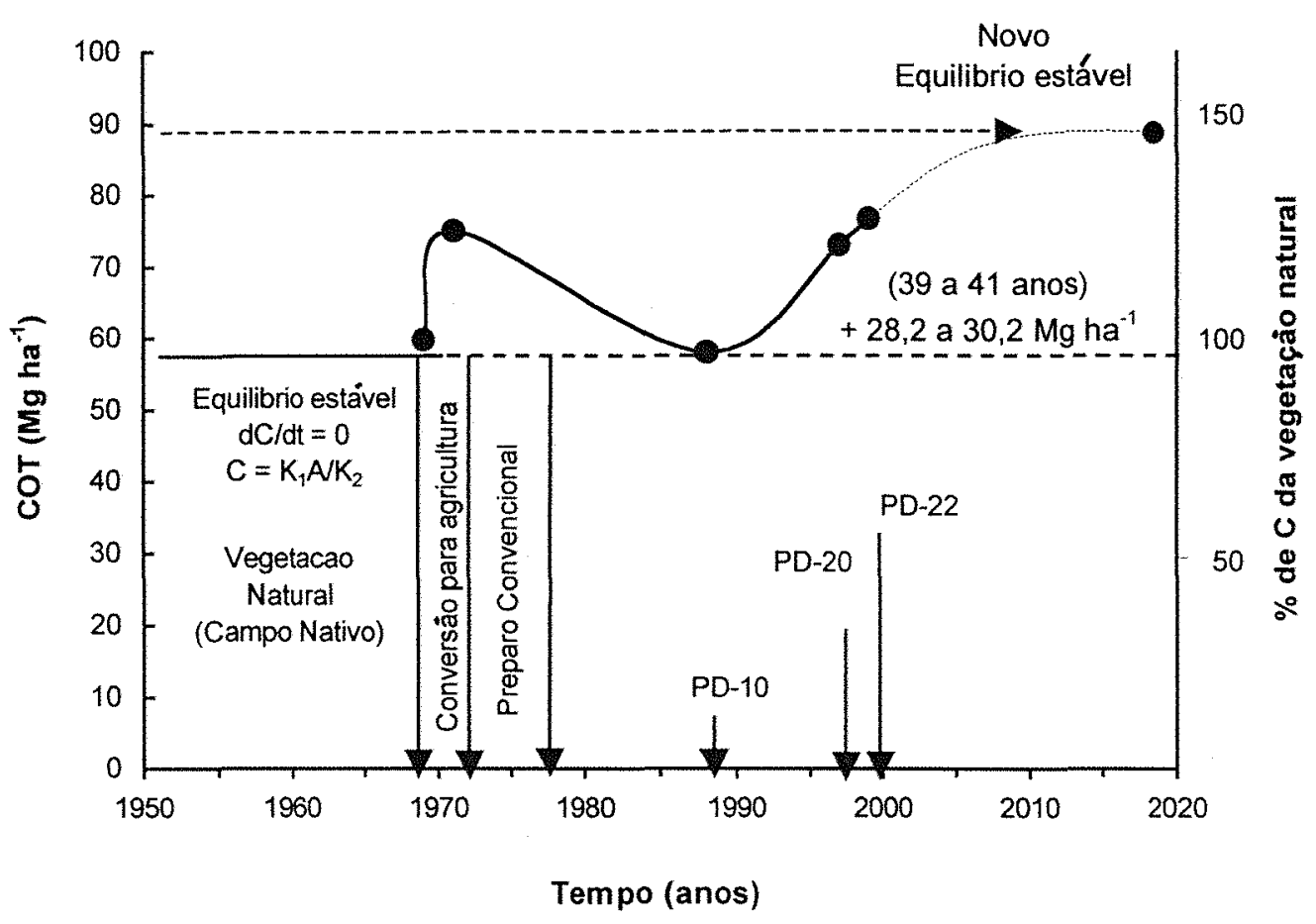

Figura 13. Representação esquemática das alterações do carbono orgânico do solo e previsão do novo nível de equilibrio estável para a camada de $20 \mathrm{~cm}$ de profundidade em uma cronossequência sob plantio direto.

No Brasil, 13,47 milhões de ha são cultivados no sistema de plantio direto, o que representa aproximadamente $32 \%$ da área com produção de grãos (Febrapdp, 2000). Desse total, 70,5\% (equivalente a 9,43 milhões de ha) estão localizados nos estados da região sul. A estimativa do potencial de sequestro de $C$ para essa região seria de $9,37 \mathrm{Tg}$ $\mathrm{C}$ ano ${ }^{-1}$ com base nos dados desse estudo e $12,54 \mathrm{Tg} \mathrm{C}$ ano $^{-1}$ de acordo com Bayer et al. 
$(2000 \mathrm{~b})$. Esse potencial é equivalente a mitigação (1 unidade de $\mathrm{C}$ é convertida para 3,67 unidades de $\mathrm{CO}_{2}$ ) de 34,3 $\mathrm{Tg} \mathrm{CO}_{2}$ ano $^{-1}$ a 46,0 $\mathrm{Tg} \mathrm{CO}_{2}$ ano $^{-1}$.

\subsection{Conclusões}

O aumento significativo do conteúdo de COT na camada de 0-10 $\mathrm{cm}$ de profundidade nos solos sob plantio direto comparado aos solos sob vegetação natural e longo período em preparo convencional foi devido às adições de resíduos culturais associado ao não revolvimento do solo. Esses efeitos foram pronunciados principalmente nas frações granulométricas mais grosseiras (200-2000 $\mu \mathrm{m}, 53-200 \mu \mathrm{m}$ e $20-53 \mu \mathrm{m})$ da MOS, embora as frações finas $(2-20 \mu \mathrm{m}$ e $<2 \mu \mathrm{m})$ também tenham sido enriquecidas na camada superficial. A avaliação da abundância natural do ${ }^{13} \mathrm{C}$ nas frações granulométricas da MOS confirmou essas evidências indicando que a manutenção do sistema de plantio direto por longo período induz à proteção da MOS em diversos compartimentos através de um fluxo contínuo de $\mathrm{C}$ das frações grosseiras em direção às frações mais finas. A taxa de sequestro de COT para a camada de $40 \mathrm{~cm}$ de profundidade foi de $99,4 \mathrm{~g} \mathrm{~m}^{-2}$ ano $^{-1}$ e o potencial de sequestro para a região sul do Brasil foi estimado em $9,37 \mathrm{Tg} \mathrm{C}$ ano $^{-1}$. 


\section{BIOMASSA MICROBIANA E COMPONENTES DA MATÉRIA ORGÂNICA AFETADOS POR SISTEMAS DE MANEJO CONVENCIONAL E PLANTIO DIRETO NUM OXISOL NO BRASIL}

\subsection{RESUMO}

O impacto do sistema plantio direto associado aos resíduos culturais no reservatório de $\mathrm{C}$ e $\mathrm{N}$ da biomassa microbiana tem sido considerado um fator chave no entendimento do fluxo de $\mathrm{C}$ nos sistemas agrícolas. $\mathrm{O}$ reservatório da biomassa microbiana de $\mathrm{C}(\mathrm{BMC})$ e $\mathrm{N}$ (BMN) no solo e as interações com os componentes orgânicos do solo foram avaliados em uma cronossequência envolvendo sistemas de manejo convencional e plantio direto em um Latossolo Vermelho localizado na região Centro-Sul do Estado do Paraná. A cronossequência constituiu-se de seis faixas representando os tratamentos de uso da terra: a) campo nativo $(\mathrm{CN})$; b) preparo do campo nativo ( $\mathrm{PCN}-1)$ envolvendo a conversão da vegetação natural em área agrícola; c) plantio direto por 10 anos (PD-10); d) plantio direto por 20 anos (PD-20); e) plantio direto por 22 anos (PD-22); f) preparo convencional por 22 anos (PC-22). Foi avaliado o conteúdo de COT, nitrogênio total, BMC e BMN, polissacarídeos totais (POT) e lábeis (POL) e o carbono orgânico dissolvido (COD) em amostras de solo coletadas em cinco profundidades $(0-2,5 ; 2,5-5 ; 5-10 ; 10-20 ;$ e $20-40 \mathrm{~cm})$. A BMC e BMN no campo nativo foi significativamente superior aos tratamentos sob plantio direto sendo $77,3 \% \mathrm{e}$ $107 \%$ maior que o PD- $10,101,4 \%$ e $64,5 \%$ maior que o PD-20 e $69,5 \%$ e $55,5 \%$ maior que o PD-22 na camada de 0-2,5 cm de profundidade, respectivamente. $\mathrm{Na}$ camada de 2,5-5 cm de profundidade, a BMC e $\mathrm{BMN}$ foi $56,6 \%$ e $106,6 \%$ superior ao PD-10, 85,9 \% e 63,4 \% superior ao PD-20 e $60 \%$ e 55,5\% superior ao PD-22, respectivamente. A relação entre a BMC e BMN com os componentes da matéria 
orgânica, baseada na média dos coeficientes de correlação incluindo todos os dados de cada tratamento $(n=150)$ decresceu conforme a sequiência: $\mathrm{COD}>$ Ntotal $>$ COT $>$ POT $=$ POL. Para a BMN a seqüência foi Ntotal $>$ COD $>$ COT $>$ POL $>$ POT. Embora a relação $\mathrm{C}_{\text {mic }}: \mathrm{C}_{\text {org }}$ na profundidade de $0-5 \mathrm{~cm}$ para os tratamentos sob plantio direto tenha sido a menor, o estoque de $\mathrm{C}$ foi superior ao campo nativo em $2,9 \mathrm{Mg} \mathrm{ha}^{-1}$ no $\mathrm{PD}$ $10,7,8 \mathrm{Mg} \mathrm{ha}^{-1}$ no PD-20 e 13,1 $\mathrm{Mg} \mathrm{ha}^{-1}$ no PD-22.

\subsection{SUMMARY: SOIL MICROBIAL BIOMASS AND ORGANIC MATTER COMPONENTS AFFECTED BY A TILLAGE CHRONOSEQUENCE IN A BRAZILIAN OXISOL}

The impact of crop residues and associated with no-tillage systems in $\mathrm{C}$ and $\mathrm{N}$ turnover by microbial biomass has been considered a key factor to understand how soil organic carbon (SOC) is built up in agricultural systems. The soil microbial biomass carbon (SMBC) and nitrogen (SMBN) pool and its interactions with organic matter components were assessed in a Brazilian Oxisol under a plowed and no-tillage chronosequence. The sites were located in the South Center of Paraná State $\left(50^{\circ} 23^{\prime} \mathrm{W}\right.$ and $24^{\circ} 36^{\prime} \mathrm{S} ; 50^{\circ} 20^{\prime} \mathrm{W}$ and $25^{\circ} 20^{\prime}$ ). The chronosequence consisted of six land use treatments: (i) native field (NF); (ii) plow tillage of the native field (PNF-1) conversion of natural vegetation to cropland; (iii) no-tillage for 10 years (NT-10); (iv) no-tillage for 20 years (NT-20); (v) no-tillage for 22 years (NT- 22); and (vi) conventional tillage for 22 years (CT-22). Soil samples were collected from five depths $(0-2.5 ; 2.5-5 ; 5-10 ; 10-20$; and $20-40 \mathrm{~cm})$. SOC, total nitrogen contents, SMBC, SMBN, total polysaccharides (TP), labile polysaccharides (LP) and dissolved organic carbon (DOC) contents were measured in a whole sample. A significant difference for SMBC and SMBN in CN compared with no-tillage treatments accounted of $77.3 \%$ and $107 \%$ greater than NT-10, $101.4 \%$ and $64.5 \%$ than NT-20, and $69.5 \%$ and $55.5 \%$ than NT22 for 0-2.5 cm depth, respectively. Also, was still high in $2.5-5 \mathrm{~cm}$ depth, and were $56.6 \%$ and $106.6 \%$ greater than NT-10, $85.9 \%$ and $63.4 \%$ than NT-20, and $60 \%$ and $55.5 \%$ than NT-22, respectively. The relationship among SMBC and SMBN with 
organic components based on the average of correlation coefficients of all treatments with all data $(n=150)$ decrease in the order of DOC $>$ TN $>$ SOC $>$ TP $=$ LP and for SMBN was TN $>$ DOC $>$ SOC $>$ LP $>$ TP. At no-tillage treatments were observed lower $\mathrm{C}_{\text {mic }}: \mathrm{C}_{\text {org }}$ ratio in 0 to 5 -cm depth, while carbon storage were superior than $\mathrm{NF}$, and accounting 2.9 $\mathrm{Mg} \mathrm{ha}^{-1}$ for NT-10, 7.8 $\mathrm{Mg} \mathrm{ha}^{-1}$ for NT-20, and 13.1 $\mathrm{Mg} \mathrm{ha}^{-1}$ for NT-22.

\subsection{INTRODUÇÃO}

A intensidade da ciclagem do $\mathrm{C}$ e $\mathrm{N}$ no solo é fortemente afetada pelo manejo de práticas agrícolas. A alteração no ambiente dos solos em macro e micro escala, altera o crescimento microbiano resultando em diferentes taxas de decomposição da MOS (Anderson \& Domsch, 1989). A biomassa microbiana responde mais rapidamente às alterações provocadas pelo manejo do solo antes que elas possam ser detectadas na determinação do conteúdo de COT (Jenkinson \& Ladd, 1981; Powlson, 1980; Powlson et al., 1987; Carter, 1992). A força que dirige a decomposição dos resíduos vegetais e detritos é o fluxo de energia que circula através da biomassa microbiana e esse fluxo determina quando o sistema está armazenando ou consumindo o reservatório de $\mathrm{C}$ (Jenkinson \& Ladd, 1981).

A ruptura dos agregados, o aumento da aeração e a incorporação de resíduos vegetais frescos pelo preparo do solo têm provocado o decréscimo da MOS, resultando em elevado fluxo de $\mathrm{CO}_{2}$ para a atmosfera (Elliot, 1986; Powlson et al., 1987; Reicosky et al., 1995). Por outro lado, a manutenção dos resíduos culturais na superfície do solo associado ao plantio direto tem conduzido ao armazenamento de $\mathrm{C}$ na camada superficial (Kern \& Johnson, 1993). Todavia, o não revolvimento da palhada, também pode direcionar para a concentração da atividade biológica e da biomassa microbiana nesta camada, embora paradoxalmente, a decomposição dos resíduos culturais seja aparentemente reduzida (Staley, et al., 1988). O principal efeito dos resíduos culturais e o plantio direto na MOS é a sua proteção dentro dos macroagregados reduzindo o ataque microbiano à matéria orgânica (Christensen, 1992; Carter, 1992; Cambardella \& 
Elliot, 1993; Beare, et al., 1994; Balesdent et al., 2000). Em simples palavras, essa proteção fisica pode ser definida como o recobrimento da matéria orgânica pelas partículas de argila e os agregados formando micro estruturas ou cápsulas (Tisdal \& Oades, 1982; Elliot, 1986). Posteriormente, Carter (1992) mostrou que esse carbono "novo" estava principalmente associado com o carbono orgânico particulado em agregados no PD.

Nas últimas duas décadas tem sido proposta a avaliação da biomassa microbiana como um indicador sensitivo das primeiras alterações da MOS em sistemas agrícolas (Carter, 1986; Powlson et al., 1987; Sparling, 1992). Em geral, o carbono microbiano $\left(\mathrm{C}_{\text {mic }}\right)$ representa 1 a $5 \%$ do COT e reflete diferentes estágios da ciclagem do $\mathrm{C}$ nos solos (Anderson \& Domsch, 1989). Além disso, a relação $\mathrm{C}_{\text {mic }}: \mathrm{C}_{\text {org }}$ e os quocientes ecofisiológicos (particularmente o $q \mathrm{CO}_{2}$ ) têm sido usados para traçar conclusões sobre a dinâmica do C em solos (Anderson \& Domsch, 1989, 1990; Anderson \& Gray, 1990; Sparling, 1992).

Anderson \& Domsch (1989) realizaram uma extensa avaliação da relação $\mathrm{C}_{\text {mic }}: \mathrm{C}_{\text {org }}$ em 134 parcelas de experimentos de longa duração em solos de regiões sob clima temperado. Os valores encontrados (expressos em porcentagem do $\mathrm{C}_{\mathrm{mic}}$ do $\mathrm{C}_{\mathrm{org}}$ ) foram de 2,3\% para os solos sob monocultura e 2,9\% para os solos com sistemas de rotação de cultura. Além disso, nas parcelas que receberam adubo orgânico e adubos verdes essa relação subiu para 4,0 ou $3,7 \%$ indicando estreito relacionamento com o uso e o manejo do solo. Franzluebbers et al. (1994) reportaram que a intensidade de cultivo associado ao plantio direto aumentou essa relação para 5,5\% e foi significativamente superior ao preparo convencional. Eles também concluíram que o $\mathrm{C}_{\text {mic }}$ aumenta com a intensidade de cultivo e estava positivamente correlacionado com o armazenamento do COT. Por outro lado, essa discussão é ainda mais intensa em regiões tropicais porque os valores reportados na literatura são muito inferiores do que os citados para regiões temperadas. Por exemplo, em um Oxisol da região Amazônica Cerri et al. (1985) encontraram valores de $\mathrm{C}_{\text {mic }}: \mathrm{C}_{\text {org }}$ de $0,73 \%$ sob floresta natural e $0,04 \%$ em área recém desmatada e queimada. Em outro Oxisol (Estado do Paraná), Balota et al. (1998) também encontraram valores da relação $\mathrm{C}_{\text {mic }}: \mathrm{C}_{\text {org }}$ bem inferiores aos citados em regiões 
temperadas mesmo sendo avaliados em sistemas com rotação de culturas e plantio direto. Esta é uma indicação de que outros fatores possam estar influenciando essas relações.

Estudos comparativos entre sistemas que envolvem o preparo do solo e o plantio direto em Oxisols, tendo como referência as condições originais da vegetação natural e o equilibrio estável do COT no solo têm sido pouco reportados. Além disso são também escassas comparações entre sistemas de manejo em cronossequência para determinar como a BMC e BMN interage com esses sistemas. Estimativas sobre o impacto em propriedades do solo, especialmente aquelas relacionadas com a biomassa microbiana do solo, são essenciais para o desenvolvimento de estratégias que visam o manejo sustentável dos solos.

Este trabalho, teve como objetivo avaliar o impacto de uma cronossequência há longo período sob sistemas de manejo convencional e plantio direto nas relações entre a matéria orgânica e a biomassa microbiana num Oxisol da região sul do Brasil.

\subsection{MATERIAL E MÉTODOS}

\subsubsection{Localização e descrição da área experimental}

O experimento de campo foi conduzido em duas áreas, sendo uma situada na Fazenda Santa Branca (FSB) próxima à cidade de Tibagi e outra na Fazenda Frankanna (FF) próxima à cidade de Ponta Grossa. Estas áreas estão enquadradas na região CentroSul do Estado do Paraná.

A vegetação natural é dominada por espécies $\mathrm{C}_{4}$ representadas por algumas gramíneas resistentes ao fogo tais como o Andropogon sp., Aristida sp., Paspalum sp., Panicum sp., e ao longo dos canais naturais de drenagem há a formação de floresta de galeria. O relevo caracteriza-se como suave ondulado com pendentes entre 2 a $7 \%$ de declividade. O material de origem é constituído por sedimentos clásticos do período Devoniano, caracterizados por materiais retrabalhados de arenitos da formação Furnas e folhelhos da formação Ponta Grossa. Os solos foram classificados como Latossolos 
Vermelhos (Typic Hapludox), textura argilosa, profundos, muitos bem estruturados e drenados. A escolha das áreas experimentais baseou-se na existência de uma cronossequência bem definida, tendo como referência as condições originais de vegetação e solo. Além disso, possuem o mesmo material de origem, a mesma classe textural e localização na vertente (posição de topo). Foram também manejadas com práticas culturais e rotação de culturas similares. Essa cronossequência oportuniza a avaliação do impacto do preparo do solo e do plantio direto há longo período nos compartimentos da MOS e de atributos da relacionados com a biomassa microbiana. A tabela 5 sumariza a descrição geral da situação selecionada e os detalhes sobre este ítem estão descritos no capítulo 3 (p.27-31).

Tabela 5. Descrição geral da área de estudo: localização, clima e solo

\begin{tabular}{llll}
\hline \multicolumn{2}{c}{ Parâmetros } & \multicolumn{2}{c}{ Descrição das áreas } \\
\cline { 3 - 4 } Localização & Município & Fazenda Santa Branca & Fazenda Frankanna \\
& Latitude & $24^{\circ} 36^{\prime} \mathrm{S}$ & Ponta Grossa \\
& Longitude & $50^{\circ} 23^{\prime} \mathrm{W}$ & $25^{\circ} 20^{\prime} \mathrm{S}$ \\
\multirow{4}{*}{ Clima } & Altitude & $880 \mathrm{~m}$ & $50^{\circ} 20^{\prime} \mathrm{W}$ \\
& Tipo $^{\ddagger}$ & mesotérmico, úmido & $910 \mathrm{~m}$ \\
& & subtropical, tipo cfb & mesotérmico, úmido \\
& TMA $^{\ddagger \ddagger}$ & $20,7^{\circ} \mathrm{C}$ & $18,7^{\circ} \mathrm{C}$ \\
\multirow{4}{*}{ Solo } & PMA $^{\ddagger \ddagger \ddagger}$ & $1532 \mathrm{~mm}$ & $1545 \mathrm{~mm}$ \\
& Tipo & Latossolo Vermelho, & Latossolo Vermelho, \\
& & Typic Hapludox & Typic Hapludox \\
& Textura & Argilosa & Argilosa \\
& Material de & Arenito + Folhelho & Arenito + Folhelho \\
& origem & (Material retrabalhado) & (Material retrabalhado) \\
& Tipo de argila & Ct; Gib; Hem.; Goe & Ct; Gib; Hem.; Goe \\
\hline
\end{tabular}

₹ Classificação climática de Koeppen;

¥ Temperatura média anual

$\ddagger \ddagger$ Precipitação media anual

${ }^{\S} \mathrm{Ct}=$ Caulinita; Gib = Gibbsita; Hem.$=$ Hematita Goe $=$ Goethita 


\subsubsection{Conversão da vegetação natural em sistemas agrícolas e descrição da cronossequência}

Antes do início da exploração agrícola na FSB e FF, as áreas estavam sob a vegetação natural, denominada de "campos nativos" e uma parte representa o tratamento campo nativo $(\mathrm{CN})$. A conversão dos campos nativos em áreas de cultivo na FSB iniciou em 1969. Entre 1969 e 1979 foi cultivado arroz (Oryza sativa) nos primeiros três anos e mantendo inverno em pousio e no restante do período, cultivou-se soja (Glicine max.) no verão e trigo (Triticum aestivum) no inverno sob preparo convencional.

Em 1979, foi adotado o plantio direto em aproximadamente 30\% do total da área e esta representa o tratamento com 20 anos sob plantio direto (PD-20). Entre 1979 e 1998 foram 39 cultivos assim distribuídos: no verão cultivou-se soja 15 vezes e milho (Zea mays $\mathrm{L}$.) cinco vezes e durante o inverno foram 11 cultivos de aveia preta (Avena strigosa, Schreb), sete cultivos de trigo e dois cultivos de tremoço azul (Lupinus angustifollios). Os cultivos de aveia preta e tremoço azul foram destinados exclusivamente para adubação verde e formação de cobertura do solo. Em 1989, foi adotado o plantio direto na área adjacente ao PD-20, e esta representa o tratamento com plantio direto há 10 anos (PD-10). Entre 1989 e 1998, foram 20 cultivos, sendo sete vezes soja e três vezes milho no verão e seis cultivos de aveia preta e quatro cultivos de trigo no inverno.

Em junho de 1996, outra área adjacente foi convertida em agricultura para representar a fase inicial da conversão da vegetação natural em área agrícola. Esta se refere ao tratamento denominado preparo do campo nativo (PCN-1). Durante o período de conversão do campo nativo (um ano e seis meses) foi cultivado soja (outubro/96), aveia preta (maio/97) e milho (setembro/97).

Na Fazenda Frankanna o início da exploração agrícola ocorreu em 1961. O manejo do solo realizado entre 1961 e 1976 (preparo do solo, culturas, calagem e quantidade de P) foi semelhante à Fazenda Santa Branca. Em 1976, duas áreas com três ha cada foram destinadas a comparação entre o preparo convencional e o plantio direto 
e estas, representam os tratamentos com plantio direto há 22 anos (PD-22) e o preparo convencional há 22 anos (PC-22). Neste último, o preparo do solo foi realizado após a colheita da cultura de verão e de inverno, através de uma aração e duas gradagens para atingir a profundidade de $20 \mathrm{~cm}$. No período entre 1976 e 1998 foram 15 cultivos de soja e 6 de milho no verão. No inverno, foram 10 cultivos de trigo, quatro de aveia preta, um de tremoço azul e o azevém (Lollium multiflorum) nas últimas quatro estações. Em 1996 e 1997, nesses dois tratamentos foram aplicados 15 a $20 \mathrm{~m}^{3} \mathrm{ha}^{-1}$ de esterco líquido de bovinos. A rotação de culturas nas áreas estudadas foi constituída por uma seqüência de seis cultivos: Trigo/Soja/Aveia preta/Soja/Aveia Preta/Milho. O ciclo da rotação se reinicia a cada três anos (figura 5, cap.3). O histórico de uso de fertilizantes, produção de grãos e a biomassa vegetal (parte aérea + raízes) estão apresentadas na tabela 3 (cap.3). Os detalhes deste item estão descritos no capítulo 3 (p.32-35).

\subsubsection{Análises químicas dos solos na cronossequência}

$\mathrm{O} \mathrm{pH}$ do solo foi determinado usando a proporção de 1:2,5 (solo: $\mathrm{H}_{2} 0$ ) conforme EMBRAPA (1979). Os cátions trocáveis $\left(\mathrm{Al}^{3+}, \mathrm{Ca}^{2+}, \mathrm{Mg}^{2+}, \mathrm{K}^{+}\right)$e o $\mathrm{P}$ foram extraídos pela resina trocadora de cátions e ânions, conforme descrito por Raij \& Quaggio (1983). A acidez potencial foi determinada pelo método descrito pela EMBRAPA (1979), extraindo o $\mathrm{H}+\mathrm{Al}$ com uma solução de $\mathrm{Ca}(\mathrm{OAc})_{2} 1 \mathrm{~N}$ tamponada a $\mathrm{pH} 7,0$ e a CTC foi obtida através da soma do valor da acidez potencial e das bases trocáveis $\left(\mathrm{Ca}^{2+}, \mathrm{Mg}^{2+}\right.$, $\mathrm{K}^{+}$). A caracterização do perfil (descrição morfológica, análise química e mineralógica) de solo de cada faixa selecionada encontra-se na tabela 1 e 2 (capítulo 3, p.30-31). A tabela 6 apresenta os dados referentes a alguns atributos da fertilidade do solo de cada tratamento em cinco profundidades. 
Tabela 6. pH, Acidez potencial, saturação por bases, P e K no solo dos sistemas de manejo (média de cinco repetições)

\begin{tabular}{|c|c|c|c|c|c|c|c|}
\hline \multirow{2}{*}{ Propriedades } & \multirow{2}{*}{$\begin{array}{l}\text { Prof. } \\
\text { (cm) }\end{array}$} & \multicolumn{6}{|c|}{ Sistemas de manejo do solo } \\
\hline & & $\mathrm{CN}$ & $\mathrm{PCN}-1$ & PD-10 & PD-20 & PD-22 & PC-22 \\
\hline pH & $0-2,5$ & 4,0 & 5,4 & 6,2 & 6,3 & 6,0 & 5,3 \\
\hline \multirow{4}{*}{$\left(\mathrm{CaCl}_{2} 0,01 \mathrm{M}\right)$} & $2,5-5$ & 3,9 & 4,4 & 5,8 & 5,8 & 5,5 & 5,4 \\
\hline & $5-10$ & 3,9 & 4,0 & 5,2 & 5,3 & 5,2 & 5,3 \\
\hline & $10-20$ & 4,0 & 3,9 & 4,9 & 4,6 & 4,6 & 5,2 \\
\hline & $20-40$ & 4,0 & 3,9 & 4,6 & 4,3 & 4,2 & 4,5 \\
\hline \multirow{5}{*}{$\begin{array}{l}\text { Acidez Potencial } \\
\left(\mathrm{mmol}_{\mathrm{c}} \mathrm{dm}^{-3}\right)\end{array}$} & $0-2,5$ & 104,8 & 78,0 & 36,2 & 44,4 & 44,0 & 50,0 \\
\hline & $2,5-5$ & 103,0 & 115,7 & 35,4 & 49,6 & 46,4 & 50,0 \\
\hline & $5-10$ & 98,0 & 146,2 & 45,4 & 59,8 & 49,0 & 51,8 \\
\hline & $10-20$ & 92,4 & 142,6 & 43,6 & 71,0 & 58,6 & 63,4 \\
\hline & $20-40$ & 80,2 & 127,2 & 47,2 & 70,8 & 61,2 & 75,2 \\
\hline \multirow{5}{*}{$\begin{array}{l}\text { Saturação por Bases } \\
(\mathrm{V} \%)\end{array}$} & $0-2,5$ & 15,4 & 75,0 & 82,3 & 81,3 & 72,4 & 64,7 \\
\hline & $2,5-5$ & 9,6 & 43,1 & 72,9 & 70,4 & 67,0 & 64,4 \\
\hline & $5-10$ & 6,4 & 18,6 & 56,1 & 55,3 & 59,8 & 62,7 \\
\hline & $10-20$ & 5,9 & 10,3 & 48,0 & 35,3 & 45,6 & 44,1 \\
\hline & $20-40$ & 3,5 & 4,8 & 31,3 & 20,7 & 25,8 & 21,4 \\
\hline \multirow{5}{*}{$\begin{array}{l}\mathbf{P} \\
\left(\mathrm{mg} \mathrm{dm}^{-3}\right)\end{array}$} & $0-2,5$ & 10,6 & 15,8 & 82,2 & 114,6 & 330,2 & 55,6 \\
\hline & $2,5-5$ & 9,4 & 17,8 & 47,4 & 58,2 & 120,4 & 43,6 \\
\hline & $5-10$ & 6,6 & 23,6 & 14,8 & 29,4 & 36,2 & 34,8 \\
\hline & $10-20$ & 4,2 & 8,8 & 9,0 & 12,2 & 14,4 & 12,6 \\
\hline & $20-40$ & 3,0 & 4,8 & 4,0 & 4,2 & 4,4 & 3,4 \\
\hline \multirow{5}{*}{$\begin{array}{l}\text { K trocável } \\
\left(\text { mmol }_{c} \mathrm{dm}^{-3}\right)\end{array}$} & $0-2,5$ & 2,4 & 6,8 & 6,2 & 9,1 & 7,4 & 6,1 \\
\hline & $2,5-5$ & 2,0 & 4,2 & 3,1 & 4,8 & 6,1 & 5,1 \\
\hline & $5-10$ & 1,2 & 3,1 & 1,6 & 3,1 & 4,8 & 3,6 \\
\hline & $10-20$ & 0,8 & 2,6 & 1,2 & 2,4 & 3,4 & 2,6 \\
\hline & $20-40$ & 0,3 & 1,2 & 0,7 & 1,1 & 2,3 & 1,9 \\
\hline
\end{tabular}

\subsubsection{Desenho experimental e amostragem do solo}

A situação selecionada constitui um delineamento experimental em faixas com um arranjo em parcelas subdividas não aleatória com cinco repetições. As faixas referem-se aos tratamentos de uso da terra implantados em épocas distintas que constituem a cronossequência. A faixa é constituída por seis níveis: a) Campo nativo 
(CN); b) Preparo do campo nativo (PCN-1); c) Plantio direto há 10 anos (PD-10); d) Plantio direto há 20 anos (PD-20); e) Plantio direto há 22 anos (PD-22) e f) Preparo convencional há 22 anos (PC-22). $\mathrm{O}$ arranjo em parcelas subdivididas não aleatória é representado pela profundidade de amostragem com cinco níveis $(0-2,5 ; 2,5-5,0 ; 5,0$ $10,0 ; 10,0-20,0$ e $20-40 \mathrm{~cm})$. As dimensões de cada faixa da cronossequência foram de $200 \mathrm{~m} \times 50 \mathrm{~m}$ e de cada repetição de $40 \mathrm{~m} \times 50 \mathrm{~m}$.

A coleta das amostras de solo em cada repetição foi realizada em minitrincheiras com dimensões de $20 \mathrm{~cm}$ x $50 \mathrm{~cm}$ (área) x $50 \mathrm{~cm}$ (profundidade). Para constituir uma amostra composta foram cavadas 9 mini-trincheiras e retirado fatias referente as camadas de 0-2.5, 2.5-5, 5-10, 10-20 e 20-40 cm. Detalhes das parcelas e da coleta das amostras de solo estão ilustrados na figura 6 do capitulo 3(p.34).

\subsubsection{Análise de carbono orgânico e nitrogênio total no solo}

As amostras de solo foram secas ao ar, homogeneizadas, destorroadas e passadas em peneira de $2 \mathrm{~mm}$. Uma sub-amostra foi moída em moinho de aço inox e peneirada em peneira de $150 \mu \mathrm{m}$. O N total foi determinado pelo sistema micro Kjeldahl e o COT pelo método da combustão seca (Nelson \& Sommers, 1982) utilizando um Carbon Analyser - LECO ${ }^{\circledast}$ CR-412.

\subsubsection{Estimativa da biomassa microbiana, respiração basal e cálculo de relações e quocientes}

As amostras de solo foram armazenadas em câmara fria a temperatura de 5 a $7^{\circ} \mathrm{C}$ até o seu uso. Antes da análise, o teor de umidade do solo foi ajustado para atingir a capacidade de campo. A BMC e a BMN foram estimadas de acordo com o método de fumigação-extração descrito por Vance et al. (1987) e Brookes et al. (1985). O conteúdo de $\mathrm{C}$ e $\mathrm{N}$ microbiano foi obtido através da diferença do $\mathrm{C}$ e $\mathrm{N}$ liberados pelos solos fumigados e não fumigados. A respiração basal foi determinada em laboratório através da incubação dos solos durante 10 dias. Em um becker de $50 \mathrm{~mL}$ pesou-se $30 \mathrm{~g}$ de solo 
e em outro adicionou-se $20 \mathrm{~mL}$ de $\mathrm{NaOH} 1 \mathrm{~N}$. Os dois beckers foram colocados em um frasco hermeticamente fechado e incubados à temperatura de $25^{\circ} \mathrm{C}$ em ambiente escuro. $\mathrm{O}$ C- $-\mathrm{CO}_{2}$ liberado após 10 dias de incubação foi determinado por titulação com uma solução de $\mathrm{HCl}$ 0,5 N saturada com cloreto de bário.

A relação $\mathrm{C}_{\text {mic }}$ :Corg e $\mathrm{N}_{\text {mic }}$ :Ntotal é relativa ao carbono e $\mathrm{N}$ microbiano $\left(\mathrm{C}_{\mathrm{mic}} \mathrm{e}\right.$ $\mathrm{N}_{\text {mic }}$ ) com o COT e $\mathrm{N}$ total do solo. Essas relações foram expressas por mg $\mathrm{C}_{\text {mic }} \mathrm{g}^{-1} \mathrm{C}_{\text {org }}$ e mg de $\mathrm{N}_{\text {mic }} \mathrm{g}^{-1} \mathrm{~N}_{\text {total. }} \mathrm{O}$ quociente metabólico microbiano $\left(q \mathrm{CO}_{2}\right)$ é a relação entre a respiração basal $\left(\mu \mathrm{g} \mathrm{CO}_{2}-\mathrm{C} \mathrm{h}^{-1}\right)$ e a biomassa microbiana e expressa em mg C- $\mathrm{CO}_{2} \mathrm{~g}^{-1}$ solo $h^{-1} \cdot \mathrm{mg} \mathrm{C}_{\text {mic }} \mathrm{Kg}^{-1}$ solo (Pirt, 1975; Anderson \& Domsch, 1978). A relação $\mathrm{C}_{\text {mic }}: \mathrm{N}_{\text {mic }}$ refere-se ao $\mathrm{C}$ e $\mathrm{N}$ da biomassa microbiana.

\subsubsection{Determinação de polissacarídeos (total e lábil) e do carbono orgânico dissolvido}

A determinação do conteúdo total e lábil de polissacarídeos baseou-se na liberação de monômeros de sacarídeos através da hidrólise com ácido sulfúrico seguida por determinação colorimétrica usando-se o fenol e ácido sulfúrico como reagentes para desenvolvimento da coloração (Lowe, 1993). Para a medida do conteúdo total de polissacarídeos transferiu-se $0,5 \mathrm{~g}$ de solo (amostras moídas e peneiradas em peneira de $150 \mu \mathrm{m}$ ) para um erlenmeyer de $250 \mathrm{~mL}$ e adicionou-se $4,0 \mathrm{~mL}$ de ácido sulfúrico 12 M. A amostra foi completamente umedecida pelo ácido e na sequência o erlenmeyer foi coberto por um vidro de relógio e mantido por duas horas em temperatura ambiente. Em seguida adicionou-se $92 \mathrm{~mL}$ de $\mathrm{H}_{2} \mathrm{O}$ deionizada para diluir o ácido. As amostras foram homogeneizadas e colocadas em autoclave durante 1 hora sob $103 \mathrm{Kpa}$ (temperatura aproximadamente de $121^{\circ} \mathrm{C}$ ). Após o resfriamento dos frascos, o hidrolisado foi filtrado em filtros de fibra de vidro (Whatman, $\mathrm{F} / \mathrm{G}$; diâmetro dos poros $=1,7 \mu \mathrm{m}$ ) em ambiente à vácuo. $\mathrm{O}$ volume do filtrado foi completado para $250 \mathrm{~mL}$ com $\mathrm{H}_{2} \mathrm{O}$ deionizada. Para os polissacarídeos lábeis, foi transferida a mesma quantidade de amostra para um erlenmeyer de $250 \mathrm{~mL}$, adionado $100 \mathrm{~mL}$ de ácido sulfúrico $0,5 \mathrm{M}$ e autoclavado por 
uma hora nas mesmas condições. A determinação dos hidrolisados foi feita em espectrofotômetro cujo comprimento de onda foi ajustado para $490 \mathrm{~nm}$.

O carbono orgânico dissolvido (COD) foi determinado em suspensão aquosa. Foi retirada uma alíquota de $25 \mathrm{~mL}$ da suspensão de argila obtida da fase final do fracionamento granulométrico da MOS e filtrada em um filtro de fibra de vidro (Whatman $\mathrm{F} / \mathrm{G}$, diâmetro dos poros $=0,45 \mu \mathrm{m}$ ). $\mathrm{O}$ carbono total foi determinado em suspensão acidulada com $\mathrm{HCl} 0,1 \mathrm{~N}$ em um equipamento denominado Carbon analyser Shimadzu TOC 5000.

\subsubsection{Análises estatísticas}

Os resultados foram submetidos à análise de variância (ANOVA) e as médias comparadas pelo teste de Tukey ao nível de $5 \%$ de probabilidade $(\mathrm{p}<0,05)$, para caracterizar as diferenças entre os tratamentos. O coeficiente de correlação de Pearson foi utilizado na avaliação do grau de afinidade das variáveis. O nível de significância estatístico para os coeficientes de correlação foi descrito como $p<0,05$; $p<0,01$ e $p<$ 0,001 representado por $*, * *, * * *$, respectivamente.

\subsection{RESULTADOS E DISCUSSÃO}

\subsubsection{Biomassa microbiana $\mathrm{C}$ e $\mathrm{N}$ na cronossequência afetadas pela acidez do solo e distribuição vertical}

$\mathrm{O} \mathrm{pH}$ do solo provocou respostas diferenciadas na BMC e BMN entre os tratamentos da cronossequência. O coeficiente de correlação de Pearson para todos os dados $(n=150)$ entre o pH e a BMC $(r=-0,05)$ e a BMN $(r=-0,05)$, foi baixo e não significativo. Todavia, a correlação entre as mesmas variáveis dentro dos tratamentos ( $\mathrm{n}$ = 25) revelou respostas contrastantes. Por exemplo, os coeficientes de correlação entre $\mathrm{pH}$ com a $\mathrm{BMC}$ e BMN foram baixos e não significativos para o $\mathrm{CN}(\mathrm{r}=-0,19$ e $\mathrm{r}=$ $0,23)$, para o PCN-1 $\left(r=0,45^{*}\right.$ e $\left.r=0,14\right)$ e para o PC-22 $(r=0,36$ e $r=0,38)$ indicando 
ausência de dependência entre essas variáveis. Dessa maneira, enquanto o $\mathrm{pH}$ do tratamento $\mathrm{CN}$ (valor médio da camada de $0-40 \mathrm{~cm}$ ) elevou-se de 3,96 para 5,14 no tratamento PC-22, a BMC e BMN reduziram-se 2,37 e 2,79 vezes, respectivamente no PC-22.

Por outro lado, nos tratamentos sob plantio direto a correlação entre o $\mathrm{pH}$ com o $\mathrm{C}$ e $\mathrm{N}$ microbiano foi altamente significativa $(\mathrm{p}<0,001)$ com os seguintes coeficientes de correlação: $r=0,81$ e $r=0,84$ no PD-10; $r=0,88$ e $r=0,90$ no PD-20 e $r=0,92$ e $r=$ 0,83 no PD-22, respectivamente. O aumento no coeficiente de correlação do PD-10 em direção ao PSD-20 indica a dependência entre esses parâmetros. Pode-se afirmar que a melhoria da fertilidade do solo devido a conversão da vegetação natural e a adoção do plantio direto por longo período associado às práticas culturais (principalmente calagem e adubação), contribuiu para o incremento da biomassa microbiana $\mathrm{C}$ e $\mathrm{N}$.

Os valores médios da $\mathrm{BMC}$ e $\mathrm{BMN}$ nas condições originais $(\mathrm{CN})$ foram significativamente superiores $(\mathrm{p}<0,05)$ a todos os tratamentos na cronossequência (Figura 14). A distribuição vertical foi observada na camada superficial $(0-2,5 \mathrm{~cm}, 2,5-5$ $\mathrm{cm}, 5-10 \mathrm{~cm}$ e $10-20 \mathrm{~cm}$ de profundidade) e na camada de $20-40 \mathrm{~cm}$ não houve diferença entre os tratamentos. Além disso, essa superioridade ocorreu na condição de maior acidez e menor saturação por bases (tabela 6). No entanto, o sistema radicular das plantas era exuberante e abundante em todo o perfil. Desta forma, outros fatores parecem estar afetando o comportamento da biomassa microbiana nessas condições. A observação de Martens (2000) comentando que os rizodepósitos em áreas pastagens naturais de gramíneas tem elevada contribuição na manutenção do nível do $\mathrm{C}$ e $\mathrm{N}$ microbiano pode respaldar os resultados apresentados. $\mathrm{O}$ aumento na BMC e BMN comparado a fase inicial da conversão da vegetação natural (PCN-1) ocorreu principalmente na camada de 0-2,5 e 2,5-5 cm de profundidade e foi superior em 59,9 e $100,1 \%(0-2,5 \mathrm{~cm})$ e 56,6 e $40,4 \%(2,5-5 \mathrm{~cm})$, respectivamente.

Em relação aos tratamentos sob plantio direto a diferença na BMC e BMN foi ainda superior ao comparado ao PCN-1. 


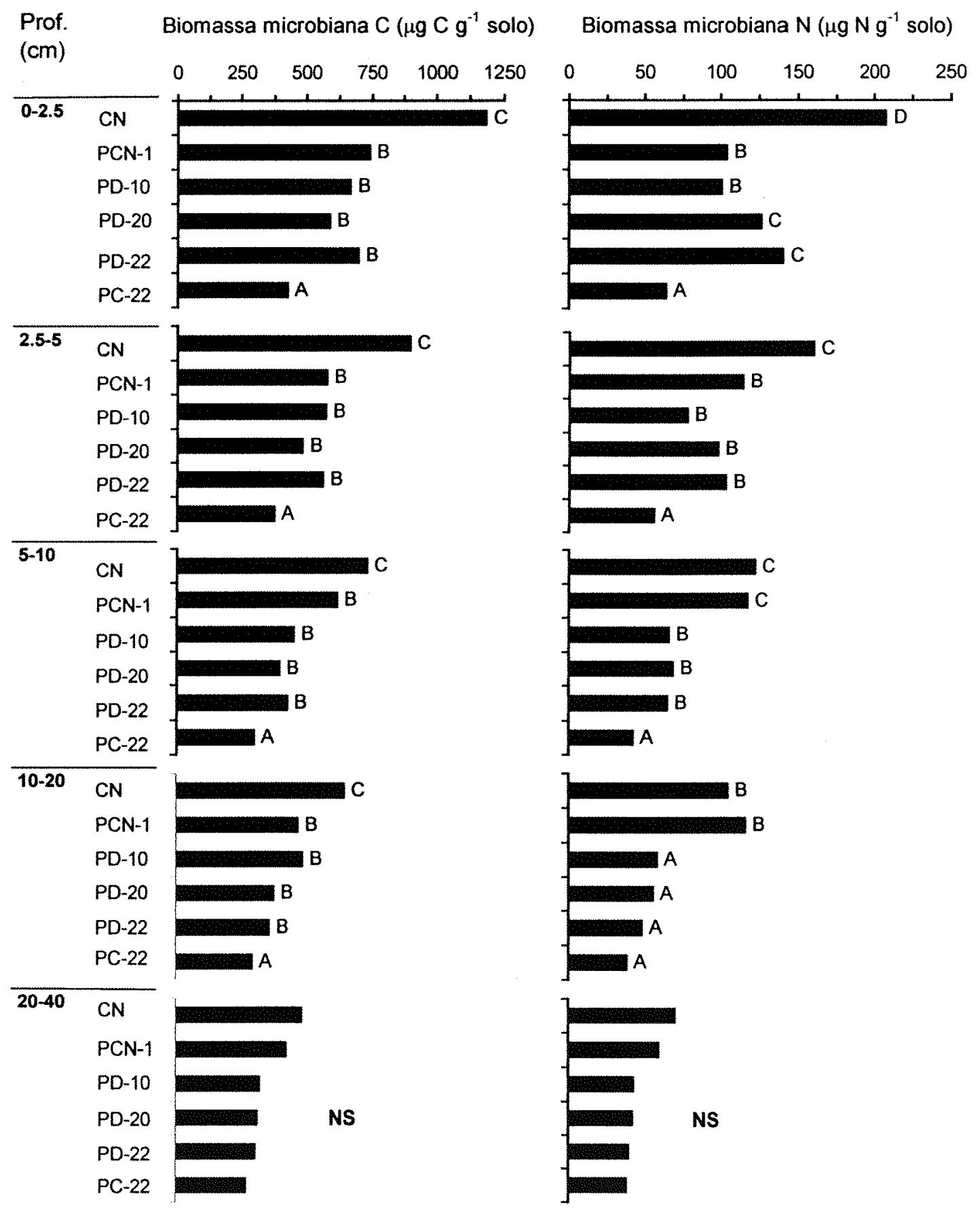

Figura 14. Alterações no conteúdo de $\mathrm{C}$ e $\mathrm{N}$ da biomassa microbiana do solo nos tratamentos da cronossequência. As letras maiúsculas referem-se à comparação das médias entre os tratamentos em cada profundidade pelo teste de Tukey ao nível de $5 \%$ de probabilidade. 
A superioridade da BMC e BMN no campo nativo representou: 77,3 \% e $107 \%$ (na camada de $0-2,5 \mathrm{~cm}$ ) e $56,6 \%$ e 106,6 \% (na camada de 2,5-5 cm) em relação ao PD$10,101,4 \%$ e $64,5 \%$ (na camada de $0-2,5 \mathrm{~cm}$ ), $85,9 \%$ e $63,4 \%$ (na camada de $2,5-5$ $\mathrm{cm}$ ) em relação ao PD-20 e 69,5 \% e 55,5 \% (na camada de 0-2,5 cm) e 60\% e 55,5 (na camada de 2,5-5 cm) em relação ao PD-22. O contraste foi ainda maior quando a BMC e BMN do CN foi comparada ao tratamento PC-22 e essa diferença representou 178,2 $\%$ e $226,5 \%$ (na camada de $0-2,5 \mathrm{~cm}$ ), $138,5 \%$ e $187,3 \%$ (na camada de $2,5-5 \mathrm{~cm}$ ), $144 \%$ e $188,2 \%$ (na camada de $5-10 \mathrm{~cm}$ ) e $120 \%$ e $172,6 \%$ na camada de $10-20 \mathrm{~cm}$ de profundidade, respectivamente.

$\mathrm{O}$ conteúdo de $\mathrm{C}_{\mathrm{mic}}$ no PD-22 foi superior ao PC-22 em 64,2 \% na camada de 0$2,5 \mathrm{~cm}, 49,0 \%$ na camada de 2,5-5 $\mathrm{cm}$ e 42,7\% na camada de 5-10 cm de profundidade. Em relação ao $\mathrm{N}_{\text {mic }}$ a superioridade foi ainda maior com aumentos de 121 $\%, 84,7 \%$ e $52 \%$, nas camadas de $0-2,5 \mathrm{~cm}, 2,5-5$ e $5-10 \mathrm{~cm}$ de profundidade, respectivamente. Os tratamentos sob $\mathrm{PD}$ tiveram uma resposta intermediária comparado ao $\mathrm{CN}$ e ao $\mathrm{PC}-22$. O efeito dos resíduos culturais associados ao plantio direto recuperou a biomassa microbiana ao nível próximo do $\mathrm{CN}$. A distribuição vertical da BMC e BMN até a camada de $10 \mathrm{~cm}$ também ocorreram nos tratamentos sob PD. Esse efeito pode ser atribuído às adições anuais de resíduos culturais que resultam na liberação de compostos orgânicos em diferentes estágios de oxidação, estimulando a diversidade da biomassa microbiana. Em amostras coletadas nos mesmos tratamentos sete meses antes da amostragem deste estudo, Venske Filho (1999) reportou a mesma tendência para a BMC e BMN, indicando que são os mesmos fatores que influenciam esses atributos. Carvalho (1997) e Balota et al. (1998) em solos do Paraná, compararam o efeito de sistemas de manejo sobre esses atributos e observaram maior conteúdo de $\mathrm{C}_{\text {mic }}$ e $\mathrm{N}_{\text {mic }}$ nos solos sob PD. A principal causa da redução no carbono microbiano no $\mathrm{PC}$ está relacionada com a rápida mineralização do $\mathrm{C}$ liberado com a ruptura dos agregados do solo reduzindo a fonte de C para a biomassa microbiana (Elliot, 1986; Powlson et al., 1987; Reicosky et al., 1995). As alterações na BMC e BMN reportadas nesse estudo confirmam observações anteriores (Carter, 1986; Powlson et al., 1987; 
Sparling, 1992) sobre o impacto de sistemas de manejo no comportamento na biomassa microbiana com reflexos na ciclagem do $\mathrm{C}$ e $\mathrm{N}$.

\subsubsection{Biomassa microbiana $\mathrm{C}$ e $\mathrm{N}$ afetadas por componentes da matéria orgânica do solo (COT, Ntotal, POT, POL, COD)}

A análise de correlação entre os componentes da matéria orgânica e a BMC e BMN resultou em coeficientes altamente significativos, indicando a interdependência entre essas variáveis (Tabela 7). Embora o coeficiente de correlação de Pearson envolvendo todos os dados de cada variável $(n=150)$ tenha sido significativo $(p<$ $0,001)$, o coeficiente dentro de cada tratamento $(n=25)$ para essas variáveis apresentou três tendências contrastantes: a) os coeficientes mais baixos no tratamento PCN-1 indicam mudanças drásticas durante a fase inicial da conversão para agricultura. $O$ conteúdo elevado de $\mathrm{C}$ e $\mathrm{N}$ na biomassa microbiana, pode ser devido ao interrelacionamento entre o preparo do solo, a incorporação do material orgânico fresco e a melhoria da fertilidade antes da amostragem do solo; b) No PC-22 os coeficientes foram significativos $(p<0,01)$ embora inferiores ao $\mathrm{CN}$ e PD. Isto indica que o preparo do solo há longo período é também afetado por esses fatores; c) ocorrendo acúmulo de MOS nos tratamentos sob PD haverá um aumento concomitante na BMC e BMN e nos coeficientes de correlação. Isto indica o impacto positivo do PD associado a práticas agronômicas (calagem, uso de fertilizantes, rotação de culturas e adição de resíduos culturais) para recuperar a biomassa microbiana $\mathrm{C}$ e $\mathrm{N}$. Além disso, a média dos coeficientes de correlação aumentou de acordo com o tempo de adoção de PD, sugerindo que esses fatores são dinâmicos e sofrem alterações conjuntas. Por exemplo, a média dos coeficientes de todas as variáveis correlacionadas no PD-22 e apresentadas na tabela $7(\mathrm{r}=0,90)$ foi superior em $5,9 \%$ ao $\mathrm{CN}(\mathrm{r}=0,85), 66,6 \%$ ao PCN-1 $(\mathrm{r}=0,54)$ e $23,3 \%$ em relação ao $\mathrm{PC}-22(\mathrm{r}=0,73)$.

$\mathrm{O}$ grau de afinidade entre a BMC e os componentes da matéria orgânica, baseado na média dos coeficientes dos tratamentos de cada variável, decresceram na 
seguinte ordem (Tabela 7): $\mathrm{COD}>$ Ntotal $>\mathrm{COT}>\mathrm{POT}=\mathrm{POL}$ e para a BMN esta ordem foi Ntotal $>\mathrm{COD}>\mathrm{COT}>\mathrm{POT}>\mathrm{POL}$.

Tabela 7. Coeficiente de correlação de Pearson entre a biomassa microbiana $\mathrm{C}$ e $\mathrm{N}$ com os componentes da matéria orgânica envolvendo todos os dados de cada variável $(n=150)$ e para cada tratamento $(n=25)$.

\begin{tabular}{|c|c|c|c|c|c|c|c|c|}
\hline \multirow{2}{*}{$\begin{array}{l}\text { Parâmetros }{ }^{\S} \\
\text { Correlacionados }\end{array}$} & \multirow{2}{*}{$\begin{array}{l}\text { Todos } \\
\text { Dados }^{*}\end{array}$} & \multicolumn{6}{|c|}{ Tratamentos ${ }^{f \mp}$} & \multirow{2}{*}{$\begin{array}{l}\text { Média } \\
\text { Trat. }{ }^{1}\end{array}$} \\
\hline & & $\mathrm{CN}$ & $\mathrm{PCN}-1$ & PD-10 & PD-20 & PD-22 & PC-22 & \\
\hline COT $\times$ BMC & 0,44 & 0,76 & 0,38 & 0,85 & 0,85 & 0,93 & 0,79 & 0,76 \\
\hline COT $\times \mathrm{BMN}$ & 0,64 & 0,91 & 0,67 & 0,85 & 0,87 & 0,89 & 0,75 & 0,82 \\
\hline NT $\times$ BMC & 0,43 & 0,75 & 0,41 & 0,85 & 0,86 & 0,93 & 0,87 & 0,78 \\
\hline NT $x$ BMN & 0,61 & 0,91 & 0,69 & 0,86 & 0,88 & 0,90 & 0,83 & 0,85 \\
\hline POT $x$ BMC & 0,44 & 0,60 & 0,42 & 0,68 & 0,87 & 0,83 & 0,78 & 0,70 \\
\hline POT $x$ BMN & 0,58 & 0,76 & 0,24 & 0,69 & 0,77 & 0,79 & 0,74 & 0,67 \\
\hline POL $\times$ BMC & 0,44 & 0,63 & 0,28 & 0,83 & 0,83 & 0,88 & 0,74 & 0,70 \\
\hline POL $\times$ BMN & 0,60 & 0,73 & 0,18 & 0,81 & 0,73 & 0,90 & 0,73 & 0,68 \\
\hline COD $\times$ BMC & $--^{\dagger}$ & 0,90 & 0,93 & 0,92 & 0,98 & 0,94 & 0,72 & 0,90 \\
\hline COD $\times B M N$ & - & 0,94 & 0,54 & 0,90 & 0,97 & 0,93 & 0,68 & 0,83 \\
\hline POT x COT & 0,68 & 0,90 & 0,41 & 0,82 & 0,84 & 0,88 & 0,69 & 0,76 \\
\hline POT $\times$ NT & 0,56 & 0,87 & 0,34 & 0,79 & 0,84 & 0,86 & 0,72 & 0,74 \\
\hline POL $x$ COT & 0,68 & 0,89 & 0,48 & 0,89 & 0,86 & 0,97 & 0,70 & 0,80 \\
\hline POL $\times$ NT & 0,56 & 0,85 & 0,46 & 0,89 & 0,85 & 0,96 & 0,72 & 0,79 \\
\hline COT x COD & - & 0,97 & 0,88 & 0,82 & 0,96 & 0,92 & 0,84 & 0,90 \\
\hline NT $x$ COD & - & 0,97 & 0,93 & 0,83 & 0,96 & 0,92 & 0,83 & 0,91 \\
\hline POT $x$ COD & - & 0,94 & 0,73 & 0,65 & 0,93 & 0,82 & 0,56 & 0,77 \\
\hline POL $x$ COD & - & 0,99 & 0,82 & 0,66 & 0,91 & 0,86 & 0,52 & 0,79 \\
\hline $\mathrm{M}$ & 0,56 & 0,85 & 0,54 & 0,81 & 0,88 & 0,90 & 0,73 & \\
\hline
\end{tabular}

${ }^{\S} \mathrm{COT}=$ Carbono orgânico total, $\mathrm{NT}=$ Nitrogênio total, $\mathrm{BMC}=$ biomassa microbiana de $\mathrm{C}, \mathrm{BMN}=$ Biomassa microbiana de $\mathrm{N}, \mathrm{POT}=$ Polissacarídeos total, $\mathrm{POL}=$ Polissacarídeos lábeis, $\mathrm{C}=$ Carbono orgânico dissolvido;

¥ Todos os dados ( 6 tratamentos $\times 5$ profundidades de amostragem $\times 5$ repetições, $\mathrm{n}=$ 150). Coeficientes $>0,41$ são significativos para $\mathrm{p}<0,001$; ${ }^{\ddagger \ddagger}$ Dentro de cada tratamento ( 5 profundidades $x 5$ repetições, $\mathrm{n}=25$ ). Coeficientes $<0,41$ não tem significância estatística; 0,41 a $0,55(\mathrm{p}=0,05) ; 0,56$ a $0,65(\mathrm{p}=0,01)$; e $>0,66(\mathrm{p}<$ $0,001) ;{ }^{\dagger}$ Sem correlação; ${ }^{1}$ Média trat. $=$ representa a média dos coeficientes dos tratamentos para cada variável correlacionada; ${ }^{2} \mathrm{Média}$ de todos os coeficientes em cada tratamento.

O estreito relacionamento entre o $C O D$ e a biomassa microbiana é também acompanhado pelo COT. $\mathrm{Na}$ realidade, o COD representa a fonte de energia 
prontamente disponivel para a biomassa microbiana. Em sistemas sob plantio direto o COD é oriundo da liberação de compostos orgânicos durante a mineralização dos resíduos culturais (Staley et al., 1988). O argumento acima pode ser respaldado pelo coeficiente de correlação entre a adição anual de resíduos culturais nos tratamentos sob PD e o COT $(r=0,86 *$ na camada de $0-2,5 \mathrm{~cm} \mathrm{e} r=0,99 * * *$ na camada de $2,5-5 \mathrm{~cm}$ de profundidade). Staley et al. (1988) também observaram estreito relacionamento entre $o$ COT e COD. Na mesma linha de trabalho, Franchini et al. (1999) observaram elevada correlação dos ácidos orgânicos liberados pela mineralização dos resíduos culturais com propriedades do solo. Adicionalmente, eles explicaram que os ácidos orgânicos possuem uma interdependência com o tipo de resíduo cultural.

Nas camadas superficiais, a distribuição vertical da BMC e BMN apresentou a mesma tendência das variáveis COT, Ntotal, POT, POL e COD. A porcentagem de C e $\mathrm{N}$ da biomassa microbiana no COT e $\mathrm{N}$ total (Tabela 9) variou de 1,17 a 3,41\% (BMC) e 2,8 a $9,08 \%(B M N)$. A maior porcentagem de $C_{\text {mic }}$ foi encontrada no $\mathrm{CN}$ e a menor porcentagem no PC-22. Os tratamentos sob PD situaram-se próximos ao $\mathrm{CN}$. Estes resultados confirmam as observações de outros autores, de que sistemas agrícolas sob plantio direto tendem a atuar como um dreno e o preparo convencional como uma fonte de $\mathrm{CO}_{2}$ para atmosfera. Além disso, a expansão do reservatório de $\mathrm{N}_{\text {mic }}$ nas camadas superficiais $(0-2,5 \mathrm{~cm}$ e $2,5-5 \mathrm{~cm}$ de profundidade) pode representar o $\mathrm{N}$ sequestrado e prevenir as perdas de $\mathrm{N}$ mineral para o lençol freático (Wood et al, 1991). Essa expansão pode ser atribuída principalmente ao processo de mineralização dos resíduos culturais e a relação $\mathrm{C} / \mathrm{N}$ do solo (Tabela 8) mais baixa nessas camadas, tornando a ciclagem de $\mathrm{N}$ mais favorável. A expansão no reservatório de $\mathrm{N}_{\text {mic }}$ pode contribuir para o suprimento de $\mathrm{N}$ no sistema de produção devido a maior oferta de $\mathrm{N}$ da ciclagem em intervalos mais curtos. $\mathrm{O}$ estoque de $\mathrm{N}_{\text {mic }}$ na camada de $0-5 \mathrm{~cm}$ aumentou em função do tempo de adoção do PD (63,8 $\mathrm{kg} \mathrm{ha}^{-1}$ no PD-10; 75,4 $\mathrm{kg} \mathrm{ha}^{-1}$ no PD-20 e 88,9 $\mathrm{N}_{\text {mic }} \mathrm{kg}$ $\mathrm{ha}^{-1}$ no PD-22) confirmando os argumentos acima, enquanto no PC-22 esse estoque foi de $35,6 \mathrm{~kg} \mathrm{~N}_{\text {mic }}$ ha $^{-1}$. Assim, o fluxo de $\mathrm{N}$ pode direcionar para a estabilização do $\mathrm{C}$ na MOS, conduzindo o sistema a atuar como um dreno de $\mathrm{CO}_{2}$, enquanto o sistema sob preparo convencional conduz o solo para tornar-se fonte de $\mathrm{CO}_{2}$ para atmosfera. 
O conteúdo médio de POT e POL diferiu significativamente entre os tratamentos e sua ocorrência se deu principalmente na camada de $0-2,5 \mathrm{~cm}$ atingindo a camada de 2,5-5 cm em alguns tratamentos (Tabela 8). Os tratamentos CN, PCN-1 e PD-22 não diferiram entre si e foram superiores ao PD-10, PD-20 e PC-22. Nos tratamentos PCN-1 e PC-22 não ocorreram variações na distribuição vertical enquanto no $\mathrm{CN}$ observou-se a estratificação nas camadas conforme aumenta a profundidade. Todavia, nos tratamentos sob PD essa diferença restringiu-se até a camada de $0-5 \mathrm{~cm}$.

A proporção do POT na MOS na camada de $0-2,5 \mathrm{~cm}$, variou de 11,4 a $17,2 \%$ e na camada de $2,5-5 \mathrm{~cm}$ de 11,78 a 18,64 . A amplitude de variação para o POL foi menor nessas camadas: 3,96 a 6,19\% (0-2,5 cm) e 4,48 a 6,66\% (2,5-5 cm). Essas faixas foram superiores as observadas por Kuo et al. (1997). O conteúdo de polissacarídeos (POT e POL) aumentou do PD-10 para o PD-22 e acompanhou o aumento do COT. O coeficiente de correlação entre a adição total de resíduos culturais e o conteúdo de polissacarídeos total $\left(\mathrm{r}=0,81^{*}\right)$ e lábil $\left(\mathrm{r}=0,82^{*}\right)$ respalda os argumentos acima. Além disso, a BMC e BMN correlacionaram bem com o POT e POL e tiveram a mesma tendência (Tabela 7). Este fato torna-se relevante para o entendimento dos mecanismos que conduzem ao acúmulo da MOS no PD, porque os polissacarídeos do solo possuem estreito relacionamento com o nível da atividade biológica no solo e com a estabilidade estrutural dos agregados (Greenland \& Oades, 1975).

A estratificação do COD foi superior ao POT e POL (Tabela 8). A proporção do COD no COT na camada de $0-5 \mathrm{~cm}$ variou de 3,7 a $7,4 \%$ e teve boa correlação com o POT e o POL (Tabela 7), mostrando que estes parâmetros também variam juntos. A proporção de POT, POL, COD e BMC em relação ao COT na camada de 0-2,5 cm de profundidade nos tratamentos da cronossequência foram: 29,$6 ; 10,3 ; 6,4$ e $3,4 \%$ no $\mathrm{CN}$, 29,$1 ; 10,6 ; 5,2 ;$ e $1,9 \%$ no PCN-1, 19,$6 ; 6,8 ; 4,6 ;$ e $1,8 \%$ no PD-10, 20,5; 7,0;3,8 e $1,3 \%$ no PD-20, 23,6; 7,6; 3,7; e $1,3 \%$ no PD-22 e 26,$1 ; 8,9 ; 7,0$; e $1,4 \%$ no PC-22. 
Tabela 8. Alterações no COT, Ntotal, C:N, POT, POL e COD nos sistemas de manejo da cronossequência sob (média de cinco repetições).

\begin{tabular}{|c|c|c|c|c|c|c|c|}
\hline \multirow{2}{*}{$\begin{array}{l}\text { Componentes } \\
\text { da MOS }\end{array}$} & \multirow{2}{*}{$\begin{array}{l}\text { Prof. } \\
(\mathrm{cm})\end{array}$} & \multicolumn{6}{|c|}{ Tratamentos } \\
\hline & & $\mathrm{CN}$ & PCN-1 & PD-10 & PD-20 & PD-22 & PC-22 \\
\hline \multirow[t]{5}{*}{ COT, $\mathrm{g} \mathrm{kg}^{-1}$} & $0-2,5$ & $34,5 b^{\ddagger}$ & $38,4 \mathrm{c}$ & $36,3 \mathrm{c}$ & $45,9 \mathrm{~d}$ & $52,8 \mathrm{~d}$ & $30,1 \mathrm{a}$ \\
\hline & $2,5-5$ & $29,5 \mathbf{a}$ & $37,2 \mathrm{~b}$ & $25,7 \mathrm{a}$ & $34,6 \mathrm{~b}$ & $35,1 \mathrm{~b}$ & $28,0 \mathrm{a}$ \\
\hline & $5-10$ & $25,3 \mathrm{~b}$ & $35,5 \mathrm{c}$ & $18,9 \mathrm{a}$ & $24,7 \mathrm{~b}$ & $25,1 \mathrm{~b}$ & $25,9 \mathrm{~b}$ \\
\hline & $10-20$ & $21,6 \mathrm{~b}$ & $31,2 \mathrm{c}$ & $14,6 \mathrm{a}$ & $21,6 \mathrm{~b}$ & $20,7 \mathrm{~b}$ & $23,5 \mathrm{~b}$ \\
\hline & $20-40$ & $16,9 \mathrm{~b}$ & $22,0 \mathrm{c}$ & $12,7 \mathrm{a}$ & $17,9 \mathrm{~b}$ & $16,9 \mathrm{~b}$ & $19,3 \mathrm{~b}$ \\
\hline$D M S_{005^{\S}}^{\S}$ & (Prof.) & 4,1 & 4,9 & 4,2 & 5,1 & 4,3 & 4,8 \\
\hline \multirow[t]{5}{*}{$\mathrm{NT}, \mathrm{g} \mathrm{kg}^{-\mathrm{I}}$} & $0-2,5$ & $2,3 \mathrm{~b}$ & $2,6 \mathrm{c}$ & $3,0 \mathrm{c}$ & $3,7 \mathrm{~d}$ & $4,0 \mathrm{~d}$ & $2,1 \mathrm{a}$ \\
\hline & $2,5-5$ & $1,9 \mathrm{a}$ & $2,5 \mathrm{~b}$ & $2,1 \mathrm{a}$ & $2,7 \mathrm{~b}$ & $2,6 \mathrm{~b}$ & $1,8 \mathrm{a}$ \\
\hline & $5-10$ & $1,6 \mathrm{~b}$ & $2,3 \mathrm{c}$ & $1,4 \mathrm{a}$ & $1,8 \mathrm{~b}$ & $1,7 \mathrm{~b}$ & $1,6 \mathrm{~b}$ \\
\hline & $10-20$ & $1,4 \mathrm{~b}$ & $2,1 \mathrm{c}$ & $0,9 \mathrm{a}$ & $1,4 \mathrm{~b}$ & $1,2 \mathrm{~b}$ & $1,3 \mathrm{~b}$ \\
\hline & $20-40$ & $1,0 \mathrm{~b}$ & $1,5 \mathrm{c}$ & $0,8 \mathrm{a}$ & $1,1 \mathrm{~b}$ & $1,0 \mathrm{~b}$ & $1,0 \mathrm{~b}$ \\
\hline$D M S_{0,05}$ & (Prof.) & 0,35 & 0,52 & 0,45 & 0,38 & 0,47 & 0,53 \\
\hline \multirow[t]{5}{*}{$\mathrm{C}: \mathrm{N}$} & $0-2,5$ & $15,2 \mathrm{~b}$ & $14,6 \mathrm{~b}$ & $12,1 \mathrm{a}$ & $12,3 \mathrm{a}$ & $13,2 \mathrm{a}$ & $14,6 \mathrm{~b}$ \\
\hline & $2,5-5$ & $15,3 \mathrm{~b}$ & $14,9 \mathrm{~b}$ & $12,2 \mathrm{a}$ & $12,6 \mathrm{a}$ & $13,4 \mathrm{a}$ & $15,5 \mathrm{~b}$ \\
\hline & $5-10$ & $15,9 \mathrm{~b}$ & $15,5 \mathrm{~b}$ & $13,1 \mathrm{a}$ & $13,8 \mathrm{a}$ & $14,8 \mathrm{~b}$ & $16,3 \mathrm{~b}$ \\
\hline & $10-20$ & $16,0 \mathrm{a}$ & $15,0 \mathrm{a}$ & $15,4 \mathrm{a}$ & $15,8 \mathrm{a}$ & $17,2 \mathrm{~b}$ & $18,0 \mathrm{~b}$ \\
\hline & $20-40$ & $16,6 \mathrm{~b}$ & $14,4 \mathrm{a}$ & $16,3 \mathrm{~b}$ & $16,6 \mathrm{~b}$ & $17,3 \mathrm{~b}$ & $18,9 \mathrm{c}$ \\
\hline$D M S_{0,05}$ & (Prof.) & 1,1 & 1,2 & 1,5 & 1,4 & 1,8 & 1,7 \\
\hline \multirow{5}{*}{ POT, $\mathrm{g} \mathrm{kg}^{-1}$} & $0-2,5$ & $10,2 \mathrm{~b}$ & $11,2 \mathrm{c}$ & $7,1 \mathrm{a}$ & $9,4 \mathrm{~b}$ & $12,5 \mathrm{c}$ & $7,9 \mathrm{a}$ \\
\hline & $2,5-5$ & $9,4 \mathrm{~b}$ & $11,5 \mathrm{c}$ & $5,2 \mathrm{a}$ & $7,1 \mathrm{~b}$ & $8,3 \mathrm{~b}$ & $7,7 \mathrm{~b}$ \\
\hline & $5-10$ & $8,9 \mathrm{~b}$ & $11,4 \mathrm{~b}$ & $5,0 \mathrm{a}$ & $6,2 \mathrm{a}$ & $7,4 \mathrm{a}$ & $7,2 \mathrm{a}$ \\
\hline & $10-20$ & $8,6 \mathrm{~b}$ & $10,9 \mathrm{c}$ & $5,1 \mathrm{a}$ & $6,0 \mathrm{a}$ & $7,3 \mathrm{~b}$ & $7,1 \mathrm{~b}$ \\
\hline & $20-40$ & $7,5 \mathrm{a}$ & $10,4 \mathrm{~b}$ & $4,9 \mathrm{a}$ & $5,8 \mathrm{a}$ & $7,2 \mathrm{a}$ & $7,2 \mathrm{a}$ \\
\hline$D M S_{0,05}$ & (Prof.) & 0,75 & 0,9 & 0,77 & 0,81 & 0,80 & 0,82 \\
\hline \multirow[t]{5}{*}{ POL, $\mathbf{g ~ k g}^{-1}$} & $0-2,5$ & $3,54 \mathrm{~b}$ & $4,07 \mathrm{c}$ & $2,46 \mathrm{a}$ & $3,20 \mathrm{~b}$ & $4,01 \mathrm{c}$ & $2,69 \mathrm{a}$ \\
\hline & $2,5-5$ & $3,37 \mathrm{a}$ & $4,10 \mathrm{~b}$ & $2,06 \mathrm{a}$ & $2,62 \mathrm{a}$ & $3,01 \mathrm{a}$ & $2,69 \mathrm{a}$ \\
\hline & $5-10$ & $3,10 \mathrm{a}$ & $4,01 \mathrm{c}$ & $1,84 \mathrm{~b}$ & $2,16 \mathrm{~b}$ & $2,47 \mathrm{a}$ & $2,49 \mathrm{a}$ \\
\hline & $10-20$ & $2,87 \mathrm{~b}$ & $3,92 \mathrm{c}$ & $1,84 \mathrm{a}$ & $2,15 \mathrm{a}$ & $2,43 \mathrm{a}$ & $2,48 a$ \\
\hline & $20-40$ & $2,59 \mathrm{a}$ & $3,59 \mathrm{~b}$ & $1,87 \mathrm{a}$ & $2,11 \mathrm{a}$ & $2,36 \mathrm{a}$ & $2,45 \mathrm{a}$ \\
\hline$D M S_{0,05}$ & (Prof.) & 0,32 & 0,35 & 0,33 & 0,41 & 0,39 & 0,34 \\
\hline \multirow[t]{5}{*}{ COD, $\mathrm{g} \mathrm{kg}^{-1}$} & $0-2,5$ & $2,22 \mathrm{~b}$ & $1,99 \mathrm{~b}$ & $1,68 \mathrm{a}$ & $1,73 \mathrm{a}$ & $1,95 \mathrm{~b}$ & $2,09 \mathrm{~b}$ \\
\hline & $2,5-5$ & $2,17 \mathrm{c}$ & $1,56 \mathrm{a}$ & $1,58 \mathrm{a}$ & $1,48 \mathrm{a}$ & $1,86 \mathrm{~b}$ & $1,65 \mathrm{a}$ \\
\hline & $5-10$ & $1,74 \mathrm{~b}$ & $1,13 \mathrm{a}$ & $1,55 \mathrm{~b}$ & $1,42 \mathrm{~b}$ & $1,73 \mathrm{~b}$ & $1,89 \mathrm{bc}$ \\
\hline & $10-20$ & $1,34 \mathrm{~b}$ & $0,76 \mathrm{a}$ & $1,49 \mathrm{~b}$ & $1,32 \mathrm{~b}$ & $1,70 \mathrm{c}$ & $1,68 \mathrm{c}$ \\
\hline & $20-40$ & $1,09 \mathrm{~b}$ & $0,52 \mathrm{a}$ & $1,25 \mathrm{c}$ & $1,16 b c$ & $1,52 \mathrm{c}$ & $1,40 \mathrm{c}$ \\
\hline$D M S_{0,05}$ & (Prof.) & 0,29 & 0,31 & 0,27 & 0,30 & 0,22 & 0,31 \\
\hline
\end{tabular}

${ }^{\ddagger}$ Médias seguidas da mesma letra na linha (minúscula) não diferem entre si pelo teste de Tukey ao nível de $5 \%$ de probabilidade. ${ }^{\S} \mathrm{DMS}_{0,05}$ refere-se a diferença mínima significativa obtida pelo teste de Tukey para a comparação das médias de cada variável entre as profundidades (coluna) dentro de cada tratamento. 
Embora a erosão do solo não tenha sido medida (a declividade média da área experimental é menor do que $1 \%$ ), as observações visuais permitem afirmar que este não foi um fator importante nessas áreas. Portanto, a diferença entre os tratamentos PD22 e PC-22 no COT podem ser atribuídas à diferença no coeficiente de humificação entre os dois tratamentos, uma vez que as adições anuais de resíduos culturais foram similares.

\subsubsection{Atividade da biomassa microbiana $\mathrm{C}$ e $\mathrm{N}$ afetada pela acidez do solo e os componentes da matéria orgânica na cronossequência}

A atividade da biomassa microbiana apresentou tendência contrastante em relação à acidez do solo e aos componentes da matéria orgânica na cronossequência. $\mathrm{Na}$ camada superficial $(0-5 \mathrm{~cm})$ a relação $\mathrm{C}_{\text {mic }}$ : $\mathrm{C}_{\text {org }}$ mais elevada ocorreu sob condições de maior acidez (tratamento $\mathrm{CN}$ ) e a relação mais baixa com a menor acidez (PD-20 e PD22). Isto sugere que no campo nativo a ciclagem do $\mathrm{C}_{\text {mic }}$ tem sido mantida por uma população microbiana heterogênea e a origem da matéria orgânica seja mais recalcitrante. Por outro lado, a melhoria da fertilidade do solo associada à adição de resíduos culturais no PD pode estimular um grupo seleto de microorganismos com elevada capacidade de degradação de compostos de celulose (Doran, 1980). Além disso,

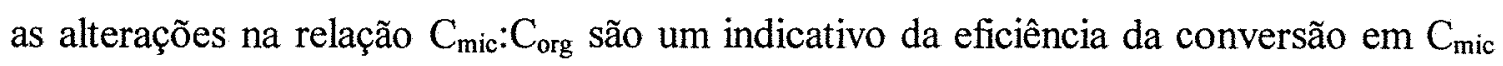
e como o C orgânico está se associando na fração mineral (Anderson \& Domsch, 1989; Sparling, 1992). Nos tratamentos $\mathrm{CN}$ e $\mathrm{PCN}-1$, a distribuição vertical da relação $\mathrm{C}_{\text {mic }}: \mathrm{C}_{\text {org }}$ restringiu-se a camada superficial e os valores foram decrescentes, enquanto nos tratamentos sob PD a tendência foi contrastante (Tabela 9). Embora a relação $\mathrm{C}_{\text {mic }}: \mathrm{C}_{\text {org }}$ nos tratamentos sob PD tenha sido significativamente inferior ao $\mathrm{CN}$ na camada de $0-5 \mathrm{~cm}$, o aumento no estoque de COT foi significativo $(\mathrm{p}<0,05)$. O ganho em COT nessa camada representou $+2,9 \mathrm{Mg} \mathrm{ha}^{-1}$ no PD-10, +7,8 $\mathrm{Mg}^{-1}$ no PD-20 e $+13,1 \mathrm{Mg} \mathrm{ha}^{-1}$ no PD-22 em relação ao $\mathrm{CN}$ (ver Figura 8, cap.3, p.45). A menor relação do $\mathrm{C}_{\mathrm{mic}}: \mathrm{C}_{\text {org }}$ no PD-20 e PD-22, pode estar relacionada com o direcionamento de 
compostos de C para a formação de agregados e promover a proteção física da MOS conforme abordagem de Tisdall \& Oades, (1982).

Tabela 9. Alterações na atividade microbiana $\left(\mathrm{C}_{\text {mic }}: \mathrm{C}_{\text {org }}, \mathrm{N}_{\text {mic }}: \mathrm{N}_{\text {total }}\right.$, respiração basal e o $q \mathrm{CO}_{2}$ ) afetadas pelos sistemas de manejo convencional e plantio direto da cronossequência (Média de cinco repetições).

\begin{tabular}{|c|c|c|c|c|c|c|c|}
\hline \multirow[t]{2}{*}{ Atributos } & \multirow{2}{*}{$\begin{array}{l}\text { Prof. } \\
\text { (cm) }\end{array}$} & \multicolumn{6}{|c|}{ Tratamentos } \\
\hline & & $\mathrm{CN}$ & PCN-1 & PD-10 & PD-20 & PD-22 & PC-22 \\
\hline$C_{\text {mic }}: C_{o r g}$ & $0-2,5$ & $34,06 \mathrm{c}$ & $19,41 \mathrm{~b}$ & $18,44 \mathrm{~b}$ & $12,95 \mathrm{a}$ & $13,25 \mathrm{a}$ & $14,19 \mathrm{a}$ \\
\hline \multirow{4}{*}{$\left(\mu \mathrm{g} \mathrm{C}_{\text {mic }} \mathrm{mg}^{-1} \mathrm{C}_{\text {org }}\right)$} & $2,5-5$ & $28,54 \mathrm{c}$ & $14,86 \mathrm{a}$ & $20,83 \mathrm{~b}$ & $13,37 \mathrm{a}$ & $15,10 \mathrm{a}$ & $12,56 \mathrm{a}$ \\
\hline & $5-10$ & $27,21 \mathrm{c}$ & $16,18 b$ & $22,67 \mathrm{c}$ & $15,11 \mathrm{~b}$ & $16,01 \mathrm{~b}$ & $10,78 \mathrm{a}$ \\
\hline & $10-20$ & $28,13 \mathrm{c}$ & $14,19 \mathrm{a}$ & $31,38 \mathrm{c}$ & $16,64 \mathrm{~b}$ & $16,26 \mathrm{~b}$ & $11,68 \mathrm{a}$ \\
\hline & $20-40$ & $27,12 \mathrm{c}$ & $16,12 \mathrm{~b}$ & $30,68 \mathrm{c}$ & $16,50 \mathrm{~b}$ & $17,07 \mathrm{~b}$ & $13,15 \mathrm{a}$ \\
\hline$D M S_{0,05}^{\S}$ & (Prof.) & 2,10 & 2,87 & 2,30 & 1,86 & 1,81 & 2,15 \\
\hline$N_{\text {mic }}: N_{\text {total }}$ & $0-2,5$ & $2,27 \mathrm{a}$ & $2,63 \mathrm{~b}$ & $3,02 \mathrm{~b}$ & $3,72 \mathrm{c}$ & $4,01 \mathrm{c}$ & $2,07 \mathrm{a}$ \\
\hline \multirow[t]{4}{*}{$\left(\mu \mathrm{g} \mathrm{N}_{\text {mic }} \mathrm{mg}^{-1} \mathrm{~N}_{\text {tơal }}\right)$} & $2,5-5$ & $1,92 \mathrm{a}$ & $2,49 \mathrm{~b}$ & $2,11 \mathrm{a}$ & $2,74 \mathrm{~b}$ & $2,62 \mathrm{~b}$ & $1,81 \mathrm{a}$ \\
\hline & $5-10$ & $1,59 \mathrm{a}$ & $2,29 \mathrm{~b}$ & $1,44 \mathrm{a}$ & $1,78 \mathrm{a}$ & $1,69 \mathrm{a}$ & $1,59 \mathrm{a}$ \\
\hline & $10-20$ & $1,35 \mathrm{a}$ & $2,07 \mathrm{~b}$ & $0,95 \mathrm{a}$ & $1,37 \mathrm{a}$ & $1,21 \mathrm{a}$ & $1,31 \mathrm{a}$ \\
\hline & $20-40$ & $1,02 \mathrm{a}$ & $1,53 \mathrm{~b}$ & $0,78 \mathrm{a}$ & $1,08 \mathrm{a}$ & $0,98 \mathrm{a}$ & $1,02 \mathrm{a}$ \\
\hline$D M S_{0,05}$ & (Prof.) & 0,33 & 0,31 & 0,35 & 0,36 & 0.30 & 0,35 \\
\hline \multirow{5}{*}{$\begin{array}{l}\text { Respiração Basal } \\
\left(\mathrm{mg} \mathrm{CO}_{2} \mathrm{~g}^{-1} \text { solo } 10 \mathrm{~d}^{-1}\right)\end{array}$} & $0-2,5$ & $0,467 \mathrm{a}$ & $0,429 \mathrm{a}$ & $0,803 \mathrm{~b}$ & $1,083 \mathrm{c}$ & $1,536 \mathrm{~d}$ & $0,750 \mathrm{~b}$ \\
\hline & $2,5-5$ & $0,247 \mathrm{a}$ & $0,433 \mathrm{~b}$ & $0,592 \mathrm{c}$ & $0,682 \mathrm{c}$ & $0,753 \mathrm{~d}$ & $0,505 \mathrm{~b}$ \\
\hline & $5-10$ & $0,149 \mathrm{a}$ & $0,419 \mathrm{c}$ & $0,317 \mathrm{~b}$ & $0,412 \mathrm{c}$ & $0,509 \mathrm{~d}$ & $0,403 \mathrm{c}$ \\
\hline & $10-20$ & $0,111 \mathrm{a}$ & $0,170 \mathrm{a}$ & $0,139 a$ & $0,243 \mathrm{~b}$ & $0,266 \mathrm{~b}$ & $0,286 b$ \\
\hline & $20-40$ & $0,094 \mathrm{a}$ & $0,131 \mathrm{a}$ & $0,109 a$ & $0,173 \mathrm{~b}$ & $0,156 \mathrm{~b}$ & $0,164 \mathrm{~b}$ \\
\hline$D M S_{0,05}$ & (Prof.) & 0,102 & 0,112 & 0,135 & 0,142 & 0,151 & 0,155 \\
\hline \multirow[t]{5}{*}{$q \mathrm{CO}_{2}$} & $0-2,5$ & $1,72 \mathrm{a}$ & $2,56 \mathrm{a}$ & $5,07 \mathrm{~b}$ & $7,73 \mathrm{c}$ & $9,20 \mathrm{~d}$ & $7,42 \mathrm{c}$ \\
\hline & $2,5-5$ & $1,24 \mathrm{a}$ & $4,59 \mathrm{~b}$ & $4,62 \mathrm{~b}$ & $6,37 \mathrm{c}$ & $6,20 \mathrm{c}$ & $6,17 \mathrm{c}$ \\
\hline & $5-10$ & $0,93 \mathrm{a}$ & $3,33 \mathrm{~b}$ & $3,18 \mathrm{~b}$ & $4,69 \mathrm{c}$ & $5,30 \mathrm{c}$ & $6,06 \mathrm{c}$ \\
\hline & $10-20$ & $0,80 \mathrm{a}$ & $1,98 \mathrm{~b}$ & $1,27 \mathrm{a}$ & $2,92 \mathrm{c}$ & $3,34 \mathrm{c}$ & $4,40 \mathrm{c}$ \\
\hline & $20-40$ & $0,83 \mathrm{a}$ & $1,96 \mathrm{~b}$ & $1,23 \mathrm{a}$ & $2,69 \mathrm{c}$ & $2,31 \mathrm{~b}$ & $2,73 \mathrm{c}$ \\
\hline$D M S_{0,05}$ & (Prof.) & 0,23 & 0,25 & 0,31 & 0,65 & 0,59 & 0,64 \\
\hline
\end{tabular}

A respiração basal e o quociente metabólico $\left(q \mathrm{CO}_{2}\right)$ foram afetados diferentemente pela acidez do solo entre os tratamentos na cronossequência. Embora o coeficiente de correlação de Pearson entre $\mathrm{pH}$ e o $q \mathrm{CO}_{2}$ foi altamente significativo $(\mathrm{p}<$ 0,$001 ; n=150$ ), não refletiu os contrates entre os tratamentos sob preparo e PD (Tabela 10). Por exemplo, a correlação dessas variáveis nos tratamentos $\mathrm{CN}$, PCN-1 e PC-22 
resultaram em coeficiente baixo e não significativo, enquanto nos tratamentos sob PD os coeficientes foram superiores a $0,82(p<0,001 ; n=25)$.

Tabela 10. Coeficiente de correlação de Pearson entre os parâmetros ecofisiológicos e os componentes da matéria orgânica envolvendo todos os dados $(n=150)$ e dentro de cada tratamento $(n=25)$ da cronossequência.

\begin{tabular}{|c|c|c|c|c|c|c|c|}
\hline \multirow{2}{*}{$\begin{array}{l}\text { Parâmetros } \\
\text { Correlacionados }\end{array}$} & \multirow{2}{*}{$\begin{array}{l}\text { Todos } \\
\text { os dados }\end{array}$} & \multicolumn{6}{|c|}{ Tratamentos } \\
\hline & & $\mathrm{CN}$ & $\mathrm{PCN}-1$ & PD-10 & PD-20 & PD-22 & $\mathrm{PC}-22$ \\
\hline $\mathrm{pH} \times \mathrm{C}_{\text {mic }}: \mathrm{C}_{\text {org }}$ & $-0,35$ & 0,12 & 0,18 & $-0,75$ & $-0,51$ & $-0,49$ & $-0,12$ \\
\hline $\mathrm{pH} \times \mathrm{N}_{\text {mic }}: \mathrm{N}_{\text {Total }}$ & $-0,44$ & 0,02 & $-0,29$ & $-0,77$ & $-0,20$ & 0,25 & $-0,32$ \\
\hline pH x Resp. Basal & 0,69 & $-0,16$ & 0,35 & 0,95 & 0,91 & 0,91 & 0,26 \\
\hline $\mathrm{pH} \times q \mathrm{CO}_{2}$ & 0,65 & $-0,23$ & 0,11 & 0,90 & 0,82 & 0,87 & 0,16 \\
\hline COT x $\mathrm{C}_{\text {mic }}: \mathrm{C}_{\mathrm{org}}$ & $-0,32$ & 0,25 & $-0,03$ & $-0,77$ & $-0,65$ & $-0,58$ & 0,09 \\
\hline COT x $N_{\text {mic }}: \mathrm{N}_{\text {Total }}$ & $-0,12$ & 0,57 & 0,26 & $-0,79$ & $-0,34$ & $-0,17$ & $-0,42$ \\
\hline COT x Resp. Basal & 0,79 & 0,88 & 0,57 & 0,96 & 0,93 & 0,97 & 0,76 \\
\hline $\mathrm{COT} \times q \mathrm{CO}_{2}$ & 0,57 & 0,79 & 0,38 & 0,88 & 0,83 & 0,89 & 0,59 \\
\hline NT $\times \mathrm{C}_{\text {mic }}: \mathrm{C}_{\text {org }}$ & $-0,29$ & 0,26 & 0,02 & $-0,75$ & $-0,64$ & $-0,57$ & 0,27 \\
\hline NT $x N_{\text {mic }}: \mathrm{N}_{\text {Total }}$ & $-0,15$ & 0,56 & 0,26 & $-0,80$ & $-0,32$ & $-0,15$ & $-0,35$ \\
\hline NT x Resp. Basal & 0,83 & 0,86 & 0,60 & 0,98 & 0,93 & 0,97 & 0,72 \\
\hline $\mathrm{NT} \times q \mathrm{CO}_{2}$ & 0,59 & 0,76 & 0,40 & 0,90 & 0,83 & 0,90 & 0,50 \\
\hline POT x Resp. Basal & 0,32 & 0,79 & 0,20 & 0,71 & 0,90 & 0,90 & 0,60 \\
\hline POT $\times q \mathrm{CO}_{2}$ & 0,11 & 0,80 & $-0,05$ & 0,70 & 0,78 & 0,76 & 0,34 \\
\hline POT x $\mathrm{C}_{\text {mic }}: \mathrm{C}_{\text {org }}$ & 0,12 & 0,08 & 0,24 & $-0,59$ & $-0,36$ & $-0,45$ & 0,45 \\
\hline POT $\times N_{\text {mic }}: N_{\text {Total }}$ & 0,16 & 0,44 & 0,10 & $-0,52$ & $-0,23$ & $-0,13$ & 0,03 \\
\hline POL x Resp. Basal & 0,27 & 0,80 & 0,12 & 0,85 & 0,91 & 0,95 & 0,60 \\
\hline POL $\times q \mathrm{CO}_{2}$ & 0,08 & 0,79 & $-0,02$ & 0,70 & 0,82 & 0,85 & 0,44 \\
\hline POL $\times C_{\text {mic }}: C_{\text {org }}$ & $-0,12$ & 0,09 & 0,02 & $-0,56$ & $-0,42$ & $-0,57$ & 0,38 \\
\hline POL $\times \mathrm{N}_{\text {mic }}: \mathrm{N}_{\text {Total }}$ & 0,17 & 0,36 & $-0,05$ & $-0,60$ & $-0,34$ & $-0,11$ & $-0,02$ \\
\hline $\mathrm{C}_{\text {mic }} \mathrm{C}_{\text {org }} \times \mathrm{COD}$ & $-{ }^{\dagger}$ & 0,66 & 0,62 & $-0,81$ & $-0,89$ & $-0,94$ & 0,12 \\
\hline $\mathrm{N}_{\text {mic }} \mathrm{N}_{\text {Total }} \times \mathrm{COD}$ & - & 0,88 & $-0,16$ & $-0,70$ & $-0,80$ & $-0,81$ & $-0,56$ \\
\hline Resp. Basal x COD & - & 0,83 & 0,87 & 0,82 & 0,96 & 0,90 & 0,86 \\
\hline$q \mathrm{CO}_{2} \times \mathrm{COD}$ & - & 0,85 & 0,52 & 0,83 & 0,95 & 0,95 & 0,90 \\
\hline
\end{tabular}

F Nível de significância para os coeficientes envolvendo todos os dados $(\mathrm{n}=150)$ : < 0,17 (NS); 0,18 a $0,26(\mathrm{p}=0,05) ; 0,27$ a $0,31(\mathrm{p}=0,01) ;>0,32(\mathrm{p}<0,001) ;$

$\$$ Nível de significância dentro dos tratamentos $(\mathrm{n}=25)$ : $<0,41(\mathrm{NS}) ; 0,41$ a $0,55(\mathrm{p}=$ $0,05) ; 0,56$ a $0,65(\mathrm{p}=0,01) ; \mathrm{e}>0,66(\mathrm{p}<0,001)$,

${ }^{\dagger}$ Não correlacionado

A quantidade de $\mathrm{CO}_{2}$ liberado na respiração basal $\left(\mathrm{mg} \mathrm{CO} \mathrm{g}^{-1}\right.$ solo $\left.10 \mathrm{~d}^{-1}\right)$ aumentou com o tempo de adoção do $\mathrm{PD}$ e apresentou elevada afinidade com o pH, o 
COT e a biomassa microbiana. A razão desse aumento pode ser atribuída ao destorroamento e o peneiramento das amostras em peneira de $2 \mathrm{~mm}$ antes da incubação provocando a ruptura dos agregados. Como consequência o $\mathrm{C}$ que atuava na ligação entre os agregados, foi exposto ao ataque microbiano em ambiente oxidativo resultando em elevado fluxo de $\mathrm{CO}_{2}$ (Elliot, 1986). Por outro lado, esse fluxo de $\mathrm{CO}_{2}$ é a indicação de que o $\mathrm{C}$ ligado aos agregados é representado por compostos orgânicos com diferentes graus de humificação e seria o fator chave na regulação da associação com a BMC e BMN nesse sistema de manejo.

A atividade da biomassa microbiana $\mathrm{C}$ e $\mathrm{N}$ no solo apresentou associações distintas com os componentes da MOS. O baixo coeficiente de correlação de Pearson para todos os dados $(n=150)$ entre o COT e $N$ total com a relação $C_{\text {mic }}: \mathrm{C}_{\text {org }}$ e $N_{\text {mic }}: N_{\text {total }}$ contrastou com o coeficiente altamente significativo $(p<0,001)$ encontrado para a respiração basal e o $q \mathrm{CO}_{2}$ (Tabela 10). Contudo, dentro dos tratamentos sob PD essas variáveis foram bem correlacionadas ( $p<0,001, n=25)$, enquanto que nos tratamentos $\mathrm{CN}, \mathrm{PCN}-1$ e PC-22 os coeficientes foram baixos e não significantes. Adicionalmente, $o$ coeficiente de correlação negativo e altamente significativo $(p<0,001 ; n=25)$ entre $\mathrm{C}_{\text {mic }}: \mathrm{C}_{\text {org }}$ e $\mathrm{N}_{\text {mic }}: \mathrm{N}_{\text {total }}$ com o POT, POL e COD representa a dependência da biomassa microbiana por fontes de $\mathrm{C}$ facilmente decomponíveis tornando-se o suporte básico para a ciclagem de $\mathrm{C}$ e $\mathrm{N}$. Por exemplo, todos os coeficientes que envolvem o $\mathrm{COD}$ aumentaram com o tempo de adoção do PD e foram superiores ao CN e PC-22 (Tabela 10). A respiração basal e o $q \mathrm{CO}_{2}$ enfatiza esses argumentos uma vez que essas variáveis também mostraram correlação positiva e altamente significativa com o COD. Embora os valores baixos de $q \mathrm{CO}_{2}$ representem a eficiência da biomassa microbiana em conservar C (Insam \& Haselwander, 1989) conforme observados no tratamento $\mathrm{CN}$ em todas as profundidades amostradas (Tabela 9), os maiores valores de $q \mathrm{CO}_{2}$ foram encontrados nos tratamentos PD-20 e PD-22. Enquanto o $q \mathrm{CO}_{2}$ e a respiração basal reduziram com a profundidade e aumentaram com o tempo de adoção de $\mathrm{PD}$, as relações $\mathrm{C}_{\text {mic }}: \mathrm{C}_{\text {org }}$ e $\mathrm{N}_{\text {mic }}: \mathrm{N}_{\text {total }}$ tiveram comportamento oposto. Esses resultados diferem dos encontrados por Sparling (1992) e Haynes (1999). Por outro lado, esses resultados mostram que o aumento no conteúdo e no estoque do COT também ocorre na camada 
superficial conforme reportado por Kern \& Johnson (1993) em regiões temperadas. Embora não tenha sido avaliada a distribuição de classes de agregados estáveis em $\mathrm{H}_{2} \mathrm{O}$, estes resultados sugerem que a explicação mais provável do acúmulo de COT nas camadas superficiais possa estar relacionada com a macroagregação mais rápida e conduzindo para a proteção fisica da MOS entre agregados. Neste caso, a adição bianual de resíduos culturais, a liberação de polissacarídeos devido ao processo de mineralização combinadas com a ausência de revolvimento do solo, favorecem uma taxa de agregação mais elevada. Desse modo, sugere-se que o tempo de ciclagem do $\mathrm{C}$ e os mecanismos de proteção física da MOS sejam as principais diferenças entre estes resultados e os obtidos em regiões temperadas.

Da mesma forma, os índices $\mathrm{C}_{\text {mic }}: \mathrm{C}_{\text {org }}$ e o $q \mathrm{CO}_{2}$ em sistemas agrícolas intensivos (rotação de culturas, retorno de resíduos culturais e plantio direto) sob solos de regiões tropicais devem ser mais discutidos conforme os comentários de Balota et al. (1998) e Colozzi-Filho (1999). Neste estudo, o ponto de referência ou linha de base para todas as comparações foi o campo nativo que representou o equilíbrio estável do COT em condições originais. $\mathrm{O}$ maior valor da relação $\mathrm{C}_{\text {mic }}: \mathrm{C}_{\text {org }}$ foi encontrado nesse tratamento e o menor valor de $\mathrm{C}_{\mathrm{mic}}$ : $\mathrm{C}_{\text {org }}$ no tratamento há longo período sob PD. Todavia, nesses tratamentos ocorreu significativo aumento no estoque de COT em comparação ao $\mathrm{CN}$ (Figura 7, cap.3, p.44). Resultados similares foram constados por Venske Filho (1999) em outra época de amostragem nestes mesmos tratamentos. Embora diferentes dos reportados por outros autores (Anderson \& Domsch, 1989; Sparling 1992; Haynes, 1999) em regiões temperadas, Wardle \& Ghani (1995), comentaram que o estresse ambiental ou distúrbio na população e na atividade microbiana ilustra a interferência e interação de outros fatores na ciclagem do $\mathrm{C}_{\text {mic }}$.

O declínio da MOS quando o solo sob vegetação natural é transformado em áreas cultivadas tende geralmente a atingir o novo nível de equilibrio estável em torno de 30 a 50 anos (Wagner, 1981). Neste estudo (cap.3, p.57) a previsão de novo ponto de equilibrio foi prevista com 40 anos da adoção do plantio direto considerando o mesmo aporte anual de resíduos culturais, o que representará $47,4 \%$ de aumento no estoque de $\mathrm{C}$ em relação ao solo sob vegetação natural. 


\subsection{Conclusões}

A maior quantidade de $\mathrm{C}$ e $\mathrm{N}$ microbiano foi encontrada no tratamento com o menor valor de $\mathrm{pH}$ representado pelo campo nativo $(\mathrm{CN})$. Enquanto a média dos valores de $\mathrm{pH}$ da camada de $0-40 \mathrm{~cm}$ do $\mathrm{CN}$ aumentou de 3,96 para 5,14 no tratamento $\mathrm{PC}-22$, o $\mathrm{C}$ e o $\mathrm{N}$ da biomassa microbiana reduziu 2,37 a 2,79 vezes. $\mathrm{O}$ pH do solo não se correlacionou com a BMC e BMN nos tratamentos CN, PCN-1 e PC-22, no entanto, apresentou forte correlação nos tratamentos sob PD. A BMC e BMN no tratamento sob $\mathrm{CN}$ foi superior aos tratamentos sob PD acima de $55 \%$. O aumento no conteúdo de POT, POL e COD acompanhou o acúmulo do COT. A afinidade entre a BMC e os componentes da MOS decresceram na seguinte ordem: $\mathrm{COD}>$ Ntotal $>\mathrm{COT}>\mathrm{POT}=$ POL. Em relação a BMN, esta série foi Ntotal $>\mathrm{COD}>\mathrm{COT}>\mathrm{POL}>\mathrm{POT}$. Embora nos tratamentos sob PD na camada de $0-2,5 \mathrm{~cm}$ e $2,5-5 \mathrm{~cm}$ de profundidade a relação $\mathrm{C}_{\text {mic }}: \mathrm{C}_{\text {org }}$ tenha sido menor, o estoque de COT foi significativamente superior ao $\mathrm{CN}$. O aumento no estoque de COT na camada de $0-5 \mathrm{~cm}$ em relação ao $\mathrm{CN}$ representou $+2,9$ $\mathrm{Mg} \mathrm{ha}^{-1}$ no PD-10, +7,8 $\mathrm{Mg} \mathrm{ha}^{-1}$ no PD-20 e $+13,1 \mathrm{Mg} \mathrm{ha}^{-1}$ no PD-22for PD-22. Estes resultados indicam que o sistema plantio direto associado ao retorno dos resíduos culturais conduza a proteção da MOS dentro de novos agregados levando o solo a atuar mais como dreno do que como fonte de $\mathrm{CO}_{2}$. 


\section{IMPACTO DE UMA CRONOSSEQUENNCIA SOB SISTEMAS DE MANEJO CONVENCIONAL E PLANTIO DIRETO NAS INTERAÇÕES ENTRE O CARBONO ORGÂNICO E A FERTILIDADE DE UM OXISOL NO BRASIL}

\subsection{RESUMO}

A adoção do plantio direto (PD) é uma ferramenta essencial para o desenvolvimento de uma agricultura sustentável e o ponto chave desse sistema é como o PD afeta o $\mathrm{C}$ orgânico. Foi avaliado o efeito de uma cronossequência sob sistemas de manejo convencional e plantio direto no carbono orgânico total (COT) e nas interações com a fertilidade em um Latossolo Vermelho, situado na região Centro-Sul do Estado do Paraná, Brasil $\left(50^{\circ} 23^{\prime}\right.$ W e $24^{\circ} 36^{\prime}$ S). A cronossequência foi constituída dos seguintes tratamentos: a) campo nativo $(\mathrm{CN})$; b) preparo do campo nativo (PCN-1) envolvendo a conversão da vegetação natural em área agrícola; c) plantio direto por 10 anos (PD-10); d) plantio direto por 20 anos (PD-20); e) plantio direto por 22 anos (PD22); e f) preparo convencional por 22 anos (PC-22) envolvendo o preparo com uma aração a $20 \mathrm{~cm}$ de profundidade, após a colheita da cultura de verão e inverno seguido de duas gradagens niveladoras. Amostras de solo foram coletadas de cinco profundidades $(0-2,5 ; 2,5-5 ; 5-10 ; 10-20$ e $20-40 \mathrm{~cm})$ e determinados o COT, o pH (em $\mathrm{H}_{2} \mathrm{O}$ e $\mathrm{KCl} 1 \mathrm{~N}$ ), o $\Delta \mathrm{pH}$, a acidez potencial, o conteúdo de bases trocáveis, $\mathrm{P}$ e $\mathrm{K}$. O aumento no conteúdo de COT, afetou positivamente $\mathrm{o} \mathrm{pH}$, as cargas negativas e a capacidade de troca de cátions (CTC) e negativamente a acidez potencial. Análises de regressão indicaram um estreito relacionamento entre o conteúdo de COT e os parâmetros estimados nesse estudo. Os dados mostraram que o plantio direto a longo período é um sistema eficiente para melhorar as propriedades químicas e aumentar a fertilidade de solos com carga variável. 


\subsection{SUMMARY: CONVENTIONAL AND NO-TILLAGE CHRONOSEQUENCE IMPACTS ON SOIL ORGANIC CARBON AND FERTILITY INTERACTIONS IN A BRAZILIAN OXISOL}

No-tillage (NT) adoption is an essential tool for development of sustainable agricultural systems and how NT affects the organic C is a key component of these systems. The effect of a plowed and no-tillage chronosequence on soil organic carbon (SOC) and fertility interactions was assessed in a variable charge Oxisol, located in the South Center quadrant of Paraná State, Brazil $\left(50^{\circ} 23^{\prime} \mathrm{W}\right.$ and $\left.24^{\circ}\right)$. The chronosequence consisted of the following six land use sites: (i) native field (NF); (ii) plow tillage of the native field (PNF-1) involving conversion of natural vegetation to cropland; (iii) notillage for 10 years (NT-10); (iv) no-tillage for 20 years (NT-20); (v) no-tillage for 22 years (NT-22); and (vi) conventional tillage for 22 years (CT-22) involving plow tillage with one disking after summer harvest and one after winter harvest to $20 \mathrm{~cm}$ depth plus two narrow diskings. Soil samples were collected from five depths (0-2.5; 2.5-5; 5-10; 10-20; and 20-40 cm) and SOC, $\mathrm{pH}$ (in $\mathrm{H}_{2} \mathrm{O}$ and $\mathrm{KCl}$ ), $\Delta \mathrm{pH}$, potential acidity, exchangeable bases, phosphorus, and potassium contents were measured. An increase in SOC concentration positively affected the $\mathrm{pH}$, the negative charge and the cation exchange capacity and negatively impacted potential acidity. Regression analyses indicated a close relationship between the SOC content and the parameters in this study. The data showed that long-term no-tillage is an efficient system to improve chemical properties and enhance fertility of soils with variable charge.

\subsection{INTRODUÇÃo}

A conversão da vegetação natural em áreas agrícolas altera as propriedades físicas, químicas e biológicas dos solos (Oades, 1984; Lal, 1976; 1997). O preparo do solo tem sido utilizado desde épocas remotas, todavia, sua intensificação tem sido crescente desde o inicio da era industrial, especialmente nas regiões de clima temperado (Lynch, 1984). Em geral, nestas regiões onde predomina solos com elevada fertilidade 
natural, o principal objetivo do preparo é o de acelerar o aquecimento do solo na primavera, controlar as plantas daninhas e promover boas condições de germinação e desenvolvimento das culturas.

Ao contrário, em regiões tropicais, a maioria dos solos possui baixa fertilidade natural, devida à elevada acidez, à escassez em bases trocáveis e ao baixo conteúdo de fósforo disponível afetando o crescimento radicular e o desenvolvimento das culturas. Assim sendo, o preparo do solo nessas regiões tem sido usado principalmente para a reduzir e/ou eliminar os efeitos nocivos da acidez e aumentar a disponibilidade de nutrientes dos solos (Kamprath, 1977). Ao mesmo tempo, o uso do preparo do solo associado à intensidade de cultivo em regiões com elevada pluviosidade, tem provocado expressivas perdas de solo por erosão, decréscimo da matéria orgânica e da fertilidade (Resck, 1998), resultando na queda da produtividade das culturas.

Em regiões de clima temperado a adoção e manutenção do PD tem conduzido a uma distribuição estratificada da matéria orgânica do solo (MOS) e dos nutrientes, cuja acumulação ocorre principalmente nas camadas superficiais entre 0 e $10 \mathrm{~cm}$ de profundidade (Shear \& Moschler, 1969; Triplett Jr. \& Van Doren Jr., 1969; Blevins et al., 1977; Dick et al., 1985; Dick \& Van Doren Jr., 1991). Embora tenham sido desenvolvidos estudos semelhantes em solos com carga variável e de baixa capacidade de troca de cátions (CTC) de regiões tropicais (Lal, 1976; Muzzili, 1983; Sidiras \& Pavan, 1985; Sá, 1993 e 1999) os resultados ainda são insuficientes para explicar as alterações na fertilidade do solo. Ainda não explicam claramente como os nutrientes reciclados dos resíduos culturais podem ser mantidos na superfície desses solos, tendo em vista os efeitos da erosão e a lixiviação dos nutrientes. Alguns autores reportaram que a estratégia de manejo apropriada para esses solos, visando elevar o seu potencial produtivo, seja através do aumento das cargas negativas e conseqüentemente de sua CTC (Sanchez, 1976; Uehara \& Keng, 1975; Uehara, 1995). Nesses solos, o uso de calcário para a correção da acidez, do gesso e de adubos fosfatados tem sido um meio para aumentar cargas negativas e o conteúdo de MOS através da maior produção de fitomassa (Fox, 1980). Em solos do Estado de São Paulo, Paraná e região dos cerrados, Raij (1969), Pavan et al. (1985) e Silva et al. (1994), constataram que a matéria 
orgânica seja responsável por 74 a $80 \%$ da CTC total, evidenciando sua importância para os solos com carga variável.

Por outro lado, de acordo com Juo \& Lal (1979) e Dick (1983) a melhoria da fertilidade do solo devido ao plantio direto se restringe a camada superficial. Eles constataram que a aplicação de fertilizantes na superficie, o retorno dos resíduos culturais e o não revolvimento do solo são as principais razões. No início da década dos 90, Havlin et al. (1990) e Buchanan \& King (1993) mostraram que a manutenção dos resíduos culturais afeta sensivelmente as propriedades do solo nas camadas superficiais. Recentemente, os resultados de Burle et al. (1997) e Bayer \& Bertol (1999) em condições subtropicais e em solos com carga variável, mostraram que o retorno de resíduos culturais com 40 a $50 \%$ de C, associado ao não revolvimento do solo aumentou a MOS e a carga negativa líquida. Também concluíram que o aumento da MOS e conseqüentemente da CTC seria o caminho para a retenção dos cátions trocáveis $\left(\mathrm{Ca}^{2+}\right.$, $\mathrm{Mg}^{2+}, \mathrm{K}^{+}$) oriundos da mineralização dos resíduos culturais.

No Brasil, a introdução do PD no início da década dos 70 , proporcionou uma técnica viável para o controle da erosão (Ramos, 1976; Wunche \& Denardin, 1978; Mondardo, 1978). Durante a década dos 80 e dos 90, grande parte do trabalho de pesquisa envolveu o efeito dos resíduos culturais na fertilidade do solo, especialmente aqueles relacionados com o manejo do fósforo, controle da acidez do solo e manejo de nitrogênio (Muzilli, 1983; Sidiras \& Pavan, 1985; Sá, 1993 e 1999).

Estudos comparativos entre sistemas que envolvem o preparo do solo e o plantio direto em Oxisols, tendo como referência as condições originais da vegetação natural e o equilíbrio estável do COT no solo têm sido pouco reportados. Estimativas do impacto de sistemas de manejo há longo período nas propriedades do solo, especialmente aquelas relacionadas com a fertilidade ainda são necessárias serem realizadas. Informações sobre a dinâmica da MOS e da fertilidade do solo em uma cronossequência sob sistemas de manejo há longo período é fundamental para desenvolver estratégias para o manejo sustentável de solos com carga variável. Dessa forma, o objetivo deste trabalho foi estudar o impacto de sistemas de manejo de uma cronossequência na interação entre o carbono orgânico e a fertilidade do solo em um Latossolo Vermelho. 


\subsection{MATERIAL E MÉTODOS}

\subsubsection{Localização e descrição da área experimental}

$\mathrm{O}$ experimento de campo foi conduzido em duas áreas, sendo uma situada na Fazenda Santa Branca (FSB) próxima à cidade de Tibagi e outra na Fazenda Frankanna (FF) próxima à cidade de Ponta Grossa. Estas áreas estão enquadradas na região CentroSul do Estado do Paraná.

A vegetação natural é dominada por espécies $\mathrm{C}_{4}$ representadas por algumas gramíneas resistentes ao fogo tais como o Andropogon sp., Aristida sp., Paspalum sp., Panicum sp., e ao longo dos canais naturais de drenagem há ocorrência de floresta de galeria. $\mathrm{O}$ relevo caracteriza-se com suave ondulado com pendentes entre 2 a $7 \%$ de declividade. O material de origem é constituído por sedimentos clásticos do período Devoniano, caracterizados por materiais retrabalhados de arenitos da formação Furnas e folhelhos da formação Ponta Grossa. Os solos foram classificados como Latossolos Vermelhos (Typic Hapludox), textura argilosa, profundos, muitos bem estruturados e drenados. A escolha das áreas experimentais baseou-se na existência de uma cronossequência bem definida, tendo como referência as condições originais de vegetação e solo. Além disso, possuem o mesmo material de origem, a mesma classe textural e localização na vertente (posição de topo). Foram também manejadas com práticas culturais e rotação de culturas similares. Essa cronossequência oportuniza a avaliação do impacto do preparo do solo e do plantio direto há longo período nos compartimentos da MOS e de atributos da relacionados com a biomassa microbiana. A tabela 11 sumariza a descrição geral da situação selecionada e os detalhes sobre este item estão descritos no capítulo 3 (p.27-31). 
Tabela 11. Descrição geral da área de estudo: localização, clima e solo

\begin{tabular}{llll}
\hline \multicolumn{2}{c}{ Parâmetros } & \multicolumn{2}{c}{ Descrição das áreas } \\
\cline { 2 - 4 } & & Fazenda Santa Branca & Fazenda Frankanna \\
\hline Localização & Município & Tibagi & Ponta Grossa \\
& Latitude & $24^{\circ} 36^{\prime} \mathrm{S}$ & $25^{\circ} 20^{\prime} \mathrm{S}$ \\
& Longitude & $50^{\circ} 23^{\prime} \mathrm{W}$ & $50^{\circ} 20^{\prime} \mathrm{W}$ \\
\multirow{4}{*}{ Clima } & Altitude & $880 \mathrm{~m}$ & $910 \mathrm{~m}$ \\
& Tipo $^{\ddagger}$ & mesotérmico, úmido & mesotérmico, úmido \\
& & subtropical, tipo cfb & subtropical, tipo cfb \\
& $\mathrm{TMA}^{\ddagger \ddagger}$ & $20,7^{\circ} \mathrm{C}$ & $18,7^{\circ} \mathrm{C}$ \\
\multirow{4}{*}{ Solo } & $\mathrm{PMA}^{\ddagger \ddagger \ddagger}$ & $1532 \mathrm{~mm}$ & $1545 \mathrm{~mm}$ \\
& Tipo & Latossolo Vermelho, & Latossolo Vermelho, \\
& & Typic Hapludox & Typic Hapludox \\
& Textura & Argilosa & Argilosa \\
& Material de & Arenito + Folhelho & Arenito + Folhelho \\
& origem & (Material retrabalhado) & (Material retrabalhado) \\
& Tipo de argila & Ct; Gib; Hem.; Goe & Ct; Gib; Hem.; Goe \\
\hline
\end{tabular}

F Classificação climática de Koeppen;

\# Temperatura média anual

¥¥ Precipitação media anual

${ }^{\S} \mathrm{Ct}=$ Caulinita; Gib = Gibbsita; Hem.$=$ Hematita; Goe = Goethita

5.4.2 Conversão da vegetação natural em área agrícola, descrição da cronossequência, rotação de culturas e práticas culturais

Antes do início da exploração agrícola na FSB e FF, as áreas estavam sob a vegetação natural, denominada de "campos nativos" e uma parte representa o tratamento campo nativo (CN). A conversão dos campos nativos em áreas de cultivo na FSB iniciou em 1969. Entre 1969 e 1979 foi cultivado arroz (Oryza sativa) nos primeiros três anos e mantendo inverno em pousio e no restante do período, cultivou-se soja (Glicine max.) no verão e trigo (Triticum aestivum) no inverno sob preparo convencional.

Em 1979, foi adotado o plantio direto em aproximadamente $30 \%$ do total da área e esta representa o tratamento com 20 anos sob plantio direto (PD-20). Entre 1979 e 1998 foram 39 cultivos assim distribuídos: no verão cultivou-se soja 15 vezes e milho (Zea mays L.) cinco vezes e durante o inverno foram 11 cultivos de aveia preta (Avena 
strigosa, Schreb), sete cultivos de trigo e dois cultivos de tremoço azul (Lupinus angustifollios). Os cultivos de aveia preta e tremoço azul foram destinados exclusivamente para adubação verde e formação de cobertura do solo. Em 1989, foi adotado o plantio direto na área adjacente ao PD-20, e esta representa o tratamento com plantio direto há 10 anos (PD-10). Entre 1989 e 1998, foram 20 cultivos, sendo sete vezes soja e três vezes milho no verão e seis cultivos de aveia preta e quatro cultivos de trigo no inverno.

Em junho de 1996, outra área adjacente foi convertida em agricultura para representar a fase inicial da conversão da vegetação natural em área agrícola. Esta se refere ao tratamento denominado preparo do campo nativo (PCN-1). Durante o período de conversão do campo nativo (um ano e seis meses) foi cultivado soja (outubro/96), aveia preta (maio/97) e milho (setembro/97).

$\mathrm{Na}$ Fazenda Frankanna o início da exploração agrícola ocorreu em 1961. O manejo do solo realizado entre 1961 e 1976 (preparo do solo, culturas, calagem e quantidade de P) foi semelhante à Fazenda Santa Branca. Em 1976, duas áreas com três ha cada foram destinadas a comparação entre o preparo convencional e o plantio direto e estas, representam os tratamentos com plantio direto há 22 anos (PD-22) e o preparo convencional há 22 anos (PC-22). Neste último, o preparo do solo foi realizado após a colheita da cultura de verão e de inverno, através de uma aração e duas gradagens para atingir a profundidade de $20 \mathrm{~cm}$. No período entre 1976 e 1998 foram 15 cultivos de soja e 6 de milho no verão. No inverno, foram 10 cultivos de trigo, quatro de aveia preta, um de tremoço azul e o azevém (Lollium multiflorum) nas últimas quatro estações. Em 1996 e 1997, nesses dois tratamentos foram aplicados 15 a $20 \mathrm{~m}^{3} \mathrm{ha}^{-1}$ de esterco líquido de bovinos. A rotação de culturas nas áreas estudadas foi constituída por uma seqüência de seis cultivos: Trigo/Soja/Aveia preta/Soja/Aveia Preta/Milho. O ciclo da rotação se reinicia a cada três anos (figura 5, cap.3). O histórico de uso de fertilizantes, produção de grãos e a biomassa vegetal (parte aérea + raízes) estão apresentadas na tabela 3 (cap.3). Os detalhes deste item estão descritos no capítulo 3 (p.32-35). 


\subsubsection{Desenho experimental e amostragem do solo}

A situação selecionada constitui um delineamento experimental em faixas com um arranjo em parcelas subdivididas não aleatório com cinco repetições. As faixas referem-se aos tratamentos de uso da terra implantados em épocas distintas constituindo uma cronossequência. A faixa é constituída com seis níveis: a) Campo nativo (CN); b) Preparo do campo nativo (PCN-1); c) Plantio direto há 10 anos (PD-10); d) Plantio direto há 20 anos (PD-20); e) Plantio direto há 22 anos (PD-22) e f) Preparo convencional há 22 anos (PC-22). O arranjo em parcelas subdivididas é representado pela profundidade de amostragem com cinco níveis $(0-2,5 ; 2,5-5,0 ; 5,0-10,0 ; 10,0-20,0$ e 20-40 cm). As dimensões de cada faixa da cronossequência foram de $200 \mathrm{~m} \times 50 \mathrm{~m}$ e de cada repetição de $40 \mathrm{~m} \times 50 \mathrm{~m}$.

A coleta das amostras de solo em cada repetição foi realizada em minitrincheiras com dimensões de $20 \mathrm{~cm}$ x $50 \mathrm{~cm}$ (área) $\times 50 \mathrm{~cm}$ (profundidade). Para constituir uma amostra composta foram cavadas 9 mini-trincheiras e retirado fatias referente as camadas de 0-2.5, 2.5-5, 5-10, 10-20 e 20-40 cm. Detalhes das parcelas e da coleta das amostras de solo estão ilustrados na figura 6 do capítulo 3(p.34).

\subsubsection{Preparo das amostras e análises}

As amostras de solo foram secas ao ar, destorroadas e peneiradas em peneira de $2 \mathrm{~mm}$. Uma porção da amostra foi moída e peneirada em peneira de $150 \mu \mathrm{m}$ para a determinação do conteúdo de $\mathrm{C}$ pelo método da combustão seca (Nelson \& Sommers, 1982), através do analisador de $\mathrm{C}\left(\mathrm{LECO}^{\circledR} \mathrm{CR}-412\right)$. $\mathrm{O} \mathrm{pH}$ do solo foi determinado por dois procedimentos: a) em água, usando a relação 1:2,5 de solo:água; e b) em uma solução de $\mathrm{KCl} 1 \mathrm{~N}$ (EMBRAPA, 1979). O "status" da carga elétrica do solo foi estimado determinando o $\mathrm{pH}$ em $\mathrm{H}_{2} \mathrm{O}$ e em $\mathrm{KCl} 1 \mathrm{~N}$ conforme descrito por Mekaru \& Uehara (1972). O valor do $\Delta \mathrm{pH}\left(\mathrm{pHxcl}-\mathrm{pHH}_{2} \mathrm{O}\right)$, corresponde ao sinal da carga nos colóides. De acordo com os mesmos autores, o valor negativo do $\Delta \mathrm{pH}$ corresponde à 
presença de cargas negativas e a capacidade de troca de cátions (CTC) enquanto o valor positivo do $\Delta \mathrm{pH}$ indica a ocorrência de cargas positivas e representa a capacidade de troca de anions (CTA). A acidez potencial foi determinada pelo método descrito pela EMBRAPA (1979), extraindo o $\mathrm{H}+\mathrm{Al}$ com uma solução de $\mathrm{Ca}(\mathrm{OAc})_{2} 1 \mathrm{~N}$ tamponada a $\mathrm{pH} 7,0$. Os cátions trocáveis $\left(\mathrm{Al}^{3+}, \mathrm{Ca}^{2+}, \mathrm{Mg}^{2+}, \mathrm{K}^{+}\right)$e o $\mathrm{P}$ foram extraídos pela resina trocadora de cátions e ânions, conforme descrito por Raij \& Quaggio (1983). A CTC total do solo foi obtida através da soma do valor da acidez potencial e das bases trocáveis $\left(\mathrm{Ca}^{2+}, \mathrm{Mg}^{2+}, \mathrm{K}^{+}\right)$. A CTC efetiva (CTCe) foi calculada através da soma dos cátions trocáveis $\left(\mathrm{Al}^{3+}, \mathrm{Ca}^{2+}, \mathrm{Mg}^{2+}, \mathrm{K}^{+}\right)$. A relação entre CTC:COT foi calculada de acordo com a seguinte expressão: faixa da CTC/faixa do COT. A faixa da CTC referese a diferença entre a média dos valores da CTC na camada de $0-2,5 \mathrm{~cm}$ e a média dos valores da camada de $0-40 \mathrm{~cm}$ de profundidade. $\mathrm{O}$ mesmo critério foi utilizado para calcular a faixa do COT.

\subsubsection{Análises estatísticas}

Os resultados foram submetidos à análise de variância (ANOVA) e as médias comparadas pelo teste de Tukey ao nível de $5 \%$ de probabilidade $(\mathrm{p}<0,05)$, para caracterizar as diferenças entre os tratamentos. O coeficiente de correlação de Pearson foi utilizado na avaliação do grau de afinidade das variáveis. Equações de regressão foram selecionadas pelo procedimento de Stepwise (SAS Institute, 1990) para ajustar os modelos em cada variável. As equações de regressão usadas para avaliar as mudanças temporais do $\mathrm{P}$ e $\mathrm{K}$ em cada profundidade de amostragem considerando-se o campo nativo como a linha de base ou ponto de referencia. A taxa das mudanças temporais para CTC, P e K foram calculadas computando a tangente da linha de regressão (dy/dx) em cada profundidade amostrada. $O$ nível de significância estatístico para as equações de regressão e os coeficientes de correlação foi descrito como $\mathrm{p}<0,05 ; \mathrm{p}<0,01$ e $\mathrm{p}<$ 0,001 representados por $*, * *, * * *$, respectivamente. 


\subsection{RESULTADOS E DISCUSSÃO}

\subsubsection{Alterações no conteúdo de carbono orgânico do solo afetado pelos sistemas} de manejo

A conversão da vegetação natural em sistemas agrícolas com preparo do solo e plantio direto resultou em uma resposta diferenciada no conteúdo de COT (Tabela 12).

Tabela 12. Alterações no COT, $\mathrm{pH}\left(\mathrm{H}_{2} \mathrm{O}\right)$ e $\Delta \mathrm{pH}\left(\mathrm{pHKCl}\right.$ - $\left.\mathrm{pH}_{2} \mathrm{O}\right)$ em um Latossolo Vermelho (Typic Hapludox) sob sistemas de manejo convencional e plantio direto (Médias de 5 repetições ${ }^{\ddagger}$ ).

\begin{tabular}{|c|c|c|c|c|c|c|c|}
\hline \multirow[t]{2}{*}{ Variável } & \multirow{2}{*}{$\begin{array}{l}\text { Prof. } \\
(\mathrm{cm})\end{array}$} & \multicolumn{6}{|c|}{ Sistemas de manejo } \\
\hline & & $\mathrm{CN}$ & PCN-1 & PD-10 & PD-20 & PD-22 & $\mathrm{PC}-22$ \\
\hline COT & $0-2,5$ & $34,5 \mathrm{~B}$ & $38,4 \mathrm{C}$ & $36,3 \mathrm{C}$ & $45,9 \mathrm{D}$ & $52,8 \mathrm{D}$ & $30,1 \mathrm{~A}$ \\
\hline \multirow[t]{4}{*}{$\left(\mathrm{g} \mathrm{kg}^{-1}\right)$} & $2,5-5,0$ & $29,5 \mathrm{~A}$ & $37,2 \mathrm{~B}$ & $25,7 \mathrm{~A}$ & $34,6 \mathrm{~B}$ & $35,1 \mathrm{~B}$ & $28,0 \mathrm{~A}$ \\
\hline & $5,0-10,0$ & $25,3 \mathrm{~B}$ & $35,5 \mathrm{C}$ & $18,9 \mathrm{~A}$ & $24,7 \mathrm{~B}$ & $25,1 \mathrm{~B}$ & $25,9 \mathrm{~B}$ \\
\hline & $10,0-20,0$ & $21,6 \mathrm{~B}$ & $31,2 \mathrm{C}$ & $14,6 \mathrm{~A}$ & $21,6 \mathrm{~B}$ & $20,7 \mathrm{~B}$ & $23,5 \mathrm{~B}$ \\
\hline & $20,0-40,0$ & $16,9 \mathrm{~B}$ & $22,0 \mathrm{C}$ & $12,7 \mathrm{~A}$ & $17,9 \mathrm{~B}$ & $16,9 \mathrm{~B}$ & $19,3 \mathrm{~B}$ \\
\hline $\mathrm{DMS}_{0,05}{ }^{\S}$ & (Prof.) & 4,1 & 4,9 & 4,2 & 5,1 & 4,3 & 4,8 \\
\hline \multirow[t]{5}{*}{ pH $\mathrm{H}_{2} \mathrm{O}$} & $0-2,5$ & $4,9 \mathrm{~A}$ & $5,97 \mathrm{BC}$ & $6,66 \mathrm{D}$ & $6,83 \mathrm{D}$ & $6,13 \mathrm{C}$ & $5,77 \mathrm{~B}$ \\
\hline & $2,5-5,0$ & $4,9 \mathrm{~A}$ & $5,07 \mathrm{~B}$ & $6,47 \mathrm{D}$ & $6,48 \mathrm{D}$ & $6,15 \mathrm{D}$ & $5,85 \mathrm{C}$ \\
\hline & $5,0-10,0$ & $4,9 \mathrm{~A}$ & $4,63 \mathrm{~A}$ & $6,01 \mathrm{C}$ & $6,09 \mathrm{C}$ & $6,04 \mathrm{C}$ & $5,86 \mathrm{~B}$ \\
\hline & $10,0-20,0$ & $4,9 \mathrm{~B}$ & $4,58 \mathrm{~A}$ & $5,85 \mathrm{C}$ & $5,70 \mathrm{C}$ & $5,61 \mathrm{C}$ & $5,63 \mathrm{C}$ \\
\hline & $20,0-40,0$ & $5,0 \mathrm{~B}$ & $4,67 \mathrm{~A}$ & $5,72 \mathrm{C}$ & $5,29 \mathrm{C}$ & $5,12 \mathrm{~B}$ & $5,20 \mathrm{~B}$ \\
\hline $\mathrm{DMS}_{0,05}$ & (Prof.) & 0,45 & 0,41 & 0,39 & 0,34 & 0,36 & 0,40 \\
\hline$\Delta \mathrm{pH}$ & $0-2,5$ & $-0,85 \mathrm{~A}$ & $-0,66 \mathrm{~B}$ & $-0,35 \mathrm{C}$ & $-0,42 \mathrm{C}$ & $-0,32 \mathrm{C}$ & $-0,29 \mathrm{D}$ \\
\hline \multirow[t]{4}{*}{ (рНкс1-рНно } & $2,5-5,0$ & $-0,78 \mathrm{~A}$ & $-0,57 \mathrm{~B}$ & $-0,50 \mathrm{~B}$ & $-0,53 \mathrm{~B}$ & $-0,41 \mathrm{C}$ & $-0,43 \mathrm{C}$ \\
\hline & $5,0-10,0$ & $-0,79 \mathrm{~A}$ & $-0,60 \mathrm{~B}$ & $-0,77 \mathrm{~A}$ & $-0,74 \mathrm{~A}$ & $-0,60 \mathrm{C}$ & $-0,51 \mathrm{C}$ \\
\hline & $10,0-20,0$ & $-0,82 \mathrm{~A}$ & $-0,61 \mathrm{~B}$ & $-0,92 \mathrm{~A}$ & $-0,98 \mathrm{~A}$ & $-0,78 \mathrm{~B}$ & $-0,74 \mathrm{C}$ \\
\hline & $20,0-40,0$ & $-0,87 \mathrm{~B}$ & $-0,59 \mathrm{C}$ & $-1,15 \mathrm{~A}$ & $-0,92 \mathrm{~A}$ & $-0,62 \mathrm{C}$ & $-0,76 \mathrm{~B}$ \\
\hline $\mathrm{DMS}_{0,05}$ & (Prof.) & $-0,22$ & $-0,14$ & $-0,16$ & $-0,18$ & $-0,12$ & $-0,19$ \\
\hline
\end{tabular}

${ }^{\ddagger}$ Médias seguidas da mesma letra (maiúscula) na linha, não diferem entre si pelo teste de Tukey ao nível de $5 \%$ de probabilidade $(\mathrm{p}=0,05)$

${ }^{\S} \mathrm{DMS}_{0,05}$ refere-se a diferença mínima significativa obtida pelo teste de Tukey ao nível de $5 \%$ de probabilidade, para a comparação das médias de cada variável entre as profundidades (coluna) dentro de cada tratamento. 
$\mathrm{O}$ efeito do longo período de preparo do solo no tratamento $\mathrm{PC}-22$, reduziu significativamente $(\mathrm{p}<0,05)$ o conteúdo médio de COT comparado ao $\mathrm{CN}$ somente na camada de 0-2,5 cm de profundidade. Nos tratamentos PD-20 e PD-22, a diferença se estendeu até a camada de $2,5-5 \mathrm{~cm}$ de profundidade.

Por outro lado, o plantio direto a longo período (PD-20 e PD-22) proporcionou aumento significativo no conteúdo de COT comparado às condições originais até cinco $\mathrm{cm}$ de profundidade. Considerando a estimativa das entradas anuais de $\mathrm{C}$ oriundo dos resíduos culturais nos tratamentos com $\mathrm{PD}$, o coeficiente de correlação entre o COT e as adições dos resíduos culturais nesses tratamentos foi $\mathrm{r}=0,86^{*}$ para a camada de $0-2,5$ $\mathrm{cm}$ e $\mathrm{r}=0,99^{* * *}$ para a camada de $2,5-5 \mathrm{~cm}$. Esses dados confirmam as observações realizadas no início da década dos 80 (Dick, 1983) afirmando que no sistema plantio direto o conteúdo de $\mathrm{C}$ é grandemente controlado pela quantidade e qualidade dos resíduos culturais que entram no sistema.

O PCN-1 também promoveu este incremento e se estendeu a outras camadas. Entretanto, a elevação no COT pode ser atribuída a incorporação de material orgânico fresco, uma vez que a amostragem do solo foi realizada um ano e seis meses após a conversão da vegetação natural em agricultura.

\subsubsection{Alterações na acidez potencial e pH na cronossequência afetada pelo carbono orgânico do solo}

As respostas da acidez potencial e do $\mathrm{pH}$ diferiram significativamente entre os tratamentos na cronossequência (Figura 15). Para o tratamento $\mathrm{CN}$, o aumento do conteúdo do COT elevou a acidez potencial sem alteração do $\mathrm{pH}$. Neste tratamento, o elevado conteúdo de $\mathrm{Al}^{3+}$ e a baixa saturação por bases $\left(9,5\right.$ mmol $_{\mathrm{c}} \mathrm{kg}^{-1}$ e $15,4 \%$ para a camada 0-2,5 cm, 13,2 mmol $\mathrm{kg}^{-1}$ e 9,6\% para 2,5-5 cm, 14,1 $\mathrm{mmol}_{\mathrm{c}} \mathrm{kg}^{-1}$ e $6,4 \%$ para

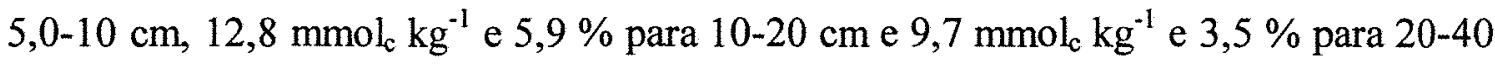
$\mathrm{cm}$ de profundidade, respectivamente) e a natureza acídica da $\mathrm{MOS}$ em $\mathrm{pH}<4,5$ são os fatores que contribuem para a manutenção do $\mathrm{pH}$ em valores inferiores a cinco. 

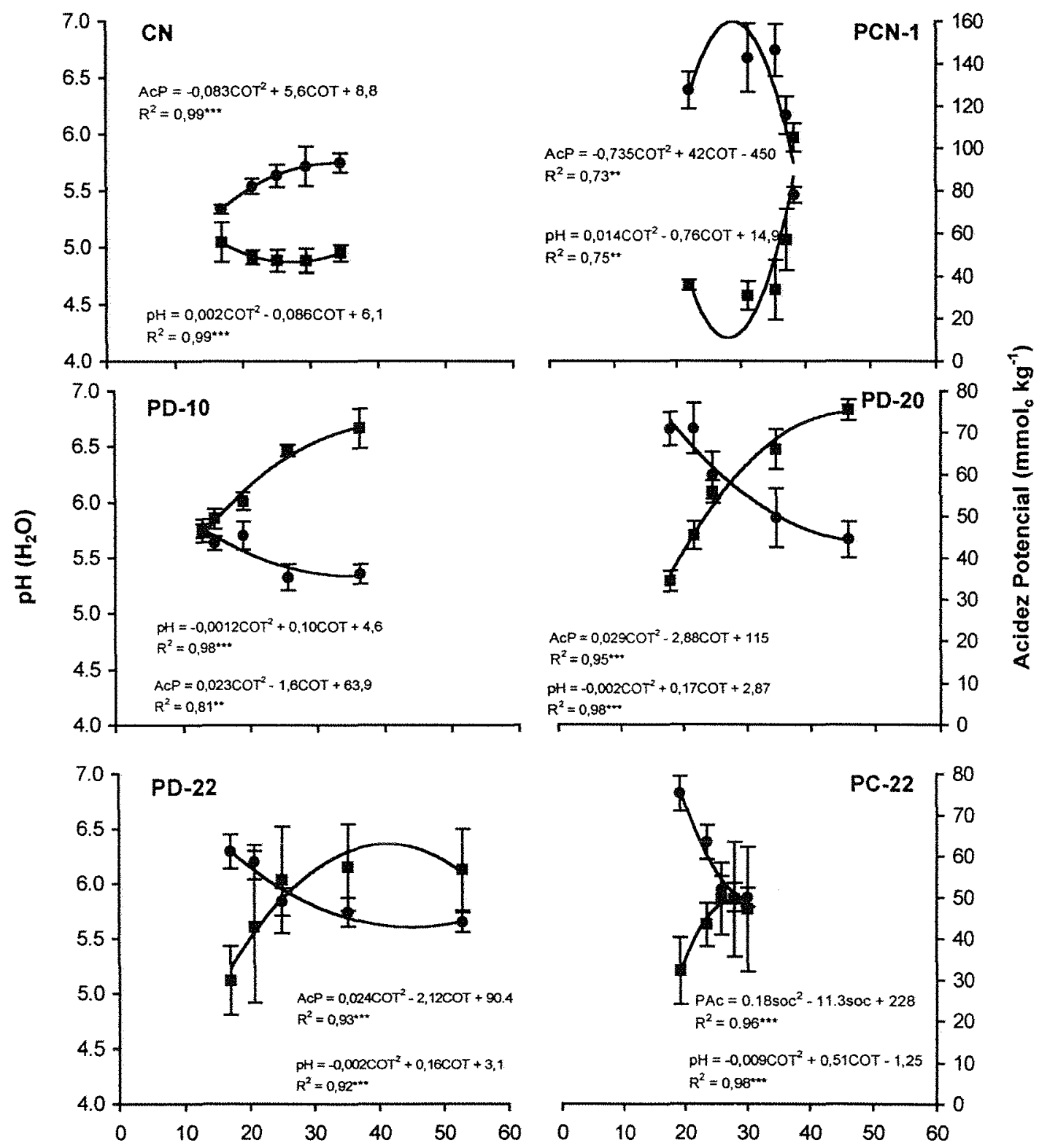

$\cot \left(\mathrm{g} \mathrm{kg}^{-1}\right)$

Figura 15. Análise de regressão entre o carbono orgânico (COT) e $\mathrm{pH}\left(\mathrm{H}_{2} \mathrm{O}\right)$ e acidez potencial (AcP) em cada tratamento. As barras referem-se ao desvio padrão da média. 
Além disso, nesta situação os ácidos fúlvicos podem se comportar como doadores de prótons. Ao contrário, nos tratamentos PCN-1 e PC-22 a incorporação de calcário elevou o $\mathrm{pH}$ e as bases trocáveis, reduzindo a acidez potencial. $\mathrm{O} \mathrm{pH}$ e a acidez potencial no PCN-1 foram afetados diferentemente pelo COT em relação aos demais tratamentos exceto no PC-22. O aumento do COT inicialmente elevou a acidez potencial e a partir $30 \mathrm{~g} \mathrm{~kg}^{-1}$ de $\mathrm{C}$ reduziu abruptamente. A comparação entre os tratamentos PCN-1 e CN, indicou que o pH do solo aumentou quando o conteúdo de $\mathrm{C}$ variou de 22,0 para $38,4 \mathrm{~g} \mathrm{~kg}^{-1}$ e a acidez potencial reduziu significativamente de 14,6 para 7,8 $\mathrm{cmol}_{\mathrm{c}} \mathrm{kg}^{-1}$. Esse decréscimo foi provavelmente devido ao efeito da reação do calcário e do deslocamento do $\mathrm{Al}^{3+}$ dos sítios de troca e consequentemente ocupação pelas bases trocáveis $\left(\mathrm{Ca}^{2+}, \mathrm{Mg}^{2+} \mathrm{e} \mathrm{K}^{+}\right)$.

A resposta dos tratamentos PD-10, PD-20 e PD-22 foram significativamente diferentes do PC-22. Nas camadas superficiais $(0-2,5 \mathrm{~cm} ; 2,5-5 \mathrm{~cm}$ e $5-10 \mathrm{~cm}$ de profundidade) o $\mathrm{pH}$ aumentou e a acidez potencial reduziu, com diferenças significativas $(p<0,05)$ entre si.

Nos tratamentos sob plantio direto, o efeito do COT sobre o $\mathrm{pH}$ foi significativo $(\mathrm{p}<0,05)$ e a variação no $\mathrm{pH}$ em relação ao COT apresentou uma tendência quadrática formando faixas de $\mathrm{pH}$ variando de 5,72 a 6,66 no PD-10, 5,29 a 6,83 no PD-20 e de 5,12 a 6,13 no PD-22 (Figura 15). Essas faixas de pH quando comparadas ao tratamento $\mathrm{CN}$, apresentaram diferença significativa $(\mathrm{p}<0,05)$ porque o $\mathrm{pH}$ nesse tratamento não variou com a profundidade.

O coeficiente de correlação de Pearson (Tabela 13) entre a acidez potencial e o $\mathrm{pH}\left(\mathrm{em} \mathrm{H}_{2} \mathrm{O}\right)$ para todos os tratamentos $(\mathrm{n}=150)$ e dentro de cada tratamento $(\mathrm{n}=25)$ foi altamente significativo ( $\mathrm{p}<0,01 \mathrm{e} p<0,001)$. Embora o coeficiente de correlação de Pearson entre esses atributos tenha sido significativo $(\mathrm{p}<0,05)$ no tratamento $\mathrm{CN}$ (Tabela 13), isto não reflete o efeito de interação entre esses atributos observados nos tratamentos com PD (Figura 15). A baixa fertilidade natural associada a elevada acidez e conteúdo de $\mathrm{Al}^{3+}$, inerente aos campos nativos dessa região, podem ser as razões da diferença entre o CN e os tratamentos com PD (Uehara \& Keng, 1975). 
Tabela 13. Coeficiente de correlação de Pearson entre a acidez potencial (AcP) e o $\mathrm{pHH}_{2} \mathrm{O}$ e CTC (total e efetiva), COT e $\Delta \mathrm{pH}, \mathrm{CTC}$ e $\Delta \mathrm{pH}, \Delta \mathrm{pH}$ e saturação por bases (V\%), CTC e V\%, envolvendo todos os dados $(n=150)$ e dentro de cada tratamento $(n=25)$ da cronossequência.

\begin{tabular}{|c|c|c|c|c|c|c|c|}
\hline \multirow[t]{2}{*}{ Parâmetros } & \multirow{2}{*}{$\begin{array}{l}\text { Todos } \\
\text { dados }\end{array}$} & \multicolumn{6}{|c|}{ Sistemas de manejo do solo ${ }^{\S}$} \\
\hline & & NF & PNF & NT-10 & NT-20 & NT-22 & CT -22 \\
\hline $\mathrm{AcP} \times \mathrm{pH}$ & $-0,80^{* * *}$ & $-0,37^{*}$ & $-0,91^{* * *}$ & $-0,88^{* * *}$ & $-0,92^{* * *}$ & $-0,62^{* * *}$ & $-0,41^{*}$ \\
\hline AcP $\times$ CTC & $0,08^{\mathrm{NS}}$ & $0,95^{* * *}$ & $-0,69^{* *}$ & $-0,70^{* *}$ & $-0,79^{* * *}$ & $-0,83^{* * *}$ & $-0,88^{* * *}$ \\
\hline AcP $x$ CTCe & $-0,43^{* * *}$ & $0,66^{* * *}$ & $-0,82^{* * *}$ & $-0,75^{* *}$ & $-0,85^{* * *}$ & $-0,90^{* * *}$ & $-0,95^{* * *}$ \\
\hline $\mathrm{COT} \times \Delta \mathrm{pH}$ & $0,58^{* * *}$ & $0,15^{\mathrm{NS}}$ & $-0,08^{\mathrm{NS}}$ & $0,90^{* * *}$ & $0,81^{* *}$ & $0,79^{* *}$ & $0,78^{* *}$ \\
\hline$\triangle \mathrm{pH} \times \mathrm{CTC}$ & $0,41^{* *}$ & $0,13^{\mathrm{NS}}$ & $-0,16^{\mathrm{NS}}$ & $0,82^{* * *}$ & $0,73^{\cdots *}$ & $0,69^{* *}$ & $0,73^{* * *}$ \\
\hline$\triangle \mathrm{pH} \times \mathrm{CTCe}$ & $0,45^{* *}$ & $-0,07^{\mathrm{NS}}$ & $-0,18^{\mathrm{NS}}$ & $0,84^{* * *}$ & $0,77^{* * *}$ & $0,71^{* *}$ & $0,74^{* * *}$ \\
\hline$\Delta \mathrm{pH} \times \mathrm{V} \%$ & $0,51^{* *}$ & $0,09^{\mathrm{Ns}}$ & $-0,08^{\mathrm{NS}}$ & $0,92^{* * *}$ & $0,86^{* *}$ & $0,62^{* *}$ & $0,71^{* * *}$ \\
\hline CTC $\times$ V\% & $0,47^{* *}$ & $0,79^{* *}$ & $0,86^{* * *}$ & $0,85^{* *}$ & $0,84^{* * *}$ & $0,94^{* * *}$ & $0,96^{* *}$ \\
\hline
\end{tabular}

F Todos os dados de cada variável ( 6 tratamentos de uso da terra $\times 5$ profundidades $\times 5$ repetições, $\mathrm{n}=150) ;{ }^{\S}$ Refere-se às 5 profundidades de amostragem $\times 5$ repetições, $\mathrm{n}=$ $25) ;{ }^{N}, *, * *, * * *$, refere-se ao nível de significância para o teste-t em $\mathrm{p}<0,05 ; \mathrm{p}<0,01$ e p $<0,001$, respectivamente.

O coeficiente de correlação de Pearson entre a acidez potencial e a CTC (total e efetiva) foi positivo no tratamento $\mathrm{CN}$ e negativo nos demais (Tabela 13). Essa tendência no coeficiente de correlação mostra que a conversão da vegetação natural em sistemas agrícolas com a adoção e manutenção do plantio direto por longo período altera o tipo de cátion ligante nos sítios de troca. Essa alteração é fruto do deslocamento do $\mathrm{Al}^{3+} \mathrm{e} \mathrm{H}^{+}$ por bases trocáveis e a CTC efetiva é a indicação do aumento da carga líquida negativa. Por sua vez, esses sítios de carga estão ocupados pelas bases trocáveis provenientes da melhoria do sistema: calagem, não revolvimento do solo, retorno dos resíduos culturais e ciclagem de bases trocáveis.

A comparação dos valores de $\mathrm{pH}\left(\mathrm{H}_{2} \mathrm{O}\right)$ entre os tratamentos PD-22 e PC-22 (Figura 16), revelou aumento significativo do $\mathrm{pH}$ na camada superficial do PD-22 em relação ao PC-22. 


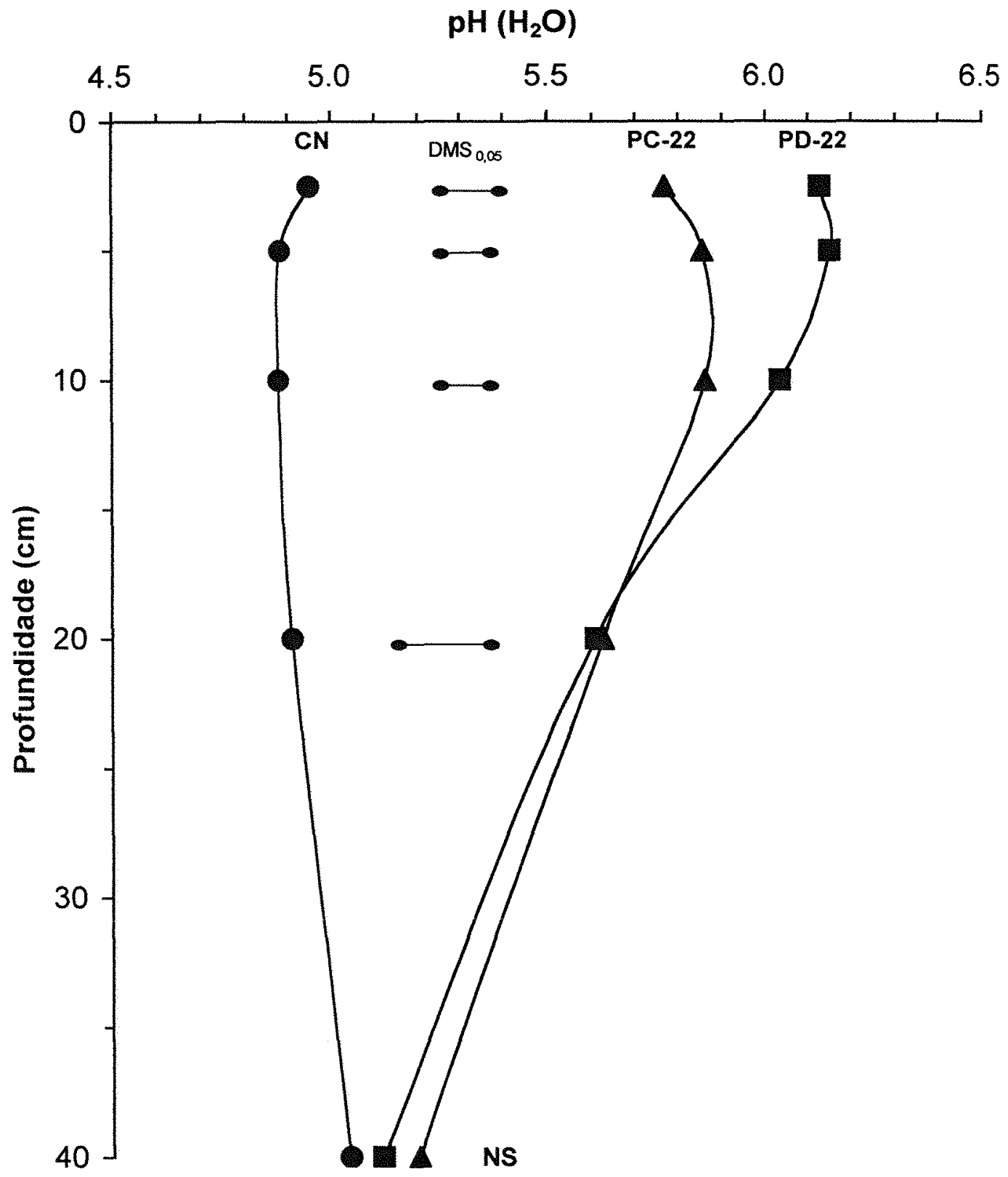

Figura 16. Variação do $\mathrm{pH}\left(\mathrm{H}_{2} \mathrm{O}\right)$ entre os tratamentos: campo nativo $(\mathrm{CN})$, plantio direto há 22 anos (PD-22) e o preparo convencional há 22 anos (PC-22) no perfil amostrado. As barras referem-se a diferença mínima significativa $\left(\mathrm{DMS}_{0,05}\right)$ para a comparação das médias entre os tratamentos em cada profundidade pelo teste de Tukey ao nível de $5 \%$ de probabilidade. 
Esses resultados diferem daqueles reportados por Dick (1983) em condições de clima temperado, quando o autor afirmou que o PD causou um decréscimo significativo no pH da camada superficial comparado ao PC. De acordo com Blevins et al. (1977), no plantio direto há uma acidificação superficial acentuada devido principalmente a nitrificação causada pela elevada taxa de fertilizante nitrogenado aplicada na cultura de milho.

Por outro lado, em Oxisols o pH e a saturação por bases decrescem enquanto o $\mathrm{Al}^{3+}$ aumenta com a profundidade do solo. Sidiras \& Pavan (1985) constataram em solos do Estado do Paraná, com valores originais de $\mathrm{pH}$ acima de 5,5 maior acidez no preparo convencional do que no plantio direto, tanto na camada superficial quanto ao longo do perfil. Nesse caso foi atribuído ao preparo convencional a ação mais intensa dos agentes de decomposição dos resíduos orgânicos, devido a incorporação ao solo, proporcionando maior superfície de contato entre ambos e liberando maior quantidade de grupos fenólicos e carboxilicos. Essa diferença foi atribuída aos seguintes fatores: a) teor de água mais favorável ao PD comparado ao PC, proporcionando a diluição dos ácidos na solução do solo; b) a taxa de mineralização no PD é lenta e gradual comparada ao $\mathrm{PC}$ e conseqüentemente libera menor quantidade de grupos fenólicos e carboxílicos. Todavia, essas causas não são suficientes para explicar essas alterações em camadas mais profundas no perfil, porque o conteúdo de MOS é similar em ambos sistemas de manejo do solo.

Por outro lado, a mineralização dos resíduos culturais mantidos na superficie do solo no PD resulta na liberação de diversos compostos orgânicos que formam ligações com $\mathrm{Al}^{3+}$, estabilizando o $\mathrm{pH}$ do solo. Oades et al. (1989) explicou que as interações entre moléculas orgânicas de baixo peso molecular e colóides com predominância de carga variável, são resultado da ação de forças eletrostáticas, troca de ligantes e pontes de hidrogênio. Dessa forma, a reação de troca entre ânions orgânicos, ligantes e os pontos de carga de $\mathrm{OH}-$ nos óxidos de $\mathrm{Fe}$ e $\mathrm{Al}$, tem sido sugerido como a principal razão do aumento do $\mathrm{pH}$ pela mineralização dos resíduos culturais. Esses argumentos são suportados por Franchini et al. (1999) para um Oxisol do Estado do Paraná, com elevado conteúdo de $\mathrm{Al}^{3+}$ e baixo $\mathrm{pH}$. Observaram, após 90 dias de incubação com 
diferentes resíduos culturais, a elevação do $\mathrm{pH}\left(0,01 \mathrm{M} \mathrm{CaCl}_{2}\right.$ e $\left.\mathrm{H}_{2} \mathrm{O}\right)$ em 2,1 a 2,4 unidades sob nabo forrageiro (Raphanus sativus), 1,9 a 2,6 unidades sob soja e 0,2 a 0,4 unidades de $\mathrm{pH}$ sob trigo. $\mathrm{O}$ conteúdo de $\mathrm{Al}^{3+}$ reduziu em todos os tratamentos com resíduo cultural.

As observações de Pierre \& Banwart (1973), vêm corroborar com os resultados acima citados, reportando a capacidade de algumas plantas de manter elevado conteúdo de cátions trocáveis, para manter a eletroneutralidade no tecido da célula vegetal. Adionalmente, Heylar (1991) observou que algumas leguminosas, (Leucena spp., por examplo), contém concentração de ânions orgânicos expressivamente superior (1000 a $1500 \mathrm{mmol}_{\mathrm{c}} \mathrm{kg}^{-1}$ ) aos encontradas em trigo (50 a $100 \mathrm{mmol}_{\mathrm{c}} \mathrm{kg}^{-1}$ ). Conseqüentemente, cátions básicos acumulam nessas plantas para formar pares cation-ânion. Desta forma, estas plantas promovem o retorno de grande quantidade de resíduos culturais na superfície do solo no PD com elevada concentração de bases trocáveis. Nesse estudo, a quantidade total de resíduos culturais que retornaram nos tratamentos sob plantio direto foi expressiva: 91,5 $\mathrm{Mg} \mathrm{ha}^{-1}$ no PD-10, 177,3 $\mathrm{Mg} \mathrm{ha}^{-1}$ no PD-20 e 167,4 $\mathrm{Mg}^{-1}$ no PD22 (Tabela 3, cap.3, p.36).

As análises de regressão (Figura 15) entre o COT como variável independente e a acidez potencial e o $\mathrm{pH}$ como variáveis dependentes, mostraram um relacionamento significativo, evidenciando a influência dos resíduos culturais nesses parâmetros.

\subsubsection{Alteração do $\triangle \mathrm{pH}$, da CTC (total e efetiva) e da saturação por bases na cronossequência afetados pelo carbono orgânico do solo}

As alterações no COT na cronossequência resultaram no aumento das cargas negativas (avaliadas pelo $\triangle \mathrm{pH}$, CTC total e efetiva). Ocorreu um aumento significativo do $\Delta \mathrm{pH}$ nas camadas superficiais $(0-2,5$ e $2,5-5 \mathrm{~cm}$ de profundidade) de todos os tratamentos (exceto $\mathrm{PCN}-1$ ) quando comparados ao $\mathrm{CN}$. Esse resultado evidencia o papel fundamental dos resíduos culturais afetando o COT e o $\Delta \mathrm{pH}$. 
O coeficiente de correlação de Pearson entre COT e $\Delta \mathrm{pH}, \mathrm{CTC}$ (total e efetiva) e $\Delta \mathrm{pH}$, saturação por bases ( $\mathrm{V} \%)$ e $\Delta \mathrm{pH}, \mathrm{CTC}$ efetiva e $\mathrm{V} \%$, com todos os dados $(\mathrm{n}=$ $150)$ e dentro de cada tratamento $(n=25)$ diferiu entre os tratamentos (Tabela 13). No tratamento $\mathrm{CN}$, o baixo coeficiente de correlação entre $\mathrm{COT}$ e $\Delta \mathrm{pH}$, indicou que estas variáveis não se relacionam entre si. Isto sugere que as cargas negativas líquidas neste tratamento podem ser devidas a liberação de grupos carboxílicos e fenólicos no processo de mineralização no campo nativo e aos minerais de argila associados com a MOS. Entretanto, nos tratamentos sob plantio direto e no CT-22, o elevado coeficiente de correlação entre o $\triangle \mathrm{pH}$ a CTC (total e efetiva) e a saturação por bases mostra que estas variáveis são controladas pelo nível de acidez.

No tratamento PCN-1, a conversão da vegetação natural em agricultura resultou no aumento do COT, embora não tenha alterado os valores de $\Delta \mathrm{pH}$ até $20 \mathrm{~cm}$ (Tabela 12). Todavia, foram superiores ao tratamento $\mathrm{CN}$ e inferiores aos demais, indicando que a calagem associada ao preparo do solo durante um ano e seis meses antes da amostragem, pode ser a principal causa desses valores mais elevados. Esses argumentos podem ser respaldados pelo elevado coeficiente de correlação entre a CTC efetiva e a saturação por bases (Tabela 13).

$\mathrm{O}$ coeficiente de correlação de Pearson entre as variáveis COT e $\Delta \mathrm{pH}, \Delta \mathrm{pH}$ e CTC (total e efetiva), $\Delta \mathrm{pH}$ e V\% (Tabela 13) envolvendo todos valores de cada tratamento $(\mathrm{n}=150)$ foi significativo. Mesmo assim, observou-se comportamento contrastante dentro dos tratamentos. Enquanto os coeficientes de correlação nos tratamentos $\mathrm{CN}$ e PCN-1 foram baixos e não significativos, o contrário ocorreu com os tratamentos sob PD (Tabela 13). Isto indica que o estreito relacionamento entre os resíduos culturais e esses parâmetros está condicionado ao aumento do COT e à liberação de elevadas quantidades de ácidos orgânicos (Franchini et al., 1999). Dessa forma, a mineralização dos resíduos culturais estimulados pela melhoria da fertilidade do solo, eleva a unidade de carga por unidade de C resultando em aumento da CTC. Esse argumento é amparado pela figura 17, que mostra o aumento da CTC nos tratamentos acompanhado pelo aumento na saturação por bases. 
- COT $\times$ CTC
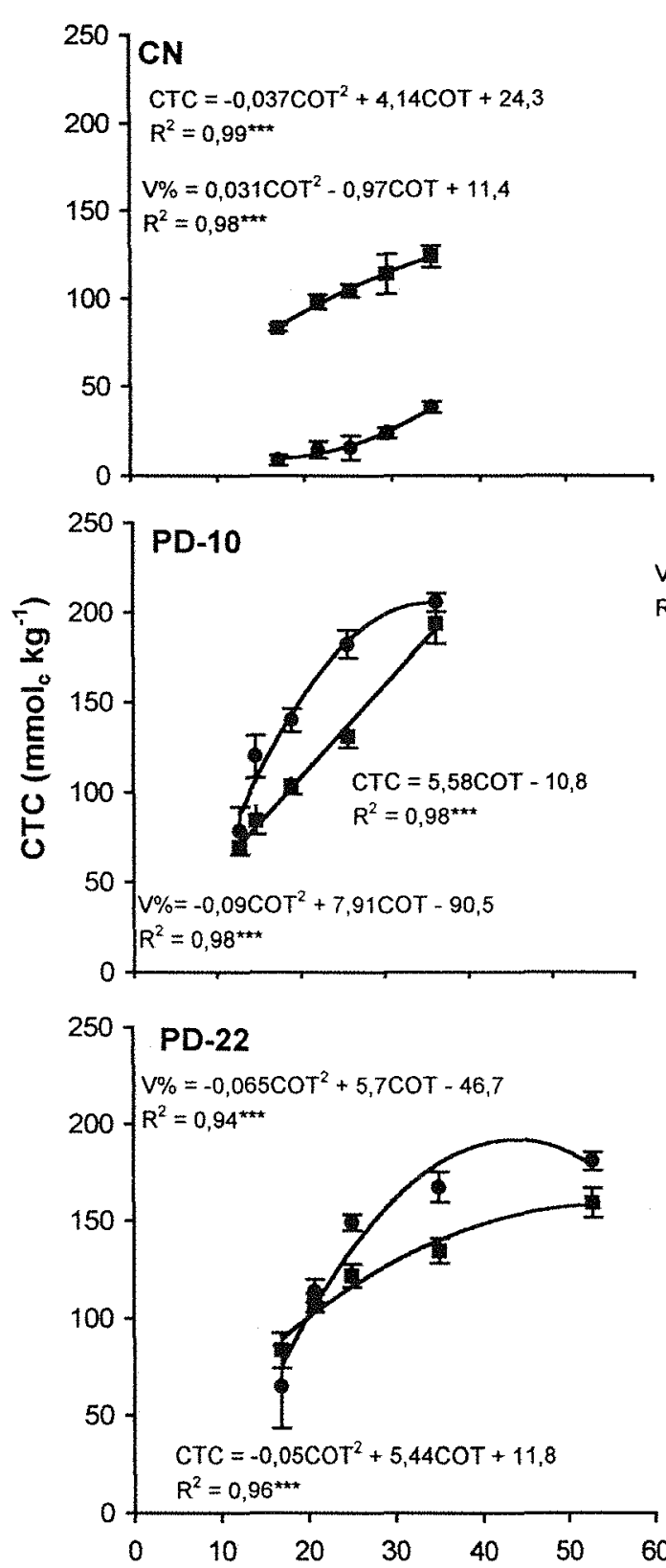

- $\operatorname{coT} \times \mathrm{V} \%$


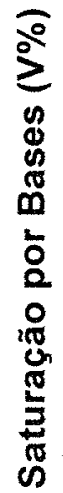

\section{$\cot \left(\mathrm{g} \mathrm{kg}^{-1}\right)$}

Figura 17. Análise de regressão entre o carbono orgânico total (COT) e a capacidade de troca de cátions (CTC) e a saturação por bases (V\%) em cada tratamento. As barras referem-se ao desvio padrão da média. 
A análise de regressão entre o COT e a CTC demonstrou elevada afinidade entre esses parâmetros (Eq. 4):

$$
\text { CTC }\left(\text { mmol }_{c} \mathrm{~kg}^{-1}\right)=37,2+3,19(\mathrm{COT}) \quad\left(\mathrm{R}^{2}=0,72^{* * *}\right)
$$

Pode-se afirmar que o aumento em $1 \mathrm{~g}$ de $\mathrm{C}$ orgânico para cada $\mathrm{kg}$ de solo aumentará a CTC em 3,19 mmol $_{\text {c }}$. Considerando que o aumento no conteúdo COT nos tratamentos sob PD restringiu-se à camada de $0-5 \mathrm{~cm}$, a taxa anual de COT foi de $0,77 \mathrm{~g}$ $\mathrm{kg}^{-1}$ e $0,32 \mathrm{~g} \mathrm{~kg}^{-1}$ para a camada de $0-2,5 \mathrm{~cm}$ e $2,5-5 \mathrm{~cm}$ de profundidade, respectivamente. A contribuição anual do plantio direto na CTC foi estimada em 2,48 mmol $_{\mathrm{c}}$ e 1,02 mmol $_{\mathrm{c}} \mathrm{kg}^{-1}$ de solo nas camadas de $0-2,5 \mathrm{~cm}$ e $2,5-5 \mathrm{~cm}$, respectivamente. Embora expressiva essa contribuição foi inferior aos resultados obtidos por Burle et al. (1997) na região sul do Brasil.

\subsubsection{Dinâmica do fósforo e do potássio na cronossequência afetada pelo carbono orgânico do solo}

Aumentos significativos ocorreram no $\mathrm{P}$ e no $\mathrm{K}$ nos tratamentos sob plantio direto comparados ao $\mathrm{CN}$ e PC-22 nas camadas de 0-2,5 e 2,5-5 cm de profundidade (Figura 18a e 18b). Por outro lado, abaixo de $20 \mathrm{~cm}$ não houve diferença entre os tratamentos. O tratamento PD-22 apresentou os maiores incrementos destes elementos na camada de 0-2,5 cm de profundidade possivelmente devido à aplicação do esterco líquido de bovino nos dois anos que antecederam à amostragem. Também se observou maior conteúdo de $\mathrm{K}$ nos tratamentos sob PD do que nos tratamentos sob $\mathrm{CN}$ e PC-22.

No PCN-1, o aumento de $\mathrm{P}$ pode ser devido a uma combinação de efeitos tais como a aplicação de calcário resultando na neutralização do $\mathrm{Al}$ trocável e no aumento do $\mathrm{pH}$, a aplicação de adubo fosfatado e à ciclagem de $\mathrm{P}$ pela decomposição do material orgânico fresco durante a fase de conversão da vegetação natural. Em relação ao $\mathrm{K}$, a principal razão pode estar relacionada com a sua rápida liberação durante a decomposição dos resíduos orgânicos por não ser um componente estrutural de compostos orgânicos. 

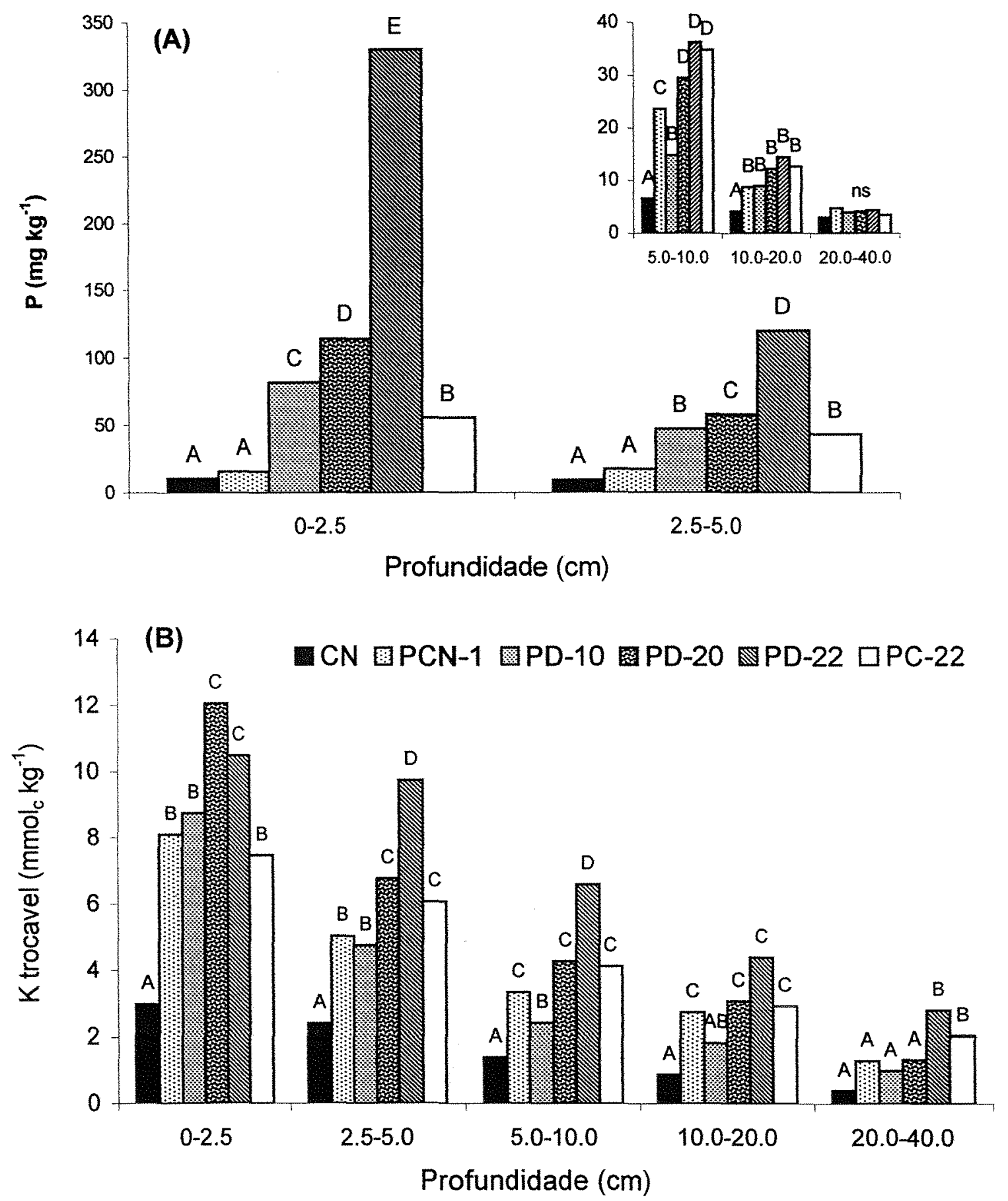

Figura 18. Alterações no conteúdo de $\mathrm{P}$ (A) e $\mathrm{K}$ trocável (B) na cronossequência. As letras referem-se a comparação das médias pelo teste de Tukey ao nível de $5 \%$ de probabilidade entre os tratamentos em cada profundidade amostrada. 
No tratamento PC-22, embora o conteúdo de $\mathrm{P}$ tenha sido muito inferior aos tratamentos sob $\mathrm{PD}$, foi significativamente superior $(\mathrm{p}<0,01)$ aos tratamentos $\mathrm{CN}$ e PCN-1 até $10 \mathrm{~cm}$ de profundidade da camada superficial.

Embora o conteúdo de P na camada superficial dos tratamentos sob PD tenha sido muito superior aos encontrados no $\mathrm{CN}$ e $\mathrm{PCN}-1$, esse incremento não pode ser explicado somente pela quantidade de fertilizante e esterco aplicado.O conteúdo mais elevado de $\mathrm{P}$ nos tratamentos sob PD pode ser atribuído: a) à redução do contato entre os colóides e o íon fosfato devido ao não revolvimento do solo, amenizando as reações de adsorção; b) ao efeito do COT nos sítios de carga minimizando as reações de adsorção e mantendo o $\mathrm{P}$ em forma disponível; c) à mineralização lenta e gradual dos resíduos proporcionando a liberação e redistribuição de formas orgânicas de $\mathrm{P}$ menos susceptíveis às reações de adsorção. $\mathrm{O}$ aumento no COT nos tratamentos sob PD apresentou forte correlação com o $\mathrm{P}$ respaldando essa observação $\left(\mathrm{r}=0.95^{* * *}, \mathrm{r}=\right.$ $0.94^{* * *}, \mathrm{r}=0.97^{* * *}$, para PD-10, PD-20 e PD-22, respectivamente). No PD, o aumento no $\mathrm{P}$ orgânico tem sido freqüentemente citado como o principal fator que regula a disponibilidade de P. Sá (1999) observou em um oxisol similar no Estado do Paraná estreita correlação entre o COT e o $\mathrm{P}$ orgânico $\left(\mathrm{r}=0,66^{* * *}, \mathrm{r}=25\right)$ e entre o COT e o $\mathrm{P}$ extraível pela solução Mehlich $1\left(\mathrm{r}=0,75^{* * *}, \mathrm{n}=25\right)$, sugerindo que o $\mathrm{P}$ orgânico e o P disponível estão fortemente ligados.

Análise de regressão entre o COT mostrou o estreito relacionamento dessas variáveis (Eq. 5):

$$
\mathrm{P}\left(\mathrm{mg} \mathrm{kg}^{-1}\right)=94,3-9,11(\mathrm{SOC})+0,24(\mathrm{SOC})^{2} \quad\left(\mathrm{R}^{2}=0,85^{* * *}\right)
$$

$\mathrm{O}$ conteúdo de $\mathrm{K}$ foi significativamente superior $(\mathrm{p}<0,01)$ aos encontrados nos tratamentos $\mathrm{CN}, \mathrm{PCN}-1$ e CT-22 em todas as profundidades, provavelmente devido ao impacto da elevada quantidade de resíduos culturais retornados nos tratamentos a longo período sob $\mathrm{PD}$. Em geral, 65 a $75 \%$ do $\mathrm{K}$ extraído pela planta retorna via resíduo cultural, tornando-se uma importante fonte para a cultura subseqüente. A análise de regressão mostrou estreito relacionamento entre o COT e o K (Eq. 6).

$$
\mathrm{K}\left(\mathrm{mmol}_{\mathrm{c}} \mathrm{kg}^{-1}\right)=-2,93+0,27(\mathrm{SOC}) \quad\left(\mathrm{R}^{2}=0,65^{* * *}\right)
$$


A taxa de ganho de $\mathrm{P}$ e $\mathrm{K}$ nos tratamentos sob $\mathrm{PD}$ para cada profundidade amostrada é apresentada na tabela 14.

Tabela 14. Equações de regressão entre o tempo de adoção do PD (anos) como variável independente e a quantidade de $\mathrm{P}$ e $\mathrm{K},\left(\mathrm{kg} \mathrm{ha}^{-1}\right)$, coeficiente de determinação $\left(\mathrm{R}^{2}\right)$, nível de significância e taxas anuais de retorno ${ }^{\S}$ cada profundidade amostrada.

\begin{tabular}{|c|c|c|c|c|c|}
\hline Nutriente & Prof. & Equação ${ }^{\ddagger}$ & $\mathrm{R}^{2}$ & $\begin{array}{c}\text { Nível de } \\
\text { significância }\end{array}$ & $\begin{array}{c}\text { Taxa } \\
(\mathrm{dy} / \mathrm{dx})^{\ddagger \dagger \ddagger}\end{array}$ \\
\hline & $\mathrm{cm}$ & & & & $\mathrm{kg} \mathrm{ha}^{-1}$ ano $^{-1}$ \\
\hline \multirow[t]{5}{*}{$\mathbf{P}$} & $0-2,5$ & $P=2,4+5$, lano $-0,133 \mathrm{ano}^{2}$ & 0,99 & $* * *$ & 5,08 \\
\hline & $2,5-5$ & $P=3,33+3,57$ ano $-0,12 \mathrm{ano}^{2}$ & 0,99 & $* * *$ & 3,56 \\
\hline & $5-10$ & $\mathrm{P}=8,24+1,018 \mathrm{ano}$ & 0,89 & ** & 1,02 \\
\hline & $10-20$ & $P=11,6+0,618$ ano & 0,43 & NS & 0,62 \\
\hline & $20-40$ & $\mathrm{P}=8,83+1,29$ ano $-0,06 \mathrm{ano}^{2}$ & 0,98 & $* * *$ & 1,28 \\
\hline \multirow[t]{5}{*}{$\mathbf{K}$} & $0-2,5$ & $\mathrm{~K}=58,1+9,1$ ano $-0,225 \mathrm{ano}^{2}$ & 0,86 & ** & 9,04 \\
\hline & $2,5-5$ & $\mathrm{~K}=38,7+3,99$ ano & 0,79 & $* *$ & 3,99 \\
\hline & $5-10$ & $\mathrm{~K}=42,2+4,9 \mathrm{ano}$ & 0,82 & $* *$ & 4,90 \\
\hline & $10-20$ & $\mathrm{~K}=68,1+5,65$ ano & 0,76 & ** & 5,65 \\
\hline & $20-40$ & $K=60,5+6,58$ ano & 0,63 & $*$ & 6,58 \\
\hline
\end{tabular}

Modelo de equação selecionado pelo procedimento de stepwise

$\ddagger$ NS, *, **, ***, refere-se ao nível de significância do test-t para: $\mathrm{NS}=$ não significativo, $\mathrm{p}=0,05, \mathrm{p}=0,01$, e $\mathrm{p}<0,001$

¥¥ A taxa anual foi obtida através da tangente do coeficiente angular ( $\mathrm{dy} / \mathrm{dx}$ ) da equação $\S \mathrm{P}=$ Fósforo, $\mathrm{kg} \mathrm{ha}^{-1} ; \mathrm{K}=$ potássio, $\mathrm{kg} \mathrm{ha}^{-1}$;

Comparando o acúmulo de $\mathrm{P}$ e $\mathrm{K}$ na camada de 0 a $10 \mathrm{~cm}$ de profundidade nos tratamentos sob PD tendo o campo nativo como o ponto de referencia, a taxa anual de incremento de $\mathrm{P}$ foi de $9,66 \mathrm{~kg} \mathrm{ha}^{-1}$ ano $^{-1}$ e $17,93 \mathrm{~kg} \mathrm{ha}^{-1}$ ano $^{-1}$ para $\mathrm{K}$. A taxa de incremento de $\mathrm{K}$ foi mais elevada do que $\mathrm{P}$, indicando que o aumento de COT na cronossequência aumentou a CTC que conduziu para uma maior retenção de $\mathrm{K}$ e das outras bases trocáveis. 


\subsection{CONCLUSÕES}

$\mathrm{O}$ aumento do conteúdo de carbono orgânico na cronossequência reduziu a acidez potencial, aumentou o $\mathrm{pH}$ e as cargas negativas avaliadas pelo $\Delta \mathrm{pH}$. $\mathrm{O}$ aumento na CTC foi atribuído ao aumento nas cargas negativas e ambas variáveis apresentaram estreita correlação com a saturação por bases. A CTC aumentou em $3,19 \mathrm{mmolc} \mathrm{kg}^{-1}$ para cada $1 \mathrm{~g}$ de $\mathrm{C} \mathrm{kg}^{-1}$ de solo $\mathrm{O}$ impacto do COT no $\mathrm{P}$ e $\mathrm{K}$ foi demonstrado pela estreita afinidade nas equações de regressão com essas variáveis. Esses dados suportam a conclusão de que o plantio direto a longo período é uma ferramenta eficiente para a melhoria da fertilidade de solos com carga variável. 


\section{CONCLUSÕES GERAIS}

A conversão da vegetação natural em área cultivada e a adoção do plantio direto tiveram efeitos significativos no conteúdo e no reservatório de $\mathrm{C}$ e $\mathrm{N}$ do solo. $\mathrm{O}$ plantio direto associado ao retorno de resíduos culturais aumentou significativamente o conteúdo e o estoque de carbono orgânico e $\mathrm{N}$ total nos primeiros $10 \mathrm{~cm}$ de profundidade. $\mathrm{O}$ impacto desse aumento foi avaliado em atributos que interferem em diferentes compartimentos da matéria orgânica, na reação da biomassa microbiana e na fertilidade do solo.

Do ponto de vista da quantificação dos ganhos $e$ perdas $e$ da compartimentalização da matéria orgânica do solo, 57,9 a $81,8 \%$ do ganho em COT nos tratamentos sob plantio direto (NT-10, NT-20 e NT-22) comparado ao campo nativo (NF) ocorreram nos primeiros $10 \mathrm{~cm}$. A mesma tendência foi observada para o $\mathrm{N}$ total do solo. A análise de regressão entre o COT e o aporte de resíduos culturais revelou estreito relacionamento entre essas duas variáveis $\left(R^{2}=0,74 ; p<0,05\right)$. Em contraste, 97\% das perdas do COT no preparo convencional (CT-22) também ocorreram nesta camada. As frações granulométricas mais afetadas foram as de $200-2000 \mu \mathrm{m}$ e 53 $200 \mu \mathrm{m}$. Estas representam as frações mais grosseiras, de maior relação C:N e MOS mais recente. A contribuição dos resíduos culturais no COT nos tratamentos sob plantio direto variou entre 52,8 a $100 \%$ na camada de $0-2,5 \mathrm{~cm} ; 55,7$ a $78,4 \%$ na camada de 2,5 a $5 \mathrm{~cm}$ e 32,9 a $96,8 \%$ na camada de $5-10 \mathrm{~cm}$. Embora os valores mais elevados tenham ocorrido nas frações mais grosseiras $(200-2000 \mu \mathrm{m}$ e 53-200 $\mu \mathrm{m})$, a concentração de COT foi inversamente proporcional, indicando duas situações distintas: a) a grande contribuição dos resíduos culturais nas frações mais grosseiras indica a fase inicial da proteção física da MOS resultante do sistema plantio direto e b) o COT tende a se 
estabilizar nas frações mais finas formando complexos organo-siltosos e organoargilosos.

O comportamento da biomassa microbiana e dos componentes da MOS foi significativamente afetado pelos tratamentos de uso da terra na cronossequência. A estimativa de $\mathrm{C}$ e $\mathrm{N}$ na biomassa microbiana $\mathrm{C}$ e $\mathrm{N}$ do solo sob o campo nativo foi superior a todos os tratamentos da cronossequência. Entretanto, os valores estimados para o plantio direto foram os que mais se aproximaram da vegetação natural. Também foram constatados maiores quantidades de carbono orgânico dissolvido, polissacarídeos lábeis e totais na camada superficial. Esse enriquecimento limitou-se a camada de 0-2,5 $\mathrm{cm}$ para os polissacarídeos e $5 \mathrm{~cm}$ de profundidade para o carbono orgânico dissolvido. A média dos coeficientes de correlação $(n=150)$ entre a BMC com os componentes orgânicos apresentou a seguinte sequência decrescente de afinidade: carbono orgânico dissolvido $>\mathrm{N}$ total $>$ carbono orgânico total $>$ polissacarídeos lábeis $=$ polissacarídeos totais. Em relação a $\mathrm{BMN}$, a seqüência foi a seguinte: $\mathrm{N}$ total > carbono orgânico dissolvido $>$ carbono orgânico total $>$ polissacarídeos lábeis $>$ polissacarídeos totais.

Do ponto de vista da fertilidade do solo, o aumento do conteúdo de carbono correlacionou positivamente com a elevação do $\mathrm{pH}$ e com as cargas negativas avaliadas pelo $\Delta \mathrm{pH}$ e negativamente com a acidez potencial. Também foi observada correlação positiva e altamente significativa entre o aporte de residuos culturais com o $\Delta \mathrm{pH}$, a CTC e a saturação por bases. No sistema PD, o impacto na relação COT/CTC comparado ao campo nativo foi 2,16 a 2,64 vezes superior.

Alterações significativas ocorreram no conteúdo de $\mathrm{P}$ disponível e $\mathrm{K}$ trocável na camada superficial dos tratamentos de uso da terra sob plantio direto comparado aos demais tratamentos. $\mathrm{O}$ aumento no $\mathrm{P}$ pode ser atribuído: a) à redução do contato entre o íon fosfato e os colóides do solo devido ao não revolvimento do solo, b) ao efeito do carbono nas cargas das partículas do solo mantendo o íon fosfato livremente, e c) à liberação e redistribuição de formas orgânicas de $\mathrm{P}$ mais estáveis e menos susceptíveis às reações de adsorção devido a mineralização lenta e gradual dos resíduos culturais. Por outro lado, o aumento no conteúdo de $\mathrm{K}$ está relacionado à elevação da CTC e ao 
aporte dos resíduos culturais, pelo fato de 65 a $75 \%$ do $\mathrm{K}$ absorvido pelas culturas retornarem como resíduo vegetal.

O modelo ajustado para simular o novo ponto de equilibrio dinâmico de $\mathrm{C}$ com a manutenção do PD e as taxas atuais de aporte de resíduos culturais para a camada de 0$20 \mathrm{~cm}$ de profundidade, estimou um aumento de $\mathrm{C}$ de $47,4 \%$ em relação ao campo nativo após 40 anos de adoção do sistema plantio direto.

Com base nos dados de estoque de $\mathrm{C}$ a taxa de sequestro na camada de 0-40 $\mathrm{cm}$ de profundidade foi estimada em $994 \mathrm{~kg} \mathrm{ha}^{-1}$ ano ${ }^{-1}$ de C. Admitindo esta taxa como um valor potencial para o PD no Brasil e a taxa anual de absorção líquida no ecossistema terrestre de $0,7 \mathrm{Gt}$ de C (IPCC, 2000), a possível contribuição do sistema PD em relação ao sequestro global de $\mathrm{C}$ corresponde a 1,91\%. A maior parte desta absorção terrestre refere-se ao reflorestamento em regiões temperadas. Entretanto uma parte significativa desta taxa é devida a adoção de sistemas conservacionistas, entre os quais se destaca o PD como a melhor alternativa. Considerando somente o sequestro estimado pela agricultura $(0,14 \mathrm{Gt})$ os valores atingiriam $9,56 \%$.

Em resumo, estes resultados permitem afirmar que a manutenção do plantio direto por longo período elevou o conteúdo da MOS a um nível superior ao campo nativo. A elevada contribuição do $\mathrm{C}$ oriundo dos resíduos culturais nas frações granulométricas mais grosseiras é uma indicação da ocorrência de uma proteção da MOS nos macroagregados. A quantidade de $\mathrm{C}$ e $\mathrm{N}$ na biomassa microbiana existente nos tratamentos sob plantio direto, comparado ao preparo convencional, é uma indicação do potencial de retorno destes elementos no sistema PD. Além disso, os valores da relação entre $\mathrm{C}_{\text {mic }}: \mathrm{C}_{\text {org }}$ na camada superficial dos tratamentos $\mathrm{PD}$ indicam que o fluxo de $\mathrm{C}$ está em direção ao sequestro. Da mesma forma, o aumento da fertilidade na camada superficial do solo nos tratamentos sob plantio direto está relacionado com o aumento da MOS. 
ANEXO 
Tabela 15. Densidade do solo (DS), estoque de carbono orgânico total (COT) e nitrogênio total (NT) das camadas amostradas nos sistemas de manejo da cronossequência. Números sobrescritos referem-se ao desvio padrão da média de cinco repetições.

\begin{tabular}{|c|c|c|c|c|c|c|c|}
\hline \multirow[t]{2}{*}{ Variáveis } & \multirow{2}{*}{$\begin{array}{l}\text { Prof. } \\
(\mathrm{cm})\end{array}$} & \multicolumn{6}{|c|}{ Sistemas de manejo } \\
\hline & & $\mathrm{CN}$ & PCN-1 & PD-10 & PD-20 & PD-22 & PC-22 \\
\hline \multirow[t]{5}{*}{$\mathrm{DS}, \mathrm{g} \mathrm{cm}^{-3}$} & $0-2,5$ & $1,23^{ \pm 0,02}$ & $1,18^{ \pm 0,20}$ & $1,40^{ \pm 0,05}$ & $1,33^{ \pm 0,06}$ & $1,42^{ \pm 0,03}$ & $1,23^{ \pm 0,02}$ \\
\hline & $2,5-5$ & $1,22 \pm 0,03$ & $1,22^{ \pm 0,23}$ & $1,53^{ \pm 0,01}$ & $1,41^{ \pm 0,03}$ & $1,60^{ \pm 0,09}$ & $1,19^{ \pm 0,02}$ \\
\hline & $5-10$ & $1,19^{ \pm 0,05}$ & $1,07^{ \pm 0,05}$ & $1,54^{ \pm 0,03}$ & $1,40^{ \pm 0,09}$ & $1,39^{ \pm 0,03}$ & $1,14^{ \pm 0,06}$ \\
\hline & $10-20$ & $1,17^{ \pm 0,05}$ & $1,08^{ \pm 0,04}$ & $1,48^{ \pm 0,03}$ & $1,31^{ \pm 0,06}$ & $1,29^{ \pm 0,09}$ & $1,11^{ \pm 0,02}$ \\
\hline & $20-40$ & $1,18^{ \pm 0,04}$ & $1,05^{ \pm 0,03}$ & $1,42^{ \pm 0,08}$ & $1,23^{ \pm 0,06}$ & $1,23^{ \pm 0,16}$ & $1,06^{ \pm 0,07}$ \\
\hline \multirow[t]{5}{*}{ COT, $\mathrm{g} \mathrm{kg}^{-1}$} & $0-2,5$ & 34,53 & 38,35 & 36,33 & 45,87 & 52,84 & 30,05 \\
\hline & $2,5-5$ & 29,49 & 37,20 & 25,68 & 34,59 & 35,09 & 28,00 \\
\hline & $5-10$ & 25,27 & 35,46 & 18,91 & 24,65 & 25,05 & 25,93 \\
\hline & $10-20$ & 21,57 & 31,15 & 14,55 & 21,63 & 20,73 & 23,54 \\
\hline & $20-40$ & 16,89 & 21,99 & 12,71 & 17,89 & 16,88 & 19,28 \\
\hline \multirow[t]{6}{*}{$\mathrm{COT}, \mathrm{Mg} \mathrm{ha}^{-1}$} & $0-2,5$ & 10,65 & 11,38 & 12,74 & 15,25 & 18,69 & 9,22 \\
\hline & $2,5-5$ & 9,00 & 11,36 & 9,79 & 12,16 & 14,05 & 8,36 \\
\hline & $5-10$ & 14,99 & 18,90 & 14,62 & 17,29 & 17,35 & 14,75 \\
\hline & $10-20$ & 25,16 & 33,42 & 21,51 & 28,31 & 26,65 & 26,22 \\
\hline & $20-40$ & 39,70 & 46,37 & 36,03 & 43,86 & 41,67 & 40,76 \\
\hline & Total & 99,51 & 121,43 & 94,68 & 116,87 & 118,41 & 99,31 \\
\hline \multirow[t]{5}{*}{$\mathrm{NT}, \mathrm{g} \mathrm{kg}^{-1}$} & $0-2,5$ & 2,27 & 2,63 & 3,02 & 3,72 & 4,01 & 2,07 \\
\hline & $2,5-5$ & 1,92 & 2,49 & 2,11 & 2,74 & 2,62 & 1,81 \\
\hline & $5-10$ & 1,59 & 2,29 & 1,44 & 1,78 & 1,69 & 1,59 \\
\hline & $10-20$ & 1,35 & 2,07 & 0,95 & 1,37 & 1,21 & 1,31 \\
\hline & $20-40$ & 1,02 & 1,53 & 0,78 & 1,08 & 0,98 & 1,02 \\
\hline \multirow[t]{6}{*}{$\mathbf{N T}, \mathbf{M g ~ h a} \mathbf{~}^{-1}$} & $0-2,5$ & 0,70 & 0,78 & 1,06 & 1,24 & 1,42 & 0,63 \\
\hline & $2,5-5$ & 0,59 & 0,76 & 0,80 & 0,96 & 1,05 & 0,54 \\
\hline & $5-10$ & 0,94 & 1,22 & 1,11 & 1,25 & 1,17 & 0,90 \\
\hline & $10-20$ & 1,57 & 2,22 & 1,40 & 1,79 & 1,55 & 1,46 \\
\hline & $20-40$ & 2,39 & 3,22 & 2,21 & 2,64 & 2,41 & 2,15 \\
\hline & Total & 6,19 & 8,21 & 6,58 & 7,88 & 7,60 & 5,69 \\
\hline
\end{tabular}


Tabela 16. Relação $\mathrm{C} / \mathrm{N}$ nas frações granulométricas da MOS nos sistemas de manejo da cronossequência em diferentes profundidades.

\begin{tabular}{llllllll}
\hline Prof. & Frações & \multicolumn{6}{c}{ Sistemas de manejo do solo na cronossequência } \\
\cline { 5 - 8 } & Gran. & CN & PCN-1 & PD-10 & PD-20 & PD-22 & PC-22 \\
\hline (cm) & $(\mu \mathrm{m})$ & & \multicolumn{5}{c}{ C/N } \\
$\mathbf{0 - 2 , 5}$ & $200-2000$ & 19,8 & 20,4 & 15,5 & 16,4 & 15,7 & 17,8 \\
& $53-200$ & 17,3 & 17,0 & 14,5 & 14,9 & 13,6 & 16,1 \\
& $20-53$ & 17,3 & 17,5 & 14,7 & 15,4 & 13,6 & 16,0 \\
& $2-20$ & 17,0 & 17,0 & 13,6 & 19,4 & 13,8 & 15,8 \\
& $0-2$ & 15,4 & 15,3 & 12,3 & 12,9 & 12,0 & 13,9 \\
& & & & & & & \\
$\mathbf{2 , 5 - 5}$ & $200-2000$ & 15,7 & 20,7 & 13,2 & 14,4 & 15,5 & 15,2 \\
& $53-200$ & 17,9 & 16,4 & 14,6 & 14,8 & 13,9 & 16,7 \\
& $20-53$ & 18,2 & 16,6 & 13,8 & 15,1 & 14,1 & 16,0 \\
& $2-20$ & 17,1 & 17,1 & 13,7 & 14,8 & 14,5 & 15,7 \\
& $0-2$ & 16,6 & 15,0 & 12,7 & 13,6 & 12,9 & 14,5 \\
& & & & & & & \\
$\mathbf{5 - 1 0}$ & $200-2000$ & 19,4 & 21,9 & 14,0 & 16,7 & 15,0 & 18,5 \\
& $53-200$ & 19,0 & 17,1 & 14,6 & 15,3 & 15,3 & 16,5 \\
& $20-53$ & 19,1 & 16,7 & 14,5 & 16,0 & 16,2 & 16,4 \\
& $2-20$ & 18,0 & 16,7 & 15,0 & 16,2 & 16,4 & 16,3 \\
& $0-2$ & 17,7 & 14,6 & 14,0 & 14,9 & 15,0 & 14,6 \\
& & & & & & & \\
$\mathbf{1 0 - 2 0}$ & $200-2000$ & 21,8 & 19,8 & 19,0 & 15,0 & 17,3 & 18,0 \\
& $53-200$ & 20,2 & 17,3 & 16,7 & 18,4 & 19,0 & 19,7 \\
& $20-53$ & 20,1 & 17,0 & 17,5 & 18,1 & 19,2 & 18,5 \\
& $2-20$ & 18,9 & 16,9 & 16,7 & 18,3 & 19,5 & 18,3 \\
& $0-2$ & 17,8 & 15,4 & 16,2 & 16,9 & 18,3 & 17,0 \\
& & & & & & & \\
$\mathbf{2 0 - 4 0}$ & $200-2000$ & 21,3 & 21,5 & 17,0 & 15,0 & 20,3 & 18,5 \\
& $53-200$ & 21,4 & 18,1 & 18,6 & 18,9 & 20,1 & 20,9 \\
& $20-53$ & 19,2 & 16,8 & 17,8 & 19,3 & 20,5 & 20,9 \\
& $2-20$ & 18,5 & 17,2 & 17,7 & 17,7 & 16,6 & 14,8 \\
& $0-2$ & 18,9 & 15,4 & 17,6 & 17,9 & 18,3 & 18,5 \\
\hline
\end{tabular}


Tabela 17. Porcentagem do COT nas frações granulométricas $>53 \mu \mathrm{m} \mathrm{e}<53 \mu \mathrm{m}$ nos sistemas de manejo da cronossequência em diferentes profundidades.

\begin{tabular}{llcccccc}
\hline Variáveis & $\begin{array}{l}\text { Prof. } \\
\text { (cm) }\end{array}$ & CN & PCN-1 & PD-10 & PD-20 & PD-22 & PC-22 \\
\cline { 3 - 7 } Frações $>\mathbf{5 3} \mu \mathbf{m}$ & $0-2,5$ & 36,8 & 28,8 & 38,0 & 35,0 & 39,0 & 29,2 \\
& $2,5-5$ & 31,6 & 29,6 & 24,3 & 28,3 & 28,7 & 21,9 \\
& $5-10$ & 27,7 & 28,2 & 17,3 & 18,9 & 20,9 & 20,0 \\
& $10-20$ & 25,6 & 26,8 & 14,9 & 16,6 & 21,4 & 23,8 \\
& $20-40$ & 25,0 & 21,7 & 17,0 & 21,4 & 23,6 & 24,3 \\
& Média & 29,3 & 27,0 & 22,3 & 24,0 & 26,8 & 23,9 \\
Frações $<\mathbf{5 3} \mu \mathbf{m}$ & & & & & & & \\
& $0-2,5$ & 63,2 & 71,2 & 62,0 & 65,0 & 61,0 & 70,8 \\
& $2,5-5$ & 68,4 & 70,4 & 75,7 & 71,7 & 71,3 & 78,1 \\
& $5-10$ & 72,3 & 71,8 & 82,7 & 81,1 & 79,1 & 80,0 \\
& $10-20$ & 74,4 & 73,2 & 85,1 & 83,4 & 78,6 & 76,2 \\
& $20-40$ & 75,0 & 78,3 & 83,0 & 78,6 & 76,4 & 75,7 \\
& Média & 70,7 & 73,0 & 77,7 & 76,0 & 73,2 & 76,1 \\
\hline
\end{tabular}


Tabela 18. Conteúdo de $\mathrm{N}$ nas frações granulométricas da MOS em cinco profundidades de amostragem nos sistemas de manejo da cronossequência

\begin{tabular}{|c|c|c|c|c|c|c|c|}
\hline \multirow[t]{2}{*}{ Prof. } & \multirow{2}{*}{$\begin{array}{l}\text { Frações } \\
\text { Gran. }\end{array}$} & \multicolumn{6}{|c|}{ Sistemas de manejo do solo na cronossequência } \\
\hline & & $\mathrm{CN}$ & PCN-1 & PD-10 & PD-20 & PD-22 & PC-22 \\
\hline (cm) & $(\mu \mathrm{m})$ & -........ & - & $-\mathrm{g} \mathrm{kg}^{-1}$ & & 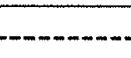 & \\
\hline \multirow[t]{5}{*}{$0-2,5$} & $200-2000$ & 1,3 & 2,5 & 1,3 & 1,6 & 2,5 & 0,9 \\
\hline & $53-200$ & 1,6 & 2,1 & 1,8 & 2,5 & 3,4 & 2,0 \\
\hline & $20-53$ & 2,2 & 1,8 & 3,0 & 3,5 & 5,3 & 3,0 \\
\hline & $2-20$ & 2,7 & 2,2 & 3,3 & 2,5 & 4,1 & 2,5 \\
\hline & $0-2$ & 2,9 & 2,4 & 3,5 & 3,5 & 5,1 & 3,2 \\
\hline \multirow[t]{5}{*}{$2,5-5$} & $200-2000$ & 1,1 & 2,4 & 0,5 & 0,9 & 1,1 & 0,6 \\
\hline & $53-200$ & 1,5 & 2,3 & 1,4 & 1,9 & 2,7 & 1,7 \\
\hline & $20-53$ & 2,0 & 1,9 & 2,8 & 3,0 & 4,1 & 2,7 \\
\hline & $2-20$ & 2,6 & 2,4 & 2,9 & 2,9 & 3,4 & 2,9 \\
\hline & $0-2$ & 2,5 & 2,5 & 3,1 & 3,0 & 4,1 & 2,9 \\
\hline \multirow[t]{5}{*}{$5-10$} & $200-2000$ & 0,7 & 1,8 & 0,2 & 0,3 & 0,5 & 0,4 \\
\hline & $53-200$ & 1,1 & 2,2 & 0,9 & 1,1 & 1,6 & 1,6 \\
\hline & $20-53$ & 1,6 & 1,8 & 1,8 & 1,9 & 2,5 & 2,6 \\
\hline & $2-20$ & 2,2 & 2,2 & 2,2 & 2,2 & 2,6 & 2,7 \\
\hline & $0-2$ & 2,1 & 2,5 & 2,5 & 2,6 & 3,0 & 2,9 \\
\hline \multirow[t]{5}{*}{$10-20$} & $200-2000$ & 0,4 & 1,4 & 0,1 & 0,2 & 0,4 & 0,4 \\
\hline & $53-200$ & 0,9 & 1,8 & 0,6 & 0,8 & 1,1 & 1,3 \\
\hline & $20-53$ & 1,3 & 1,5 & 1,2 & 1,4 & 1,7 & 1,9 \\
\hline & $2-20$ & 1,7 & 2,0 & 1,7 & 1,8 & 1,8 & 2,0 \\
\hline & $0-2$ & 1,8 & 2,2 & 1,9 & 2,1 & 2,2 & 2,3 \\
\hline \multirow[t]{5}{*}{$20-40$} & $200-2000$ & 0,3 & 0,6 & 0,1 & 0,3 & 0,3 & 0,4 \\
\hline & $53-200$ & 0,7 & 1,4 & 0,5 & 0,7 & 0,9 & 1,0 \\
\hline & $20-53$ & 1,0 & 1,2 & 0,9 & 1,1 & 1,2 & 1,3 \\
\hline & $2-20$ & 1,3 & 1,6 & 1,2 & 1,4 & 2,3 & 3,3 \\
\hline & $0-2$ & 1,3 & 1,8 & 1,4 & 1,6 & 1,6 & 1,6 \\
\hline
\end{tabular}




\section{REFERÊNCIAS BIBLIOGRÁFICAS}

AMADO, T.J.; PONTELLI, C.B.; JÚNIOR, G.G.; BRUM, A.C.R.; ELTZ, F.L.F.; PEDRUZZI, C. Seqüestro de carbono de carbono em sistemas conservacionistas na Depressão Central do Rio Grande do Sul. In: REUNIÓN BIENAL DE LA RED LATINO AMERICANA DE AGRICULTURA CONSERVACIONISTA, 5., Florianópolis, 1999. Resumos. Florianópolis: Universidade Federal de Santa Catarina, 1999. p.42-43.

ANDERSON, D.W.; SAGGAR, S.; BETTANY, J.R.; STEWART, J.W.B. Particle size fractions and their use in studies of soil organic matter: I. The nature and distribution of forms of carbon, nitrogen and sulfur. Soil Science Society of America Journal, v.45, p.767-772, 1981.

ANDERSON, J.P.E.; DOMSCH, K.H. Physiological method for the quantitative measurement of microbial biomass in soil. Soil Biology \& Biochemistry, v.10, p.215-221, 1978.

ANDERSON, T.H.; DOMSCH, K.H. Carbon link between microbial biomass and soil organic matter. In: INTERNATIONAL SYMPOSIUM ON MICROBIAL ECOLOGY, 4., Ljubjana, 1986. Proceedings. Ljubjana: Slovene Society for Microbiology, 1986. p.466-471.

ANDERSON, T.H.; DOMSCH, K.H. Ratios of microbial biomass carbon to total organic carbon in arable soils. Soil Biology \& Biochemistry, v.21, p.471-479, 1989. 
ANDERSON, T.H.; DOMSCH, K.H. Application of eco-physiological quotients ( $q \mathrm{CO} 2$ and $q \mathrm{D}$ ) on microbial Biomasses from soils of different cropping histories. Soil Biology \& Biochemistry, v.22, p.251-255, 1990.

ANDERSON, T.H.; GRAY, T.R.G. Soil microbial carbon uptake characteristics in relation to soil management. Microbiology Ecology, v.74, p.11-20, 1990.

ANGERS, D.A; GIROUX, M. Recently deposited organic matter in soil water-stable aggregates. Soil Science Society of America Journal, v.60, p.1547-1551, 1996.

ARSHAD, M.A.; SCHINITZER, M.; ANGERS, D.A.; RIPMEESTER, J.A. Effects of till vs no-till on the quality of soil organic matter. Soil Biology \& Biochemistry, v.22, p.595-599, 1990.

ASSOCIACION ARGENTINA DE PRODUCTORES EN SIEMBRA DIRECTA. http//www.aapresid.com.ar. 25 ago. 2000.

BALDOCK, J.A.; OADES, J.M.; WATERS, A.G.; PENG, X.; VASSALO, A.M; WILSON, M.A. Aspects of the chemical structure of soil organic materials as revealed by solid-state ${ }^{13} \mathrm{C}$ NMR spectroscopy. Biogeochemistry, v.16, p.1-42, 1992.

BALESDENT, J.; CHENU, C.; BALABANE, M. Relationship of soil organic matter dynamics to physical protection and tillage. Soil \& Tillage Research, v.53, p.215$230,2000$.

BALESDENT, J.; MARIOTTI, A.; BOISGONTIER, D. Effect of tillage on soil organic carbon mineralization estimated from $13 \mathrm{C}$ abundance in maize fields. Journal of Soil Science, v.41, p.587-596, 1990. 
BALESDENT, J.; MARIOTTI, A.; GUILLET, B. Natural ${ }^{13} \mathrm{C}$ abundance as a tracer for soil organic matter dynamics studies. Soil Biology \& Biochemistry, v.19, p.25-30, 1987.

BALESDENT, J.; WAGNER, G.H.; MARIOTTI, A. Soil organic matter turnover in long-term field experiments as revealed by carbon-13 natural abundance. Soil Science Society of America Journal, v.52, p.118-124, 1988.

BALOTA, E.L.; COLOZZI-FILHO, A.; ANDRADE, D.S.; HUNGRIA, M. Biomassa microbiana e sua atividade em solos sob diferentes sistemas de preparo e sucessão de culturas. Revista Brasileira de Ciência do Solo, v.22, p.641-649, 1998.

BATJES, N.H. Total carbon and nitrogen in the soils of the world. European Journal of Soil Science, v.47, p.151-163, 1996.

BAYER, C.; BERTOL, I. Características químicas de um cambissolo húmico afetadas por sistemas de preparo, com ênfase à matéria orgânica. Revista Brasileira de Ciência do Solo, v.23, p.687-694, 1999.

BAYER, C.; MARTIN-NETO, L.; MIELNICZUK, J.; CERETTA, C.A. Effect of notill cropping systems on soil organic matter in a sandy clay loam Acrisol from southern Brazil monitored by electron spin resonance and nuclear magnetic resonance. Soil \& Tillage Research, v.53, p.95-104, 2000 a.

BAYER, C.; MIELNICZUK, J.; AMADO, T.J.C.; MARTIN-NETO, L.; FERNANDES, S.V. Organic matter storage in a sandy clay loam Acrisol affected by tillage and cropping systems in southern Brazil. Soil \& Tillage Research, v.54, p.101-109, 2000 b. 
BEARE, M.H.; HENDRIX, P.F.; COLEMAN, D.C. Water-stable aggregates and organic matter fractions in conventional and no-tillage soils. Soil Science Society of America Journal, v.58, p.777-786, 1994 a.

BEARE, M.H.; CABRERA, M.L.; HENDRIX, P.F.; COLEMAN, D.C. AggregateProtected and Unprotected organic matter pools in conventional and no-tillage soils. Soil Science Society of America Journal, v.58, p.787-795, 1994 b.

BIERDERBECK, V.O.; CAMPBELL, C.A.; ZENTNER, R.P. Effect of crop rotation and fertilization on some biological properties of a loam in Southwestern Saskattchewan. Canadian Journal of Soil Science, v.64, p.355-367, 1984.

BLAKE, G.R.; HARTAGE, K.H. Bulk density. In: KLUTE, A. (Ed.) Methods of soil analysis. 2. ed. Madison: American Society of Agronomy, 1986. pt.1: Physical and mineralogical methods, p.364-367. (Agronomy, 9).

BLEVINS, R.L.; THOMAS, G.W.; CORNELIUS, P.L. Influence of no-tillage and nitrogen fertilization on certain soil properties after 5 years of continuos corn. Agronomy Journal, v.69, p.383-386, 1977.

BOHN, H. On organic soil C and $\mathrm{CO}_{2}$. Tellus, v.30, p.472-475, 1978.

BONDE, T.A. Size and dynamics of active soil organic matter fraction as influenced by soil management. Linköping: Linköping University, 1991. 34p. (Linköping Studies in Arts and Science, 63). 
BROOKES, P.C.; LANDMAN, A.; PRUDEN, G.; JENKINSON, D.S. Chloroform fumigation and the release of soil nitrogen: a rapid direct extraction method for measuring microbial biomass nitrogen in soil. Soil Biology \& Biochemistry, v.17, p.837-842, 1985.

BRUCE, J.P.; FROME, M.; HAITES, E.; JANZEN, H.; LAL, R. Carbon sequestration in soils. Journal of Soil and Water Conservation, v.54, p.382-389, 1999.

BUCHANAN, M.; KING, L.D. Carbon and phosphorus losses from decomposing crop residues in no-till and conventional till agroecosystems. Agronomy Journal, v.85, p.631-638, 1993.

BURINGH, P. Organic carbon in soils of the world. In: WOODWELL, G.M. (Ed.) The role of terrestrial vegetation in the global carbon cycle. Chichester: John Wiley, 1984. p.41-109.

BURLE, M.L.; MIELNICZUK, J.; FOCCHI, S. Effect of cropping systems on soil chemical characteristics with emphasis on soil acidification. Plant and Soil, v.190, p.309-316, 1997.

CAMBARDELLA, C.A; ELLIOT, E.T. Particulate soil organic matter changes across a grassland cultivation sequence. Soil Science Society of America Journal, v.56, p.77-783, 1992.

CAMBARDELLA, C.A.; ELLIOT, E.T. Carbon and nitrogen distribution in aggregates from cultivated and native grasslands soils. Soil Science Society of America Journal, v.57, p.1071-1076, 1993. 
CAMBARDELLA, C.A; ELLIOT, E.T. Carbon and nitrogen dynamics of soil organic matter fractions from cultivated grassland soils. Soil Science Society of America Journal, v.58, p.123-130, 1994.

CAMPBELL, C.A; SOUSTER, W. Loss of organic matter and potentially mineralizable nitrogen from Saskatchewan soils due to cropping. Canadian Journal of Soil Science, v.62, p.651-656, 1982.

CARTER, M.R. Microbial biomass as an index for tillage-induced changes in soil biological properties. Soil \& Tillage Research, v.7, p.29-40, 1986.

CARTER, M.R. Influence of reduced tillage systems on organic matter, microbial biomass, macro-aggregate distribution and structural stability of the surface soil in humid climate. Soil \& Tillage Research, v.23, p.361-372, 1992.

CARTER, M.R.; RENNIE, D.A. Changes in soil quality under zero tillage farming systems: Distribution of microbial biomass and mineralizable $\mathrm{C}$ and $\mathrm{N}$ potentials. Canadian Journal of Soil Science, v.62, p.587-597, 1982.

CARVALHO, Y. Densidade e atividade dos microorganismos do solo em plantio direto e convencional, na região de Carambeí-PR. Curitiba, 1997. 84p. Dissertação (Mestrado) - Universidade Federal do Paraná.

CERRI, C.C.; FELLER, C.; BALESDENT, J.; VICTORIA, R.; PLENECASSAGNE, A. Application du traçage isotopique naturel en ${ }^{13} \mathrm{C}$, à l'étude de la dynamique de la matière organique dans le sols. Comptes Rendu Academie Seances Paris, série II, t.300, v.9, p.423-428, 1985. 
CHAGA, R.C.S. Alterações de parâmetros microbiológicos do solo em função do sistema de produção sob plantio direto na região dos cerrados. Piracicaba, 2000. 90p. Dissertação (Mestrado) - Centro de Energia Nuclear na Agricultura, Universidade de São Paulo.

CHRISTENSEN, B.T. Physical fractionation of soil and organic matter in primary particle size and density separates. Advances in Soil Science, v.20, p.2-90, 1992.

CHRISTENSEN, B.T.; SORENSEN, L.H. The distribution of native and labeled carbon between soil particle size fractions isolated from long-term incubation experiments. Journal of Soil Science, v.36, p.219-229, 1985.

CIHACEK, L.J.; ULMER, M.G. Effects of tillage on profile soil carbon distribution in the Northern great plains of the U.S. In: LAL, R.; KIMBLE, J.M.; FOLLET, R.F.; STEWART, B.A. (Ed.) Management of carbon sequestration in soil. Boca Raton: CRC Lewis Publ., 1997. p.83-97.

COLOZZI-FILHO, A.; BALOTA, E.L.; ANDRADE, D. Microrganismos e processos biológicos no sistema plantio direto. In: SIQUEIRA, J.O.; MOREIRA, F.M.S.; LOPES, A.S.; GUILHERME, L.R.G.; FAQUIN, V.; FURTINI NETO, A.E.; CARVALHO, J.G. (Ed.) Soil fertility, soil biology, and plant nutrition interrelationships. Lavras: UFLA, Sociedade Brasileira de Ciência do Solo, 1999. p.267-320.

CORAZZA, E.J.; SILVA, J.E.; RESCK, D.V.S.; GOMES, A.C. Comportamento de diferentes sistemas de manejo como fonte ou depósito de carbono em relação à vegetação de cerrado. Revista Brasileira de Ciência do Solo, v.23, p.425-432, 1999. 
CRAIG, $\mathrm{H}$. Isotopic standards for carbon and oxygen and correction factors for mass spectrometric analysis of carbon dioxide. Geochimica Cosmochimica Acta, v.12, p.133-149, 1957.

DALAL, R.C.; HENRY, R.J. Cultivation effects on carbohydrate contents of soil and soil fractions. Soil Science Society of America Journal, v.52, p.112-117, 1988.

DERPSCH, R. Alguns resultados sobre adubação verde no Paraná. In: FUNDAÇÃO CARGILL. Adubação verde no Brasil. Campinas, 1983. p.268-279.

DEXTER, A.R. Advances in characterization of soil structure. Soil \& Tillage Research, v.11, p.199-238, 1988.

DICK, W.A. Organic carbon, nitrogen and phosphorus concentrations and $\mathrm{pH}$ profiles as affected by tillage intensity. Soil Science Society of America Journal, v.47, p.102-107, 1983.

DICK, W. A.; VAN DOREN, Jr. Continuous tillage and rotation combinations effects on corn, soybean and oats yields. Agronomy Journal, v.77, p.459-465, 1985.

DICK, W.A.; McCOX, E.L.; EDWARDS, W.M.; LAL, R. Continuous application of no-tillage to Ohio Soils. Agronomy Journal, v.83, p.65-73, 1991.

DICK, W.A.; BLEVINS, R.L.; FRYE, W.W.; PETERS, S.E.; CHRISTENSON, D.R.; PIERCE, F.J.; VITOSH, M.L. Impacts of agricultural management practices on C sequestration in forest-derived soils of the eastern Corn Belt. Soil \& Tillage Research, v.47, p.235-344, 1998.

DORAN, J.W. Soil microbial and biochemical changes associated with reduced tillage. Soil Science Society of America Journal, v.44, p.765-771, 1980. 
DORAN, J.W. Microbial biomass and mineralizable nitrogen distributions in no-tillage and plowed soils. Biology \& Fertility of Soils, v.5, p.68-75, 1987.

DUXBURY, J.M.; SMITH, M.S.; DORAN, J.W. Soil organic matter as a source and sink of plant nutrients. In: COLEMAN, D.C.; OADES, J.M.; UEHARA, G. (Ed.) Dynamics of soil organic matter in tropical ecosystems. Honolulu: University of Hawaii Press, NifTAL Project, 1989. p.33-67.

ELLIOT, E.T. Aggregate structure and carbon, nitrogen and phosphorus in native and cultivated soils. Soil Science Society of America Journal, v.50, p.627-633, 1986.

EMPRESA BRASILEIRA DE PESQUTSA AGROPECUÁRIA. Serviço Nacional de Levantamento e Classificação do Solo. Manual de métodos de análise do solo. Rio de Janeiro, 1979. 390p.

ESWARAN, H.; VAN DER BERG, E.; REICH, P. Organic carbon in soils of the world. Soil Science Society of America Journal, v.57, p.192-194, 1993.

ESWARAN, H.; VAN DER BERG, E.; REICH, P.; KIMBLE, J.M. Global soil carbon resources. In: LAL, R.; KIMBLE, J.M.; LEVINE, E.; STEWART, B.A. (Ed.) Soils and global change. Boca Raton: CRC Press, 1995. p.27-43.

FARQUHAR, G.D.; EHLERINGER, J.R.; HUBICK, K.Y. Carbon isotope discrimination and photosynthesis. Annual Review of Plant Molecular Biology, v.40, p.503-537, 1989.

FEDERAÇÃO BRASILEIRA DE PLANTIO DIRETO NA PALHA. Evolução da área de plantio direto no Brasil. http://www.agri.com.br/febrapdp/pd. 25 ago. 2000. 
FELLER, C. Organic imputs, soil organic matter and functional soil organic compartiments in low activity clay soils in tropical zones. In: MULONGOY, K.; MERCKX, R. (Ed.) Soil organic matter dynamics and sustainability of tropical agriculture. Chichester: John Wiley, 1993. p.77-88.

FELLER, C. La matière organique dans le sols tropicaux à argiles 1:1. Recherche de compartiments organiques fontionnels. Une approche granulometrique. Strasbourg, 1994. 393p. Thèse (Doctorate) - Universitè Strasbourg.

FELLER, C.; ALBRECHT, A.; TESSIER, D. Aggregation and organic matter storage in kaolinitic and smectitic soils. In: CARTER, M.R.; STEWART, B.A. (Ed.) Structure and organic matter in agricultural soils. Boca Raton: CRC Press, 1996. p.309-359.

FLACH, K. W.; BARNWELL JR., T.O.; CROSSON, P. Impacts of agriculture on atmospheric carbon dioxide. In: PAUL, E.A.; ELLIOT, E.T.; PAUSTIAN, K.; COLE, C.V. (Ed.) Soil organic matter in temperate agroecosystems. Boca Raton: CRC Press, 1997. p.3-13.

FOX, R.H. Soil with variable charge: agronomic and fertility aspects. In: THENG, B.K.G. (Ed.) Soils with variable charge. Lower Hutt: New Zealand Society of Soil Science, 1980. p.195-224.

FRANCHINI, J.C.; MALAVOLTA, E.; MIYAZAWA, M.; PAVAN, M.A. Chemical changes in acid soils after application of plant residues. Revista Brasileira de Ciência do Solo, v.23, p.533-542, 1999.

FRANZLUEBBERS, A.J.; HONS, F.M.; ZUBERER, D.A. Long-term changes in soil carbon and nitrogen pools in wheat management systems. Soil Science Society of America Journal, v.58, p.1639-1645, 1994. 
GALE, W.J.; CAMBARDELLA, C.A.; BAILEY, T.B. Surface residue and root derived $\mathrm{C}$ in stable and unstable aggregates. Soil Science Society of America Journal, v.64, p.196-201, 2000 a.

GALE, W.J.; CAMBARDELLA, C.A.; BAILEY, T.B. Root-derived carbon and the formation and stabilization of aggregates. Soil Science Society of America Journal, v.64, p.201-207, 2000 b.

GEE, G.W.; BAUDER, J.W. Particle-size analyses. In: KLUTE, A. (Ed.) Methods of soil analysis. 2. ed. Madison: American Society of Agronomy, 1986. pt.1: Physical and mineralogical methods, p.383-412. (Agronomy, 9).

GOLCHIN, A.; OADES, J.M.; SKJEMSTAD, J.O; CLARKE, P. Soil structure and carbon cycle. Australian Journal of Soil Research, v.32, p.1043-1068, 1994.

GREENLAND, D.J. Changes in the nitrogen status and physical condition of soils under pasture, with special reference to the maintenance of the Australian soils used for growing wheat. Soil Fertility, v.34, p.237-251, 1971.

GREENLAND, D.J.; NYE, P.H. Increases in the carbon and nitrogen contents of tropical soils under natural fallows. Journal of Soil Science, v.9, p.284-289, 1959.

GREENLAND, D.J.; OADES, J.M. Saccharides. In: GEISEKING, J.E. (Ed.), Soil components. New York: Spring Verlag, 1975. v.1, p.213-257.

GREENLAND, D.J.; LINDSTROM, G.R.; QUIRK, J.P. Organic materials which stabilize natural soil aggregates. Soil Science Society of America Proceedings, v.26, p.366-371, 1962 . 
GUGGENBERG, G.; ZECH, W.; THOMAS, R.J. Lignin and carbohydrate alteration in particle size separates of an oxisol under tropical pastures following native savana. Soil Biololy \& Biochemistry, v.27, p.1629-1638, 1995.

HAVLIN, J.L.; KISSEL, D.E.; MADDUS, L.E.; CLAASSEN, M.M.; LONG, J.H. Crop rotation and tillage effects on soil organic carbon and nitrogen. Soil Science Society of America Journal, v.54, p.448-452, 1990.

HAYNES, R.J. Size and activity of the soil microbial biomass under grass and arable management. Biology \& Fertility Soils, v.30, p.210-216, 1999.

HENDRIX, P.F.; FRANZLUEBBERS, A.J.; McCRACKEN, D.V. Management effects on $\mathrm{C}$ accumaltion and loss in soils of the southern Appalachian Piedmont of Georgia. Soil \& Tillage Research, v.47, p.245-251, 1998.

HENDRIX, P.F.; PARMELEE, R.W.; CROSSLEY Jr., D.A.; COLEMAN, D.C.; ODUM, E.P.; GROFFMAN, P.M. Detritus food webs in conventional and no-tillage agroecosystems. Bio-Science, v.36, p.374-380, 1986.

HENIN, S.; DUPUIS, M. Essais du bilan de la matiére organique du sol. Annales Agronomiques, Paris, v.15, p.17-29, 1945.

HEYLAR, K.R. The management of acid soils. In: WRIGHT, R.J.; BAGLIAR, V.C.; MURRANAN, R.P. (Ed.) Plant and soil interactions at low pH. Dordrecht: Kluwer Academic Publ., 1991. p.365-382.

HOUGHTON, R.A. Changes in the storage of industrial carbon since 1850. In: LAL, R.; KIMBLE, J.M.; LEVINE, E.; STEWART, B.A. (Ed.) Soils and global change. Boca Raton: CRC Press, 1995. p.45-65. 
HOUGHTON, R.A.; SKOLE, D.L. "Carbon". In: TURNER, B.S.; CLARK, W.C.; KATES, R.W.; RICHARDS, J.F.; MATHEWS, J.T.; MEYERS, W.B. (Ed.) The Earth as transformed by human action. Cambridge: Cambridge University Press, 1990. p.393-408.

HUGGINS, D.R.; CLAPP, C.E.; ALLMARAS, R.R.; LAMB, J.A.; LAYESE, M.F. Carbon dynamics in corn-soybean sequences as estimated from carbon-13 abundance. Soil Science Society of America Journal, v.62, p.195-203, 1998.

INSAM, H.; HASELWANDTER, K. Metabolic quocient of the soil microflora in relation to plant succession. Oecologia, v.79, p.174-178, 1989.

INTERGOVERNMENTAL PANEL ON CLIMATE CHANGE. Climate change 1995. In: HOUGHTON, J.T.; MEIRA FILHO, L.G.; CALLANDER, B.A.; HARRIS, N.; KATTENBERG, A.; MASKELL, K. (Eds.).The science of climate change. Cambridge: Cambridge University Press, 1996. 572p.

INTERGOVERNMENTAL PANEL ON CLIMATE CHANGE. Global perspective. In: WATSON, R.T.; NOBLE, I.R.; BOLIN, B.; RAVINDRANATH, N.H.; VERARDO, D.J.; DOKKEN D.J. (Eds.) Land use, land-use change, and forestry. Cambridge: Cambridge University Press, 2000. p.25-50.

ISMAIL, I.; BLEVINS, R.L; FRYE, W.W. Long-term no-tillage effects on soil properties and continuous corn yields. Soil Science Society of America Journal, v.58, p.193-198, 1994.

JACKSON, M.L. Soil chemical analysis: Advanced course. 2. ed. Madison: JACKSON, M.L., 1969. 895p. 
JANSSEN, B.H. A simple method for calculating decomposition and acumulation of "Young" soil organic matter. Plant and Soil, v.76, p.297-304, 1984.

JANZEN, H.H.; CAMPBELL, C.A.; GREGORICH, E.G.; ELLERT, B.H. Soil organic carbon dynamics in Canadian agroecosystems. In: LAL, R.; KIMBLE, J.M.; FOLLETT, R.F.; STEWART, B.A. (Ed.) Soil processes and carbon cycles. Boca Raton: CRC Press, 1997. p.57-80.

JASTROW, J.D.; BOUTTON, T.W.; MLLER, R.M. Carbon dynamics of aggregateassociated organic matter estimated by carbon-13 natural abundance. Soil Science Society of America Journal, v.60, p.801-807, 1996.

JENKINSON, D.S.; LADD, J.N. Microbial in soil: measurement and turnover. In: PAUL, E.A.; LADD, J.N. (Ed.) Soil biochemistry. New York: Marcel Decker, 1981. v.6, p.415-471.

JENKINSON, D.S.; RAYNER, J.H. The turnover of soil organic matter in some of the Rothamsted classical experiments. Journal of Soil Science, v.123, p.298-305, 1977.

JUMA, N.G.; McGILL, W.B. Decomposition and nutrient cycling in agro-ecosystems. In: MITCHEL, M.J.; NAKAS, J.P. (Ed.) Microfloral and faunal interactions in natural and agro-ecosystems. Dordrecht: Nijhoff Junk, 1986. p.74-136.

JUO, A.S.R.; LAL, R. Nutrient profile in tropical Alfisol under conventional and no-till systems. Journal of Soil Science, v.127, p.168-173, 1979.

KAMPRATH, E.J. Exchangeable aluminum as a criterion for liming leached mineral soils. Soil Science Society of America Proceeding, v.34, p.252-254, 1977. 
KERN, J.S.; JOHNSON, M.G. Conservation tillage impacts on national soil and atmospheric carbon levels. Soil Science Society of America Journal, v.57, p.200$210,1993$.

KONONOVA, M.M. Soil organic matter: its nature, its role in soil formation and soil fertility. Oxford: Pergamon Press, 1961. p.13-45: The main stages in the history of soil humus study.

KUO, S.; SAINJU, U.M.; JELLUM, J.E. Winter cover crop effects on soil organic carbon and carbohydrate in soil. Soil Science Society of America Journal, v.61, p.145-152, 1997.

LAL, R. No-tillage effects on soil properties under different crops in Western Nigeria. Soil Science Society of America Journal, v.40, p.762-768, 1976.

LAL, R. Long-term tillage and monoculture effects on a tropical Alfisol in Western Nigeria: II. Soil chemical properties. Soil \& Tillage Research, v.42, p.161-174, 1997.

LAL, R. Soil management and restoration for $\mathrm{C}$ sequestration to mitigate the accelerated greenhouse effect. Progress in Environmental Science, v.1, p.307-326, 1999.

LAL, R.; LOGAN, T.J. Agricultural activities and greenhouse gas emissions from soils of the tropics. In: LAL, R.; KIMBLE, J.M.; LEVINE, E.; STEWART, B.A. (Ed.) Soil management greenhouse effect. Boca Raton: CRC Press, 1995. p.293-307. 
LAL, R.; KIMBLE, J.M.; FOLLET, R.F.; COLE, C.V. Land conversion and restoration. In: LAL, R.; KIMBLE, J.M.; FOLLET, R.F.; COLE, C.V (Ed.) The potential of U.S. cropland to sequester carbon and mitigate the greenhouse effect. Chelsea: Ann Arbor Press, 1998. p.35-51.

LAL, R.; KIMBLE, J.M.; LEVINE, E.; WHITMAN, C. World soils and greenhouse effect: An overview. In: LAL, R.; KIMBLE, J.M.; LEVINE, E.; STEWART, B.A. (Ed.) Soils and global change. Boca Raton: CRC Press, 1995. p.1-7.

LASHOF, D.; HARE, B. The role of the biotic carbon stocks in stabilizing greenhouse gas concentrations at safe levels. Environmental Science and Policy, v.2, p.101109, 1999.

LEEMANS, R. Land use change and the terrestrial carbon cycle. Newsletter, v.37, p.24-26, 1999.

LOWE, L.E. Total and labile polysaccharide analysis of soils. In: CARTER, M.R. (Ed.) Soil sampling and methods analysis. Boca Raton: CRC Press, Lewis Publ., 1993. p.73-376.

LUGO, A.E.; BROWN, S. Management of tropical soil as sinks or sources of atmospheric carbon. Plant and Soil, v.149, p.27-41, 1993.

LYNCH, J.M. Interactions between biological process, cultivation and soil structure. Plant and Soil, v.76, p.307-318, 1984.

MAACK, R. Geografia física do Paraná. 2. ed. Rio de Janeiro: Livraria José Olímpio Editora S.A, 1981. p.175-189: Classificação do clima do Estado do Paraná. 
MANN, L.K. A regional comparison of carbon in cultivated and uncultivated Alfisols and Molisols in the central United States. Geoderma, v.36, p.241-253, 1985.

MARTENS, D.A. Plant residue biochemistry regulates soil carbon cycling and carbon sequestration. Soil Biology \& Biochemistry, v.32, p.361-369, 2000.

McMAHON, M.A.; THOMAS, G.W. Anion leaching in two Kentucky soils under conventional tillage and a killed-sod mulch. Agronomy Journal, v.68, p.437-442, 1976.

MEKARU, T.; UEHARA, G. Anion adsorption in ferruginous tropical soils. Soil Science Society America Proceedings, v.36, p.296-300, 1972.

MONDARDO, A. Resultados de pesquisa. In: ENCONTRO NACIONAL DE PESQUISA SOBRE CONSERVAÇÃO DO SOLO, Passo Fundo, 1978. Anais. Passo Fundo: EMBRAPA-CNPTrigo, 1978. p.249-252.

MONROZIER, L.J.; LADD, J.N.; FITZPATRICK, R.W.; FOSTER, R.C.; RAUPACH, M. Components and microbial biomass content of size fractions in soils of contrasting aggregation. Geoderma, v.49, p.37-62, 1991.

MOSCHLER, W.W.; SHEAR, G.M.; MARTENS, D.C.; JONES, G.D.; WILMOUTH, R.R. Comparative yield and fertilizer efficiency of no-tillage and conventionally tilled corn. Agronomy Journal, v.64, p.229-231, 1972.

MUZILLI, O. Princípios e perspectivas de expansão. In: FUNDAÇÃO INSTITUTO AGRÔNOMICO DO PARANÁ. Plantio direto no Paraná. Londrina, 1981. p.1117. (Circular, 23). 
MUZILLI, O. Manejo da fertilidade do solo. In: FUNDAÇÃO INSTITUTO AGRONÔMICO DO PARANÁ. Plantio direto no Paraná. Londrina, 1981. p.4357. (Circular, 23).

MUZILLI, O. Influência do sistema de plantio direto, comparado ao convencional sobre a fertilidade da camada arável do solo. Revista Brasileira de Ciência do Solo, v.7, p.95-102, 1983.

MUZILLI, O. Fertilidade do solo em plantio direto. In: FUNDAÇÃO CARGILL. Atualização em plantio direto. Campinas, 1985. p.147-160.

NELSON, D.W.; SOMMERS, L.E. Total carbon, organic carbon and organic matter. In: PAGE, A.L.; MILLER, R.H.; KEENEY, D.R. (Ed.) Methods of soil analysis. 2. ed. Madison: American Society of Agronomy, 1986. pt.2: Chemical and microbiological properties, p.539-579. (Agronomy, 9).

OADES, J.M. Studies on soil polysaccharides. III. Composition of polysaccharides in some Australian soils. Australian Journal of Soil Research, v.10, p.113-126, 1972.

OADES, J.M. Soil organic matter and structural stability: mechanisms and implications for management. Plant and Soil, v.76, p.19-337, 1984.

OADES, J.M. The retention of organic matter in soils. Biogeochemistry, v.5, p.35-70, 1988.

OADES, J.M.; WATERS, A.G. Aggregate hierarchy in soils. Australian Journal of Soil Science, v.29, p.815-828, 1991. 
OADES, J.M.; GILLMAN, G.P.; UEHARA, G.; HUE, N.V.; NOORDWIJK, M.van.; ROBERTSON, G.P.; WADA, K. Interactions of soil organic matter and variablecharges clays. In: COLEMAN, D.C.; OADES, J.M.; UEHARA, G. (Ed.) Dynamics of soil organic matter in tropical ecosystems. Manitoba: University of Hawaii Press, Niftal project, 1989. p.69-95.

OLDEMAN, L.R. The global extent of soil degradation. In: GREENLAND, D.J.; SZABOLCS, I. (Ed.) Soil resilience and sustainable land use. Wallingford: CAB International, 1994. p.99-118.

PARTON, W.J.; SCHIMEL, D.S.; COLE, C.V.; OJIMA, D.S. Analysis of factors controlling soil organic matter levels in Great Plains. Soil Science Society of America Journal, v.51, p.1173-1179, 1987.

PAUSTIAN, K; ANDREN, O; JANZEN, H.; LAL, R.; SMITH, P.; TIAN, G.; TIESSEN, H.; NOORDWIJK, M. VAN; WOOMER, P. Agricultural soils as a C sink to offset $\mathrm{CO}_{2}$ emissions. Soil Use and Management, v.13, p.230-244, 1997.

PAVAN, M.A.; BINGHAM, F.T.; PRATT, P.F. Chemical and mineralogical characteristics of selected acid soils of the State of Paraná, Brazil. Turrialba, v.35, p.131-139, 1985.

PIERRE, W.H.; BANWART, W.L. Excess-base and excess-base/nitrogen ratio of various crop species and plant parts. Agronomy Journal, v.65, p.91-96, 1973.

PIRT, S.J. Principles of microbe and cell cultivation. Oxford: Blackwell, 1975. 274p.

POWLSON, D.S. The effect of grinding on microbial and non-microbial organic matter in soil. Journal of Soil Science, v.31, p.77-85, 1980. 
POWLSON, D.S.; BROOKES, P.C.; CHRISTENSEN, B.T. Measurament of soil microbial biomass provides an early indication of changes in total soil organic matter due to straw incorporation. Soil Biology \& Biochemistry, v.19, p.159-164, 1987.

RAIJ, B. van. Capacidade de troca de cátions de frações orgânicas e minerais de solos. Bragantia, v.28, p.85-112, 1969.

RAIJ, B. van; QUAGGIO, J.A. Métodos de análises de solo para fins de fertilidade. Campinas: IAC, 1983. 31p.

RAMOS, M. Sistemas de preparo mínimo do solo: técnicas e perspectivas para o Paraná. Ponta Grossa: EMBRAPA, Representante Estadual do Paraná, 1976. 23p. (Comunicado Técnico, 1).

RASMUSSEN, P.E.; ALBRECHT, S.L.; SMILEY, R.W. Soil C and N changes under tillage and cropping systems in semi-arid Pacific Northwest agriculture. Soil \& Tillage Research, v.47, p.197-205, 1998.

REICOSKY, D.C.; KEMPER, W.D.; LANGDALE, G.W.; DOUGLAS Jr., C.L.; RASMUSSEN, P.E. Soil organic matter changes resulting from tillage and biomass production. Journal of Soil and Water Conservation, v.50, p.253-261, 1995.

RESCK, D.V.S. Agricultural intensification systems and their impotential acidityt on soil and water quality in the Cerrados of Brazil. In: LAL, R. (Ed.) Soil quality and agricultural sustainability. Chelsea: Ann Arbor Press, 1998. p.288-300.

SÁ, J.C.M. Manejo da fertilidade do solo no plantio direto. Castro: Fundação $A B C$, 1993. 96p. 
SÁ, J.C.M. Manejo da fertilidade do solo no sistema plantio direto. In: SIQUEIRA, J.O.; MOREIRA, F.M.S.; LOPES, A.S.; GUILHERME, L.R.G.; FAQUIN, V.; FURTINI NETO, A.E.; CARVALHO, J.G. (Ed.) Soil fertility, soil biology, and plant nutrition interrelationships. Lavras: UFLA, Sociedade Brasileira de Ciência do Solo, 1999. p.267-320.

SANCHEZ, P.A. Properties and management of soils in the tropics. New York: A Wiley-Interscience, 1976. p.135-161: Clay mineralogy and ion exchange process.

SAS INSTITUTE. SAS/STAT user's guide: statistics, version 6. 4. ed. Cary, 1990.

SCHIMEL, D. S. Terrestrial ecosystems and carbon cycle. Global Change Biology, v.1, p.77-91, 1995.

SHEAR, G.M.; MOSCHLER, W.W. Continuous corn by the no-tillage and conventional tillage methods: a six-year comparison. Agronomy Journal, v.61, p.524-526, 1969.

SIDIRAS, N.; PAVAN, M.A. Influência do sistema de manejo no seu nível de fertilidade. Revista Brasileira Ciência do Solo, v.9, p.249-254, 1985.

SILVA, J.E.; LEMANSKI, J.; RESCK, D.V.S. Perdas de matéria orgânica e suas relações com a capacidade de troca catiônica em solos da região de cerrados do oeste baiano. Revista Brasileira de Ciência do Solo, v.18, p.541-547, 1994.

SIX, J.; ELLIOT, E.T.; PAUSTIAN, K. Aggregate and soil organic matter dynamics under conventional and no-tillage systems. Soil Science Society of America Journal, v.63, p.1350-1358, 1999. 
SIX, J.; MERCKX, R.; KIMPE, K; ELLIOT, E.T.; PAUSTIAN, K. A reevaluation of the enriched labile soil organic matter fraction. European Journal of Soil Science, v.51, p.283-293, 2000.

SMITH, J.L.; PAPENDICK, R.I.; BEZDICEK, D.F.; LYNCH, J. Soil organic matter dynamics and crop residue management. In: METTING Jr., F.B. (Ed.) Soil microbial ecology: applications in agricultural and environmental management. New York: Marcel Dekker, 1992. p.65-94.

SPARLING, G.P. Ratio of microbial biomass carbon to soil organic carbon as a sensitive indicator of change in soil organic matter. Australian Journal of Soil Research, v.30, p.195-207, 1992.

SPARLING, G.P.; SHEPERD, T.G.; KETTLES, H.A. Changes in soil organic C, microbial $\mathrm{C}$ and aggregate stability under continuous maize and cereal cropping, and after restoration to pasture in soils from the Manawatu region, New Zealand. Soil \& Tillage Research, v.24, p.225-241, 1992.

STALEY, T.E.; EDWARDS, C.L.; SCOTT, C.L.; OWENS, L.B. Soil microbial biomass and organic component alterations in a no-tillage chronosequence. Soil Science Society of America Journal, v.52, p.998-1000, 1988.

STEVENSON, F.J.; ELLIOT, E.T.; COLE, C.V.; INGRAM, J.; OADES, J.M.; PRESTON, C.; SOLLINS, P.J. Methodologies for assessing the quantity and quality of soil organic matter. In: COLEMAN, D.C.; OADES, J.M.; UEHARA, G. (Ed) Dynamics of soil organic matter in tropical ecosystems. Manitoba: University of Hawaii Press, Niftal Project, 1989. p.173-199.

THOMAS, G.W.; BLEVINS, R.L.; PHILlIPS, R.E.; McMAHON, M.A. Nitrate nitrogen in killed corn sod. Agronomy Journal, v.65, p.736-739, 1973. 
TIESSEN, H.; STEWART, J.W.B. Particle size fractions and their use in studies of soil organic matter: II. Cultivation effects on organic matter composition in size fractions. Soil Science Society of America Journal, v.47, p.509-514, 1983.

TISDALL, J.M. Formation of soil aggregates and accumulation of soil organic matter. In: CARTER, M.R.; STEWART, B.A. (Ed.) Structure and organic matter storage in agricultural soils. Boca Raton: CRC Press, 1996. p.57-95.

TISDALL, J.M.; OADES, J.M. Organic matter and water-stable aggregates in soils. Journal of Soil Science, v.33, p.141-163, 1982.

TRIPLETT Jr., G.B.; VAN DOREN Jr., D.M. Nitrogen, phosphorus, and potassium fertilization on no-tillage maize. Agronomy Journal, v.61, p.637-639, 1969.

TRIPLETT Jr., G.B.; VAN DOREN Jr., D.M.; SCHMIDT, B.L. Effect of corn (Zea mays $L$.) stover mulch on no-tillage corn yield and water infiltration. Agronomy Journal, v.60, p.236-239, 1968.

UEHARA, G. Management of isoelectric soils of humid tropics. In: LAL, R.; KIMBLE, J.M.; LEVINE, E.; STEWART, B.A. (Ed.) Soil management and greenhouse effect. Boca Raton: CRC Press, 1995. p.271-278.

UEHARA, G.; KENG, J. Management implications of soil mineralogy in Latin America. In: BORNEMIZA, E.; ALVARADO, A. (Ed.) Soil management in tropical America. Raleigh: North Carolina State University, 1975. p.351-362.

VAN VEEN, J.A.; PAUL, E.A. Organic carbon dynamics in grassland soil. I. Background information and computer simulation. Canadian Journal of Soil Science, v.61, p.185-201, 1981. 
VANCE, E.D.; BROOKES, P.C.; JENKINSON, D.S. An extraction method for measuring soil microbial biomass C. Soil Biology \& Biochemistry, v.6, p.703-707, 1987.

VENSKE FILHO, S.P. Microbiota e sua atividade em uma cronossequência sob sistema plantio direto. Piracicaba, 1999. 65p. Dissertação (Mestrado) - Escola Superior de Agricultura "Luiz de Queiróz", Universidade de São Paulo.

WAGNER, G.H. Humus under different long-term cropping systems. In: COLLOQUE, HUMUS-AZOTE, Reims, France, 1981. Paris: Association of International Soil Science e Associacion. Francaise Etude du Sol, 1981. p.23-29.

WANDER, M.M.; YANG, X. Influence of tillage on the dynamics of loose and occluded particulate organic matter and humified organic matter fractions. Soil Biology \& Biochemistry, v.32, p.1151-1160, 2000.

WALLACE, A. Soil organic matter must be restored to near original levels. Communications in Soil Science Plant Analysis, v.25, p.29-35, 1994.

WARDLE, D.A.; GHANI, A. A critique of the microbial metabolic quotient $\left(q \mathrm{CO}_{2}\right)$ as a bioindicator of disturbance and ecosystem development. Soil Biology \& Biochemistry, v.27, p.1601-1610, 1995.

WATSON, J.R. Ultrasonic vibration as a method of soil dispersion. Soil Fertility, v.34, p.127-134, 1971.

WATSON, J.R.; PARSONS, J.W. Studies of soil organo-mineral fractions: I. Isolation by ultrasonic dispersion. Journal of Soil Science, v.25, p.1-8, 1974. 
WOOD, C.W.; WESTFALL, D.G.; PETERSON, G.A. Soil carbon and nitrogen changes on initiation of no-till cropping systems. Soil Science Society of America Journal, v.55, p.470-476, 1991.

WUNCHE, W.A.; DENARDIN, J.E. Perdas de solo e escorrimento de água sob chuva natural em Latossolo Vermelho-Escuro nas culturas de trigo e soja. In: ENCONTRO NACIONAL DE PESQUISA SOBRE CONSERVAÇÃO DO SOLO, Passo Fundo, 1978. Anais. Passo Fundo: EMBRAPA/CNP-Trigo, 1978. p.289-96. 